NUREG/CR-XXXX

IS-5130

\title{
Three-dimensional Analysis of AP600 Standard Plant Shield Building Roof
}

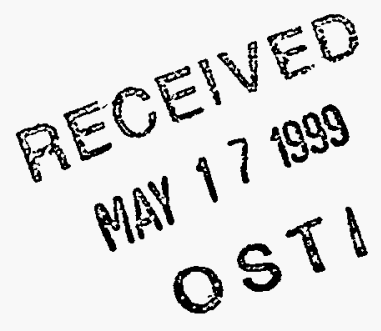

Prepared by

L. Greimann, F. Fanous, S. Safar, A. Khalil, D. Bluhm

Ames Laboratory

Iowa State University

Prepared for

U.S. Nuclear Regulatory Commission 


\section{DISCLAIMER}

This report was prepared as an account of work sponsored by an agency of the United States Government. Neither the United States Government nor any agency thereof, nor any of their employees, makes any warranty, express or implied, or assumes any legal liability or responsibility for the accuracy, completeness, or usefulness of any information, apparatus, product, or process disclosed, or represents that its use would not infringe privately owned rights. Reference herein to any specific commercial product, process, or service by trade name, trademark, manufacturer, or otherwise does not necessarily constitute or imply its endorsement, recommendation, or favoring by the United States Government or any agency thereof. The views and opinions of authors expressed herein do not necessarily state or reflect those of the United States Government or any agency thereof. 


\section{DISCLAIMER}

Portions of this document may be illegible in electronic image products. Images are produced from the best available original document. 


\begin{abstract}
The AP600 passive containment vessel is surrounded by a concrete cylindrical shell covered with a truncated conical roof. This roof supports the passive containment cooling system (PCS) annular tank, shield plate and other nonstructural attachments. When the shield building is subjected to different loading combinations as defined in the Standard Review Plan (SRP), some of the sections in the shield building could experience forces in excess of their design values. This report summarized the three-dimensional finite element analysis that was conducted to review the adequacy of the proposed Westinghouse shield building design.
\end{abstract}

The ANSYS finite element software was utilized to analyze the Shield Building Roof (SBR) under dead, snow, wind, thermal and seismic loadings. A three-dimensional model that included a portion of the shield building cylindrical shell, the conical roof and its attachments, the eccentricities at the cone-cylinder connection and at the compression ring and the PCS tank was developed. Mesh sensitivity studies were conducted to select appropriate element size in the cylinder, cone, near air intakes and in the vicinity of the eccentricities. Also, a study was carried out to correctly idealize the water-structure interaction in the PCS tank.

Response spectrum analysis was used to calculate the internal forces at different sections in the SBR under Safe Shutdown Earthquake (SSE). Forty-nine structural modes and twenty sloshing modes were used. Two horizontal components of the SSE together with a vertical component were used. Modal stress resultants were combined taking into account the effects of closely spaced modes. The three earthquake directions were combined by the Square Root of the Sum Squares method. Two load combinations were 
studied. The load combination that included dead, snow, fluid, thermal and seismic loads was selected to be the most critical. Interaction diagrams for critical sections were developed and used to check the design adequacy. The results demonstrated that provided area of steel on each face of several sections of the AP600 SBR was inadequate. This was also noticed when comparing the total provided area of steel per section i.e., the area of steel on both faces. The discrepancy between Westinghouse results and these reported herein could have resulted from the different finite element mesh sizes and the assumption used in Westinghouse design.

To the authors knowledge, Westinghouse has incorporated some changes in the design of the AP600 SBR such as reducing the thickness of the conical roof slab and the PCS tank walls. These changes need to be taken in consideration when interpreting the results in this report. 


\section{CONTENTS}

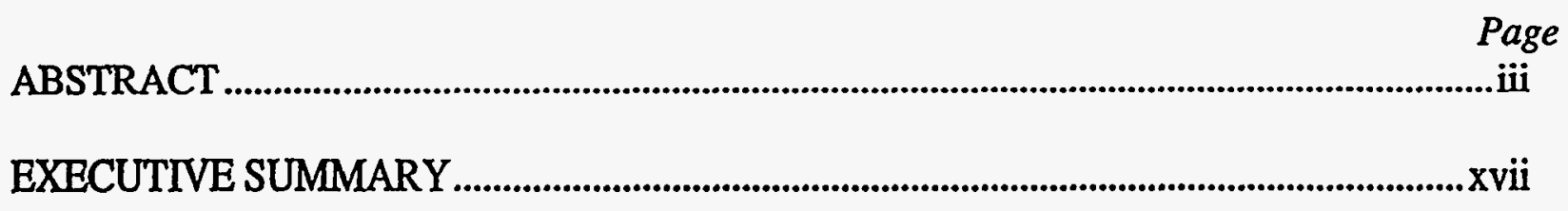

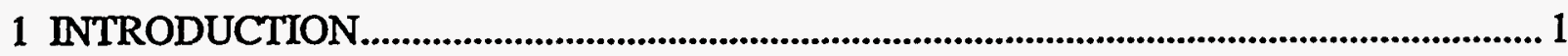

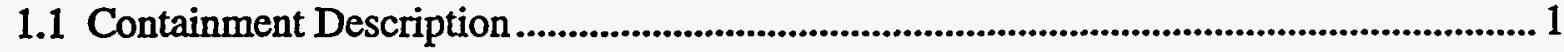

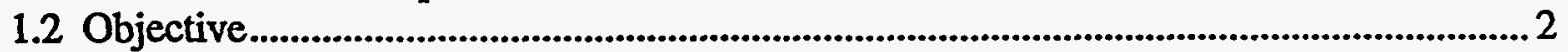

1.3 Methodology ............................................................................................................ 2

1.4 References.......................................................................................................................... 3

2. THREE-DIMENSIONAL MODEL PARAMETERS ............................................................ 5

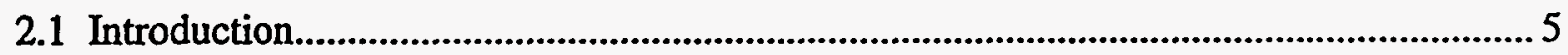

2.2 Modeling Procedure................................................................................................................

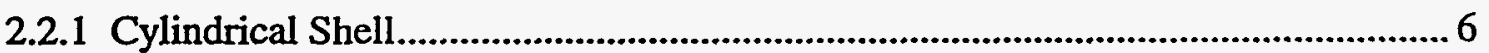

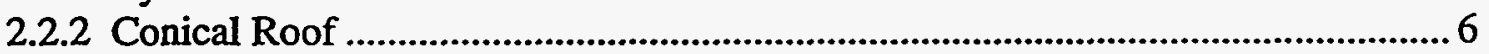

2.2.3 Cylindrical Shell Around Air Intake Opening …….................................................... 7

2.2.4 Middle Surface Eccentricities ................................................................................... 8

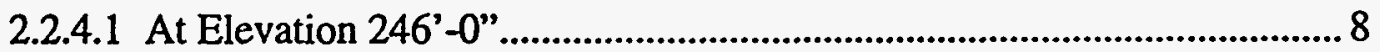

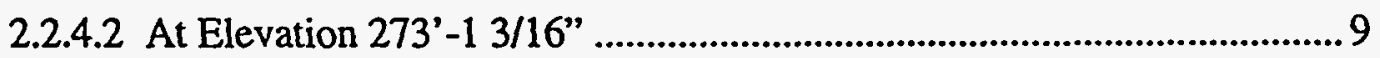

2.2.4.3 At Elevation 288'-10 29/32" ....................................................................

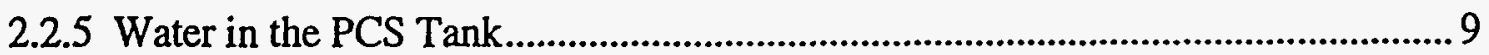

2.2.6 Conical Roof Stiffeners....................................................................................... 10

2.2.7 Shield Plate..................................................................................................... 10

2.2.8 Stair Enclosure, Valve Room and Air Baffle Upper Portion ............................... 10

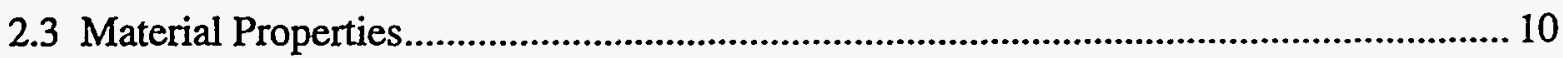

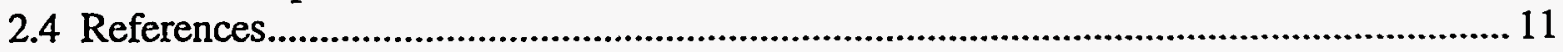

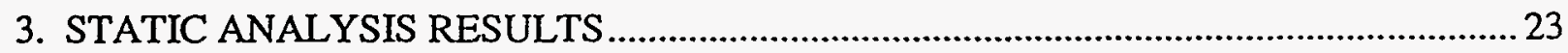

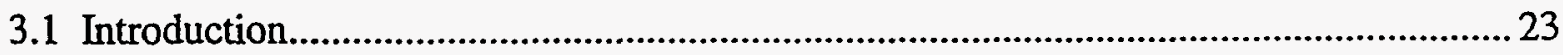

3.2 Dead Load Case (including hydrostatic pressure) ….......................................................23

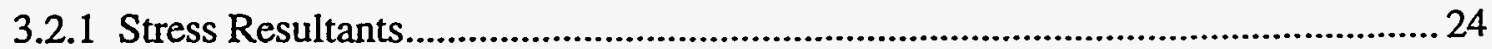

3.2.2 Member Forces in the Tension and Compression Rings..................................... 25 


\section{CONTENTS (Continued)}

3.3 Snow Load Case

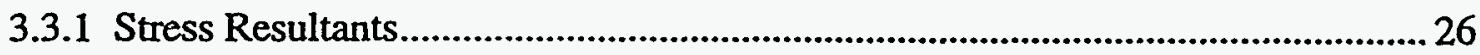

3.3.2 Member Forces in the Tension and Compression Rings......................................26

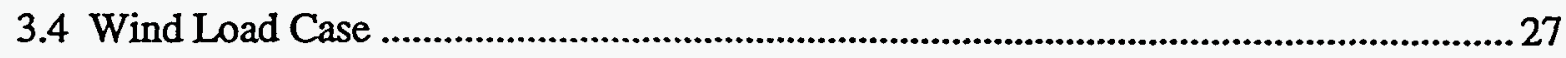

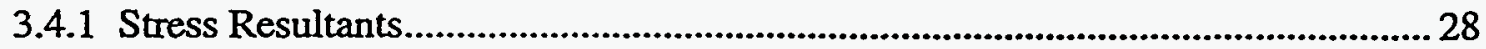

3.4.2 Member Forces in the Tension and Compression Rings.......................................2 29

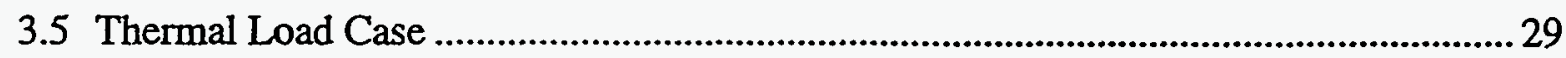

3.5.1 Case "n" (global temperature decrement) …............................................................ 30

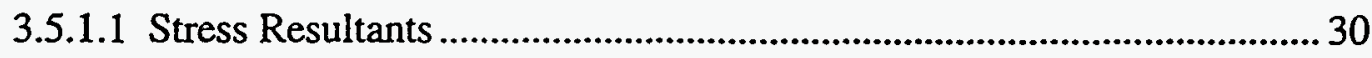

3.5.1.2 Member Forces in the Tension and Compression Rings .......................... 31

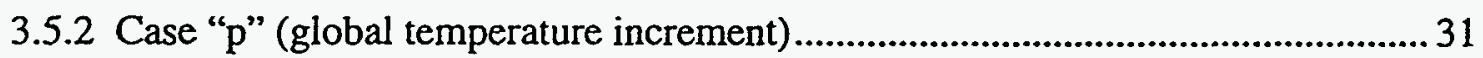

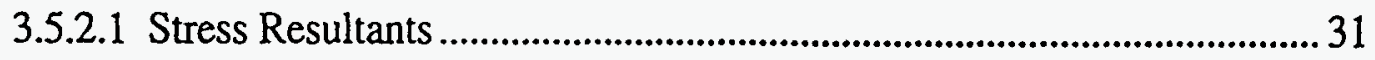

3.5.2.2 Member Forces in the Tension and Compression Rings ......................... 32

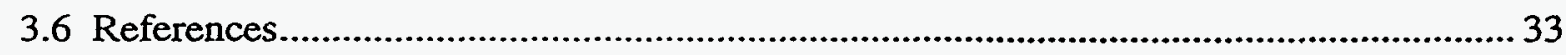

4. RESPONSE SPECTRUM ANALYSIS OF THE AP600 SHIELD BUILDING ..................77

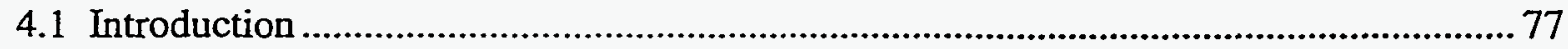

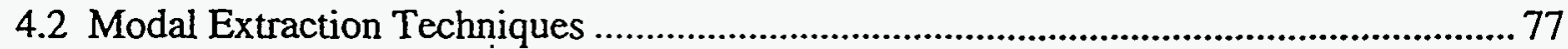

4.3 Mode Shapes and Frequencies …….............................................................................. 79

4.4 Response Spectrum Analysis ....................................................................................... 82

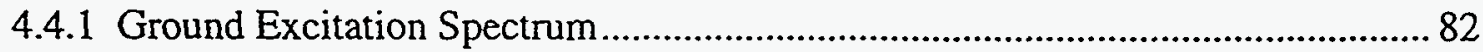

4.4.2 Modal Stress Resultants and Nodal Forces ....................................................... 83

4.4.3 High-Frequency Stress Resultants and Nodal Forces ......................................... 84

4.4.4 Modal and Directional Combination................................................................... 85

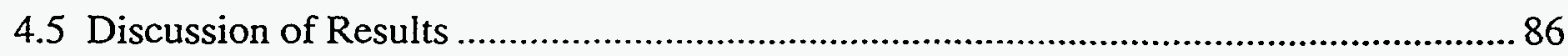

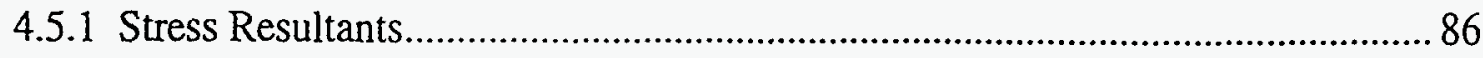

4.5.2 Member Forces in the Tension and Compression Rings....................................... 86

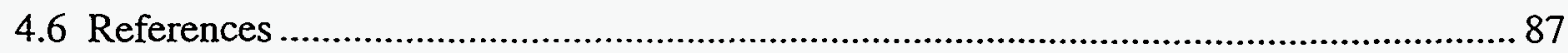




\section{CONTENTS (Continued)}

5. LOAD COMBINATION ……............................................................................. 105

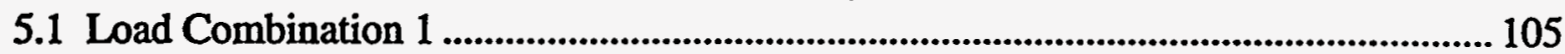

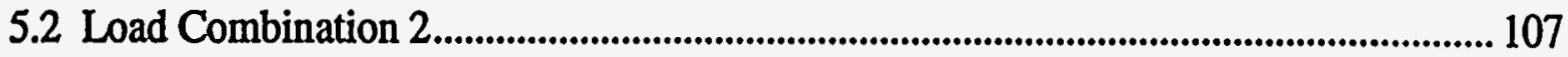

5.3 Design Adequacy of the Critical Sections................................................................. 108

5.3.1 Selection of Critical Section.................................................................................. 108

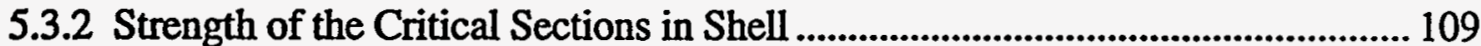

5.3.3 Reinforcement for Composite Precast T-Beam Units.......................................... 117

5.3.4 Reinforcement of the Tension Ring Above the Air Intakes................................ 117

5.3.5 Reinforcement for the Compression Ring........................................................... 118

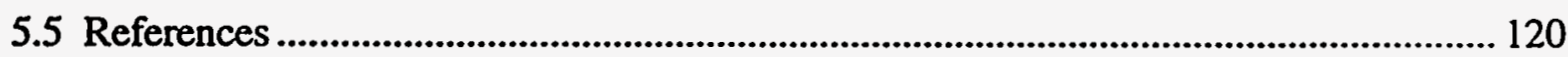

APPENDIX A 


\section{LIST OF FIGURES}

Figure 1.1 General Layout of the AP600 Shield Building Roof ................................................ 4

Figure 2.1 Three-dimensional Finite Element Model of the AP600 SBR...............................12

Figure 2.2 Mesh Sensitivity Study for a Cylindrical Shell Subjected to Edge Loads............ 13

Figure 2.3 Finite element and Theoretical Meridional Moments in the Cylindrical

Shell in Fig. 2.2.

Figure 2.4 Mesh Sensitivity Study for a Conical Shell Subjected to Edge Loads................... 15

Figure 2.5 Finite Element and Theoretical Meriodional Moment in the

Conical Shell in Fig. 2.4

Figure 2.6 Mesh Sensitivity Study for an Axially Load Cylindrical Shell

with an Opening

Figure 2.7 Comparison of Strain Energy Error and Mesh Size ........................................... 18

Figure 2.8 Displacement, Moment and Circumferential Force at Point B in the Cylindrical Shell in Fig. 2.6 ................................................................... 19

Figure 2.9 Cylindrical Shell Middle Surface Eccentricity Near the Tension Ring ................ 20

Figure 2.10 Conical Roof Module Surface Eccentricity at the Junctions with the PCS Tank 20

Figure 2.11 Finite element Model for the Water Inside the PCS Tank ................................... 21

Figure 2.12 Finite Element Model for the Conical Roof Radial and Circumferential Stiffeners

Figure 2.13 Westinghouse Finite element Model for Stair Enclosure, Valve Room, and Air Baffle Upper Portion.

Figure 3.1 Deformed Shape of the AP600 SBR Under Dead Load Plus

Water in the PCS Tank 34

Figure 3.2 Distribution of the Meridional Stress Resultant, N1, (Dead Load)...................... 35

Figure 3.3 Distribution of the Circumferential Stress Resultant, N2, (Dead Load) .................36

Figure 3.4 Distribution of the Meridional Moment, M1, (Dead Load) ................................... 37 


\section{LIST OF FIGURES (continued)}

Figure 3.5 Distribution of the Circumferential Magent

Figure 3.6 A Sketch of the Tension and Compression Rings in the SBR .............................39

Figure 3.7 A Sketch of the Tension and Compression on Rings in the

Member Forces.

Figure 3.8 Distribution of the Axial Force in the Tension Ring (Dead Load) ......................40

Figure 3.9 Distribution of the Moment, Mx, in the Tension Ring (Dead Load) .....................40

Figure 3.10 Distribution of the Torsional Moment, $\mathrm{T}$, in the Tension Ring (Dead Load) ....... 41

Figure 3.11 Distribution of the Axial Force in the Compression Ring (Dead Load) ................ 41

Figure 3.12 Distribution of the Moment, Mx, in the Compression Ring (Dead Load) ............ 42

Figure 3.13 Distribution of the Torsional Moment, $\mathrm{T}$, in the Compression Ring (Dead Load).

Figure 3.14 Deformed Shape of the AP600 SBR Under Snow Load Plus Water in the PCS Tank

Figure 3.15 Distribution of the Meridional Stress Resultant, Nl, (Snow Load) ........................ 44

Figure 3.16 Distribution of the Circumferential Stress Resultant, N2, (Snow Load) ...............45

Figure 3.17 Distribution of the Meridional Moment, M1, (Snow Load) ..................................46

Figure 3.18 Distribution of the Circumferential Moment, M2, (Snow Load) ........................... 47

Figure 3.19 Distribution of the Axial Force in the Tension Ring (Snow Load)....................... 48

Figure 3.20 Distribution of the Moment, Mx, in the Tension Ring (Snow Load)....................48

Figure 3.21 Distribution of the Torsional Moment, $\mathrm{T}$, in the Tension Ring (Snow Load) ...... 49

Figure 3.22 Distribution of the Axial Force in the Compression Ring (Snow Load) ............... 49

Figure 3.23 Distribution of the Moment, $\mathrm{Mx}$, in the Compression Ring (Snow Load) ........... 50

Figure 3.24 Distribution of the Torsional Moment, $\mathrm{T}$, in the Compression Ring (Snow Load) 


\section{LIST OF FIGURES (continued)}

Figure 3.25 Wind Pressure on the SBR in the Southeast Direction 51

Figure 3.26 Deformed Shape of the AP600 SBR Under Wind Load Plus Water in the PCS Tank. 52

Figure 3.27 Distribution of the Meridional Stress Resultant, N1, (Wind Load) ..................... 53

Figure 3.28 Distribution of the Circumferential Stress Resultant, N2, (Wind Load)............... 54

Figure 3.29 Distribution of the Meridional Moment, M1, (Wind Load)................................. 55

Figure 3.30 Distribution of the Circumferential Moment, M2, (Wind Load) ..........................56

Figure 3.31 Distribution of the Axial Force in the Tension Ring (Wind Load) ..................... 57

Figure 3.32 Distribution of the Moment, Mx, in the Tension Ring (Wind Load).................. 57

Figure 3.33 Distribution of the Torsional Moment, $T$, in the Tension Ring (Wind Load)....... 58

Figure 3.34 Distribution of the Axial Force in the Compression Ring (Wind Load).............. 58

Figure 3.35 Distribution of the Moment, Mx, in the Compression Ring (Wind Load)............ 59

Figure 3.36 Distribution of the Torsional Moment, $T$, in the Compression Ring (Wind Load)

Figure 3.37 Deformed Shape of the AP600 SBR Under Temp. Decrease Plus Water in the PCS Tank

Figure 3.38 Distribution of the Meridional Stress Resultant, N1, (Temp. Decrease) ............. 61

Figure 3.39 Distribution of the Circumferential Stress Resultant, N2, (Temp. Decrease)....... 62

Figure 3.40 Distribution of the Meridional Moment, M1, (Temp. Decrease)........................ 63

Figure 3.41 Distribution of the Circumferential Moment, M2, (Temp. Decrease) ................. 64

Figure 3.42 Distribution of the Axial Force in the Tension Ring (Temp. Decrease) ..............65

Figure 3.43 Distribution of the Moment, $\mathrm{Mx}$, in the Tension Ring (Temp. Decrease) ........... 65

Figure 3.44 Distribution of the Torsional Moment, T, in the Tension Ring (Temp. Decrease)66 


\section{LIST OF FIGURES (continued)}

Page

Figure 3.45 Distribution of the Axial Force in the Compression Ring (Temp. Decrease)........66

Figure 3.46 Distribution of the Moment, Mx, in the Compression Ring (Temp. Decrease).... 67

Figure 3.47 Distribution of the Torsional Moment, $\mathrm{T}$, in the Compression

Ring (Temp. Decrease)

Figure 3.48 Deformed Shape of the AP600 SBR Under Temp. Increase

Plus Water in the PCS Tank. 68

Figure 3.49 Distribution of the Meridional Stress Resultant, N1, (Temp. Increase).................69

Figure 3.50 Distribution of the Circumferential Stress Resultant, N2, (Temp. Increase) ......... 70

Figure 3.51 Distribution of the Meridional Moment, M1, (Temp. Increase) ............................. 71

Figure 3.52 Distribution of the Circumferential Moment, M2, (Temp. Increase).................... 72

Figure 3.53 Distribution of the Axial Force in the Tension Ring (Temp. Increase) ................. 73

Figure 3.54 Distribution of the Moment, $\mathrm{Mx}$, in the Tension Ring (Temp. Increase) ..............73

Figure 3.55 Distribution of the Torsional Moment, $\mathrm{T}$, in the Tension

Ring (Temp. Increase) .............................................................................................. 74

Figure 3.56 Distribution of the Axial Force in the Compression Ring (Temp. Increase) ......... 74

Figure 3.57 Distribution of the Moment, $\mathrm{Mx}$, in the Compression Ring (Temp. Increase) ..... 75

Figure 3.58 Distribution of the Torsional Moment, $\mathrm{T}$, in the Compression

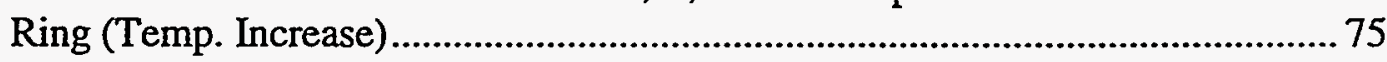

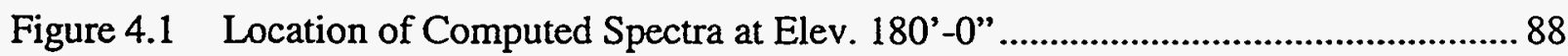

Figure 4.2 Envelope of North-South Spectra for all Soil Conditions at

Center of Mass in the North-South (X-X) Direction............................................... 89

Figure 4.3 Envelope of East-West Spectra for all Soil Conditions at

Center of Mass in the Vertical (Z-Z) Direction.

Figure 4.4 Envelope of Vertical Spectra for all Soil Conditions at

Center of Mass in the East-West ( $Y-Y)$ Direction. 91

Figure 4.5 Location of the Critical Section in the SBR Structure .92 


\section{LIST OF FIGURES (continued)}

Figure 4.6 First and Twelfth Sloshing Vibration Mode of Water in the PCS Tank Page

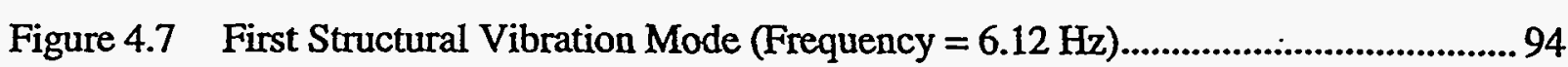

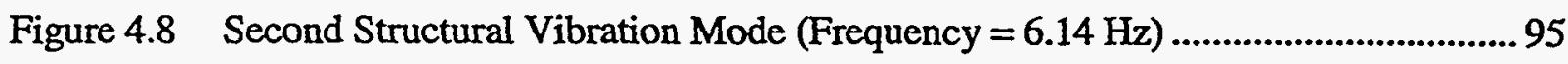

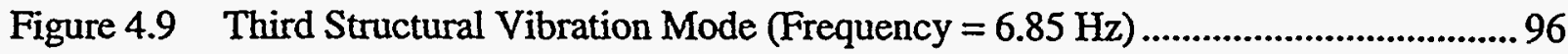

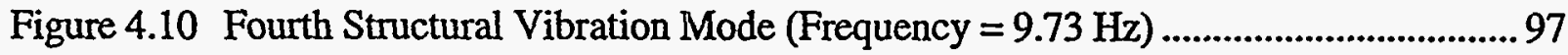

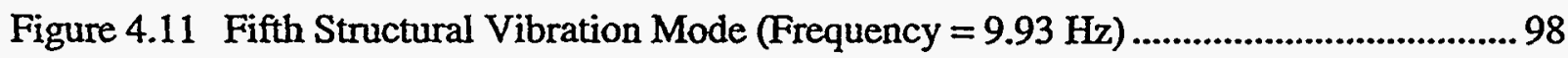

Figure 4.12 Distribution of the Meridional Stress Resultant, N1, (Seismic Load) ..................99

Figure 4.13 Distribution of the Circumferential Stress Resultant, N2, (Seismic Load) ........ 100

Figure 4.14 Distribution of the Meridional Moment, M1, (Seismic Load) ........................... 101

Figure 4.15 Distribution of the Circumferential Moment, M2, (Seismic Load) .................. 102

Figure 4.16 Distribution of Axial Force, Moment, Mx, and Torsion, $T$, in the

Tension Ring Due to Seismic Load.............................................................. 103

Figure 4.17 Distribution of Axial Force, Moment, Mx, and Torsion, $\mathrm{T}$, in the Compression Ring Due to Seismic Load .............................................. 104

Figure 5.1 Envelopes of Meridional Stress Resultants, N1, for Load Combination 1 ........ 121

Figure 5.2 Envelopes of Circumferential Stress Resultants, N2, for Load Combination 1.. 122

Figure 5.3 Envelopes of Meridional Moment Stress Resultants, M1, for Load Combination 1

Figure 5.4 Envelopes of Circumferential Moment Stress Resultants, M2, for Load Combination 1

Figure 5.5 Envelopes of Meridional Stress Resultants, N1, for Load Combination 2 ......... 125

Figure 5.6 Envelopes of Circumferential Stress Resultants, N2, for

Load Combination 2.

Figure 5.7 Envelopes of Meridional Moment Stress Resultants, M1, for

Load Combination 2 


\section{LIST OF FIGURES (continued)}

Figure 5.8 Envelopes of Circumferential Moment Stress Resultants, M2, for Load Combination 2

Figure 5.9 Interaction Diagram for the Tension Ring Above Two Air Intakes 129

Figure 5.10 Interaction Diagram for the Compression Ring 130

Figure 5.11 Compression Ring Including the Thickened Portion of Conical Shell 131

Figure 5.12 Interaction Diagram for the Compression Ring in Fig. 5.11

Figure A.1 Acoustic Elements 147

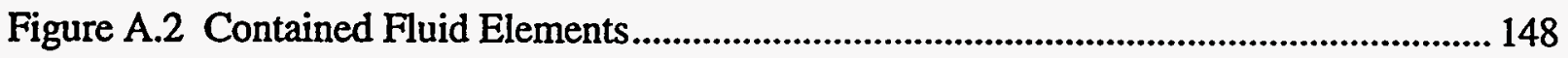

Figure A.3 Finite Element Model for Acoustic Modes.

Figure A.4 Dynamic Pressure Contour Plots Using Acoustic Elements. 150

Figure A.5 Displaced Shape and Dynamic.Pressure Contour Plots Using Contained Fluid Elements

Figure A.6 Mode Shapes and Dynamic Pressure Contour Plots Using Contained Fluid Elements 152

Figure A.7 Dynamic Pressure Due to Inertia Forces of Mode 1 153

Figure A.8 Comparison Between Dynamic Pressure Calculated by Theory and ANSYS ..... 153

Figure A.9 Annular Tank Filled with Water. 154

Figure A.10 Finite Element Model for the Annular Tank. 155

Figure A.11 Mode Shapes and Dynamic Pressure for Mode 1 155

Figure A.12 Mode Shapes and dynamic pressure for Mode 2 156

Figure A.13 Mode Shapes and Dynamic Pressure for Mode 5 157

Figure A.14 Fluid Column Supported by a Spring 158

Figure A.15 Deformed Shape and Pressure Distribution for the Fluid Column in Fig. A.14. 


\section{LIST OF FIGURES (continued)}

Figure A.16 Deformed Shape and Pressure Distribution at $\mathrm{t}=0.0096 \mathrm{Sec}$.

Figure A.17 Comparison Between Results (Case (a)) ….................................................... 161

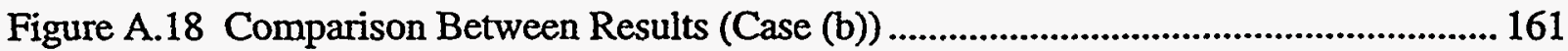

Figure A.19 Example of an Elevated Tank Filled with Water........................................ 162

Figure A.20 Theoretical Idealization of the Tank in Fig. A.19......................................... 163

Figure A.21 Finite Element Model for the Tank in Fig. A.19 ......................................... 164

Figure A.22 Modes of Vibration for the Tank in Fig. A.19 ............................................. 165

Figure A.23 Displaced Shape Due to Application of the SRSS Method .............................. 166 


\section{LIST OF TABLES}

Table 4.1 Table 4.1. Modal Mass and Frequency for Structural Modes............................. 80

Table 4.2 Participator Factors for Structural Modes ............................................................. 81

Table 4.3 Base Shear and Moment Results at Elev. 180'-0" Due to the Spectra for Four Different Soils............................................................................... 83

Table 5.1 Maximum and Minimum Member Forces - Tension Ring ................................. 106

Table 5.2 Maximum and Minimum Member Forces - Compression Ring......................... 107

Table 5.3 Maximum and Minimum Member Forces - Tension Ring ................................ 108

Table 5.4 Maximum and Minimum Member Forces - Compression Ring........................ 108

Table 5.5 Design Forces at the Critical Shell Sections ..................................................... 110

Table 5.6 Provided and Calculated Area of Steel on each Face of the Critical ................. 115

Table 5.7 Provided and Calculated Total Area of Steel at Each Critical Section in the Shell 


\section{EXECUTIVE SUMMARY}

The AP600 steel containment vessel is surrounded by a Shield Building Roof (SBR) consisting of a 3'-0" thick cylindrical shell that is covered with a $2^{\prime}-0$ " thick truncated cone. The conical shell supports a Passive Cooling System (PCS) annular water storage tank. Fifteen $16^{\prime}-0^{\prime \prime}$ by $5^{\prime}-0^{\prime \prime}$ air intake openings are located at 22.5 degrees on center around the circumference of the shell at Elev. 241'-0". Tension and compression rings are provided at the cone-cylinder and at the top of the truncated cone, respectively. As the shield building is subjected to various loading conditions, all critical sections in the structure must be carefully examined. This is necessary to ensure that the generated forces at these sections do not exceed the design values at these locations. For this purpose, a three-dimensional finite element model for the AP600 SBR structure was developed and utilized to determine the forces at different locations due to different loading conditions using the ANSYS finite element software.

The finite element model consisted of 10,698 elements with 5,733 active degrees of freedom. Shell elements were used to model the cylindrical and conical shells. Sensitivity studies were carried out to determine the element size in the cylinder, around the air intakes and in the cone. In addition, modeling middle surfacing eccentricities at the tension and compression rings were carefully incorporated. All attachments within the part of the shield building modeled for the finite element, e.g., shield plate, stair enclosure, valve room and air baffle upper portion, were included in the finite element model. 
Continued fluid elements were utilized to model the water in the PCS tank. These elements were defined by eight nodes with three translation degrees of freedom per node (Fluid 80 in the ANSYS element library). This element was selected so that the sloshing modes associated with water vibration can be obtained. Several simple fluid-structure interaction problems were solved to verify the performance of the Fluid 80 element by comparison with published theoretical solutions.

The finite element model was subjected to dead (own weight plus hydrostatic) load, snow load, thermal load with and without thermal gradient, wind and seismic loads. Each of these cases was individually analyzed. Stress resultants, i.e., meridional and circumferential axial loads and moments around the SBR structure and in the tension and compression ring were calculated.

Response spectrum analysis was used to determine the forces induced in the SBR due to safe shutdown earthquake (SSE). Two horizontal components together with a vertical component of the SSE with an assumed 7\% damping were used in the analysis. Four different soil conditions were considered and the most critical spectrum was selected.

Free vibration modes were extracted by the reduced method in the ANSYS program. Approximately 1200 master degrees of freedom were employed in the analysis. Sixtynine vibration modes (49 structural and 20 sloshing modes) were obtained. The stress resultants associated with high frequency modes were approximated using the procedure outlined in Appendix A of Sec. 3.7.2 of the Standard Review Plan (SRP). Modal and 
high-frequency stress resultants were combined taking into account the effect of the coupling of closely spaced modes. These were then used to calculate the maximum stress resultants due to the three earthquake directions by the Square Root of the Sum of Squares (SRSS) method.

The design adequacy of several sections in the SBR was checked considering two different load combinations listed in the SRP. For Load Combination 1, dead, fluid, snow and wind loads were combined using the appropriate load factor. In Load Combination 2, dead, fluid, snow, thermal and SSE loadings were combined. The stress resultants associated with these two load combinations were compared to define the most critical loading combinations. Sections in the cylindrical shell, the conical roof, and in the walls of the PCS tank were analyzed considering the sections under moment, axial loads, in plane shear and torsion. The two rings were investigated considering the interaction between torsion, axial loads, shear forces and biaxial moments. Interaction diagrams for the tension and compression rings were constructed using the PCACOL software, a program developed by The Portland Cement Association (PCA) for designing concrete sections.

The analysis and design revealed that the provided steel at several sections in the SBR was inadequate. The discrepancy between Westinghouse provided steel and the steel calculated in this report is due to: (1) the difference between the design forces which resulted from the different finite element mesh sizes used in the two analyses (this report used finer mesh than that used by Westinghouse); (2) the conservative assumption used 
in this report such as considering membrane and moment stress resultants to occur at the same Azimuth; and (3) by placing equal amount of steel rather than providing the calculated area on each face of the shell. The latter was used by Westinghouse.

To the authors knowledge, Westinghouse has incorporated some changes in the design of the AP600 SBR such as reducing the thickness of the conical roof slab and the PCS tank walls. These changes need to be taken into consideration when interpreting the results in this report. 


\section{ACKNOWLEDGMENT}

The authors would like to express their appreciation for the members of the U.S. Nuclear Regulatory Commission, Dr. Thomas Cheng (Project Officer), Dr. Seung Lee (Structural Engineer), Mr. David Terao (Section Chief), Mr. Goutam Bagchi (Branch Chief, Structural and Geosciences), and Mr. Bernard L. Greiner, (Program Manager, Division of Engineering) for their help throughout the course of this work. The authors would also like to acknowledge the project secretaries, Ms. Jeanine Crosman and Ms. Denise Wood, for word processor operations and secretarial services associated with this project. Additionally, they would like to thank Ms. Connie Bates, Administrative Specialist, for her assistance on financial planning and tracking. 


\section{INTRODUCTION}

\subsection{Containment Description}

The AP600 steel containment vessel is surrounded by a reinforced concrete shield building structure. This building consists of a 3'-0" thick cylindrical portion that is covered with a 2'-0" thick truncated conical shell. The general layout of the shield building is illustrated in Fig. 1.1.

The cylindrical section of the shield building provides a radiation shield function, a missile barrier function, and a passive cooling function. Additionally, this cylindrical portion supports the roof and the passive containment cooling system (PCS) water storage tank. The inside diameter of the cylinder is $139^{\prime}$. The floor slabs and the structural walls of the auxiliary building are connected to the cylindrical section of the shield building below Elev. 180'-0". At Elev. $241^{\prime}-0$ ", the cylinder is provided with fifteen $16^{\prime}-0^{\prime \prime}$ by $5^{\prime}-0^{\prime \prime}$ air intake openings located at 22.5 degrees on center around the circumference of the cylinder. This arrangement results in a slightly unsymmetrical cylindrical shell. At Elev. 250'-4 1/6", the cylinder is provided with a 42" wide ring beam. The portion of the ring beam above the air intake openings is referred to hereafter as the tension ring. While the portion of the ring above the cylindrical shell between these openings will be referred to as columns. These columns supports the tension ring at Elev. 246'-0". The function of this beam is to support the radial, vertical and torsional loads induced at the cylindercone junction.

The conical roof of the AP600 shield building supports the passive containment cooling system tank and air diffuser. In constructing the conical roof, sixteen precast concrete double-tee sections with a 6" thick slab are used to support an 18" cast in place reinforced concrete slab. These sections are attached to the tension ring beam at Elev. 246'-0" and are supported on a temporary compression steel beam at Elev. 281'-2 1/8". Sufficient numbers of shear studs along the interface surface are provided to insure complete composite action between the precast and the cast-in-place concrete. 
The passive cooling system tank is an annular tank supported by the conical roof as shown in Fig. 1.1. The inside and the outside diameters of this tank are $32^{\prime}-0^{\prime \prime}$ and $80^{\prime}-0^{\prime \prime}$ respectively, with a 2'-0" thick walls lined with stainless steel plates. This tank is covered by a 2'-0" thick slab. At Elev. 273'-1 55/64", the conical roof supports a hanging 2'-0" thick concrete shield plate. This plate is supported by several hangers that are attached to the conical roof and the compression ring at Elev. 281'-2 1/8'. Other nonstructural elements attached to the conical roof are: (1) valve room; (2) stair enclosure; and (3) walkway.

\subsection{Objective}

As the AP600 shield building structure is subject to various loading conditions, all the critical regions in and near the roof, i.e., the cylindrical and conical shells, tension ring, compression ring and the junction between the cooling system tank and the conical roof must be carefully examined. Therefore, a detailed three-dimensional structural analysis for the shield building roof (SBR) is needed to calculate the design forces at these locations under different load combinations.

\subsection{Methodology}

The general purpose finite element program ANSYS [1.1], Version 5.1 was selected to perform the analysis of the AP600 shield building roof. The ANSYS program was previously used by the authors to analyze several steel nuclear containment buildings. Despite the authors experience with the structural analysis portion of the program it was found important to study the waterstructure interaction features of ANSYS when conducting the seismic analysis of the SBR. This was accomplished by analyzing several simple structures and comparing the ANSYS results with those published in the literature. Appendix A gives complete details of the examples that were used in these investigations.

The SBR structure was first analyzed under dead, snow, fluid, wind and seismic loads. Of the several load combinations given in the ACI 349 [1.3] and the Standard Review Plan (SRP) [1.2], 
two load combinations were considered which had been identified as the most critical load cases [1.4].

The finite element modeling of the AP600 SBR structure is described in Chapter 2. The results of the individual load cases are listed in Chapter 3. The seismic analysis is presented in Chapter 4. These results are illustrated in several graphs showing the distribution of meridional and circumferential stress resultants along two meridians, one located at the center of an air intake ( 0 deg Azimuth) and the second midway between two air intakes (11.25 deg Azimuth). The individual load cases are combined to check the design adequacy of the critical sections in the AP600 SRB as listed in Chapter 5.

\subsection{References}

1.1. ANSYS, Inc., “ANSYS User's Manual," Revision 5.1, Southpoint, Cansonsburg, PA, 1995.

1.2. U.S. Nuclear Regulatory Commission, Section 3.8.4, "Standard Review Plan (SRP)," Office of Nuclear Reactor Regulation, NUREG-0800, 1981.

1.3. American Concrete Institute, "Code Requirements for Nuciear Safety-Related StructuresACI 349," Part 4, Farmington Hills, MI, 1996.

1.4. Letter from L. Greimann from Ames Laboratory to T. Cheng from USNRC, June 17, 1996.

1.5. U.S. Nuclear Regulatory Commission, Section 3.7.2, "Standard Review Plan (SRP)," Office of Nuclear Reactor Regulation, NUREG-0800, 1981. 


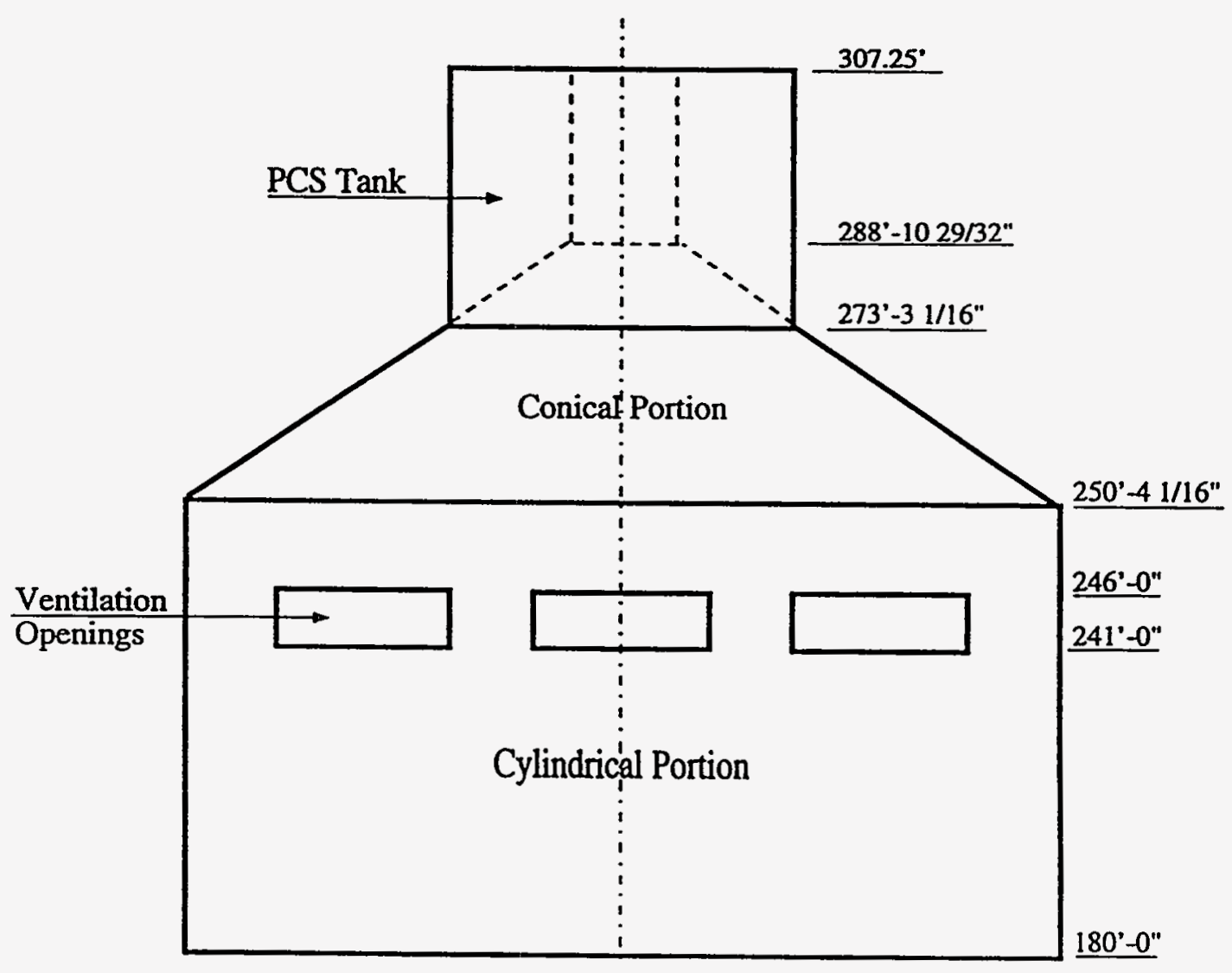

Figure 1.1 General Layout of the AP600 Shield Building Roof 


\section{THREE-DIMENSIONAL MODEL PARAMETERS}

\section{$2.1 \quad$ Introduction}

In this chapter, the three-dimensional model of the AP600 SBR was constructed. The roof structure was divided into several regions to facilitate the modeling process. A mesh sensitivity study was conducted to determine the suitable element sizes that would compute the expected stress field in each region. In the next chapter, the model was checked by comparing static analysis results to simple theoretical computations.

\subsection{Modeling Procedure}

The main components of the SBR are illustrated in Fig. 1.1. The cylindrical and conical portions were modeled with elastic shell element, Shell63, included in the ANSYS [2.1] element library. Shell63 is a four-noded shell element with both membrane and bending capabilities. The cylindrical portion was assumed to be fixed at Elev. 180'-0" where it intersects the roofs of other building. Radial and hoop stiffeners of the conical roof were modeled with the Shell63 elements and connected to the conical roof with beam elements, Beam4 [2.1] having effectively rigid bending and axial stiffnesses. Tie rods and hangers connecting the shield plate to the conical roof were modeled with truss elements, Link8 [2.1]. Water in the PCS tank was modeled with the three-dimensional contained fluid element, Fluid80 [2.1], with representative bulk and sloshing stiffness. The valve room, stair enclosure and the air baffle upper portion were modeled with the lumped mass element, Mass21, and were attached to the conical roof middle surface at their respective support locations.

The model contained 15,097 nodes and 10,698 elements. The total number of active degrees of freedom in the model was 57,330 with a wave front [2.1] of 1,498 . The assembled model is illustrated in Fig. 2.1. In the following sections, the mesh selection and modeling of each region of the roof structure are described. 


\subsubsection{Cylindrical Shell}

The cylindrical shell is subjected to membrane force in the direction of the conical roof that will cause edge radial load and hoop moment [2.2] at the cone-to-cylinder juncture at Elev. 250' - 4 $1 / 16 "$. Therefore, a high stress concentration region is expected to occur at the tension ring location (Elev. 250' - 4 1/16").

A mesh sensitivity study was conducted on a cylinder with radius, $r$, of $71^{\prime}$ and wall thickness, $t$, of $3^{\prime}$. The cylinder is provided with a guided support at the base that permits radial displacement, whereas axial displacement and rotation are prohibited. The top of the cylinder is subjected to edge load of $1200 \mathrm{k} / \mathrm{ft}$ and hoop moment of $1000 \mathrm{k}-\mathrm{ft} / \mathrm{ft}$. The theoretical solution [2.3] showed that the width of the peak meridional moment, $X_{c}$, is $2.3(\mathrm{rt})^{1 / 2}$. Therefore, element sizes were reduced at the top of the cylinder in proportion to $\mathrm{X}_{c}$. A coarse mesh was used at the lower part remote from the edge loads. Three meshes were constructed as shown in Fig. 2.2 in which the element sizes were progressively halved from Mesh A to Mesh C. The meridional moments obtained from the three meshes were compared to the theoretical solution in Fig. 2.3. The figure indicates that the finite element solution obtained by Mesh $B$ and $C$ has converged to the theoretical values. Therefore, Mesh B was selected for the SBR cylindrial portion and the PCS vertical walls to achieve adequate computation of stresses economically.

\subsubsection{Conical Roof}

The finite element mesh of the conical roof was also selected to capture high stress concentration regions due to edge loads at the tension ring location [2.2]. A mesh sensitivity study was conducted on a frustum of a cone (see Fig. 2.6) with an upper radius of 17', lower radius of 71' and a wall thickness of 2'. The cone generators are inclined to the horizontal by $35 \mathrm{deg}$. The top edge of the cone was free, whereas the lower edge was provided with a roller support and was subjected to an edge load of $1200 \mathrm{k}-\mathrm{ft}$ and an edge moment of $1000 \mathrm{k}-\mathrm{ft} / \mathrm{ft}$. 
The theoretical solution [2.3] indicated that the width of the peak meridional moments along the cone vertical axis is 18'. Therefore, a finer mesh was selected for the lower portion of the cone to capture the expected high stress concentration in that region. Three meshes were constructed as shown in Fig. 2.4 in which the element sizes were progressively halved from Mesh A to Mesh C. Finite element solutions for meridional moments along the cone vertical axis were compared to theory in Fig. 2.5. The comparison indicated that Mesh B and C results converged to the theoretical solution. Therefore, the element sizes of the conical portion of the SBR were based on Mesh B. A fine mesh was selected near the tension ring and at the PCS external wall, whereas a coarser mesh was utilized at the compression ring.

\subsubsection{Cylindrical Shell Around Air Intake Opening}

A state of stress singularity exits at the corner of the rectangular air intakes of the cylindrical shell. In order to select the mesh size that would achieve the best results economically, an hrefinement procedure was conducted based on minimizing total strain energy error, E [2.4] defined as:

$$
E=\sum_{i=1}^{N_{\varepsilon}} \int_{v}\{\Delta \sigma\}^{T}[D]^{-1}\{\Delta \sigma\} d V
$$

where $\Delta \sigma$ is an estimate of the error in stresses which is computed as the difference between the averaged stresses at each node from all attached elements and the stresses computed from individual elements, $\mathrm{D}$ is the modular matrix, $\mathrm{V}$ is the volume of each element and $\mathrm{N}_{\mathrm{e}}$ is the total number of elements in the model.

An axially loaded cylindrical sector that subtends an angle of $11.25 \mathrm{deg}$ at the center was solved (see Fig. 2.6). The geometric configurations of the sector were similar to the SBR cylindrical shell. A rectangular opening with a height of 5' and a width of $16^{\prime}-5^{\prime \prime}$ was included in the model 
(Fig. 2.6 (a)). Symmetry boundary conditions were applied at both vertical edges. An axial load of $1200 \mathrm{k} / \mathrm{ft}$ was applied at the top edge whereas the bottom edge was fixed.

Figure 2.6 (b) illustrates the four meshes generated during the refinement process. A coarse mesh was selected (Mesh A) and progressively refined based on the strain energy error criterion. A contour plot of the strain energy error was determined by ANSYS and the mesh was manually refined at the location of highest strain energy error. The total strain energy error, E, for the four meshes were compared in Fig. 2.7. The bending moment, $\mathrm{M}$, axial load, $\mathrm{N}$ and the vertical displacement at section B were computed from the four models and compared in Fig. 2.8. Figures 2.7 and 2.8 indicate that convergence was achieved by utilizing Mesh C. Consequently, element sizes at the vicinity of the air inlets were based on Mesh $C$.

\section{- 2.2.4 Middle Surface Eccentricities}

The SBR structure was basically modeled with shell elements located at the shell middle surface. Due to changes in the shell thickness at some locations, the middle surface changed its position and became eccentric. Surface eccentricities at Elevs. 246' $-0^{\prime \prime}, 273^{\prime}-1$ 3/16" and 288'-10 29/32" were included in the three-dimensional model.

\subsubsection{At Elevation 246'-0"'}

Figure 2.9 shows the middle surface eccentricity of 3" caused by the sudden increase in shell thickness from $3^{\prime}-0^{\prime \prime}$ at the columns between air intakes to $3^{\prime}-6^{\prime \prime}$ at the tension ring. Shell elements representing the tension ring and the columns between air inlets were connected with beam elements Beam4 [2.1], with effectively rigid bending and axial stiffnesses. 


\subsubsection{At Elevation 273'-1 3/16"'}

The thickness of the conical roof was increased at the external wall of the PCS tank. This caused a change in the middle surface direction as illustrated in Fig. 2.10. To account for this configuration tapered shell elements were used to model the thickened portion of the conical roof. Shell elements modeling the PCS tank external wall was connected to the roof with rigid beam elements to avoid material repetition.

\subsubsection{At Elevation 288'-10 29/32'"}

The change in the middle surface direction at the conical roof juncture with the internal PCS tank vertical wall was included in the model as discussed in Sec. 2.2.4.2. Tapered shell elements at the roof-thickened portion were connected to the PCS vertical wall with effectively rigid beam elements.

\subsubsection{Water in the PCS Tank}

Water in the PCS tank was modeled with the fluid element, Fluid80 (see Fig. 2.11). The element is defined by eight nodes with three translational degrees of freedom per node. The element formulation is based on modifying structural solid elements to simulate fluid media contained in a vessel with no net flow rate [2.1]. The elastic modulus defining the bulk modulus of water was assumed to be $360 \mathrm{ksi}$. The element is provided with grounded springs at the water-free surface to model the fluid sloshing stiffness [2.1]. Degrees of freedom of nodes at the water/structure interface were coupled with constraint equations to allow relative tangential motion of water with respect to the structure and to prevent relative motion normal to the water/structure interface. The water model adopted in this work was verified by solving several simple fluid-structure interaction problems and comparing the solution with the theory (Appendix A). 


\subsubsection{Conical Roof Stiffeners}

Radial and hoop stiffeners of the conical roof (see Fig. 2.12) were modeled with the shell element, Shell63. Effectively rigid beam elements were introduced to connect the stiffeners to the conical roof and the tension ring as illustrated in Fig. 2.12.

\subsubsection{Shield Plate}

The shield plate at Elev. 266'-0" was modeled with the shell element, Shell63. It was connected to the conical roof with eight vertical hangers and seven inclined tie rods. The eighth tie rod facing the valve room does not exist. Both tie rods and hangers were modeled with the threedimensional truss element, Link8 [2.1].

\subsubsection{Stair Enclosure, Valve Room and Air Baffle Upper Portion}

The stair enclosure, valve room and air baffle upper portion were modeled with lumped mass elements, Mass21, that produces translational inertia loads only. The lumped mass elements were located at the middle surface of the conical roof. The magnitude and location of the lumped masses for each of these components was determined from a Westinghouse three-dimensional finite element model (see Fig. 2.13) which provided support reactions [2.5] due to dead load and one quarter of the live load. The total mass was 40,159 , and $284.5 \mathrm{lb}-\mathrm{sec}^{2} /$ in for the stair enclosure, valve room and the air baffle upper portion, respectively.

\subsection{Material Properties}

The SBR structure is made of reinforced concrete with a unit weight of $150 \mathrm{lb} / \mathrm{ft}^{3}$. The stress strain relation was assumed to be perfectly elastic with an elastic modulus of $3605 \mathrm{ksi}$ [2.6] and a Poisson's ratio of 0.2 . The coefficient of thermal expansion was assumed to be $5.5 \times 10^{-6} /{ }^{\circ} \mathrm{F}[2.6]$. 


\subsection{References}

2.1. ANSYS, Inc., "ANSYS User's Manual," Revision 5.1, Southpoint, Cansonsburg, PA, 1995.

2.2. Billington, D. P., "Thin Shell Concrete Structures," McGraw Hill, New York, NY, 1965.

2.3. Young, W. C., "Roark's Formulas for Stress and Strain," McGraw Hill, New York, NY, 6th Ed., 1989.

2.4. Zeinkiewicz, O. C., and Taylor, R. L., "The Finite Element Method," Vol. 1, McGraw Hill, New York, NY, 3rd Ed., 1989.

2.5. Letter from Westinghouse to U.S. NRC, Docket No. STN-52-003, May 30, 1996.

2.6. American Concrete Institute, "Building Code Requirements for Structural Concrete-ACI 318-95," Farmington Hills, MI, 1995. 


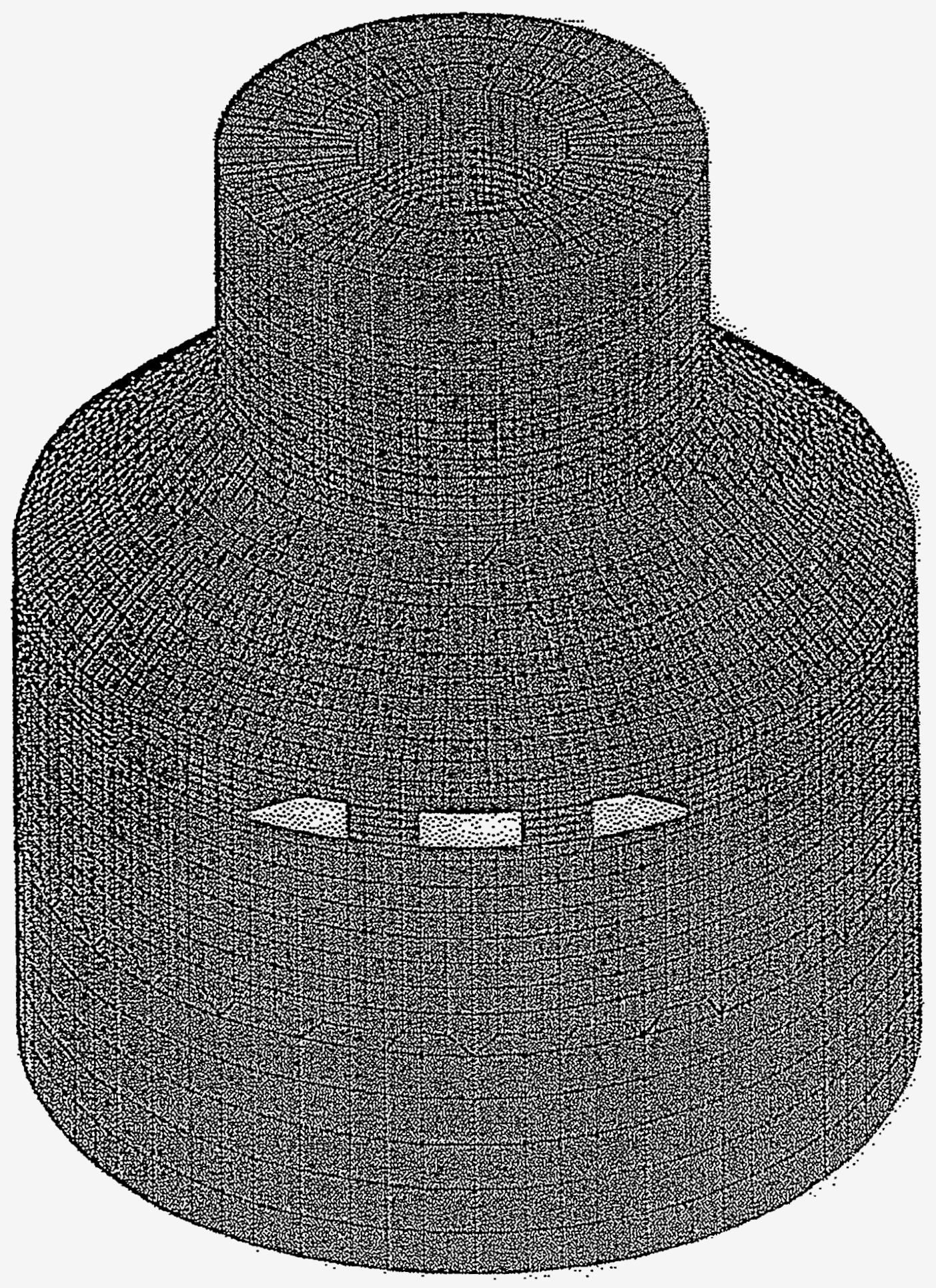

Figure 2.1 Three-dimensional Finite Element Model of the AP600 SBR 


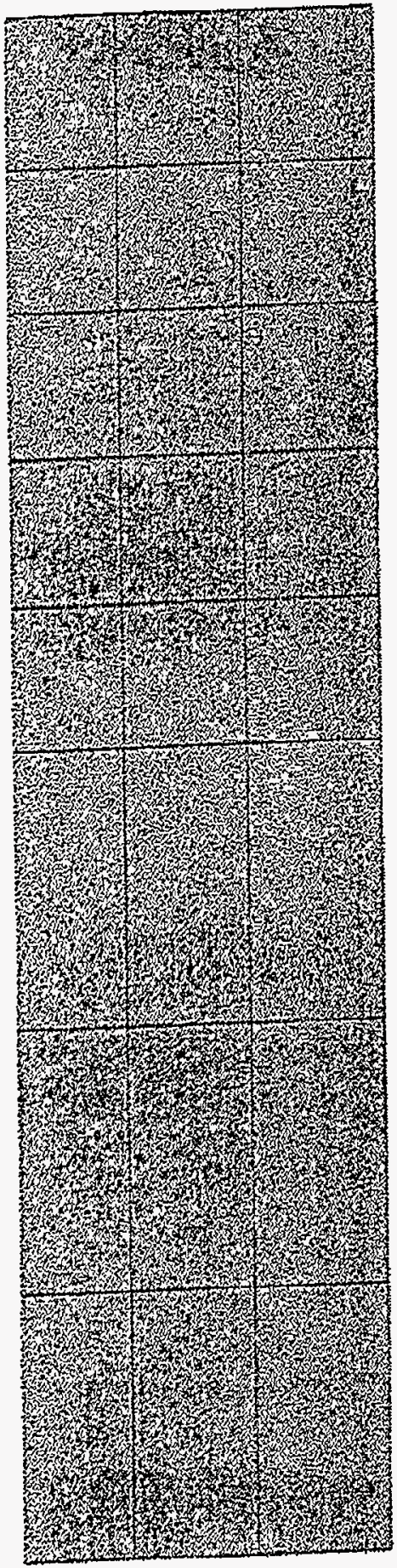

Mesh A

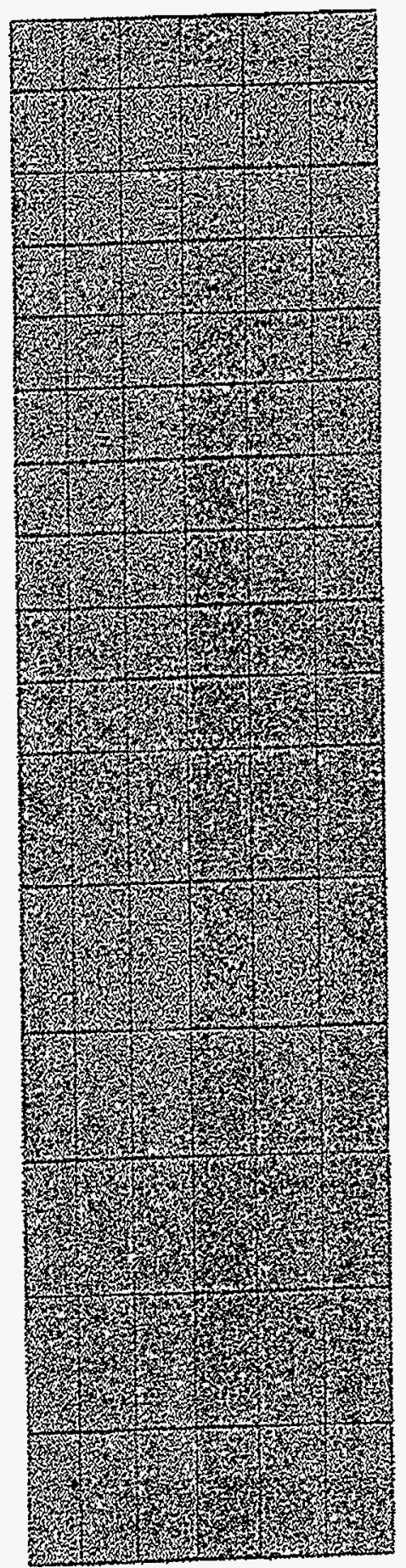

Mesh B

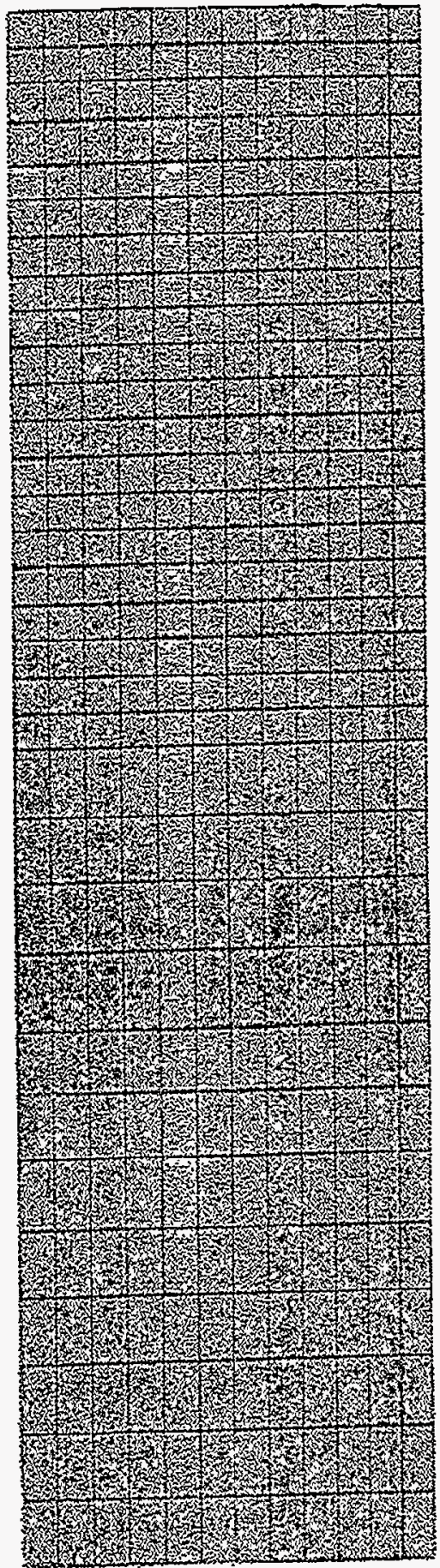

Mesh C

Figure 2.2 Mesh Sensitivity Study for a Cylindrical Shell Subjected to Edge Loads 


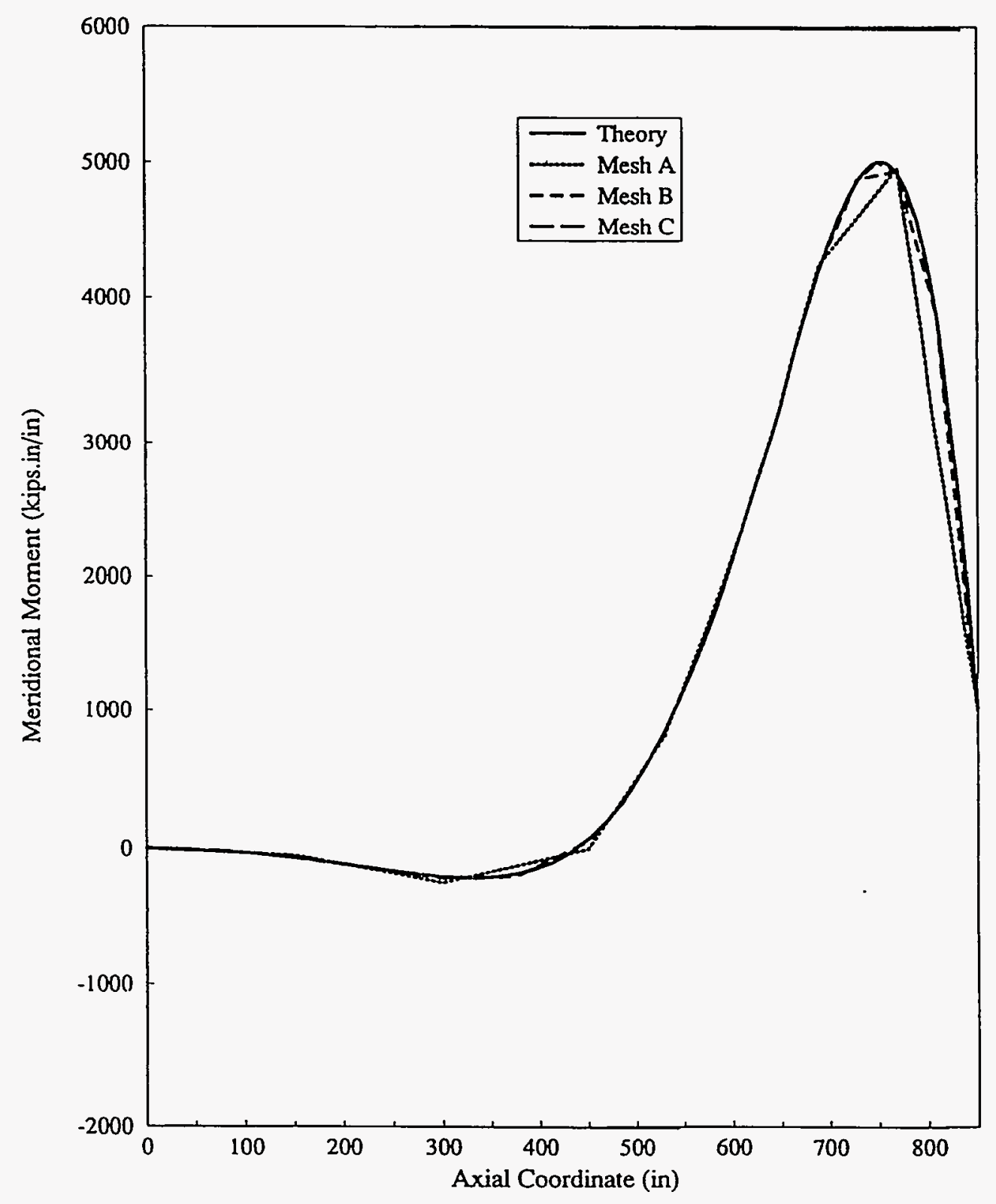

Figure 2.3 Finite element and Theoretical Meridional Moments in the Cylindrical Shell in Fig. 2.2 


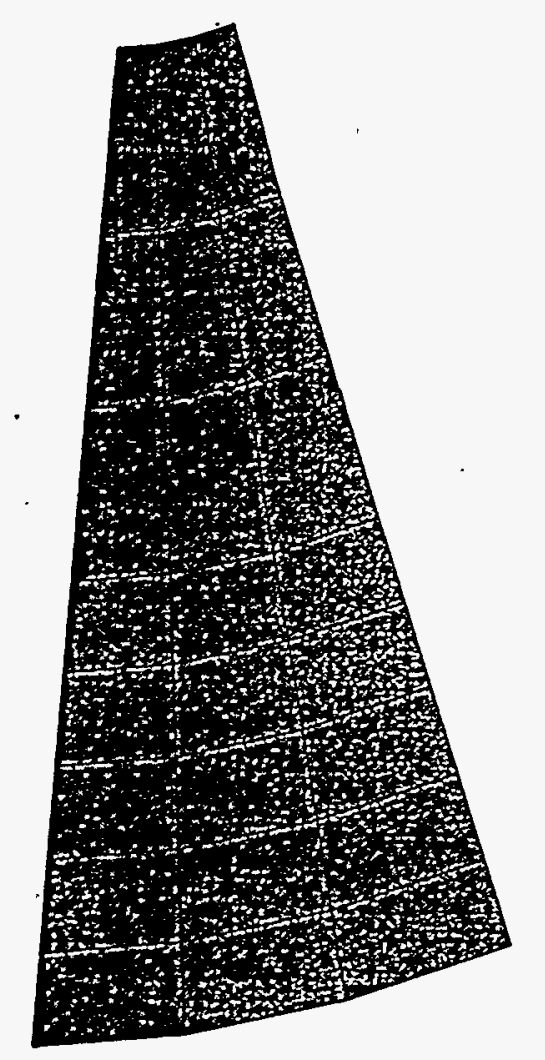

Mesh A

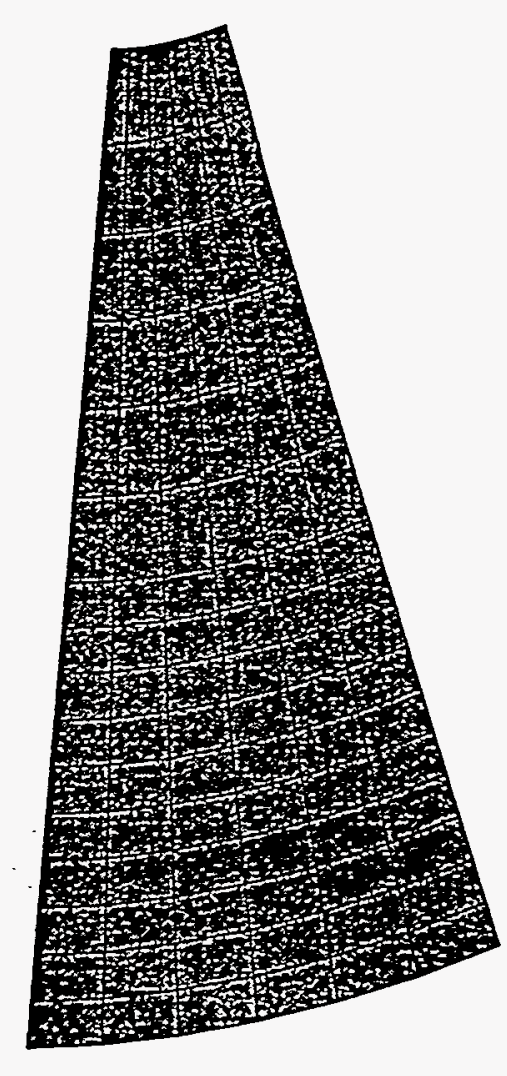

Mesh B

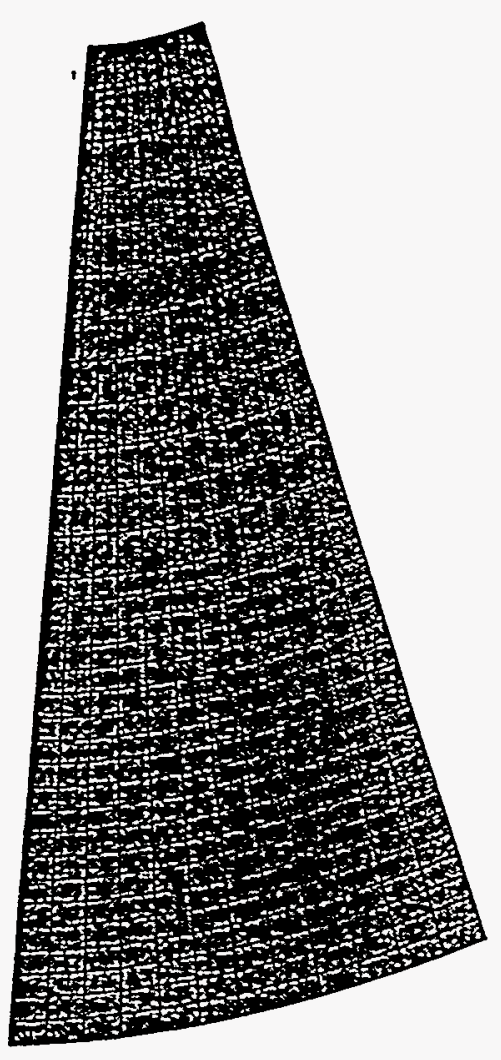

Mesh C

Figure 2.4 Mesh Sensitivity Study for a Conical Shell Subjected to Edge Loads 


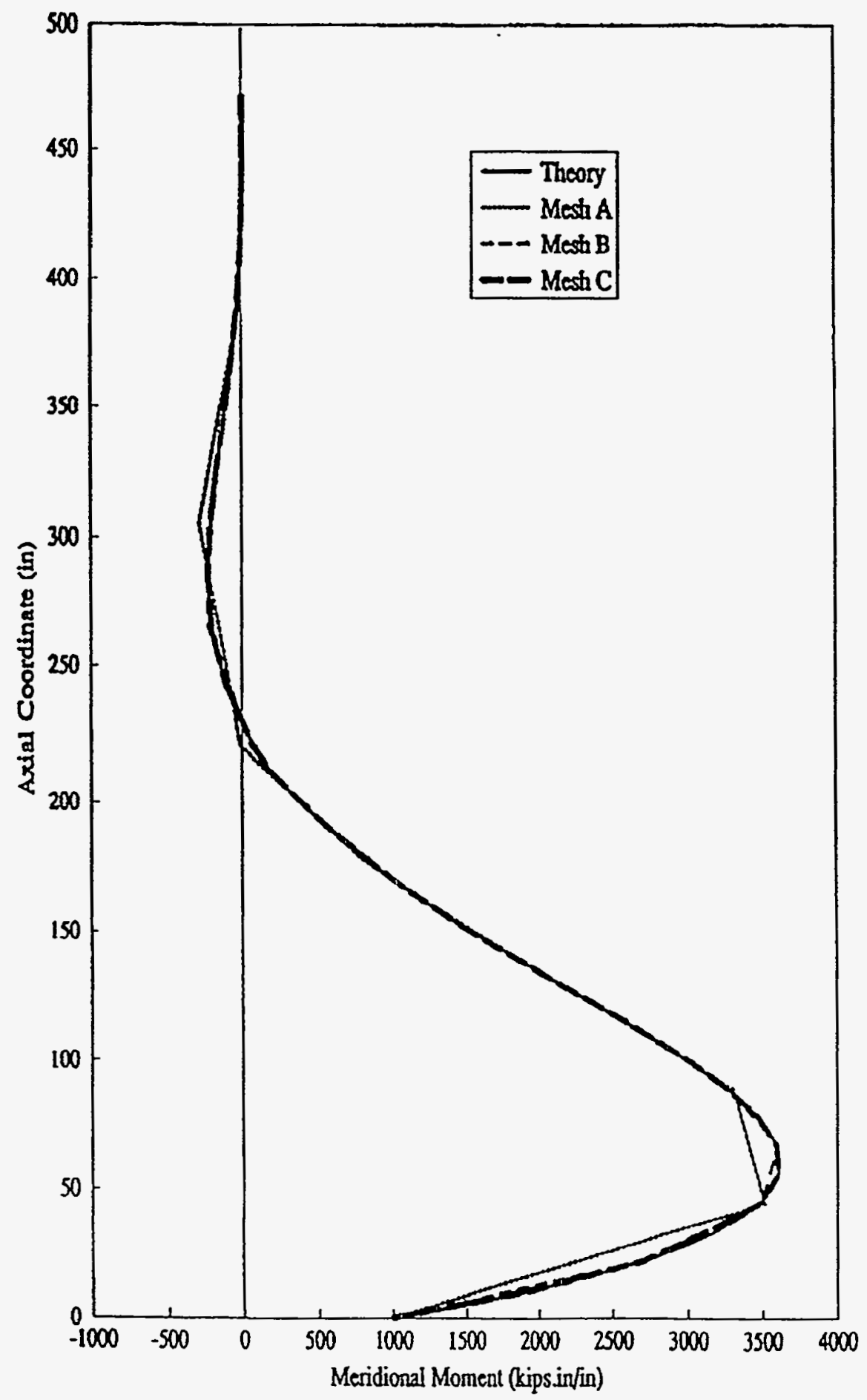

Figure 2.5 Finite Element and Theoretical Meridional Moment in the Conical Shell in Fig. 2.4. 


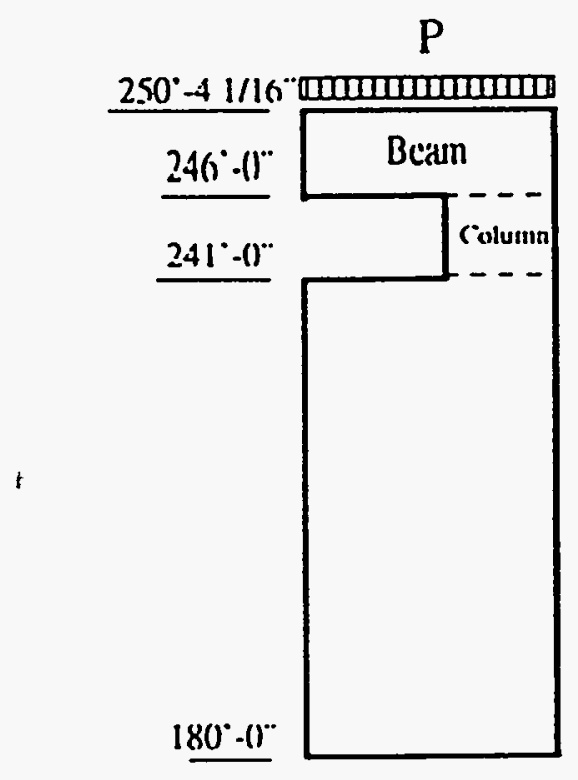

(a) Elevation view of a portion from a cylinder with an opening

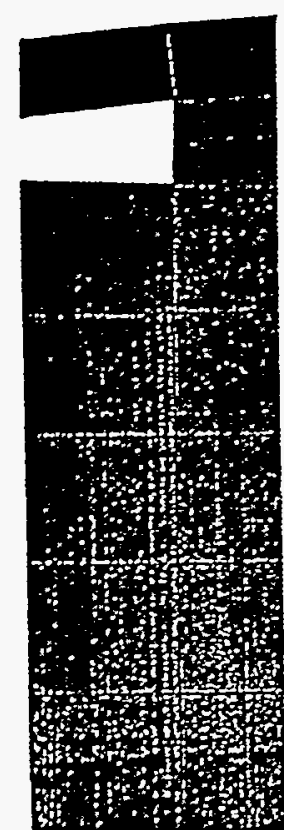

Mesh A

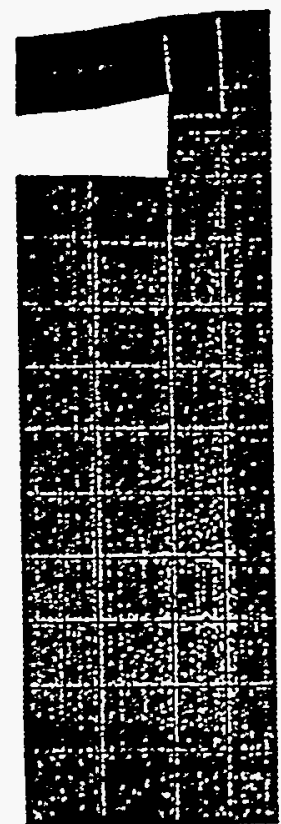

Mesh B

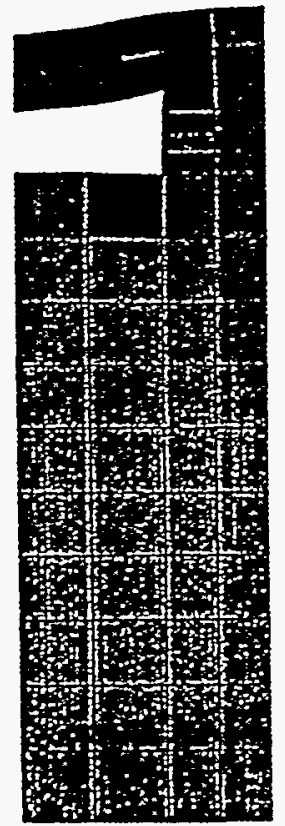

Mesh C

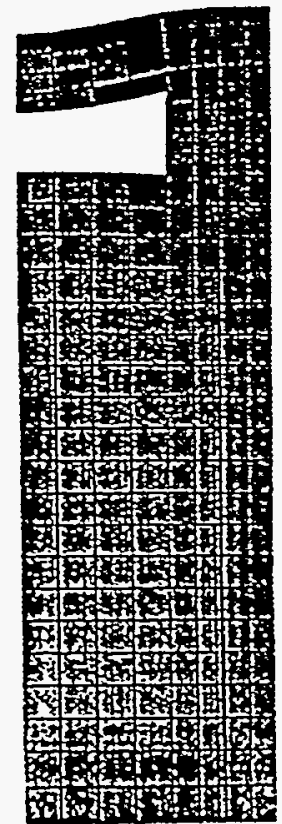

Mesh D

(b) Different mesh size

Figure 2.6 Mesh Sensitivity Study for an Axially Load Cylindrical Shell with an Opening 


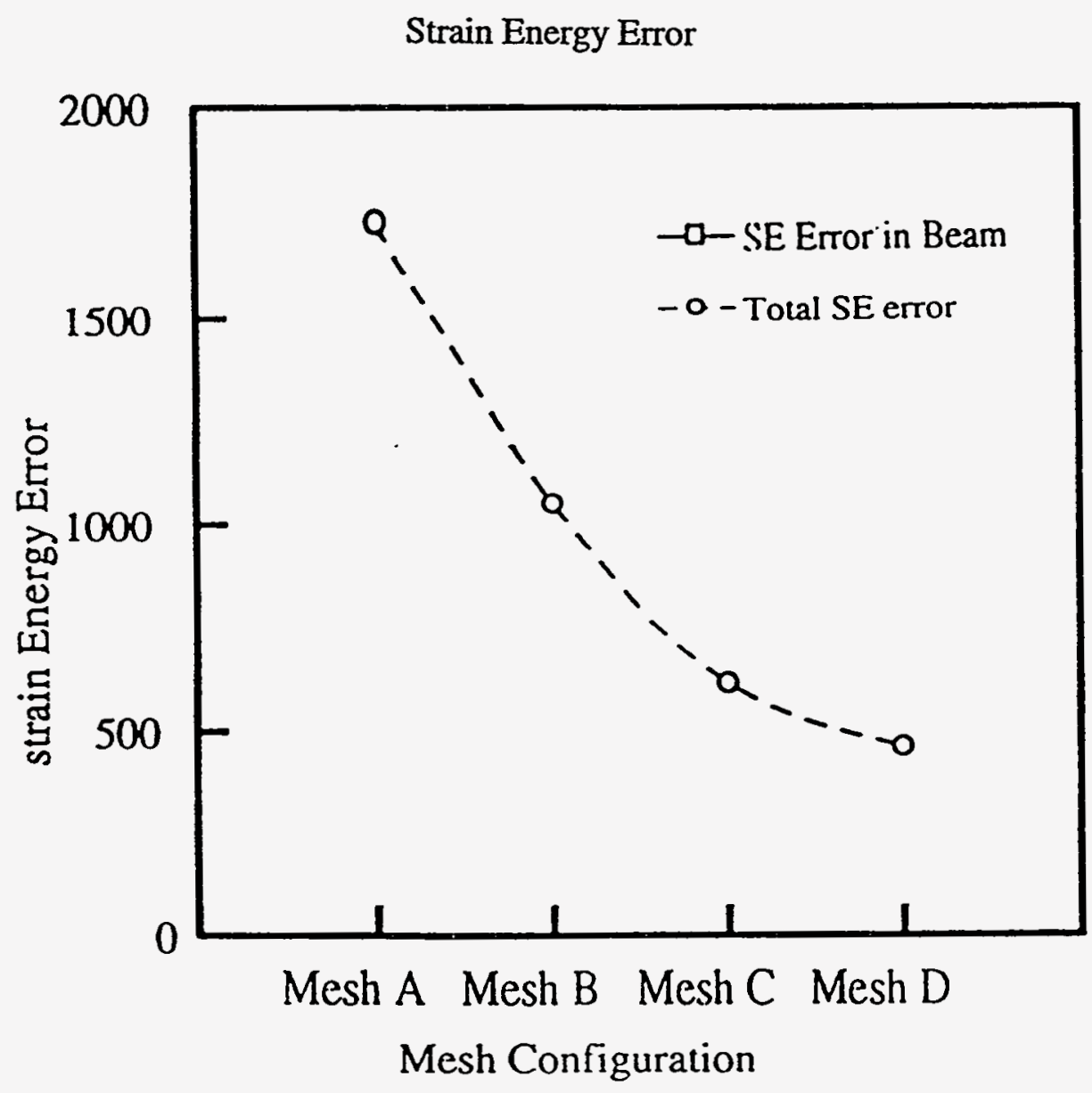

Figure 2.7 Comparison of Strain Energy Error and Mesh Size 


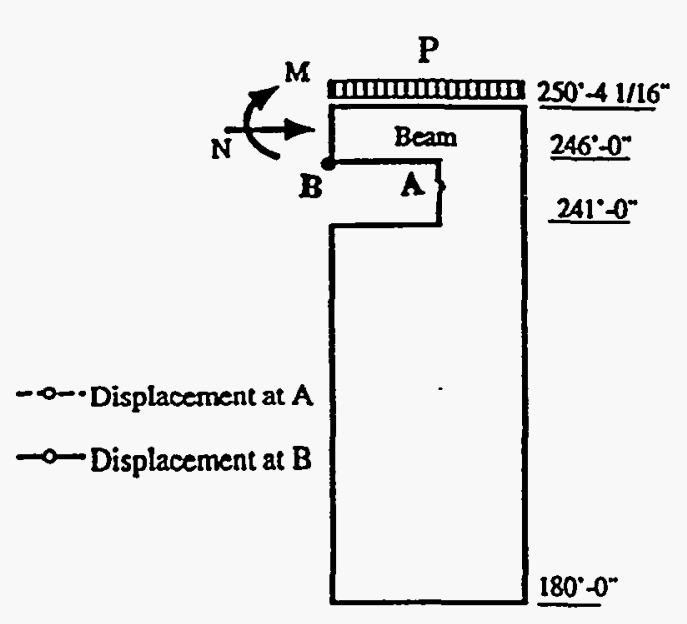

(a) Cylinder with Rectangular Opening

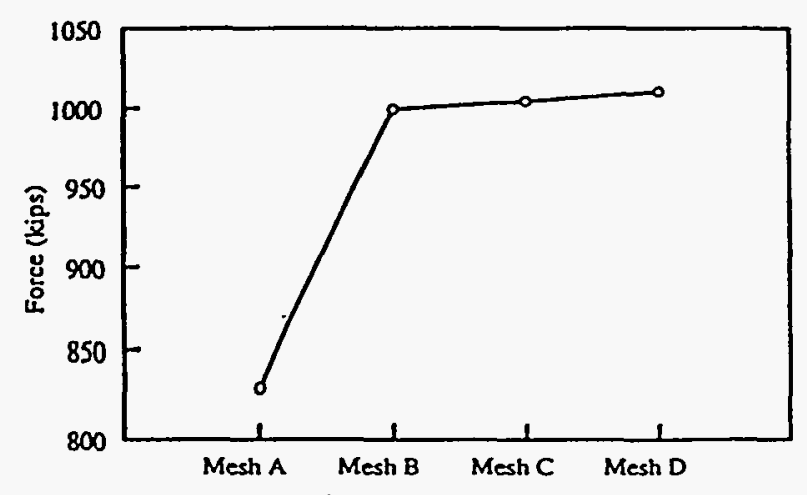

(c) Normal Force, $\mathrm{N}$

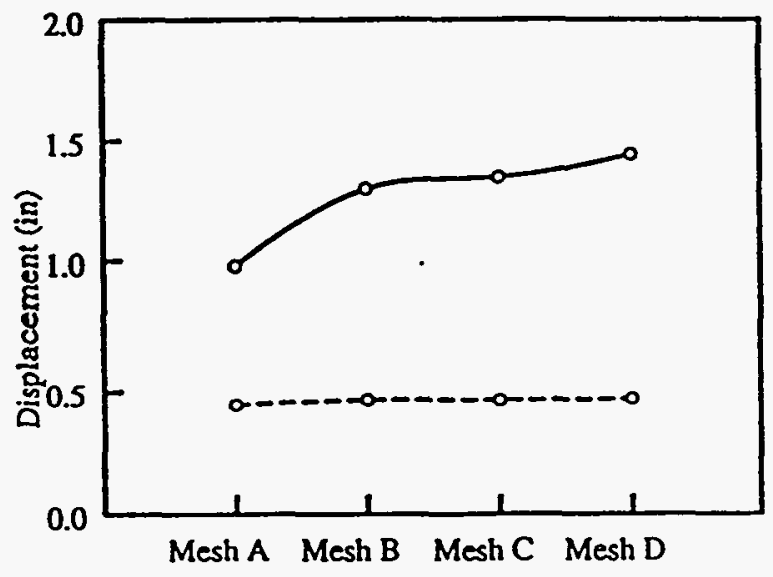

(b) Vertical Displacement

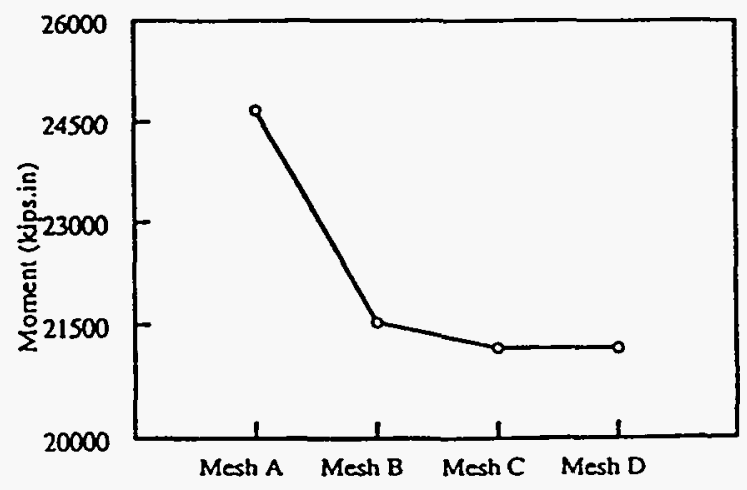

(d) Bending Moment, $M$

Figure 2.8 Displacement, Moment and Circumferential Force at Point B in the Cylindrical Shell in Fig. 2.6 


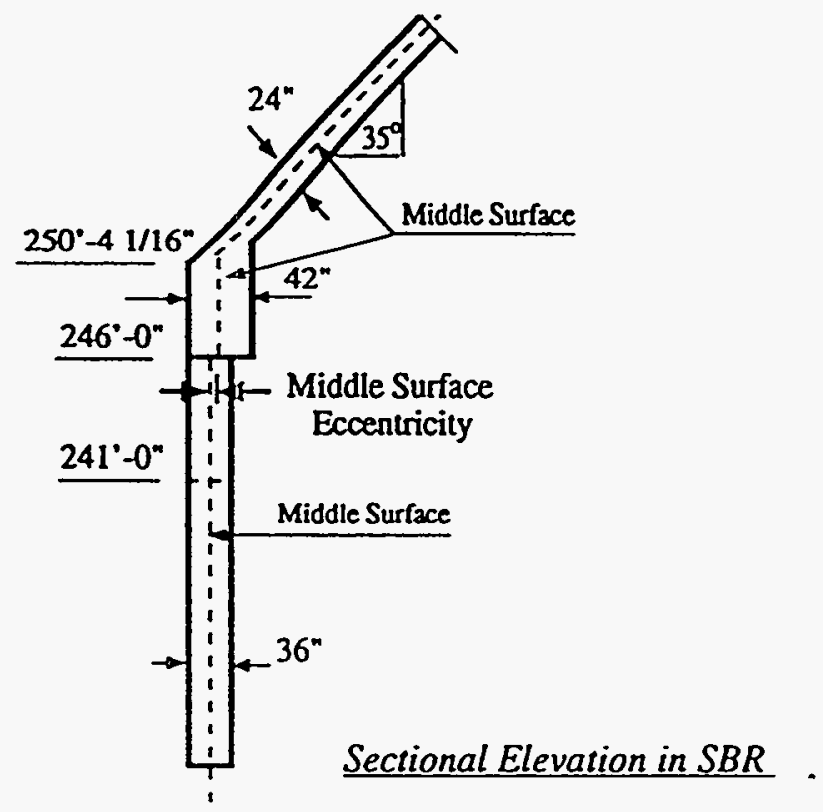

Figure 2.9 Cylindrical Shell Middle Surface Eccentricity Near the Tension Ring

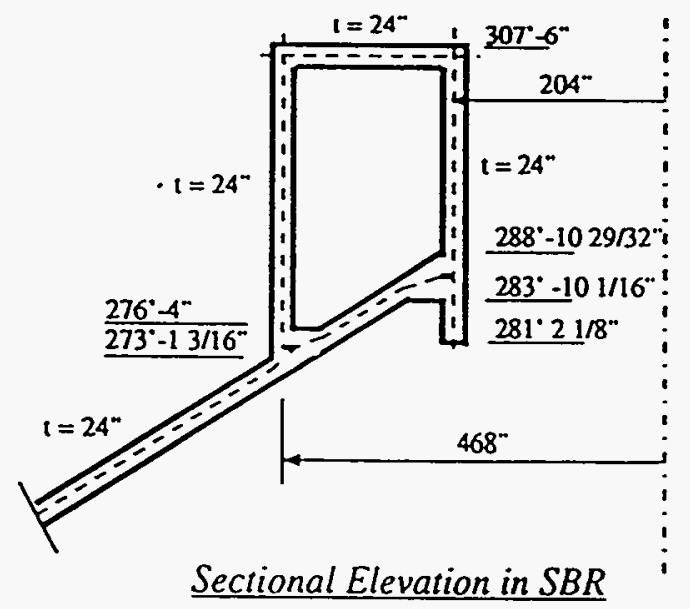

Figure 2.10 Conical Roof Module Surface Eccentricity at the Junctions with the PCS Tank 


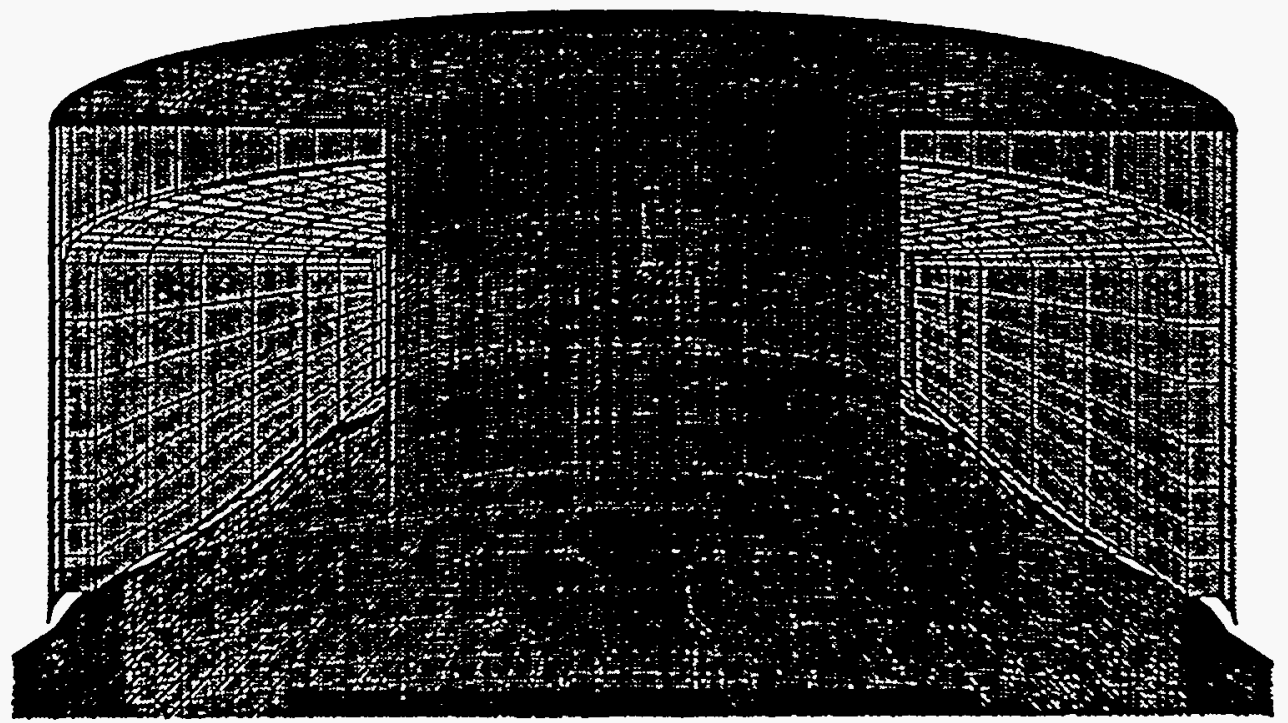

Figure 2.11 Finite Element Model for the Water Inside the PCS Tank

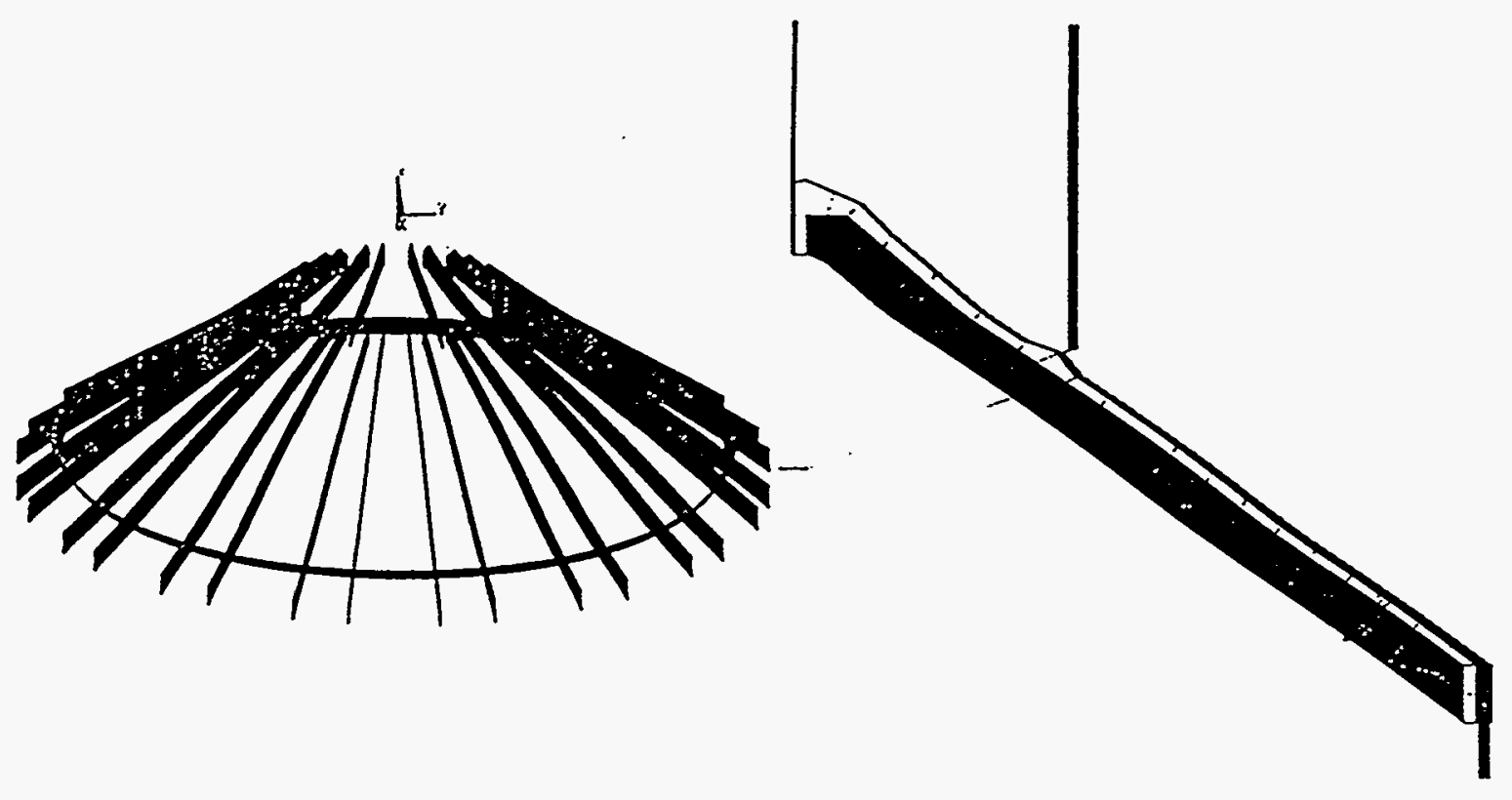

Figure 2.12 Finite Element Model for the Conical Roof Radial and Circumferential Stiffeners 


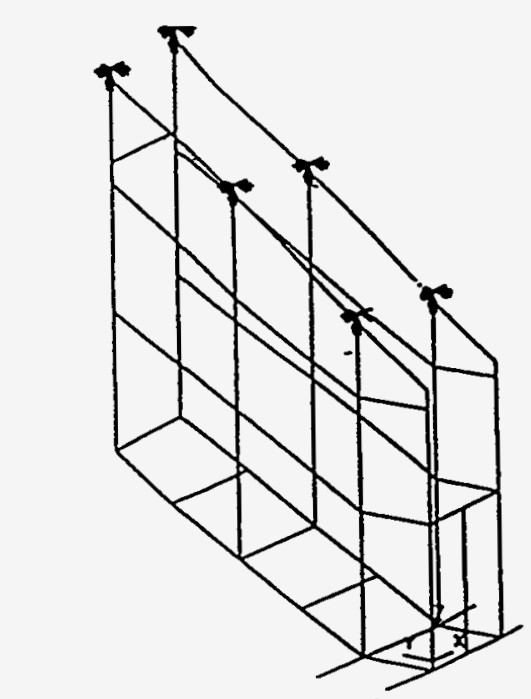

(Total Mass $=39.39 \mathrm{lb} \cdot \mathrm{sec}^{2} / \mathrm{in}$ )

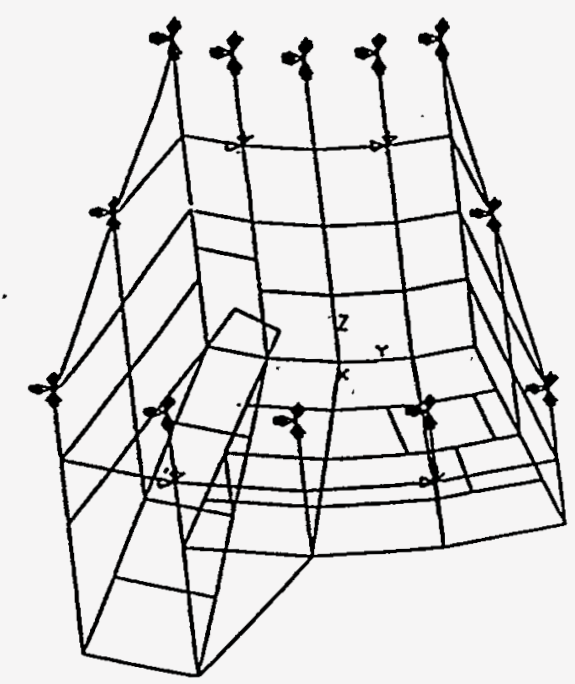

(Total Mass $=158.86 \mathrm{lb} \cdot \mathrm{sec}^{2} / \mathrm{in}$ )

(b) Valve Room

(a) Stair Enclosure

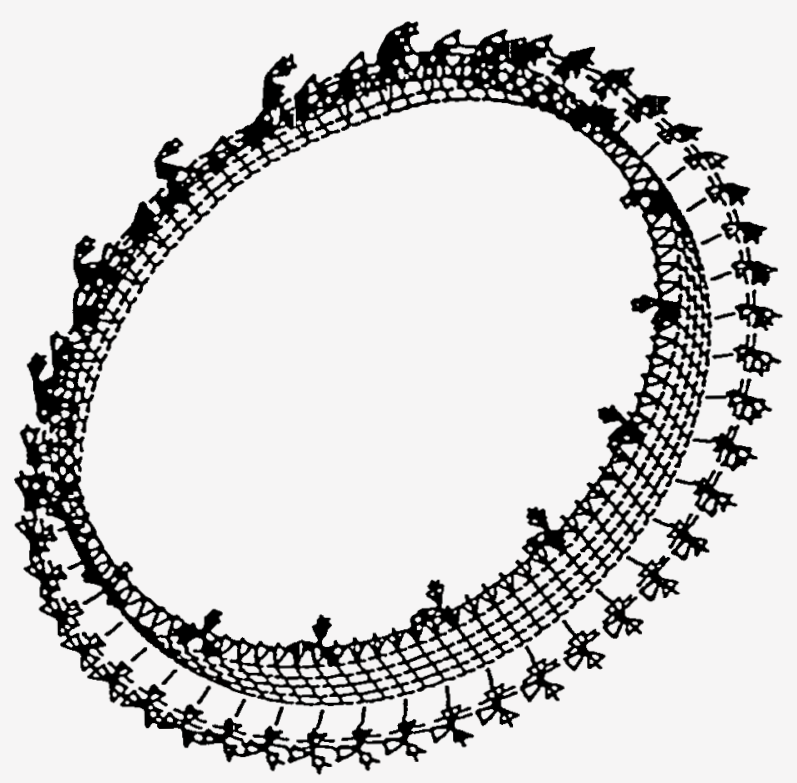

(Total Mass $=286.45 \mathrm{lb} \cdot \sec ^{2} / \mathrm{in}$ )

(c) Walkway and Air Baffle Upper Portion

Figure 2.13 Westinghouse Finite element Model for Stair Enclosure, Valve Room, and Air Baffle Upper Portion. 


\section{STATIC ANALYSIS RESULTS}

\subsection{Introduction}

In this chapter, the results of the static analysis utilizing the three-dimensional model will be presented and discussed. Four loading configurations were considered: dead load (including hydrostatic pressure), snow load, wind load and thermal load (including thermal gradient). These loads were considered because they are included in the two load combination [3.1] considered in this work (see Chapter 5). Stress resultants in the cylindrical and conical portions together with member forces in the tension and compression rings will be presented for each loading configuration. Seismic loads due to the Safe Shutdown Earthquake (SSE) spectra will be discussed in the next chapter.

\subsection{Dead Load Case (including hydrostatic pressure)}

The model is subjected to a vertical acceleration of $386 \mathrm{in} / \mathrm{sec}^{2}$ to simulate dead load. Results were verified by comparing the sum of the vertical reactions of 29641 kips to the total weight of the AP600 SBR of 29800 kips above Elev. 180' - 0". Water in the tank produced hydrostatic pressure on the conical roof and the PCS tank vertical walls equal to the weight of the column of water measured from the free water surface to the point at which the pressure is computed.

Figure 3.1 illustrates an isometric view and a sectional elevation of the deformed shape of the SBR due to its own weight and hydrostatic pressure. Maximum vertical deflections took place in the conical roof below the PCS tank, whereas maximum radial deflections took place at the tension ring due to membrane forces in the direction of the conical roof [3.2]. 


\subsubsection{Stress Resultants}

Figure 3.2 illustrates the distribution of meridional stress resultants, N1, along the cylindrical and conical portions of the SBR. The distribution of $\mathrm{N} 1$ is illustrated along a meridian passing through the center of ( 0 deg Azimuth) an air intakes and another located midway between two air intakes of (11.25 deg Azimuth) (referred to hereafter as the column). The value of N1 at the base was $66.2 \mathrm{k} / \mathrm{ft}$ compared to a theoretical value of $66.8 \mathrm{k} / \mathrm{ft}$. The maximum compressive value of $\mathrm{N} 1$ reached $85 \mathrm{k} / \mathrm{ft}$ which took place at the center of the columns between the air inlets compared to a theoretical value of $89 \mathrm{k} / \mathrm{ft}$. Figure 3.3 illustrates the distribution of hoop stress resultants, $\mathrm{N} 2$, along the cylindrical and conical shells. The value of $\mathrm{N} 2$ approached zero at the base because of the artificial fixed boundary effect at Elev. 180'- 0". The value of N2 in the tension ring reached $175 \mathrm{k} / \mathrm{ft}$ above the columns between the air inlets, whereas the maximum value of $\mathrm{N} 2$ was $236 \mathrm{k} / \mathrm{ft}$ above the air inlets.

The distribution of the meridional moments per unit length, $\mathrm{M} 1$, along the meridional direction is illustrated in Fig. 3.4. The value of $M 1$ peaked at a maximum value of $105 \mathrm{k}-\mathrm{ft} / \mathrm{ft}$ at the edge of a column because of the stress concentration in the vicinity of the penetration. A thorough investigation of the M1 distribution through a column indicated a sudden increase in $M 1$ values at the tension ring because of the meridional moment produced by the middle surface eccentricity at that location (see Sec. 2.2.4.1). The value of $\mathrm{M} 1$ in the conical roof peaked at a value of 19.3 $\mathrm{k}-\mathrm{ft} / \mathrm{ft}$ due to the surface eccentricity at the PCS vertical wall. Figure 3.5 illustrates the variation of the hoop moments per unit length, M2, in the meridional direction. The value of $\mathrm{M} 2$ reached zero at the base due to artificial fixity. The maximum value of $\mathrm{M} 2$ was $30 \mathrm{k}-\mathrm{ft} / \mathrm{ft}$ and took place in the cylinder below an air inlet. 


\subsubsection{Member Forces in the Tension and Compression Rings}

Figure 3.6 illustrates the location of the tension and compression rings in the SBR structure. The tension ring is defined as the concrete block above the air intakes between Elevs. 250'-4 1/16" and 246'-0" with wall thickness of $3^{\prime}-6$ ". The compression ring is the concrete block between Elevs. 288'-10 29/32" and 281'-2 1/8" with wall thickness of 2'-0". Member forces in the tension and compression rings were computed from shell element nodal forces as follows (see Fig. 3.7):

$$
\begin{array}{ll}
N=\sum \mathrm{f}_{\mathrm{y}}^{\mathrm{i}} & \mathrm{M}_{\mathrm{x}}=\sum \mathrm{f}_{\mathrm{y}}^{\mathrm{i}} \mathrm{h}^{\mathrm{i}} \\
\mathrm{Q}_{\mathrm{x}}=\sum \mathrm{f}_{\mathrm{x}}^{\mathrm{i}} & \mathrm{T}=\sum \mathrm{f}_{\mathrm{x}}^{\mathrm{i}} \mathrm{h}^{\mathrm{i}}+\mathrm{m}_{\mathrm{y}}^{\mathrm{i}} \\
\mathrm{Q}_{z}=\sum \mathrm{f}_{\mathrm{i}}^{\mathrm{i}} & \mathrm{M}_{\mathrm{z}}=\sum \mathrm{m}_{\mathrm{z}}{ }^{\mathrm{i}}
\end{array}
$$

where $N, Q_{x}$ and $Q_{z}$ are the normal force, shear in the radial direction and shear in the vertical direction, respectively. $M_{x}, T$ and $M_{z}$ are the moment about the radial axis, torque and moment about the vertical axis, respectively. The quantities $f_{x}{ }^{i}, f_{y}{ }^{i}$ and $f_{z}^{i}$ are the nodal forces in the radial, hoop and vertical directions at node $i$, respectively. The quantities $m_{x}{ }^{i}$ and $m_{y}{ }^{i}$ are the nodal moments in the radial and hoop directions, respectively. In Eq. (3.1) $h^{\mathrm{i}}$ is the vertical distance from node $i$ to the section centroid. The summation in equation 3.1 is carried over all the nodes in the ring section.

Figures 3.8 through 3.10 illustrate the variation of $N, M_{x}$ and $T$ in the tension ring from 0 to 22.5 deg Azimuth. The maximum tensile value of $\mathrm{N}$ took place over an air intake and reduces to a minimum over the columns. Moments $\mathrm{M}_{\mathrm{x}}$ ranges from $325 \mathrm{k}-\mathrm{ft}$ over air intakes to $-270 \mathrm{k}-\mathrm{ft}$ over columns. The analysis indicated a significant value of torsion, $\mathrm{T}$, that ranges from $300 \mathrm{k}-\mathrm{ft}$ to $300 \mathrm{k}-\mathrm{ft}$ at the face of the columns between air intakes.

Figures 3.11 through 3.13 illustrate the distribution of $\mathrm{N}, \mathrm{M}_{\mathrm{x}}$ and $\mathrm{T}$ in the compression ring from 0 to $45 \mathrm{deg}$ Azimuth. The distribution of $\mathrm{N}$ is almost uniform with an average value of -360 kips. The value of $M_{x}$ ranges from $-290 \mathrm{k}-\mathrm{ft}$ to $-370 \mathrm{k}-\mathrm{ft}$, whereas the value of $\mathrm{T}$ ranges from 10 
$\mathrm{k}-\mathrm{ft}$ to $25 \mathrm{k}-\mathrm{ft}$. Considering the bending and torsional rigidity of the tension and compression rings, results indicate that the tension ring is more critical than the compression ring.

\subsection{Snow Load Case}

Based on a ground snow load of 75 psf, importance factor of 1.2 and exposure factor of 1.0, a snow load on the PCS tank roof of 63 psf was computed. A snow load of 31.5 psf acting on the horizontal projection was computed for the conical roof considering a roof slope factor of 0.5 [3.2]. Snow loads were applied as gravity loads on the PCS roof and the exposed portion of the conical roof. The loading was checked by comparing the total snow load of 589 kips to the sum of the vertical reactions of 588 kips.

Figure 3.14 illustrates an isometric view and a sectional elevation in the deformed shape. Maximum vertical deflections took place at the PCS roof, whereas maximum radial deflections took place at the tension ring.

\subsubsection{Stress Resultants}

Figures 3.15 through 3.18 illustrate the distribution of N1, N2, M1 and M2 along the meridional direction, respectively. The shape of the stress resultants distributions is comparable to stress resultants due to dead load (see Sec. 3.2.1), however, their values are significantly smaller, indicating that snow loads have a minor effect on the SBR design.

\subsubsection{Member Forces in the Tension and Compression Rings}

Figures 3.19 through 3.21 illustrate the variation of $N, M_{x}$ and $T$, respectively, in the tension ring. The shape of the distribution is similar to the dead load case, however, the magnitude of forces is almost one tenth those produced due to dead load. The value of $\mathrm{N}$ ranged from a maximum of 31 
kips to a minimum of 21 kips. The value of $\mathrm{M}_{\mathrm{x}}$ ranged from $11.5 \mathrm{k}-\mathrm{ft}$ over air inlets to $-8.0 \mathrm{k}-\mathrm{ft}$ over columns. A maximum torque of $10 \mathrm{k}-\mathrm{ft}$ took place at the face of the column.

Figures 3.22 through 3.24 depict the variation of $\mathrm{N}, \mathrm{M}_{\mathrm{x}}$ and $\mathrm{T}$, respectively in the compression ring. The average value of $N$ was $-8.4 \mathrm{kips}$, whereas the value of $M_{x}$ ranged from -2.5 to $-4.1 \mathrm{k}$ $\mathrm{ft}$. The value of $\mathrm{T}$ was insignificant and ranged from 0.75 to $0.17 \mathrm{k}-\mathrm{ft}$.

\subsection{Wind Load Case}

Wind loads on the SBR structure were computed based on a basic wind speed of $110 \mathrm{mph}$ and an importance factor of 1.10 [3.2]. As shown in Fig. 3.25 (a), the SBR structure was divided into three parts: (1) cylinder from Elev. 180' to Elev. 250'-4 1/16"; (2) exposed conical roof from Elev. 250'-4 1/16" to Elev. 273'-3 1/16"; and (3) PCS tank external wall from Elev. 273'-3 1/16" to Elev. 307'-3". The average wind pressure on the projected area, $w_{d}$, of the three parts were computed as $30.5,34$ and 35 psf respectively [3.2].

Wind loads were applied on the finite element model in the form of element pressures in the radial direction. Wind pressures on the elements, $w_{e}$, were assumed to have a sinusoidal distribution (see Fig. 3.25(b)) such that the total wind force in the wind direction is equal to the product of the wind pressures, $w_{d}$, and the projected area. The value of $w_{e}$ at any circumferential location, $\theta$, measured counter clockwise from the northeast direction i.e., the direction normal to the wind direction was computed as follows:

$$
w_{e}(\theta)=2 w_{p} \sin (\theta) / \pi
$$

Since the air intake nearest to the valve room was closed, wind loads were applied twice on the SBR structure: (1) from the southeast, i.e., Azimuth $135 \mathrm{deg}$, direction corresponding to maximum unpenetrated surface area; and (2) from the normal direction (i.e., southwest direction). 
The finite element analysis indicated stress resultants and member forces generated due to the two wind load cases (i.e., southeast and southwest directions) were almost identical. Therefore analysis results due only to wind loads in the southeast direction will be presented. The deformed shape of the SBR due to wind loads is depicted in Fig. 3.26 in which the elevation view was taken from the northeast direction.

\subsubsection{Stress Resultants}

The distribution of the meridional stress resultants at the base took the shape of a complete sine wave due to the cantilever action of the SBR when subjected to lateral loads. The maximum value of $\mathrm{Nl}$ for the southeast was $1.14 \mathrm{k}-\mathrm{ft}$ and took place at the $135 \mathrm{deg}$ and $303.75 \mathrm{deg}$ Azimuths at Elev. 180'-0". Note that the two Azimuths are not exactly 180 deg apart because stresses are computed at the element centroidal locations. Figure 3.27 depicts the distribution of N1 stress resultants along the $135 \mathrm{deg}$ and $303.75 \mathrm{deg}$ Azimuth meridians. The magnitude of N1 stress resultants along the two meridians were identical in magnitude but with reversed sign, with tensile stresses at the $135 \mathrm{deg}$ Azimuth meridian and compressive stresses at the $303.75 \mathrm{deg}$ Azimuth meridian. The distribution of N2 stress resultants were also identical but with reversible order due to Poisson's effect as shown in Fig. 3.28. The maximum value of $\mathrm{N} 2$ was $1.75 \mathrm{k} / \mathrm{ft}$ and took place at the tension ring whereas the value of $\mathrm{N} 2$ approached zero at the base due to fixation. Figures 3.27 and 3.28 illustrate that N1 and N2 stress resultants approached zero at the 225 deg Azimuth meridians corresponding to the location of the neutral axis.

The maximum value of the $\mathrm{M} 1$ moment stress resultants was $1.17 \mathrm{k}-\mathrm{ft} / \mathrm{ft}$ and took place at the base at the $135 \mathrm{deg}$ and $303.75 \mathrm{deg}$ Azimuth meridians. The value of M1 rapidly reduced to approach zero in the remainder of the SBR structure as shown in Fig. 3.29. The maximum value of M2 moment stress resultants was $0.24 \mathrm{k}-\mathrm{ft} / \mathrm{ft}$ and took place in the conical roof at the compression ring. The value of M2 approached zero in the remainder of the structure except at the base due to artificial fixation as shown in Fig. 3.30. 
The finite element results indicated that stress resultants generated due to wind loads were insignificant.

\subsubsection{Member Forces in the Tension and Compression Rings}

Figures 3.31 through 3.33 illustrate the variation of $N, M_{x}$ and $T$, respectively in the tension ring between $100 \mathrm{deg}$ Azimuth and $200 \mathrm{deg}$ Azimuth. The tension ring was subjected to a compressive axial force $\mathrm{N}$ with a maximum value of 10.53 kips that took place at the $162.5 \mathrm{deg}$ Azimuth over an air inlet. The maximum value of $\mathrm{M}_{\mathrm{x}}$ was $10.2 \mathrm{k}$ - $\mathrm{ft}$ and took place over a column at 195 deg Azimuth. The maximum value of the torque, T, was $1.94 \mathrm{k}$-ft.

Figures 3.34 through 3.36 depict the variation of $N, M_{x}$ and $T$, respectively, in the compression ring along the entire circumference. The distributions of $N$ and $M_{x}$ were sinusoidal with the peak values located at the $135 \mathrm{deg}$ and $315 \mathrm{deg}$ Azimuths. The peak values of $\mathrm{N}$ and $\mathrm{M}_{\mathrm{x}}$ were 0.63 kips and $1.98 \mathrm{k}-\mathrm{ft}$ respectively. The distribution of the torque, $\mathrm{T}$, was sinusoidal with a peak value of $0.4 \mathrm{k}-\mathrm{ft}$ located at the 45 and the $225 \mathrm{deg}$ Azimuths.

\subsection{Thermal Load Case}

Two thermal loading configurations were analyzed: (1) global temperature decrement or Case " $\mathrm{n}$ " at which the atmospheric temperature decreases to $-40^{\circ} \mathrm{F}$ whereas the temperature of the water in the PCS tank was kept at $+40^{\circ} \mathrm{F}$; and (2) global temperature increment or Case " $\mathrm{p}$ " at which the atmospheric temperature increased to $+115^{\circ} \mathrm{F}$ and the temperature of the water in the PCS tank was kept at $+40^{\circ} \mathrm{F}$ as well. In both cases, the temperature of the cylindrical portion, exposed conical roof and the compression ring was taken equal to the atmospheric temperature. The PCS tank vertical walls and roof and the conical roof below the PCS tank were subjected to thermal gradient loading that ranged from the atmospheric temperature at the outer fibers to the water temperature at the inner fibers. Stress resultants in the conical roof and cylinder and member forces in the tension and compression rings were computed from the finite element model based on the uncracked section. 


\subsubsection{Case " $n$ " (global temperature decrement)}

Figure 3.37 illustrates the deformed shape of the SBR due to global temperature decrement. A uniform radial deflection took place in the cylinder and the exposed conical roof except at the base due to fixation. The conical roof below the PCS tank and the vertical walls of the PCS tank were slightly bent due to the thermal gradient loading.

\subsubsection{Stress Resultants}

Figure 3.38 illustrates the distribution of $\mathrm{N} 1$ stress resultants along the meridional direction. The maximum compressive $\mathrm{N} 1$ stress resultants was $26.07 \mathrm{k} / \mathrm{ft}$ and took place in the conical roof at its juncture with the compression ring. Figure 3.39 depicts the distribution of N2 stress resultants along the meridian. Maximum tensile N2 was $112.4 \mathrm{k} / \mathrm{ft}$ and took place in the conical roof juncture with the PCS external wall, whereas the maximum compressive N2 was $186.8 \mathrm{k} / \mathrm{ft}$ and took place at the conical roof near the compression ring. The meridional and hoop stress resultants in the exposed conical roof and the cylinder were zero because they are structurally unrestricted shells subjected to a uniform decrease in temperature. N2 stress resultants were artificially increased at Elev. $180^{\prime}-0$ "' due to the effect of the fixation.

The distribution of M1 stress resultants is illustrated in Fig. 3.40. The peak value of $127.4 \mathrm{k}-\mathrm{ft} / \mathrm{ft}$ took place in the conical roof near the compression ring and the PCS external wall. The values of M1 computed near Elev. 180'-0" are artificial due to the effect of the assumed fixation at this elevation. Figure 3.41 depicts the distribution of M2 stress resultants. The maximum value of M2 was $525 \mathrm{k}-\mathrm{ft} / \mathrm{ft}$ and took place in the conical roof at its juncture with the compression ring. The values of M1 and M2 stress resultants were reduced to zero at the remainder of the SBR because of the uniform thermal loading. 


\subsubsection{Member Forces in the Tension and Compression Rings}

Figures 3.42 through 3.44 illustrate the distribution of $N, M_{x}$ and $T$ in the tension ring from 0 deg to 45 deg Azimuths. The axial force, $\mathrm{N}$, in the tension ring is generally compressive throughout the circumference with a maximum value of 34.5 kips. The maximum value of the moment, $M_{x}$, was $10 \mathrm{k}-\mathrm{ft}$ and took place at the tension ring section at the face of the columns between air intakes. The value of the torque, $T$, was insignificant with a peak value of $4.0 \mathrm{k}-\mathrm{ft}$.

Figures 3.45 through 3.47 illustrate the distribution of $N, M_{x}$ and $T$ in the compression ring from 0 deg to 45 deg Azimuths. The compression ring was subjected to a uniform axial tensile force of 1370 kips. The distribution of $M_{x}$ was almost uniform with a maximum value of $1230 \mathrm{k}$-ft. The value of $\mathrm{T}$ varied from $+82 \mathrm{k}-\mathrm{ft}$ to $-82 \mathrm{k}-\mathrm{ft}$ with the peak values computed at the intersection of the radial stiffeners with the compression ring as illustrated in Fig. 3.47.

\subsubsection{Case "p" (global temperature increment)}

Figure 3.48 illustrates the deformed shape of the SBR due to global temperature increment. A uniform outward radial deflection took place in the cylindrical and exposed conical roof whereas the PCS vertical walls and the conical roof below the PCS tank were slightly bent because of the thermal gradient.

\subsubsection{Stress Resultants}

The distribution of the stress resultants in the cylindrical part and the conical roof is similar to that due to thermal load case ' $n$ ' except with an opposite sign and slightly different magnitudes. Figure 3.49 illustrates the distribution of $\mathrm{N} 1$ stress resultants along the meridional direction. The maximum tensile $\mathrm{N} 1$ stress resultants was $24.44 \mathrm{k} / \mathrm{ft}$ and took place in the conical roof at its juncture with the compression ring. Figure 3.50 depicts the distribution of N2 stress resultants along the meridian. Maximum compressive N2 was $-105.4 \mathrm{k} / \mathrm{ft}$ and took place in the conical roof juncture with the PCS external wall, whereas the maximum tensile N2 was $175.1 \mathrm{k} / \mathrm{ft}$ and took 
place at the conical roof near the compression ring. Meridional and hoop stress resultants in the exposed conical roof and the cylinder were zero because they were structurally unrestricted shells subjected to a uniform increase in temperature. Artificially large values of N2 were computed at Elev. 180' -0 " due to the effect of the fixation.

The distribution of M1 stress resultants is illustrated in Fig. 3.51. A peak value of $119.4 \mathrm{k}-\mathrm{ft} / \mathrm{ft}$ took place in the conical roof near the compression ring and the PCS external wall. Large artificial values of M1 were computed near the base because of the fixation. Figure 3.52 depicts the distribution of M2 stress resultants. The maximum value of M2 was $492 \mathrm{k}-\mathrm{ft} / \mathrm{ft}$ and took place in the conical roof at its juncture with the compression ring. The values of M1 and M2 stress resultants were reduced to zero at the exposed conical roof and the cylindrical shell since they were not subjected to the thermal gradient.

\subsubsection{Member Forces in the Tension and Compression Rings}

Figures 3.53 through 3.55 illustrate the distribution of $N, M_{x}$ and $T$ in the tension ring from 0 deg to $45 \mathrm{deg}$ Azimuths. The axial force, $\mathrm{N}$, in the tension ring is tensile with a maximum value of 40.52 kips. The maximum value of the moment, $M_{x}$, was $10 \mathrm{k}-\mathrm{ft}$ and took place at the tension ring section at the face of the columns between air inlets. The value of the torque, $T$, was insignificant with a peak value of $4.0 \mathrm{k}$ - $\mathrm{ft}$.

Figures 3.56 through 3.58 illustrate the distribution of $\mathrm{N}, \mathrm{M}_{\mathbf{x}}$ and $\mathrm{T}$ in the compression ring from $0 \mathrm{deg}$ to $45 \mathrm{deg}$ Azimuths. The compression ring is subjected to an axial compressive force of 1284 kips. The distribution of $M_{x}$ is almost uniform with a maximum value of $1150 \mathrm{k}-\mathrm{ft}$. The value of $\mathrm{T}$ varies from $+88 \mathrm{k}-\mathrm{ft}$ to $-88 \mathrm{k}-\mathrm{ft}$ with the peak values computed at the juncture of the radial stiffeners with the compression ring as illustrated in Fig. 3.58. 


\subsection{References}

3.1. Letter from Westinghouse to U.S. NRC, Docket No. STN-52-003, October 9, 1996.

3.2 Kellkar, V. S., and Sewell, R. T., "Fundamentals of Analysis and Design of Shell Structures," Prentice Hall, Englewood Cliffs, NJ, 1987. 

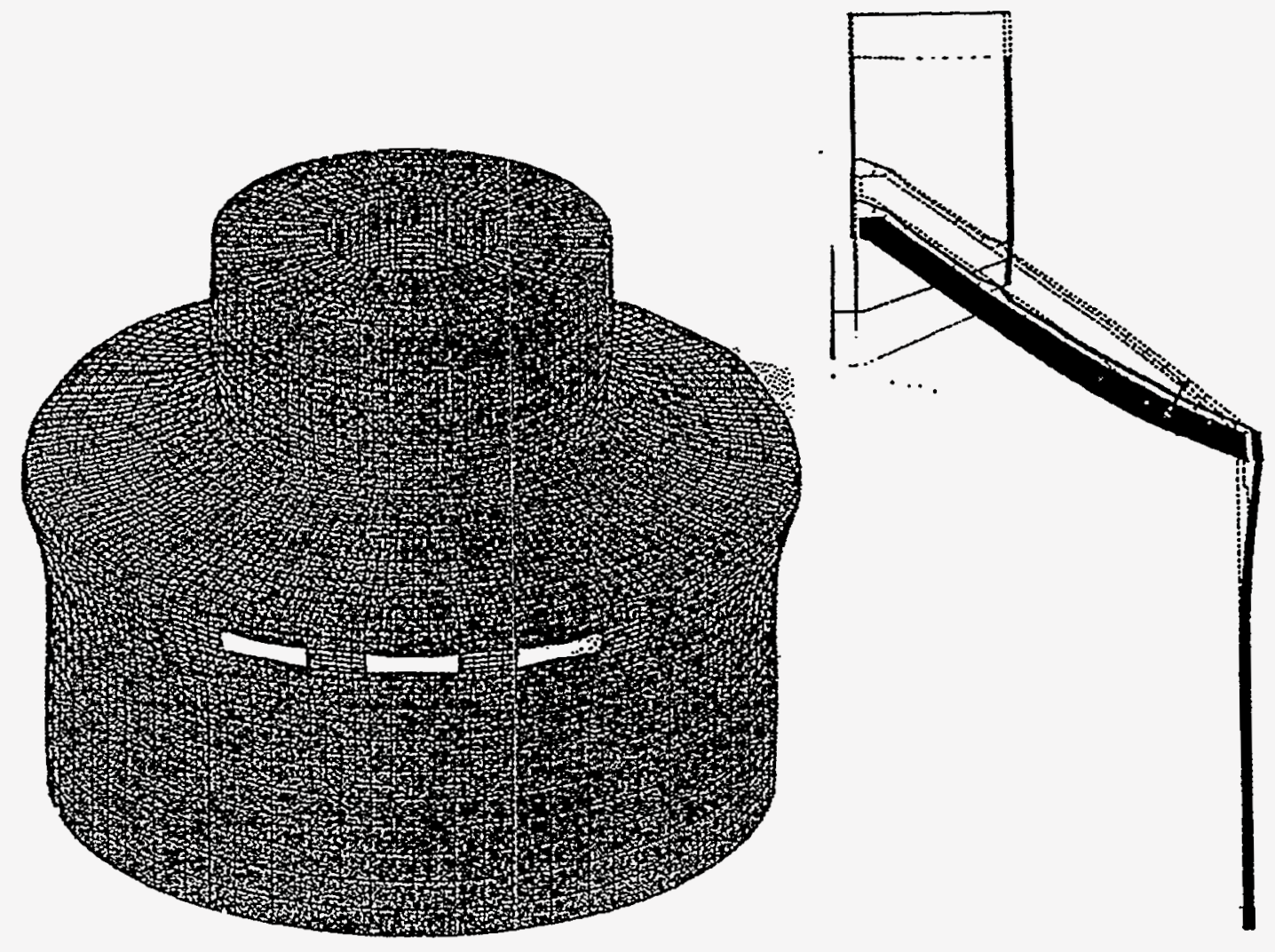

Figure 3.1 Deformed Shape of the AP600 SBR Under Dead Load Plus Water in the PCS Tank 


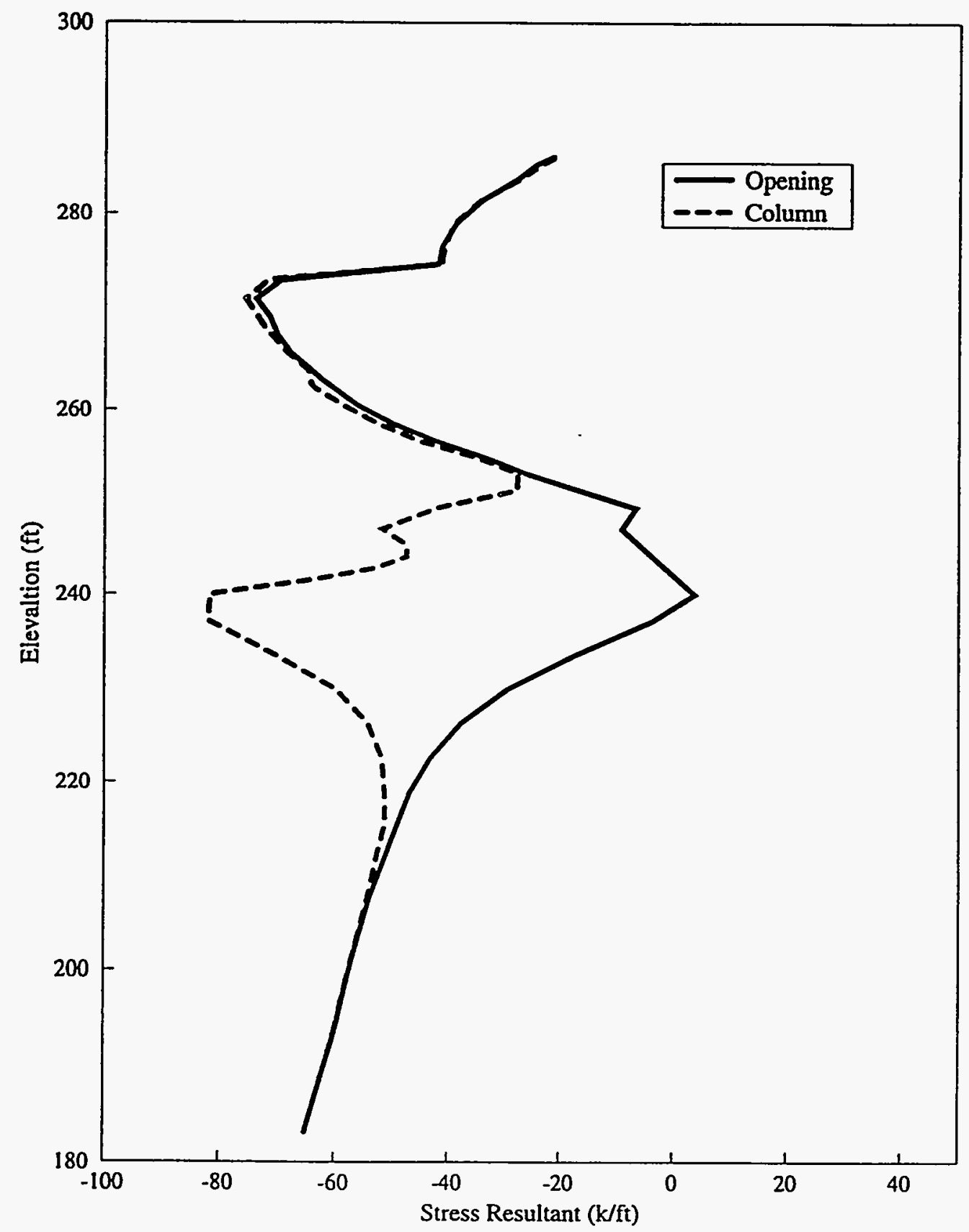

Figure 3.2 Distribution of the Meridional Stress Resultant, N1, (Dead Load) 


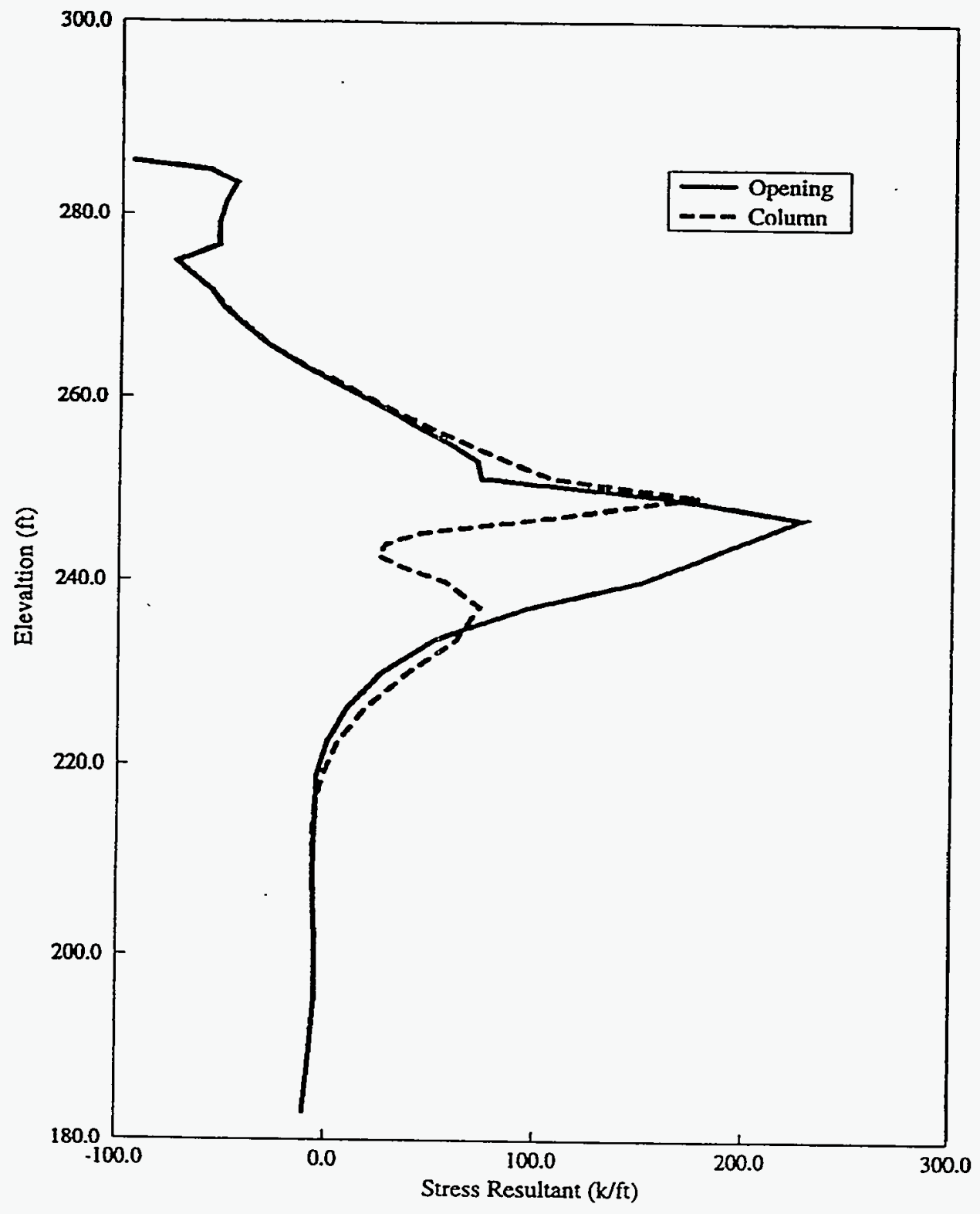

Figure 3.3 Distribution of the Circumferential Stress Resultant, N2, (Dead Load) 


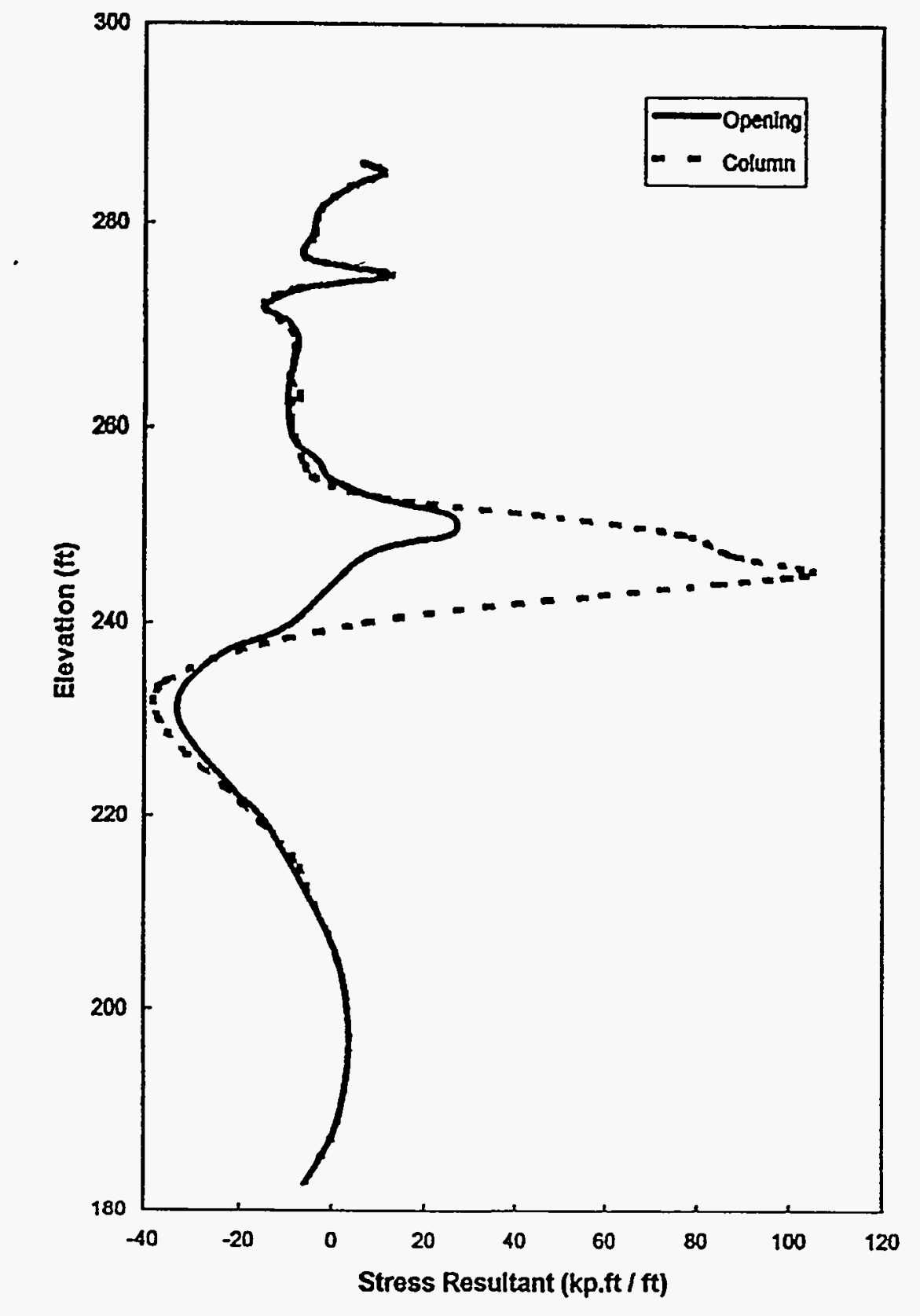

Figure 3.4 Distribution of the Meridional Moment, M1, (Dead Load) 


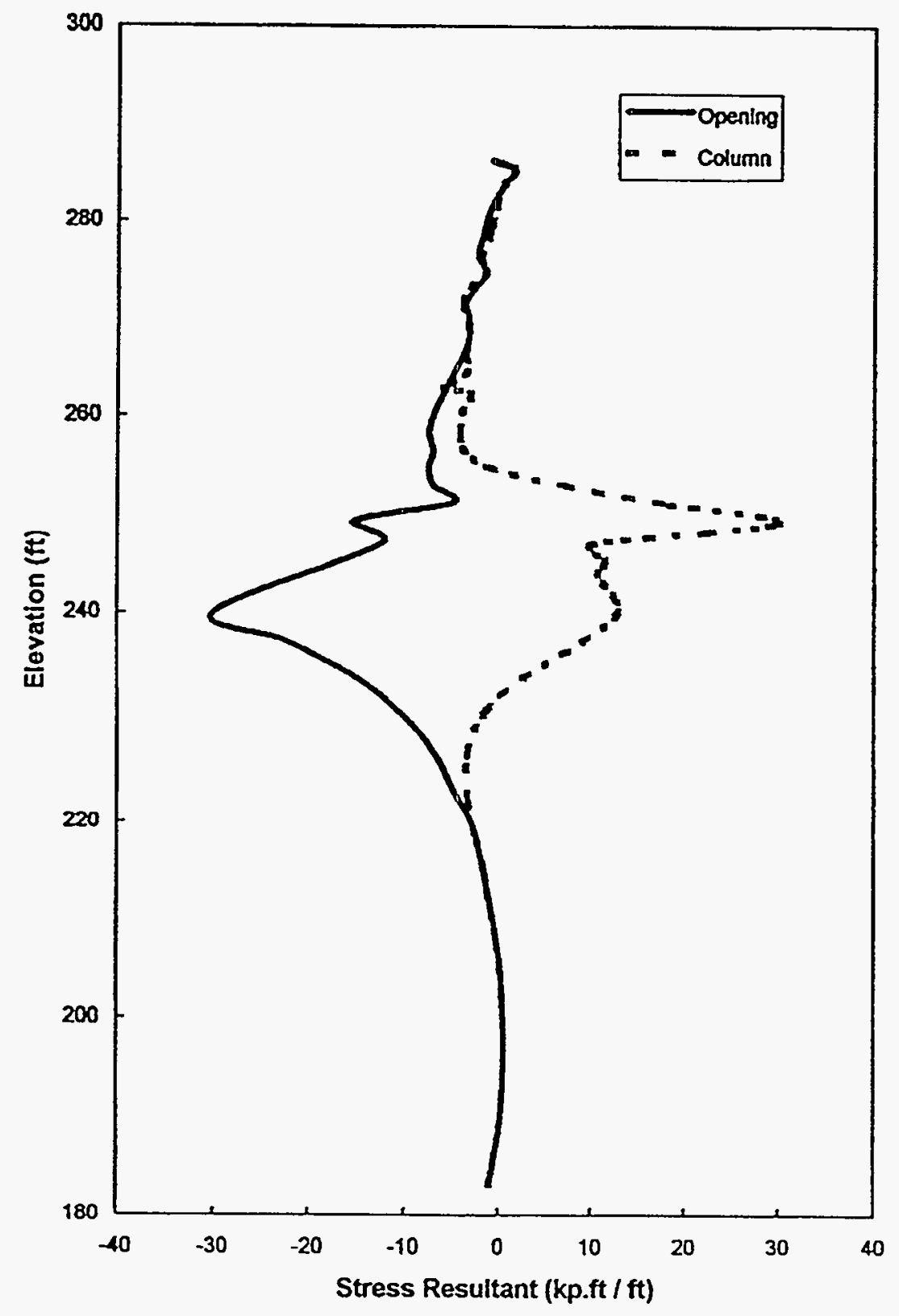

Figure 3.5 Distribution of the Circumferential Moment, M2, (Dead Load) 


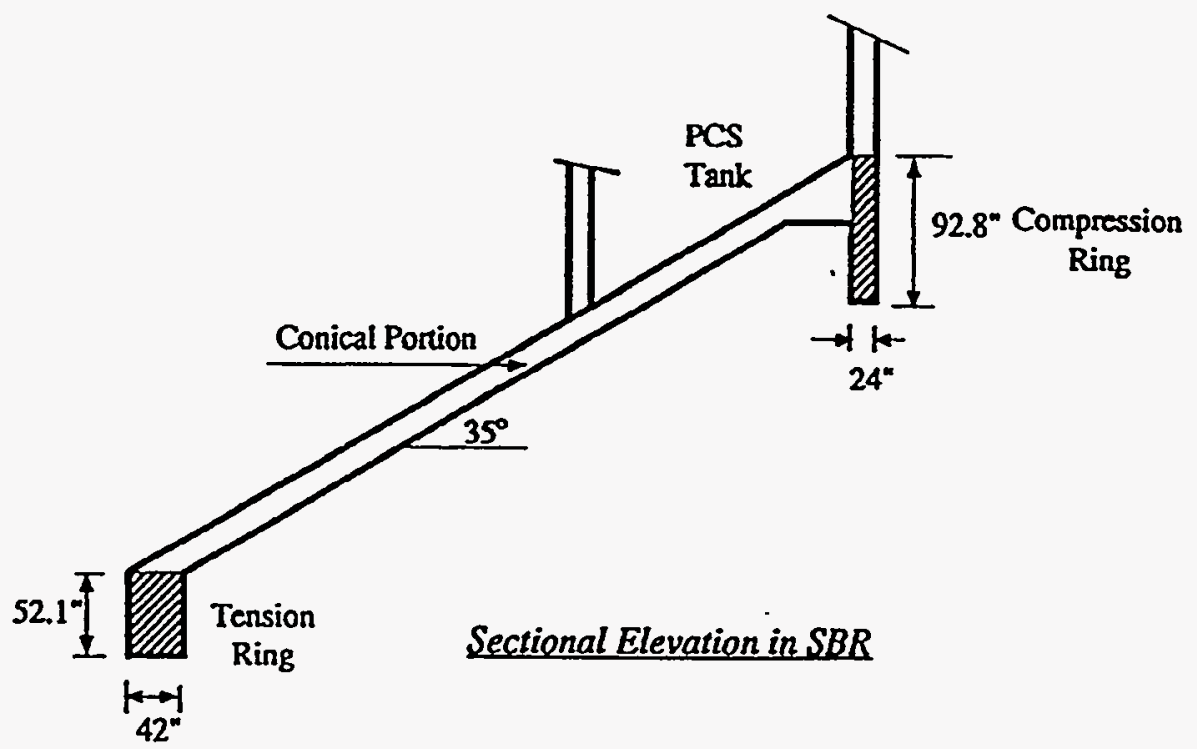

Figure 3.6 A Sketch of the Tension and Compression Rings in the SBR

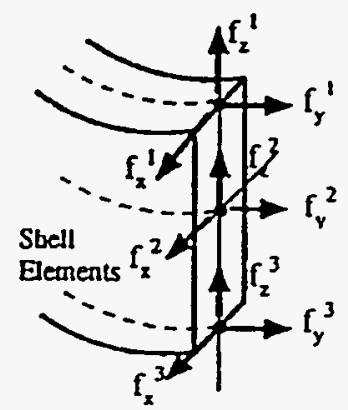

Finite Element Nodal

Forces

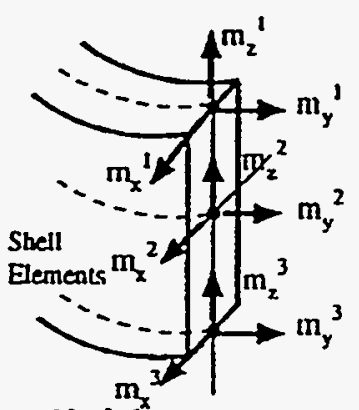

Section

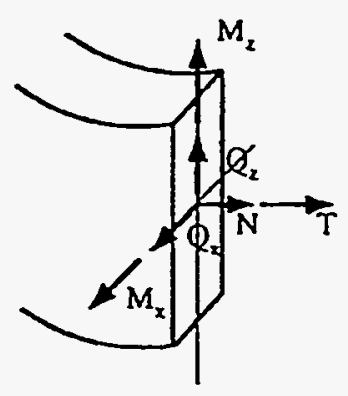

Actions

$$
\begin{array}{ll}
N=\sum_{i} f_{y} & M_{x}=\sum_{i} f_{y} h^{i} \\
Q_{x}=\sum_{i} f_{x} & T=\sum_{i}^{i} f_{x}^{i}+M_{y}^{i} \\
Q_{z}=\sum_{i}^{i} f_{z} & M_{z}=\sum_{i} M_{z}^{i}
\end{array}
$$

Figure 3.7 A Sketch of the Tension and Compression on Rings in the Member Forces 


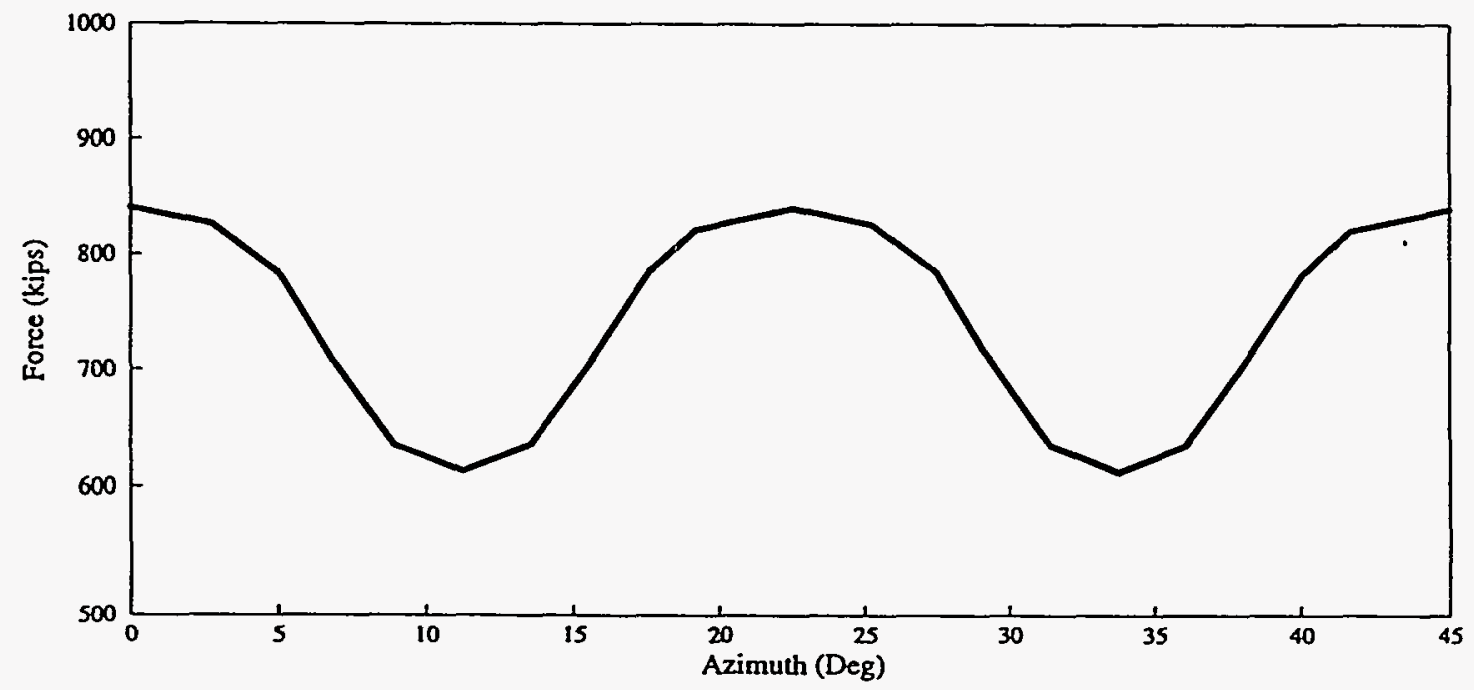

Figure 3.8 Distribution of the Axial Force in the Tension Ring (Dead Load)

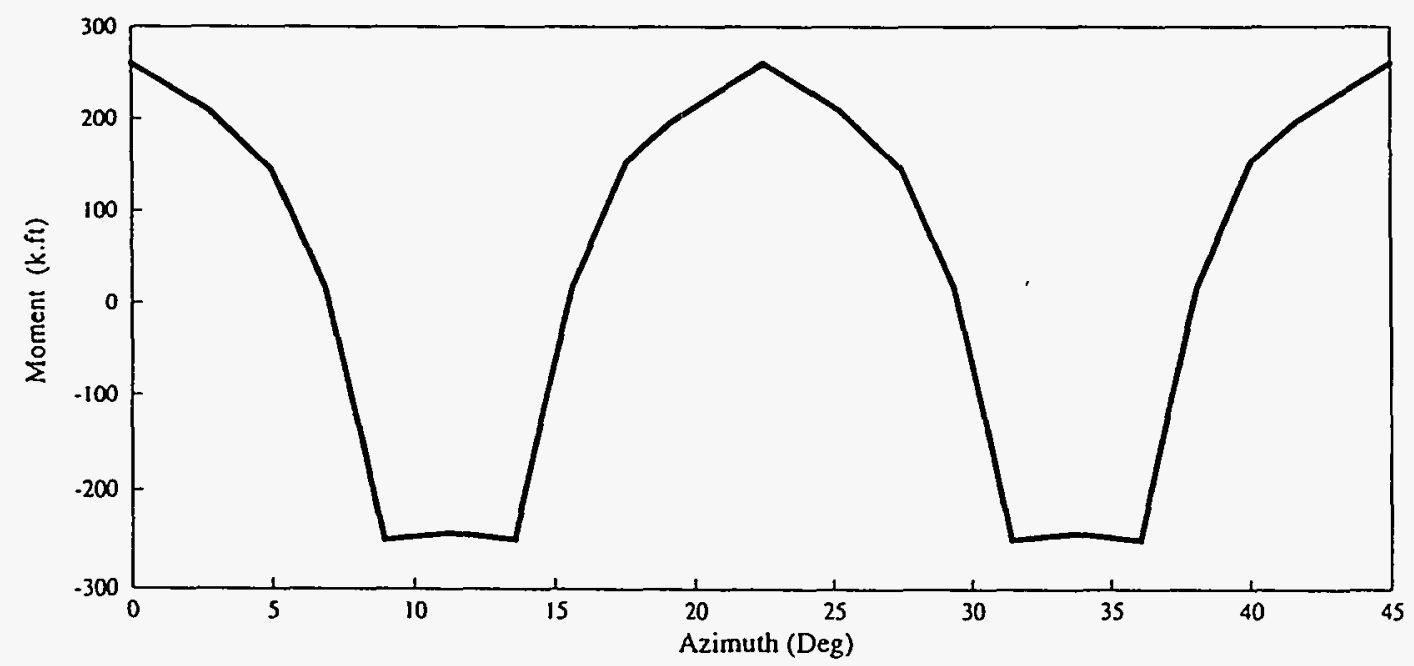

Figure 3.9 Distribution of the Moment, Mx, in the Tension Ring (Dead Load) 


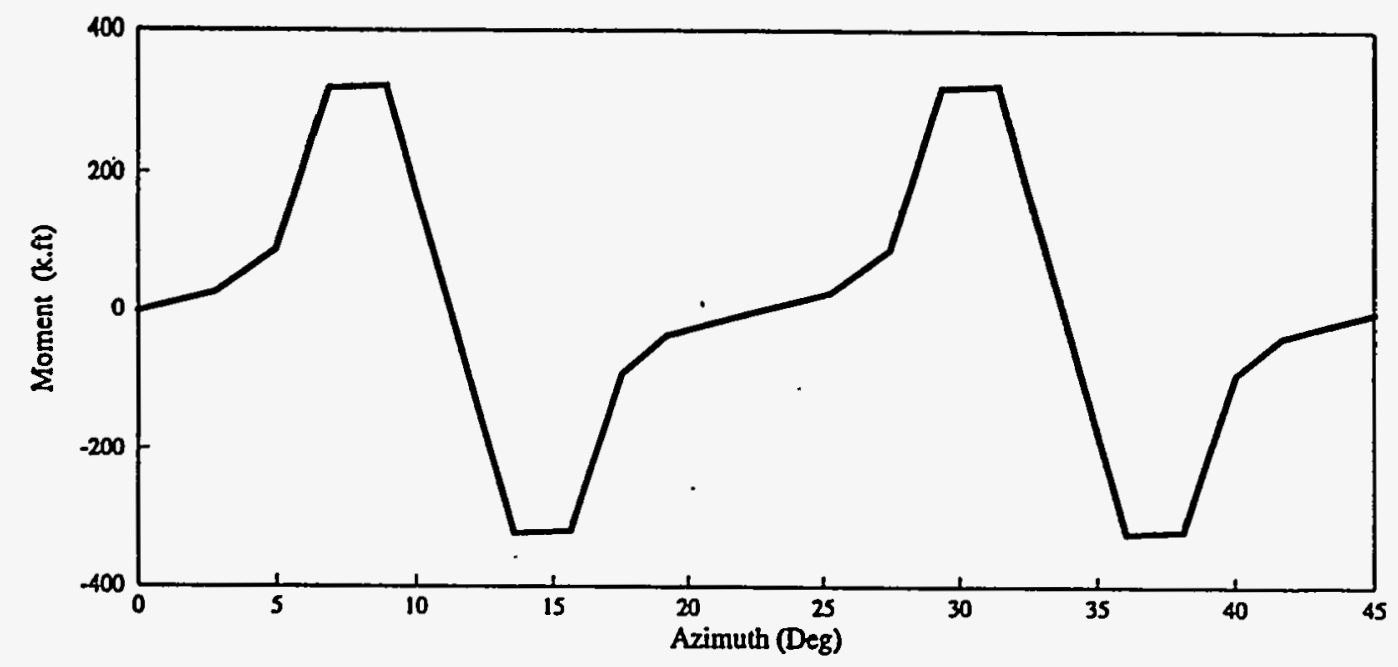

Figure 3.10 Distribution of the Torsional Moment, T, in the Tension Ring (Dead Load)

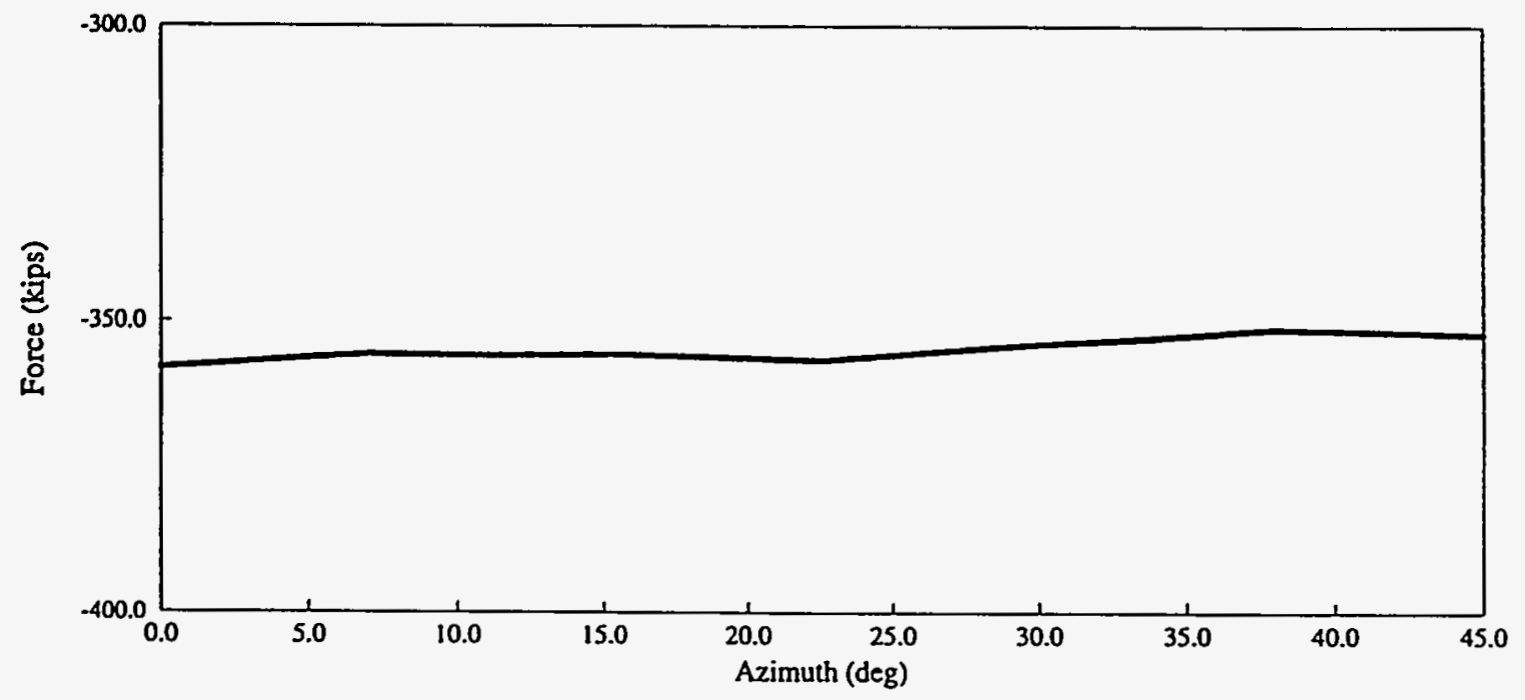

Figure 3.11 Distribution of the Axial Force in the Compression Ring (Dead Load) 


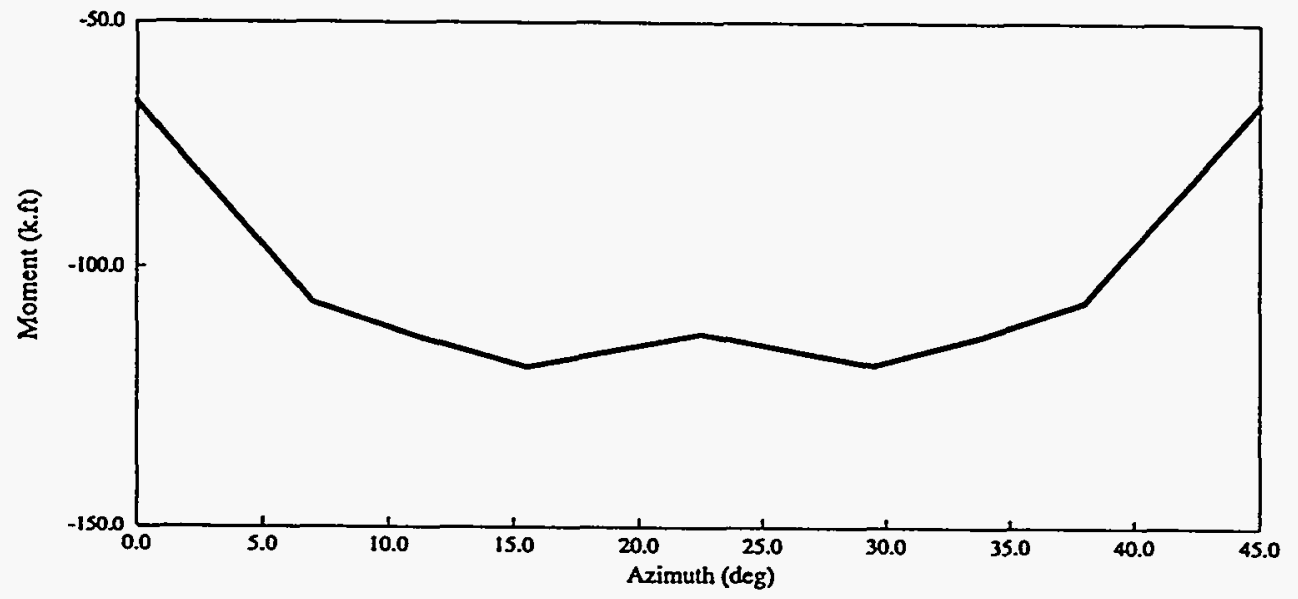

Figure 3.12 Distribution of the Moment, Mx, in the Compression Ring (Dead Load)

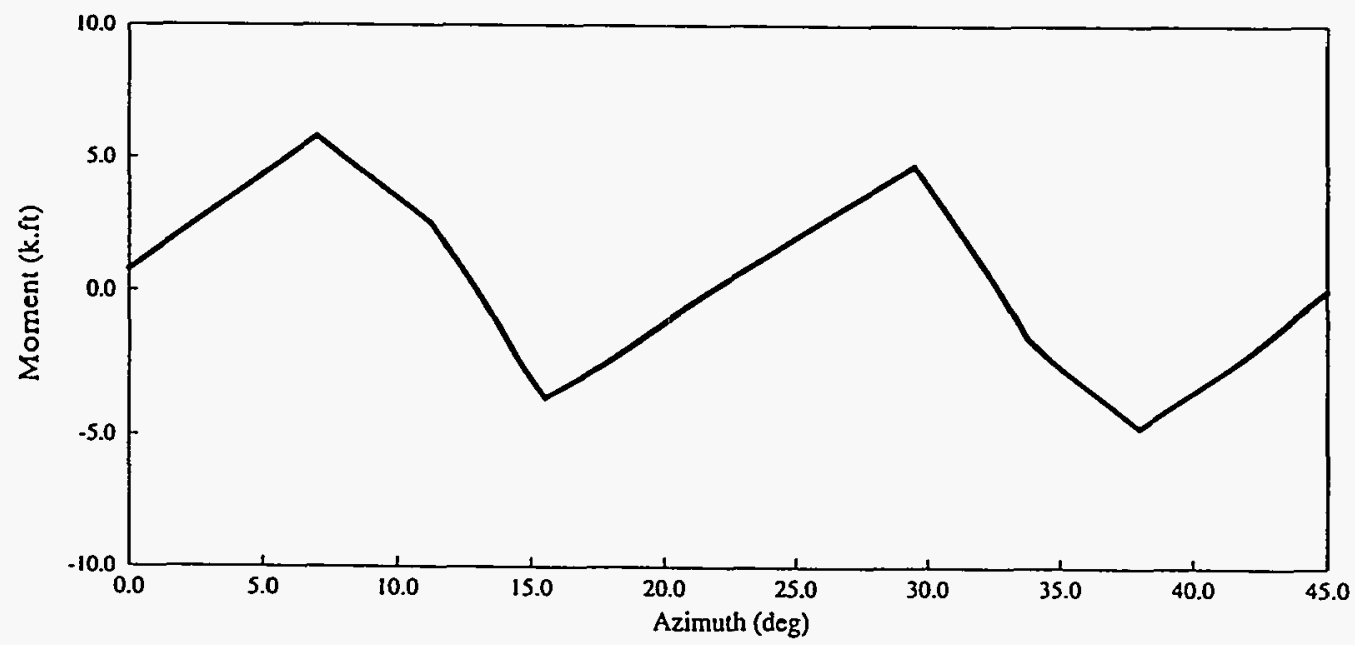

Figure 3.13 Distribution of the Torsional Moment, $\mathrm{T}$, in the Compression Ring (Dead Load) 


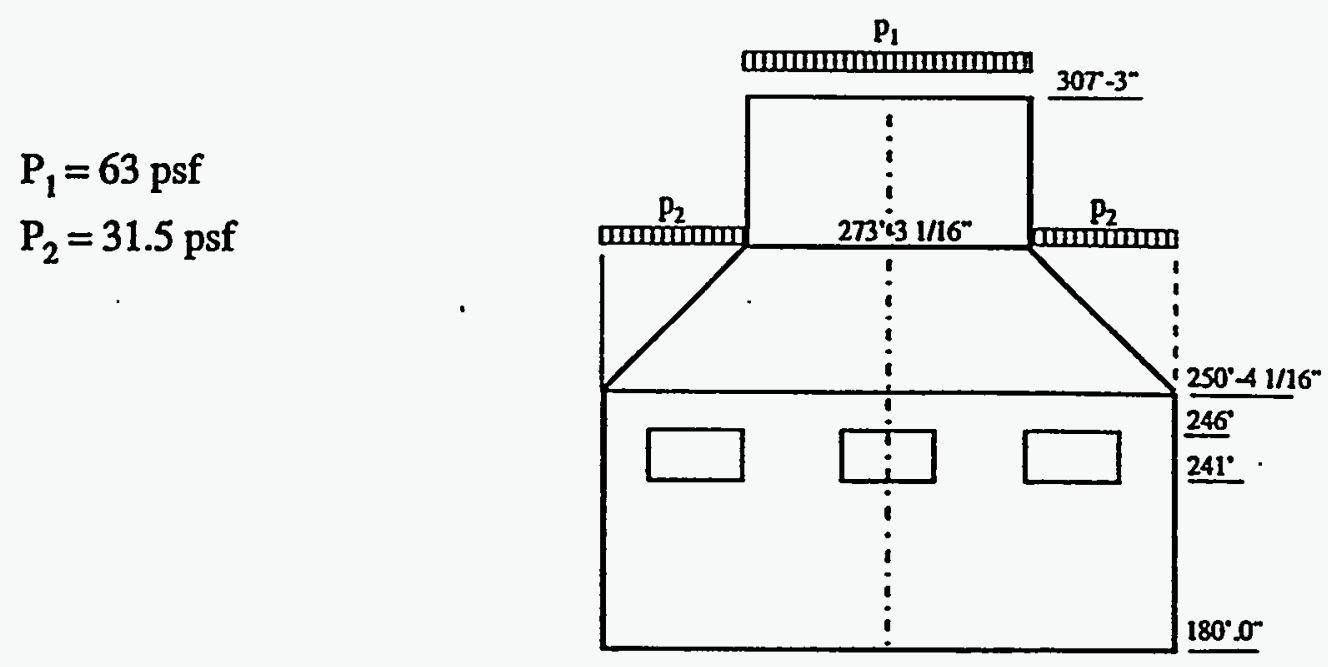

(a) Snow Loads on the AP600 SRR

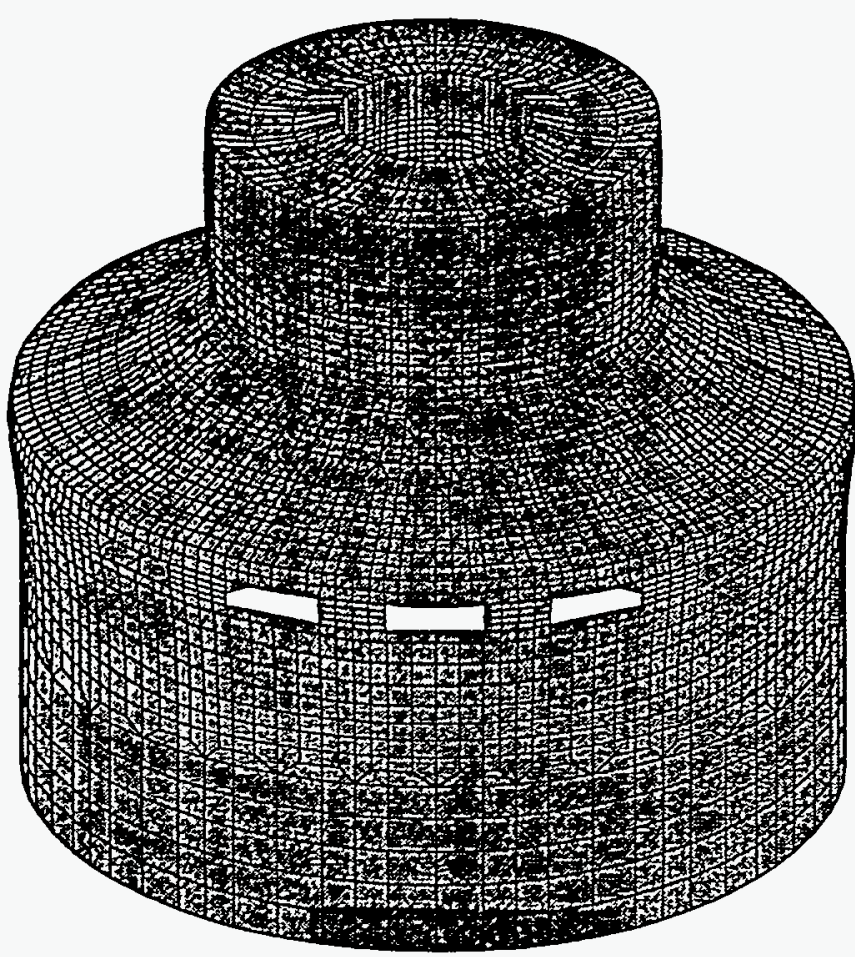

$\underline{\text { Isometric View }}$

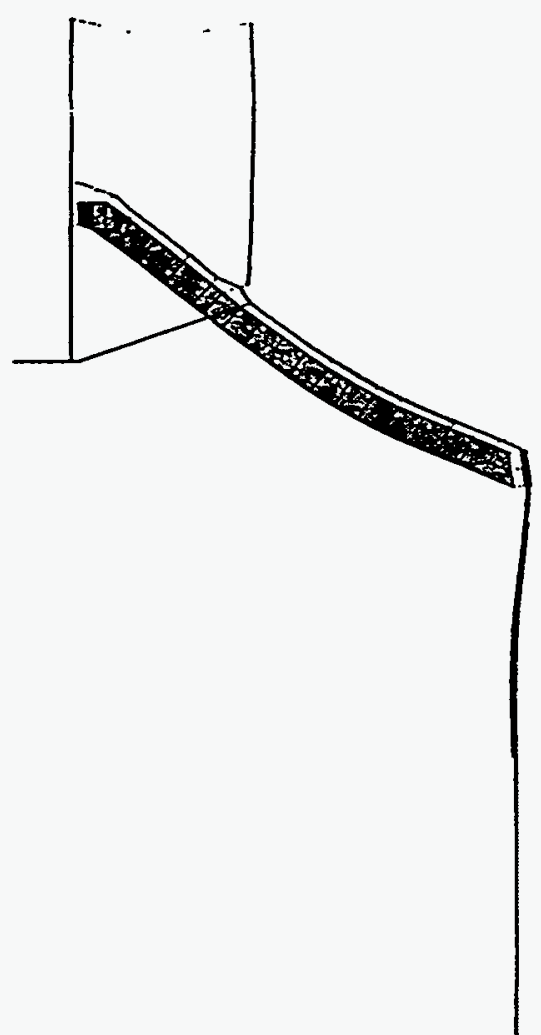

Sectional Elevation

(b) Deformed Shape

Figure 3.14 Deformed Shape of the AP600 SBR Under Snow Load Plus Water in the PCS Tank. 


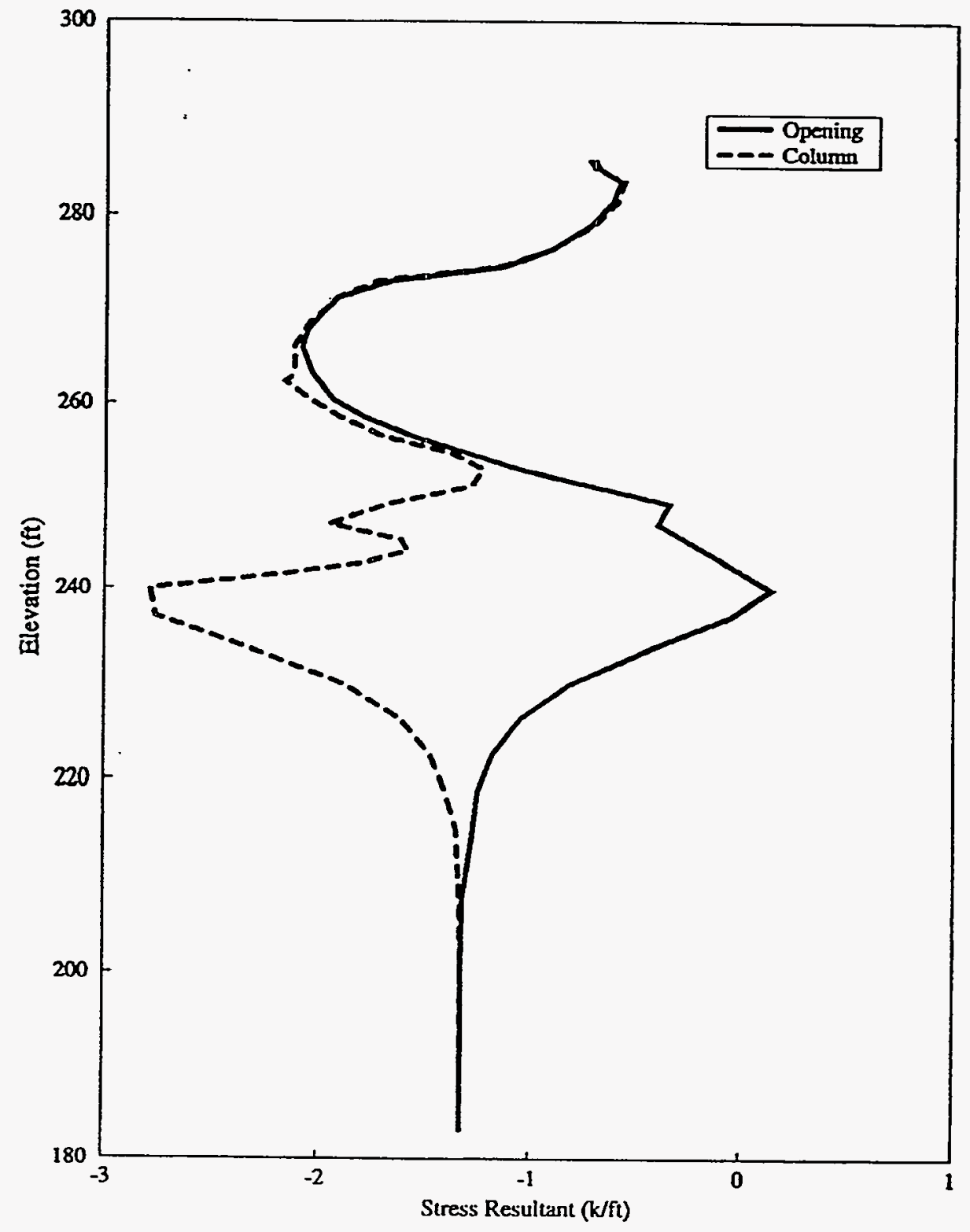

Figure 3.15 Distribution of the Meridional Stress Resultant, NI, (Snow Load) 


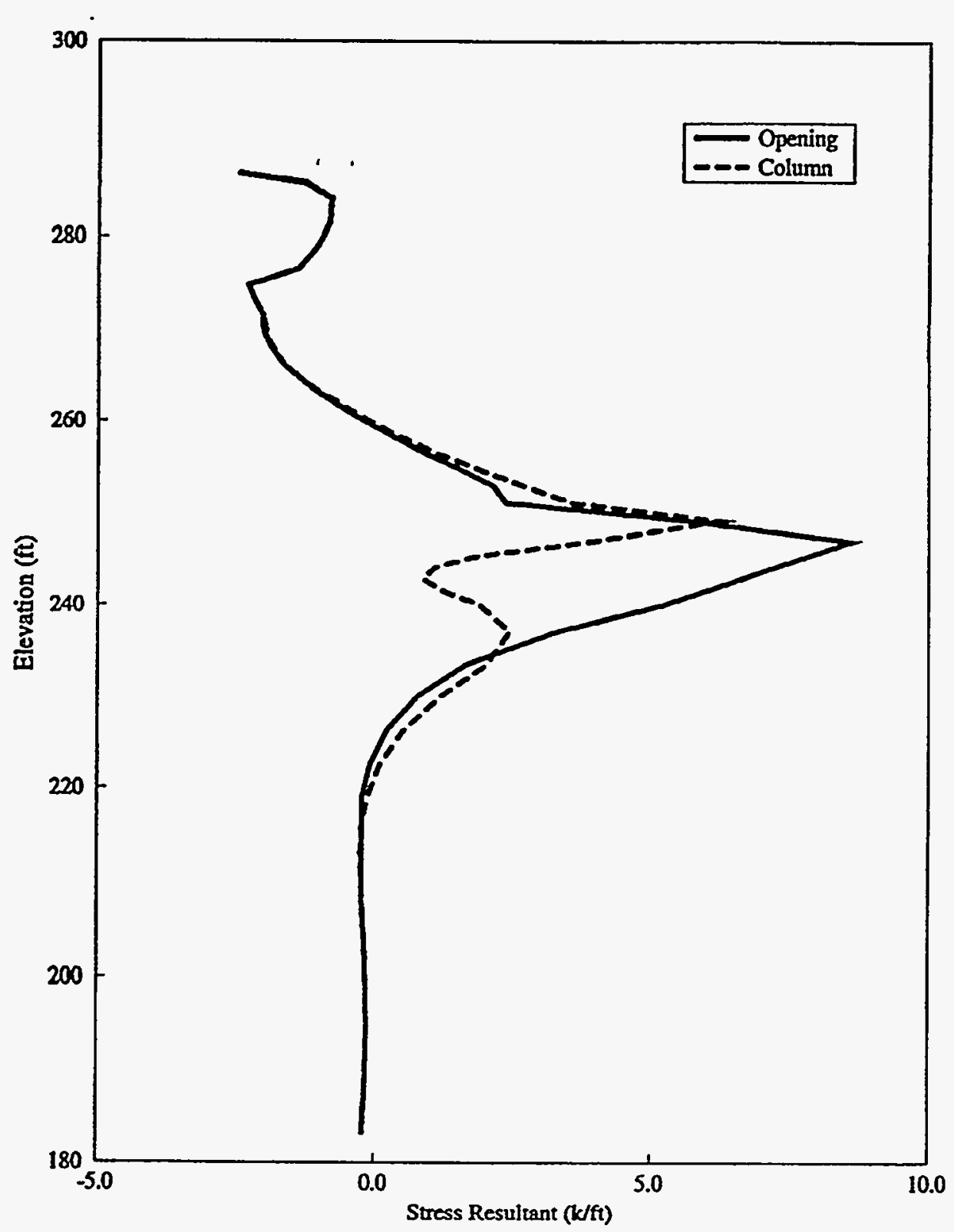

Figure 3.16 Distribution of the Circumferential Stress Resultant, N2, (Snow Load) 


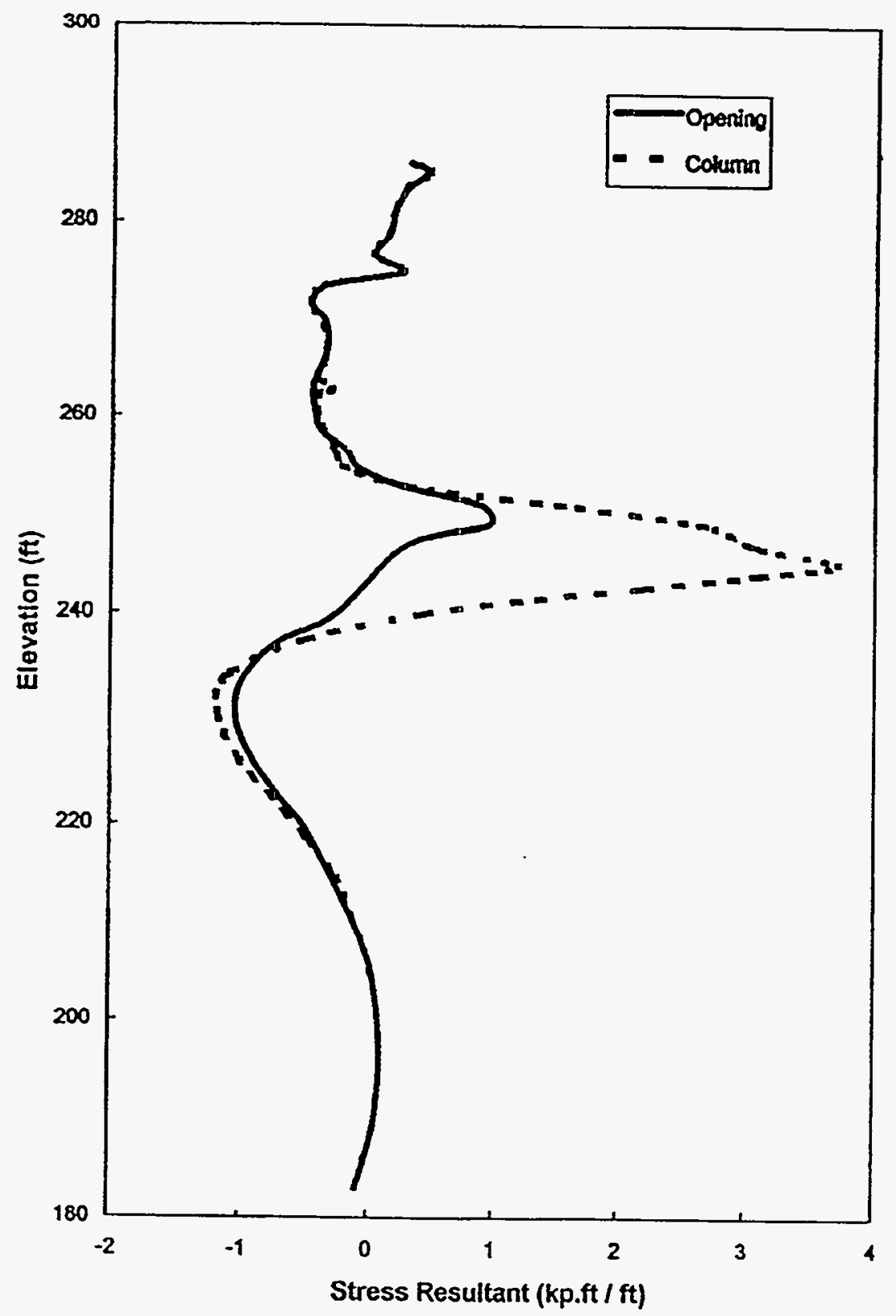

Figure 3.17 Distribution of the Meridional Moment, M1, (Snow Load) 


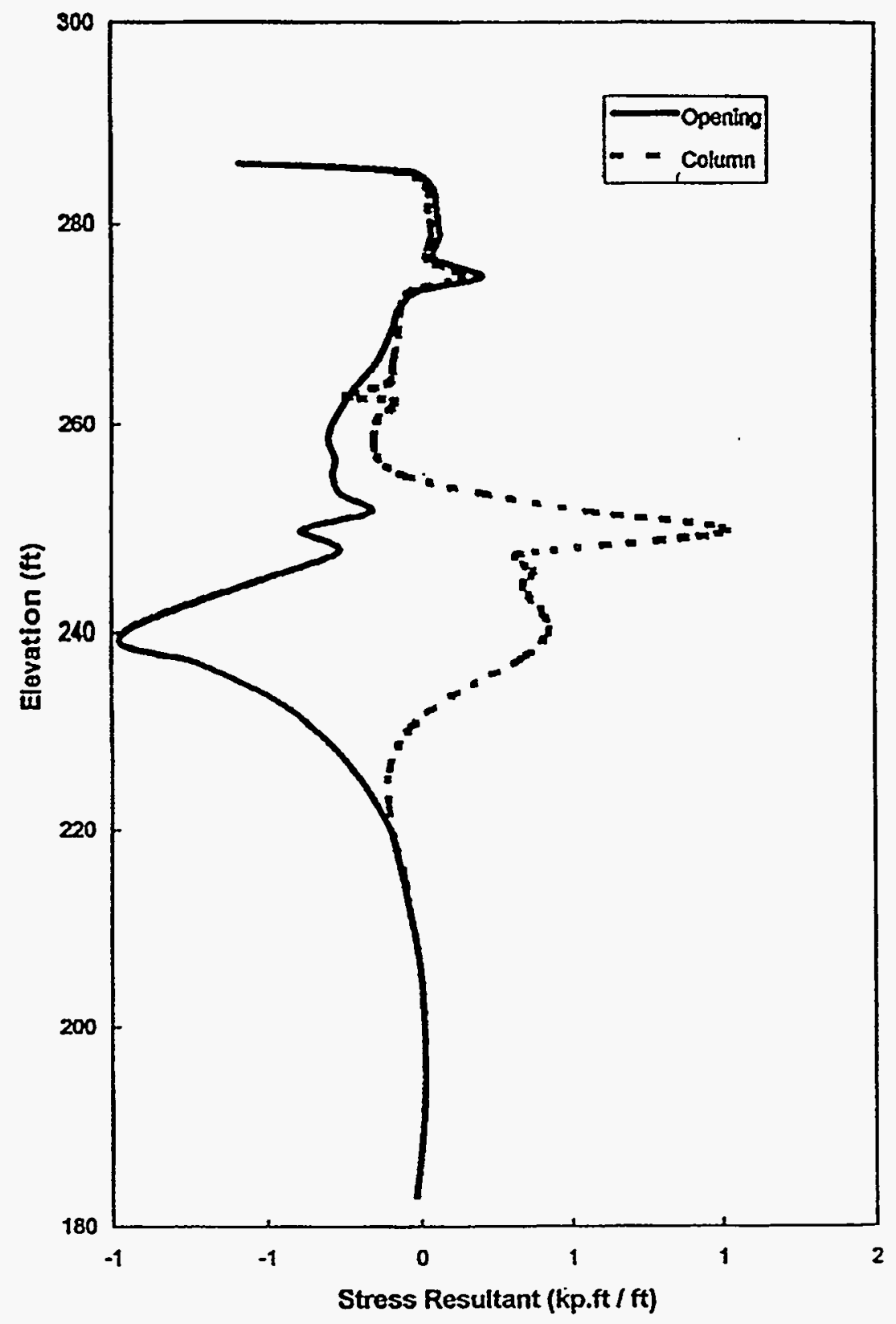

Figure 3.18 Distribution of the Circumferential Moment, M2, (Snow Load) 


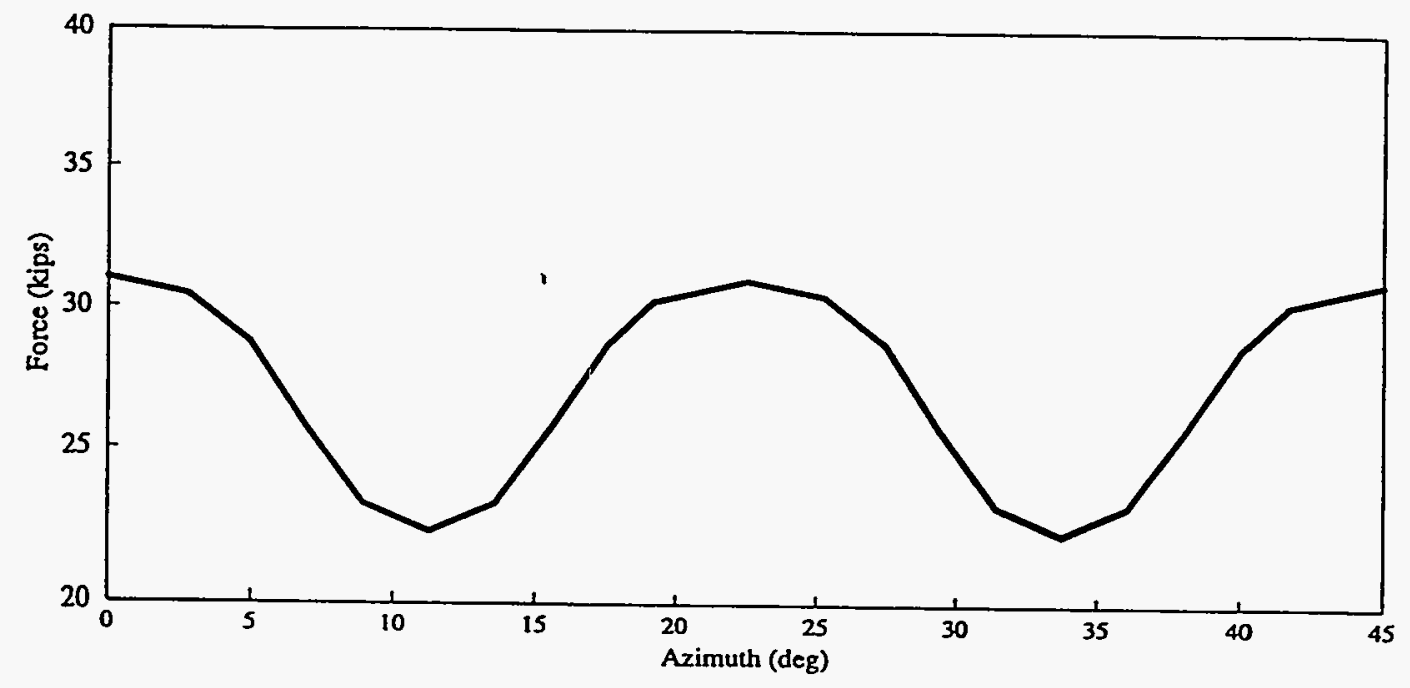

Figure 3.19 Distribution of the Axial Force in the Tension Ring (Snow Load)

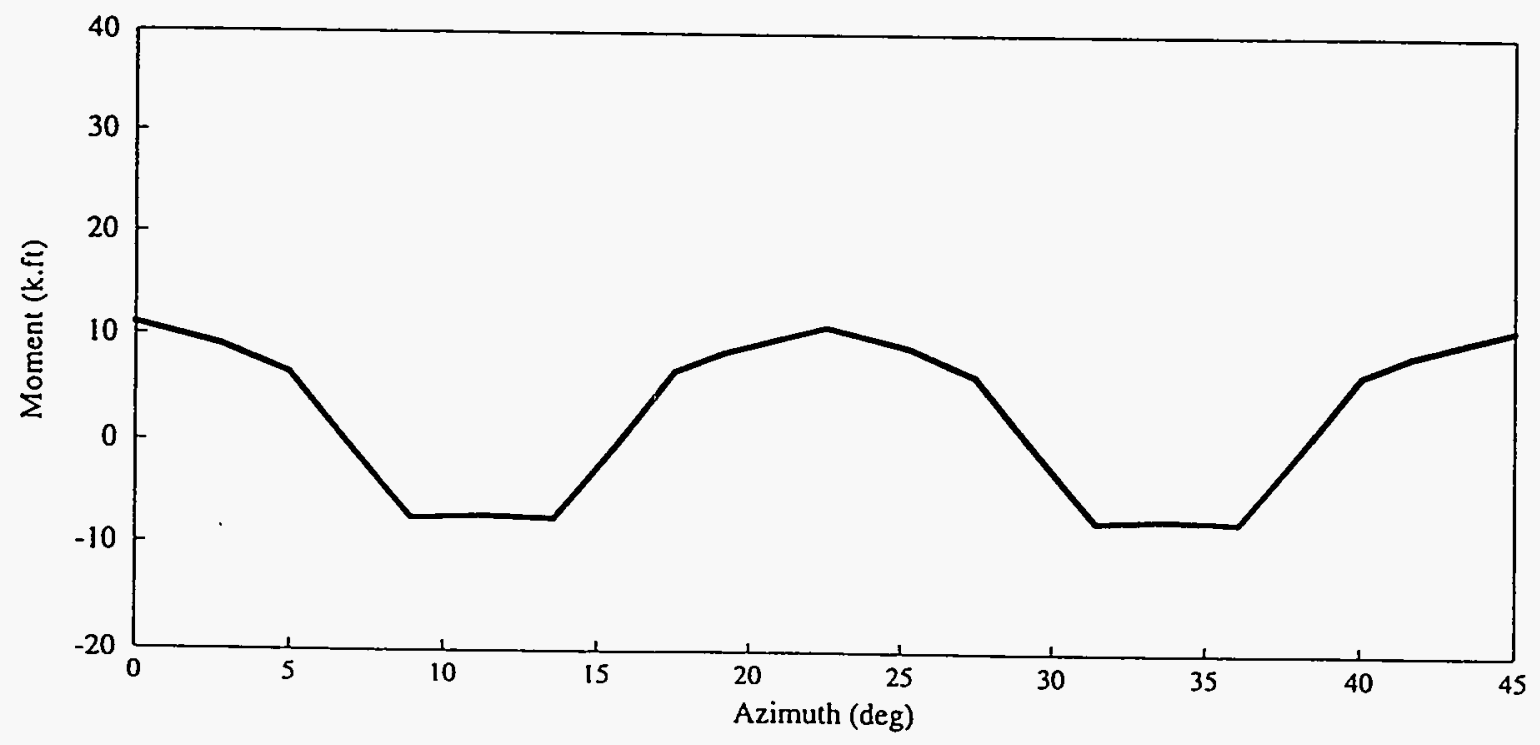

Figure 3.20 Distribution of the Moment, Mx, in the Tension Ring (Snow Load) 


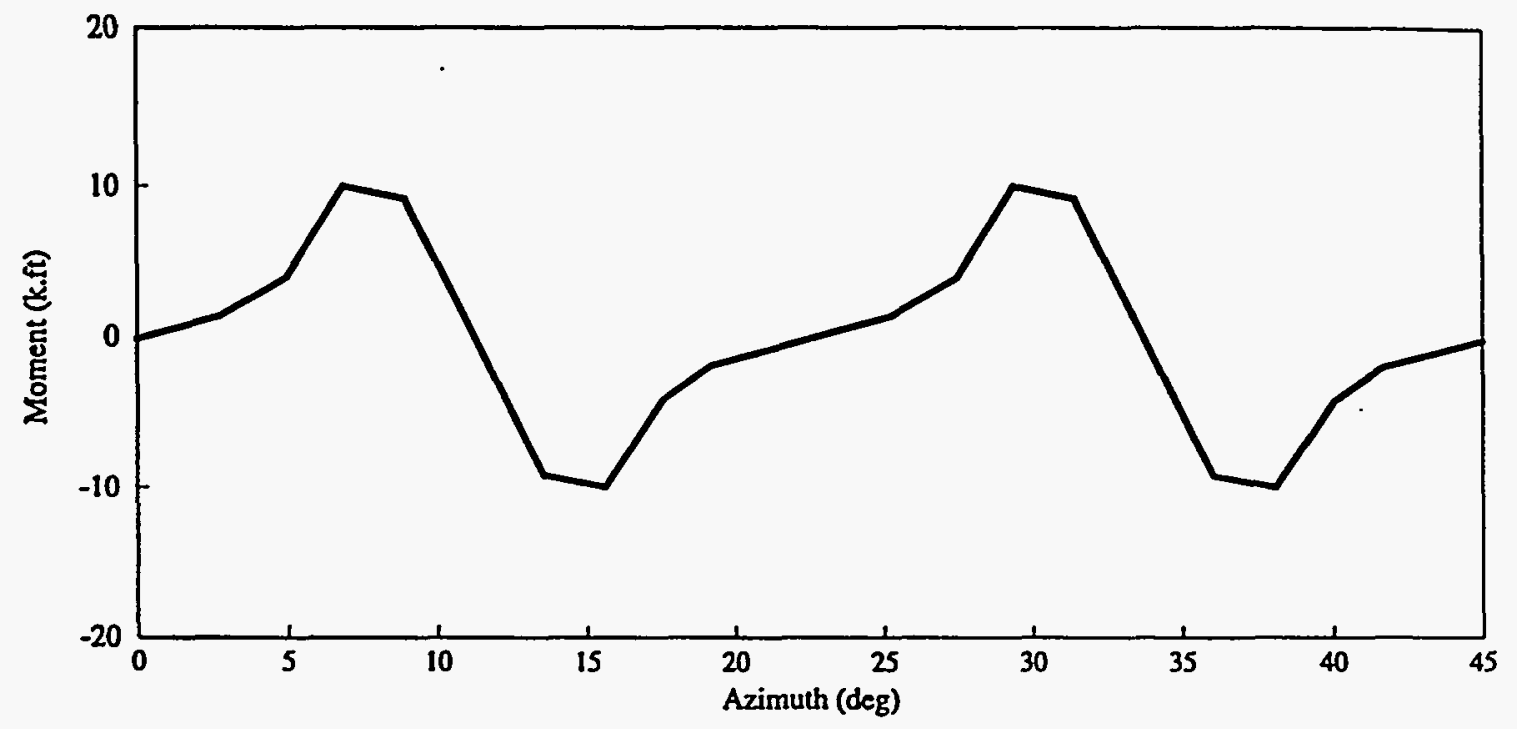

Figure 3.21 Distribution of the Torsional Moment, $\mathrm{T}$, in the Tension Ring (Snow Load)

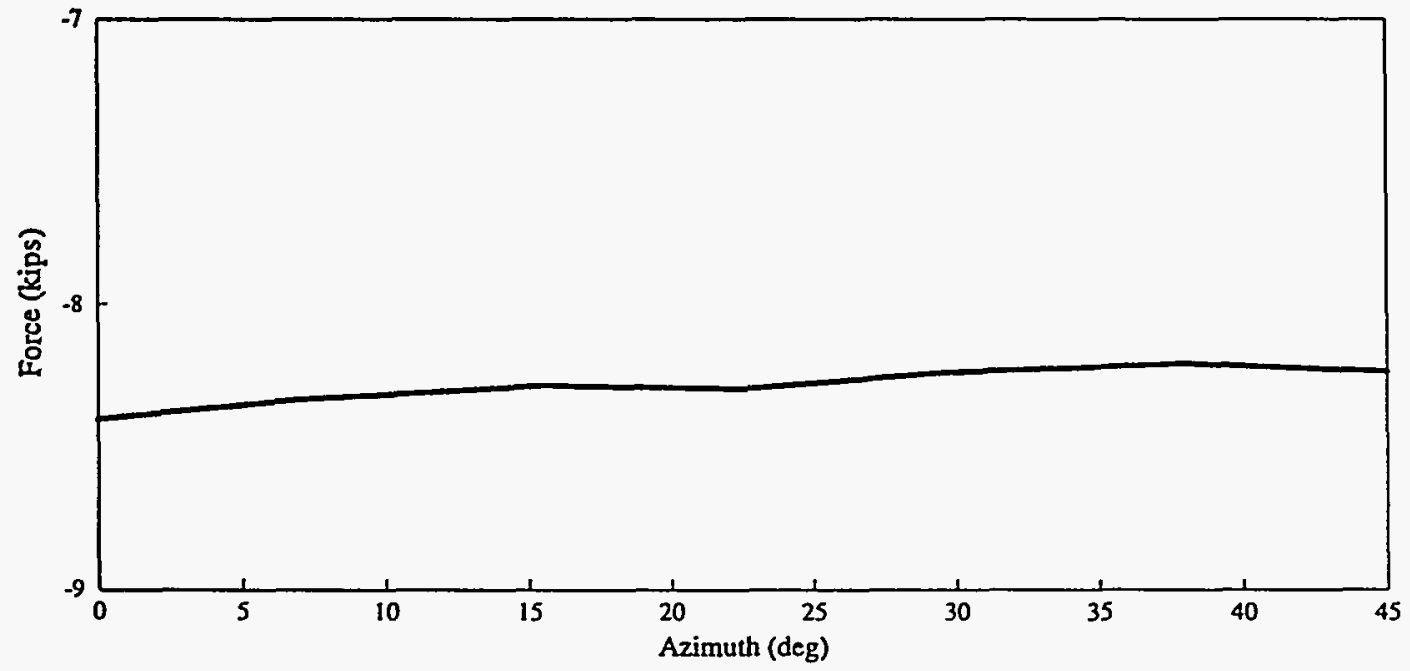

Figure 3.22 Distribution of the Axial Force in the Compression Ring (Snow Load) 


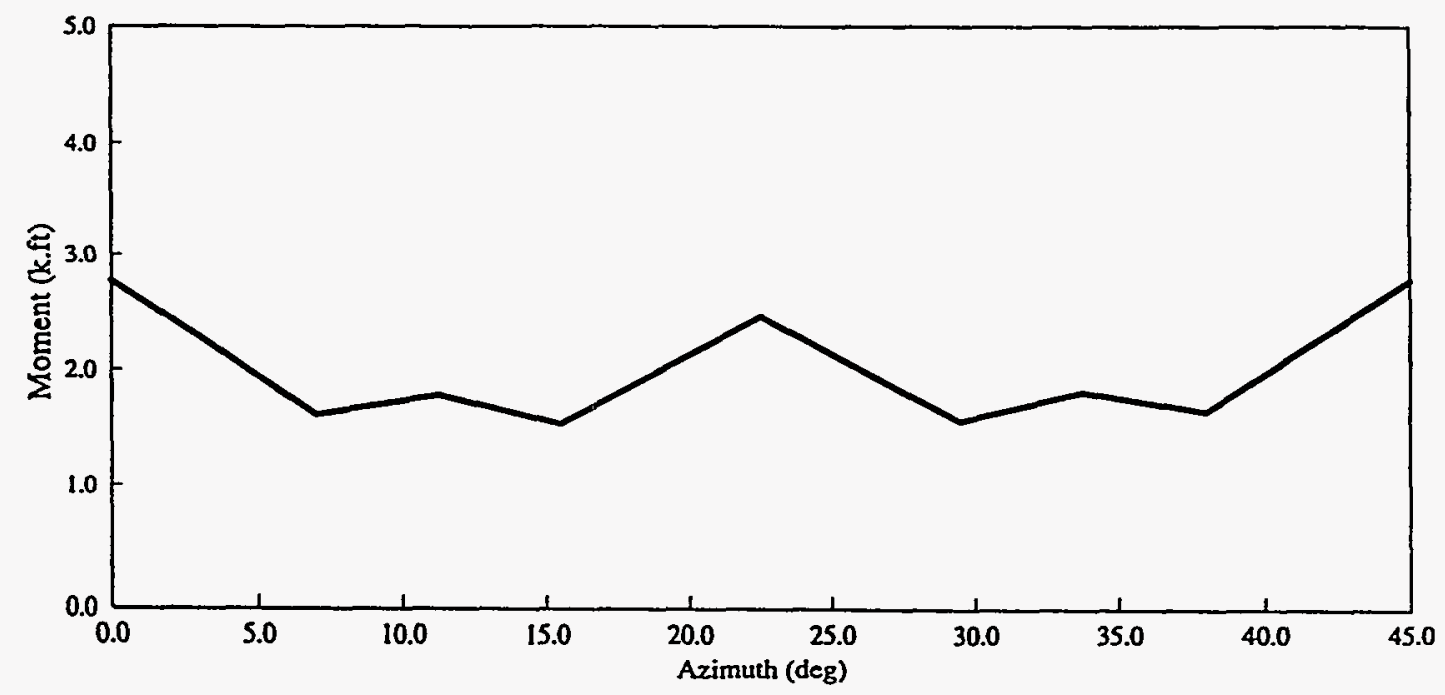

Figure 3.23 Distribution of the Moment, Mx, in the Compression Ring (Snow Load)

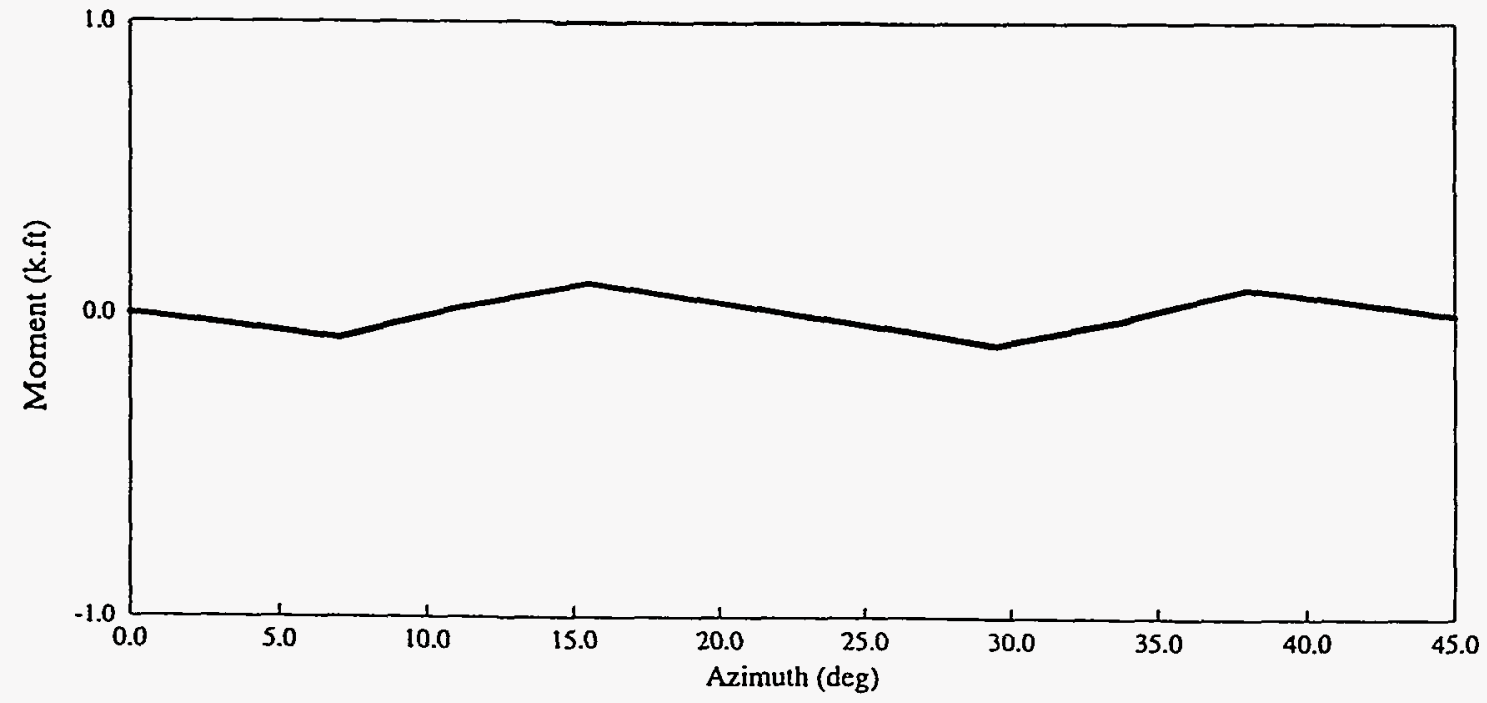

Figure 3.24 Distribution of the Torsional Moment, $\mathrm{T}$, in the Compression Ring (Snow Load) 
- Basic Wind Speed = $110 \mathrm{mph}$

- Importance Factor $=1.10$

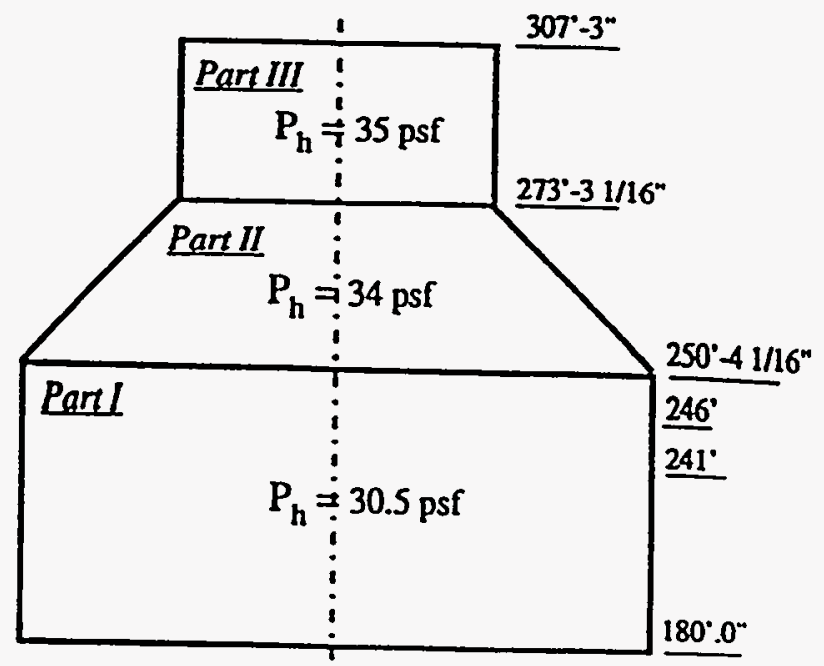

(a) Wind Pressure on Projected Area

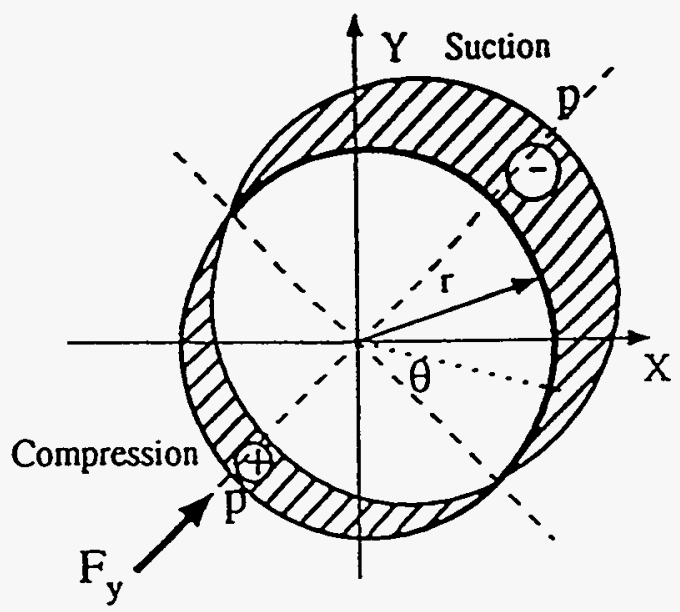

(b) Assumed Wind Pressure Distribution

Figure 3.25 Wind Pressure on the SBR in the Southeast Direction 


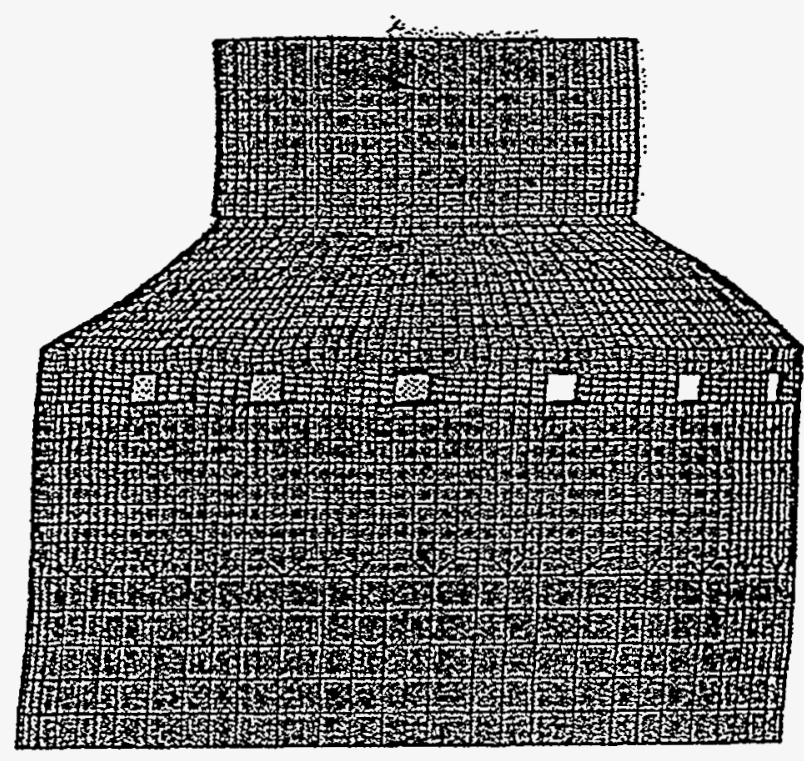

Figure 3.26 Deformed Shape of the AP600 SBR Under Wind Load Plus Water in the PCS Tank 


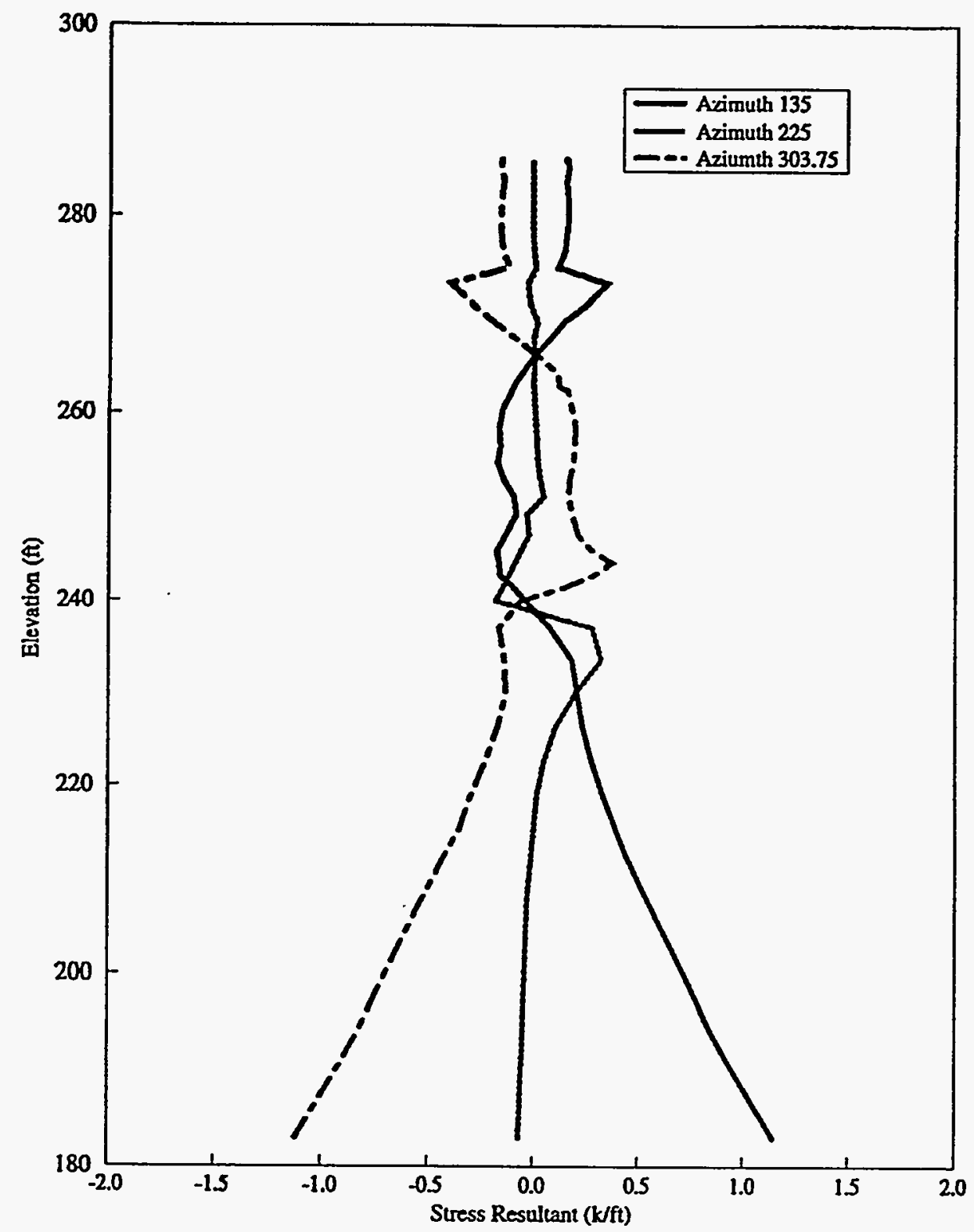

Figure 3.27 Distribution of the Meridional Stress Resultant, N1, (Wind Load) 


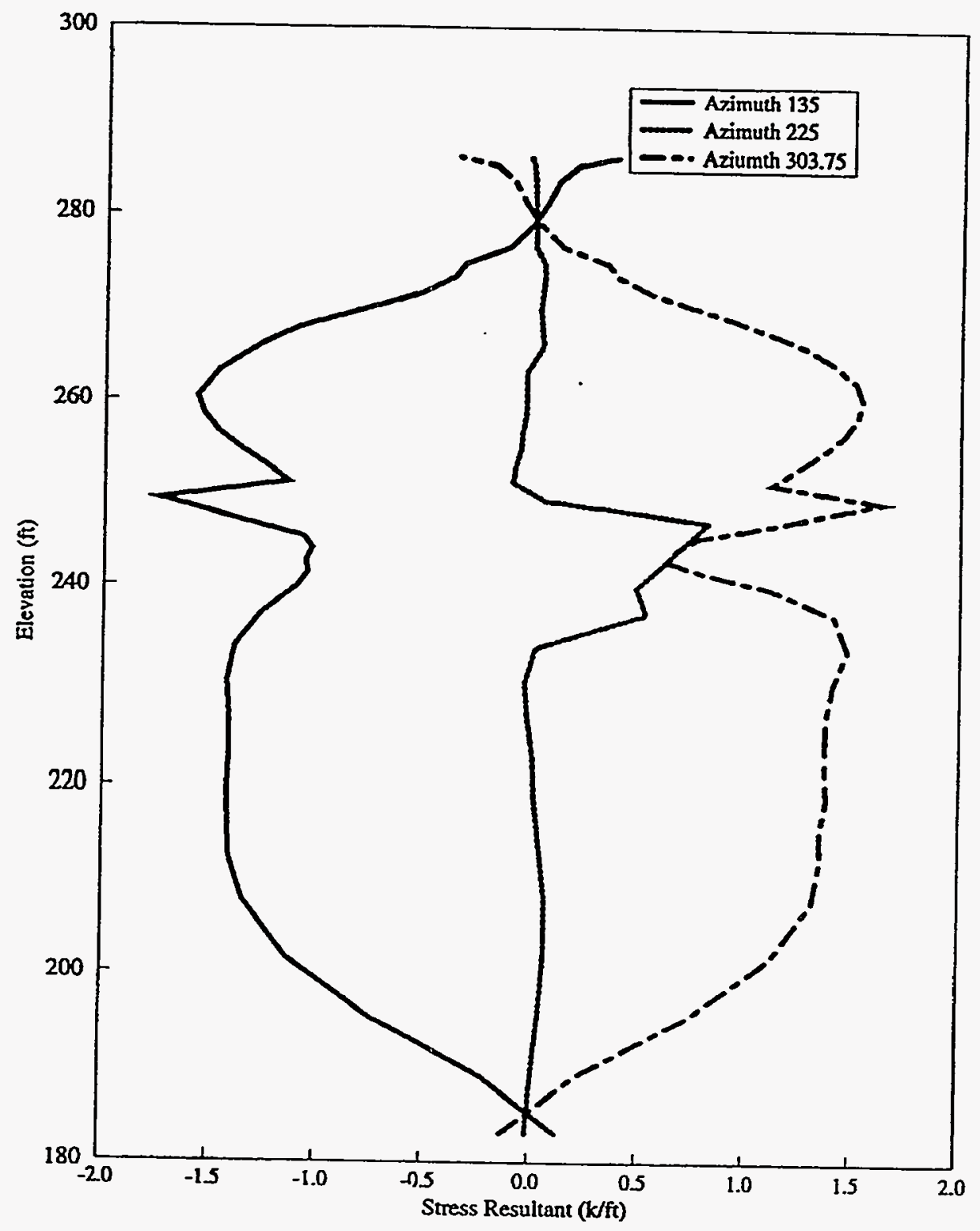

Figure 3.28 Distribution of the Circumferential Stress Resultant, N2, (Wind Load) 


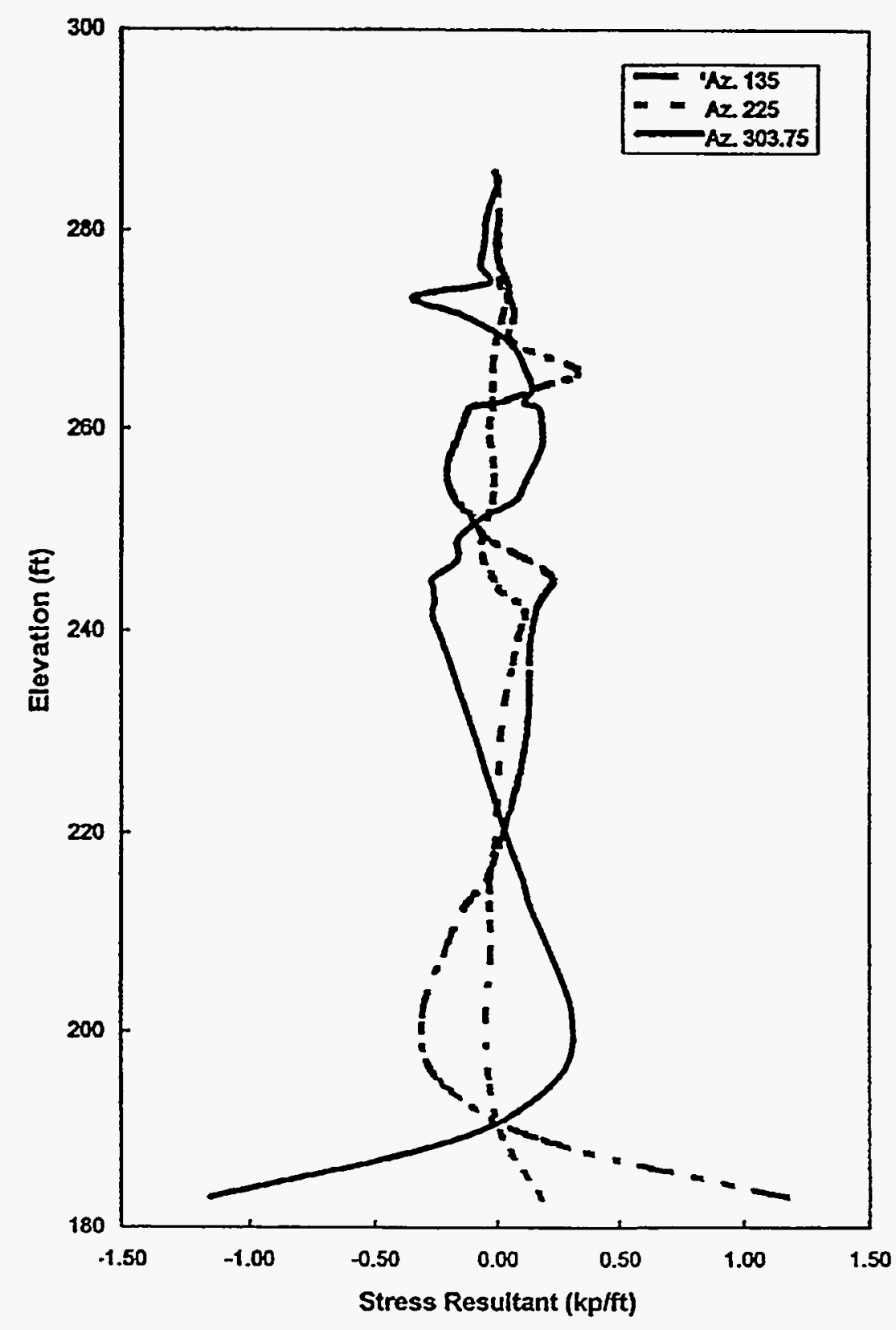

Figure 3.29 Distribution of the Meridional Moment, M1, (Wind Load) 


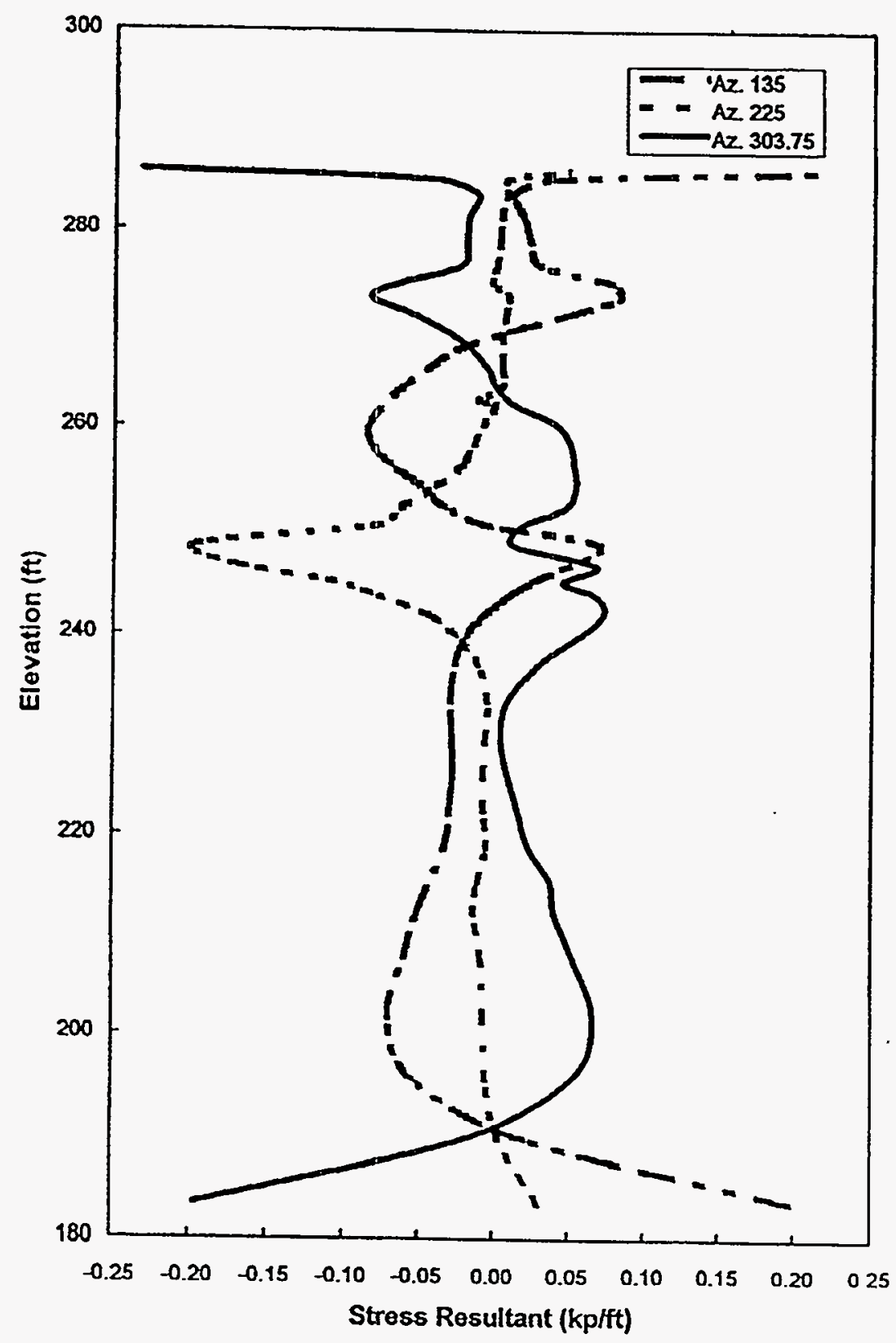

Figure 3.30 Distribution of the Circumferential Moment, M2, (Wind Load) 


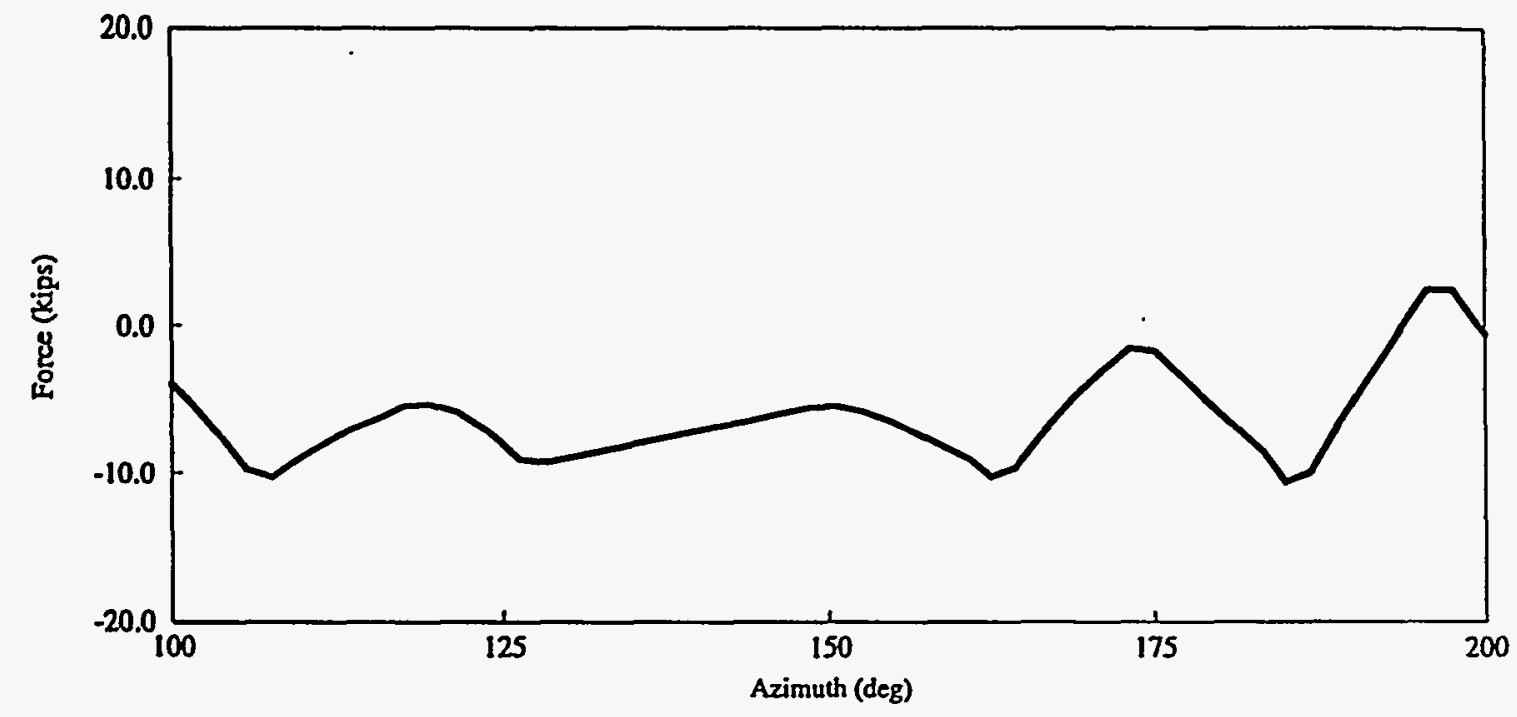

Figure 3.31 Distribution of the Axial Force in the Tension Ring (Wind Load)

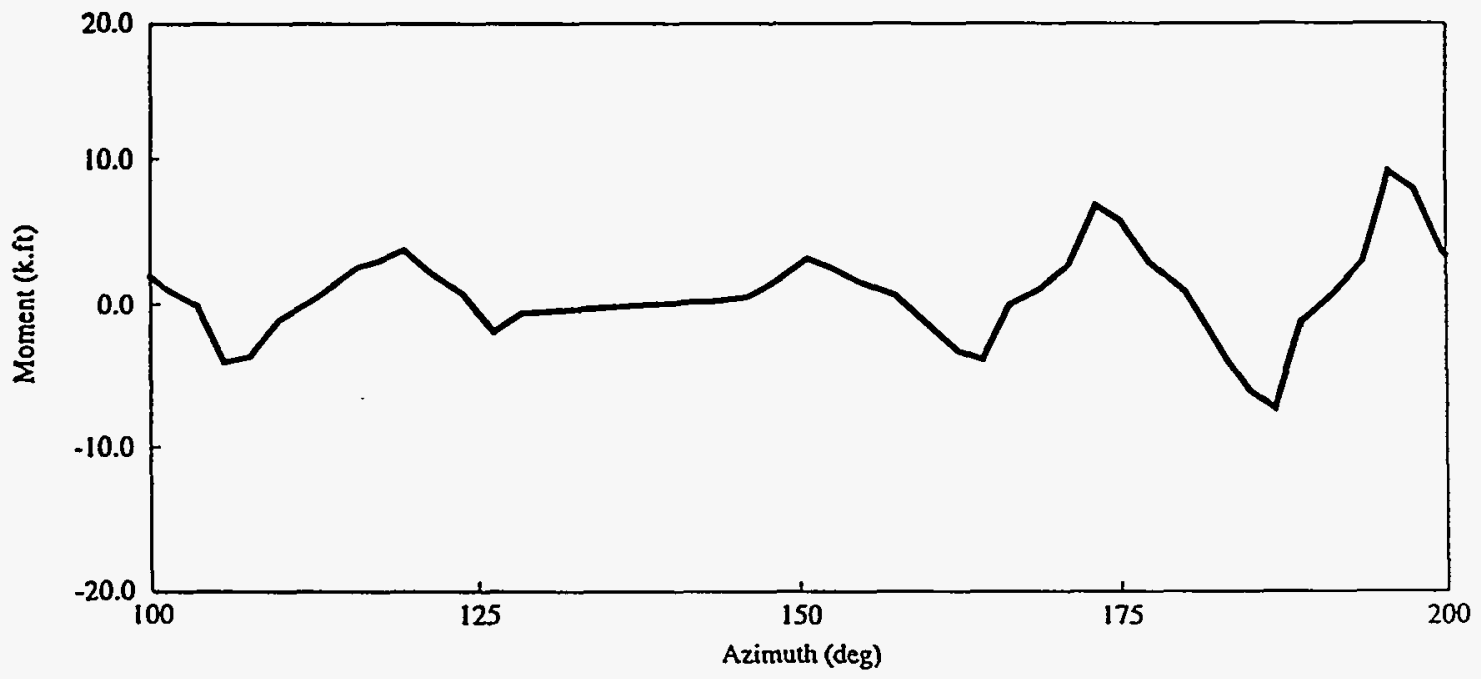

Figure 3.32 Distribution of the Moment, Mx, in the Tension Ring (Wind Load) 


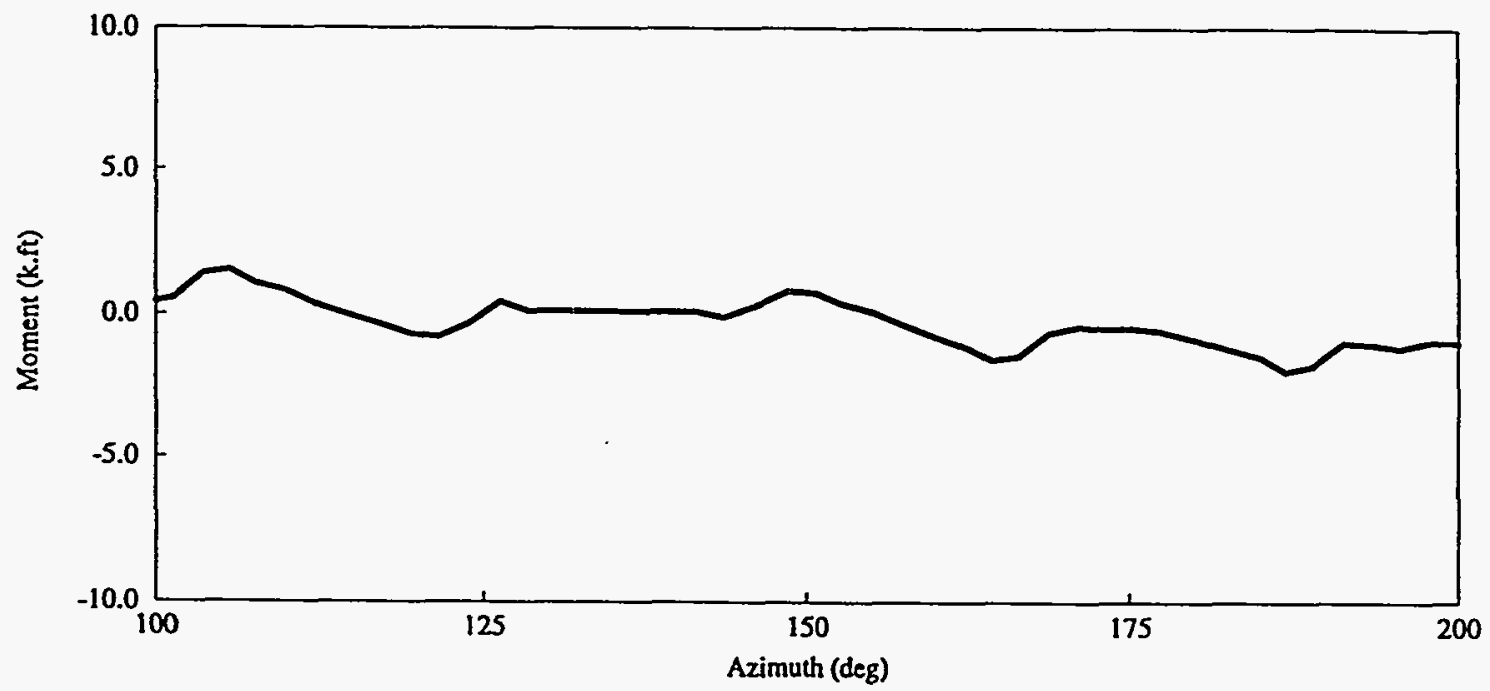

Figure 3.33 Distribution of the Torsional Moment, $T$, in the Tension Ring (Wind Load)

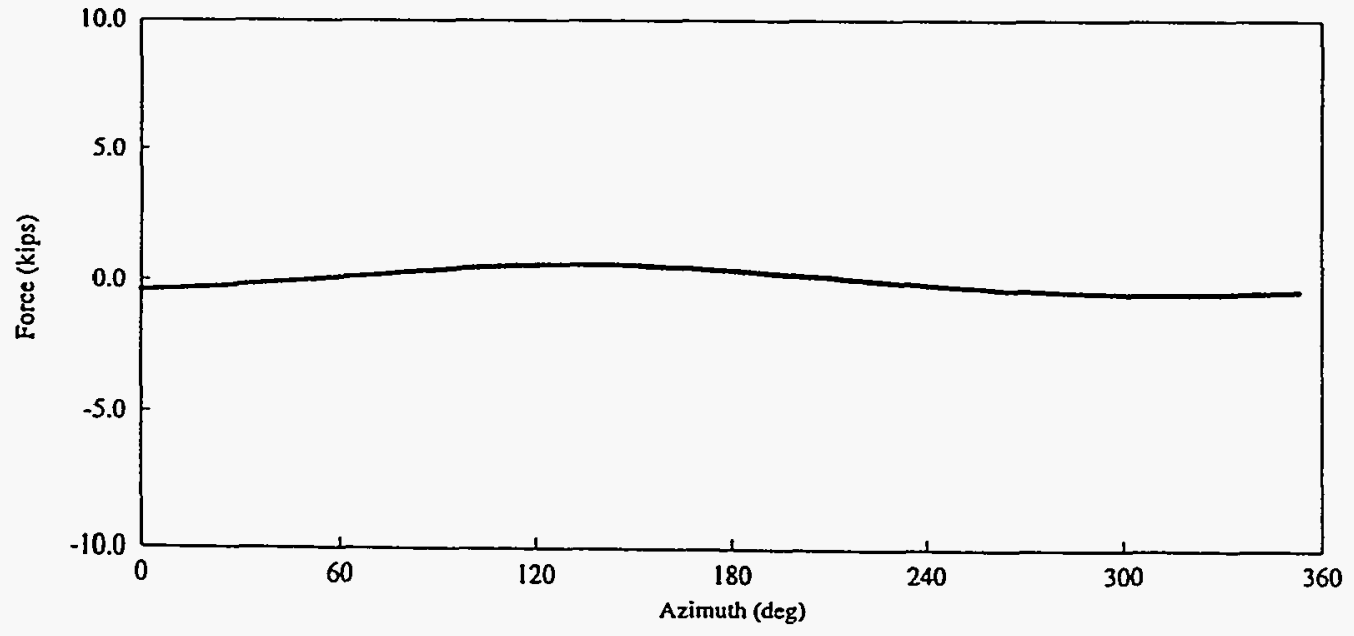

Figure 3.34 Distribution of the Axial Force in the Compression Ring (Wind Load) 


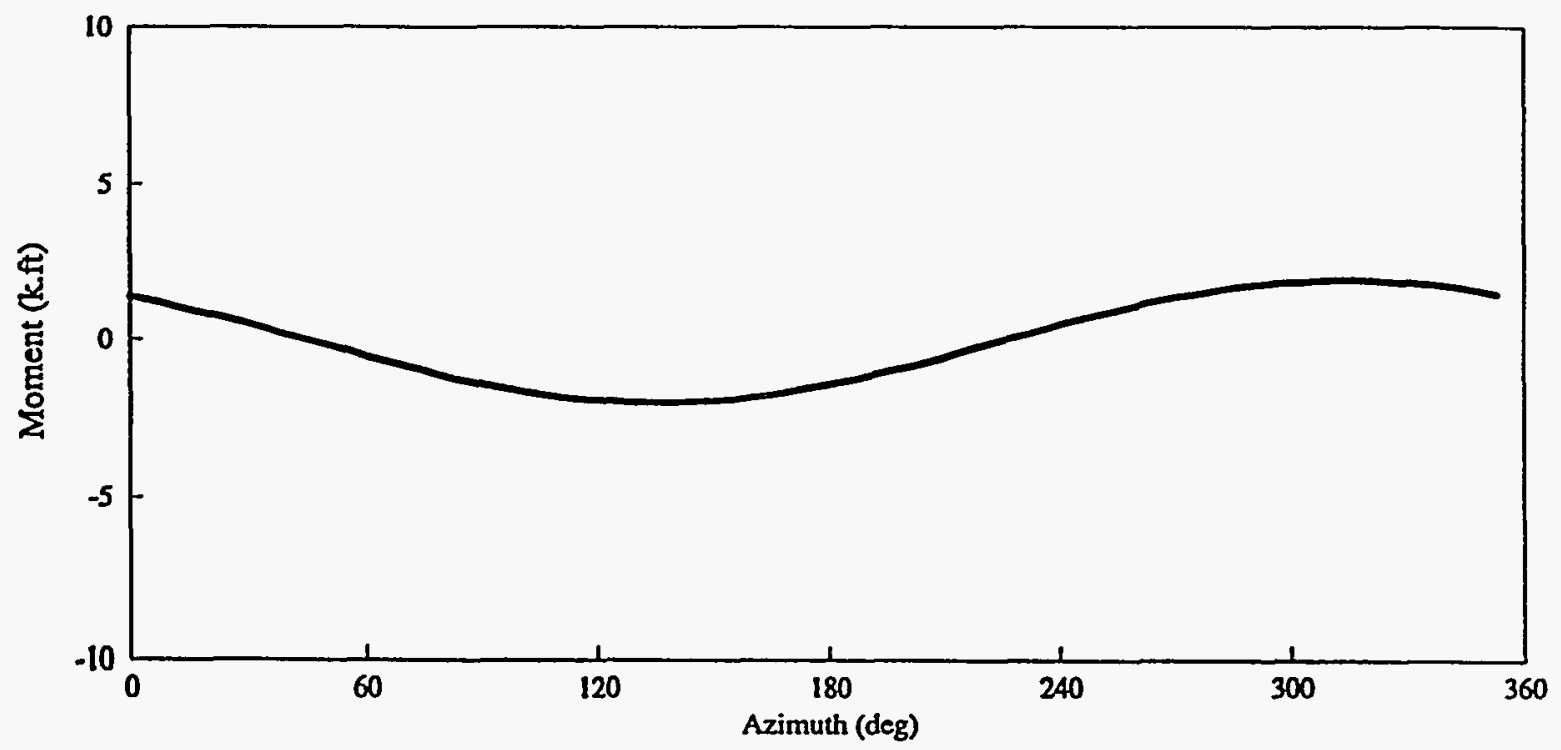

Figure 3.35 Distribution of the Moment, Mx, in the Compression Ring (Wind Load)

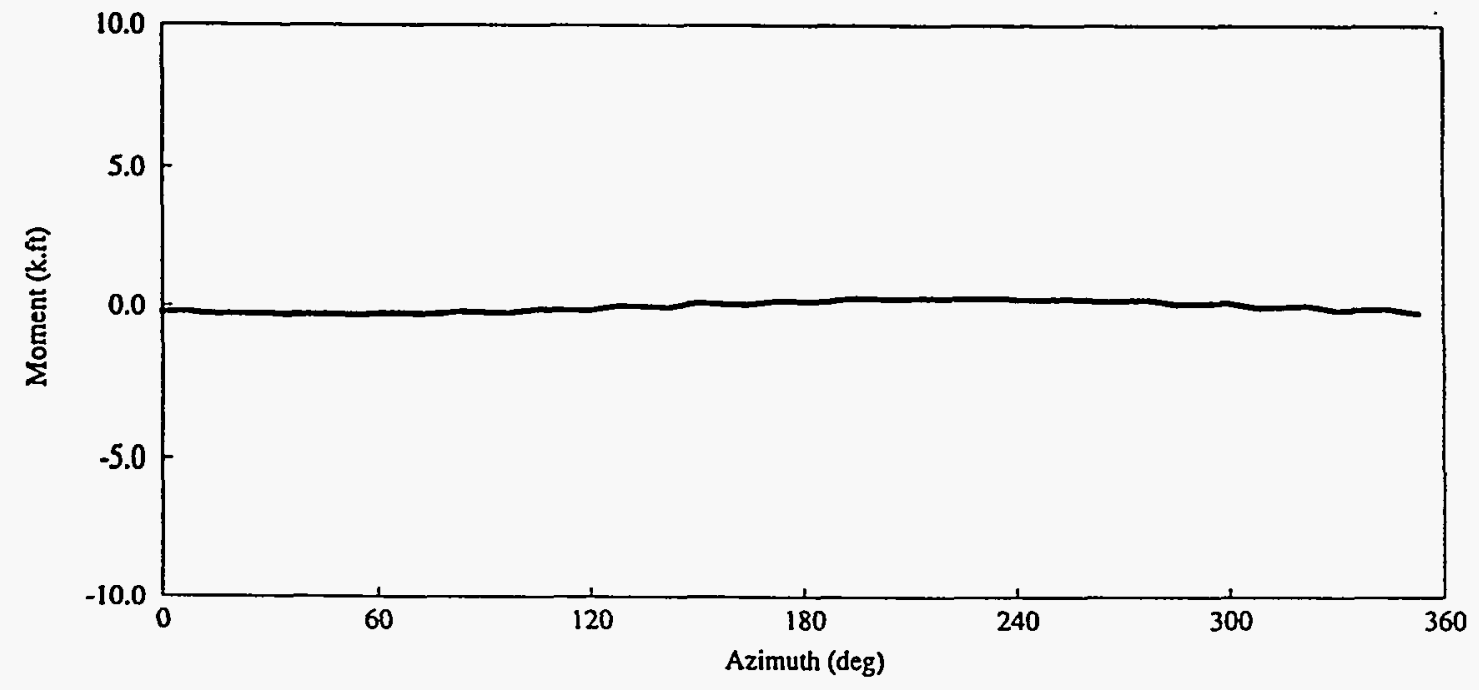

Figure 3.36 Distribution of the Torsional Moment, $\mathrm{T}$, in the Compression Ring (Wind Load). 


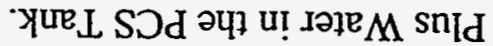

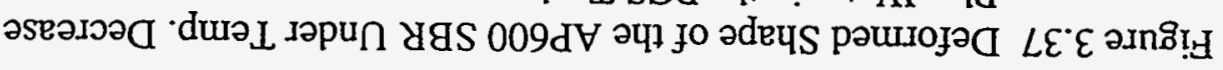
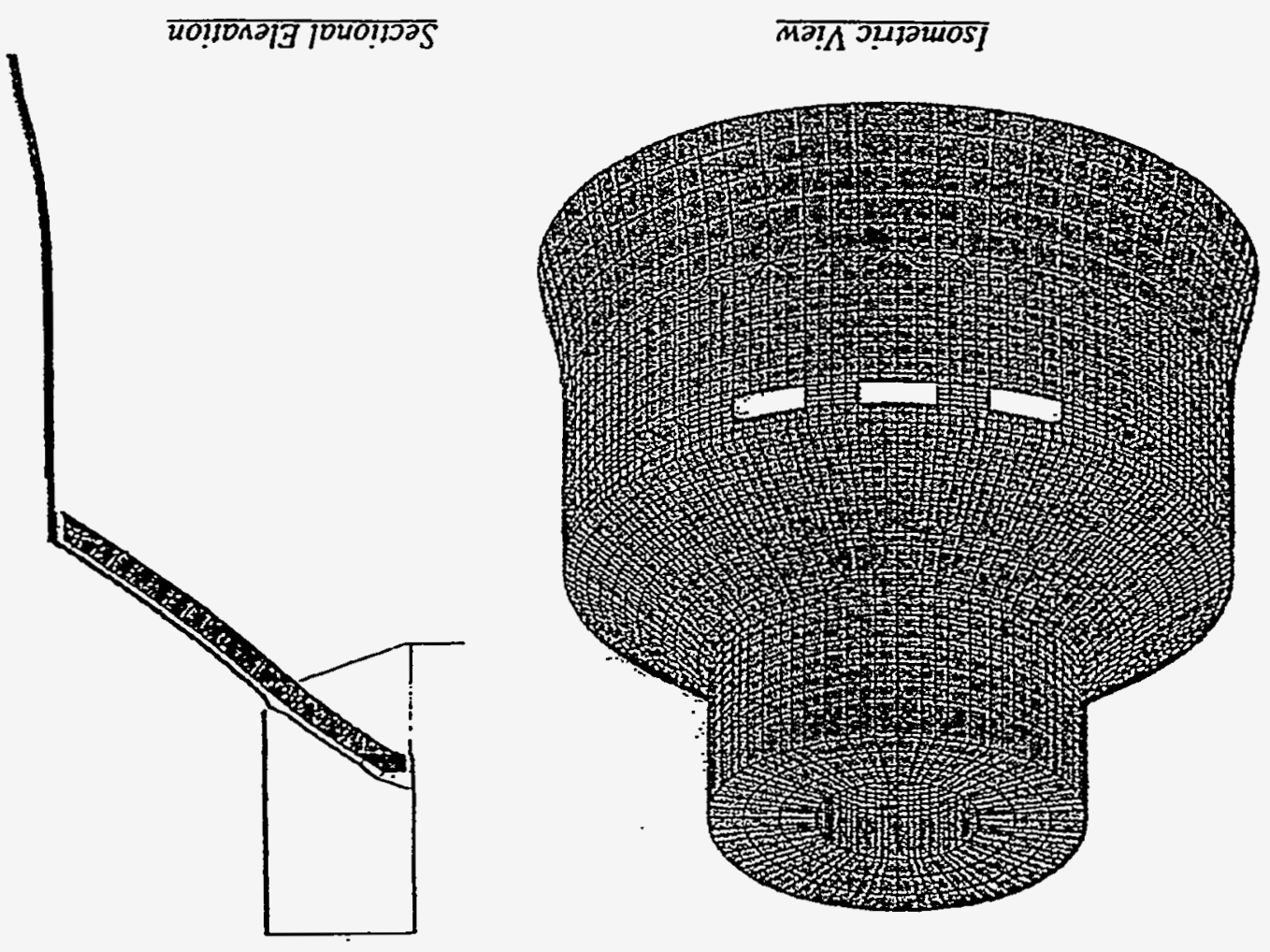


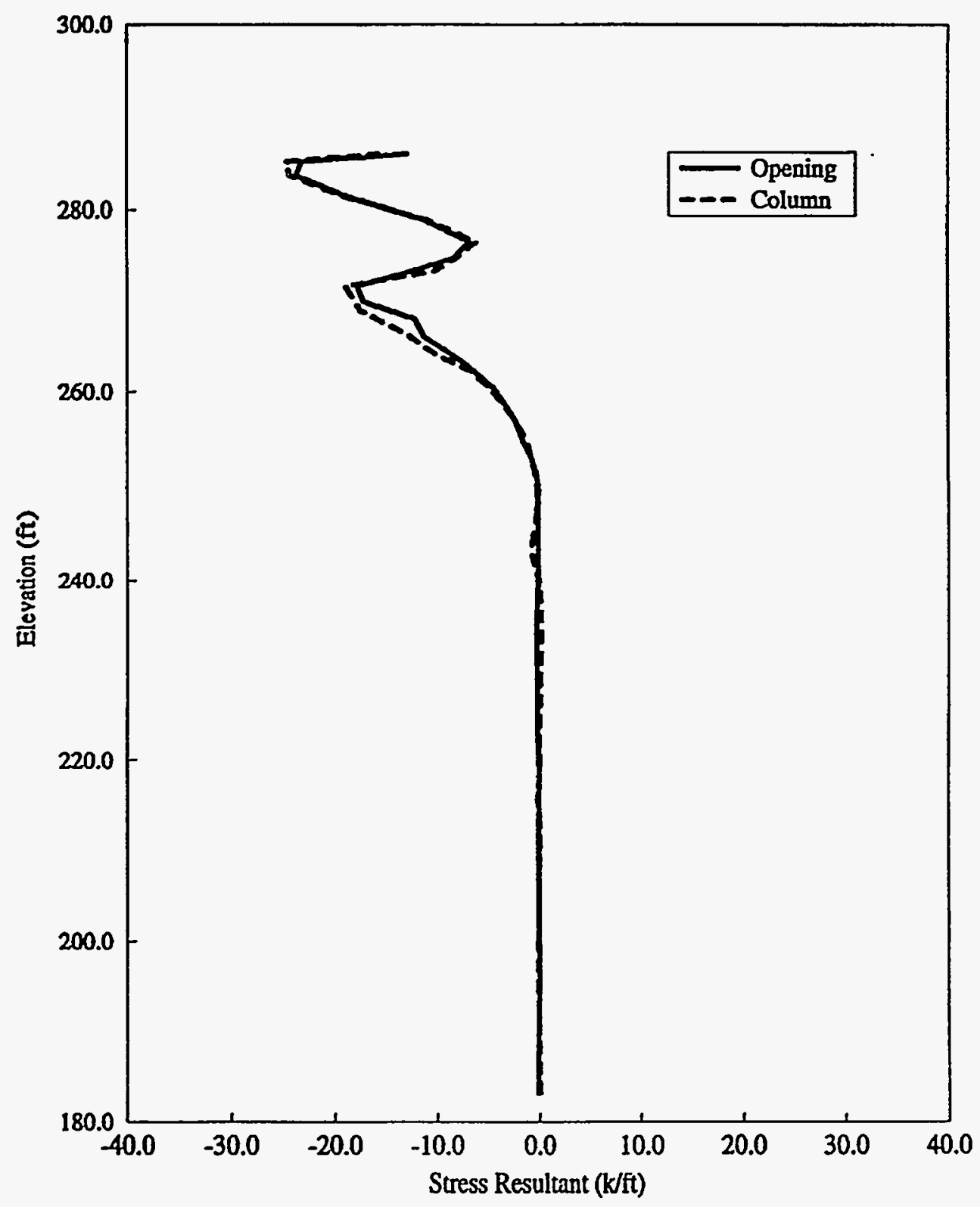

Figure 3.38 Distribution of the Meridional Stress Resultant, N1, (Temp. Decrease) 


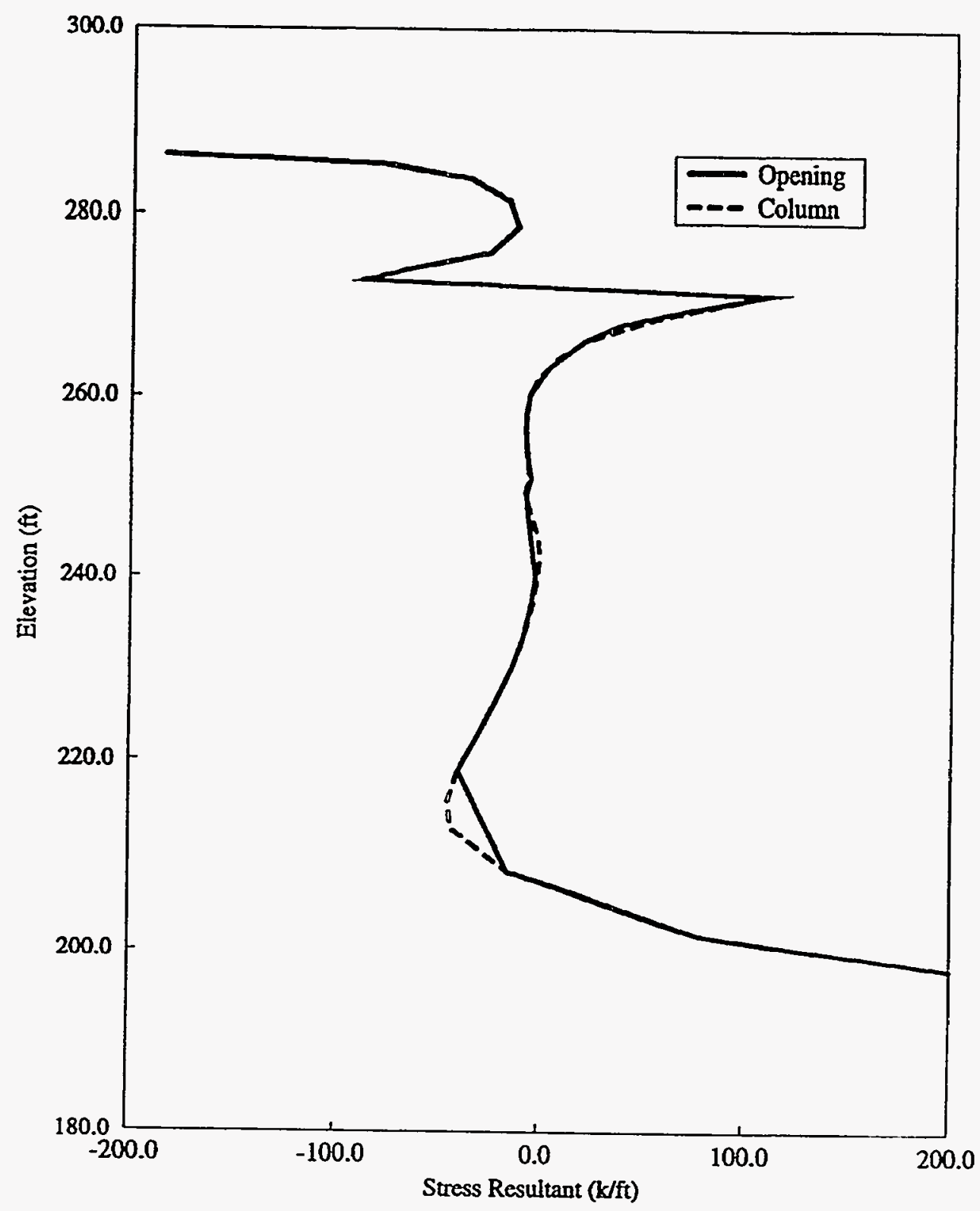

Figure 3.39 Distribution of the Circumferential Stress Resultant, N2, (Temp. Decrease) 


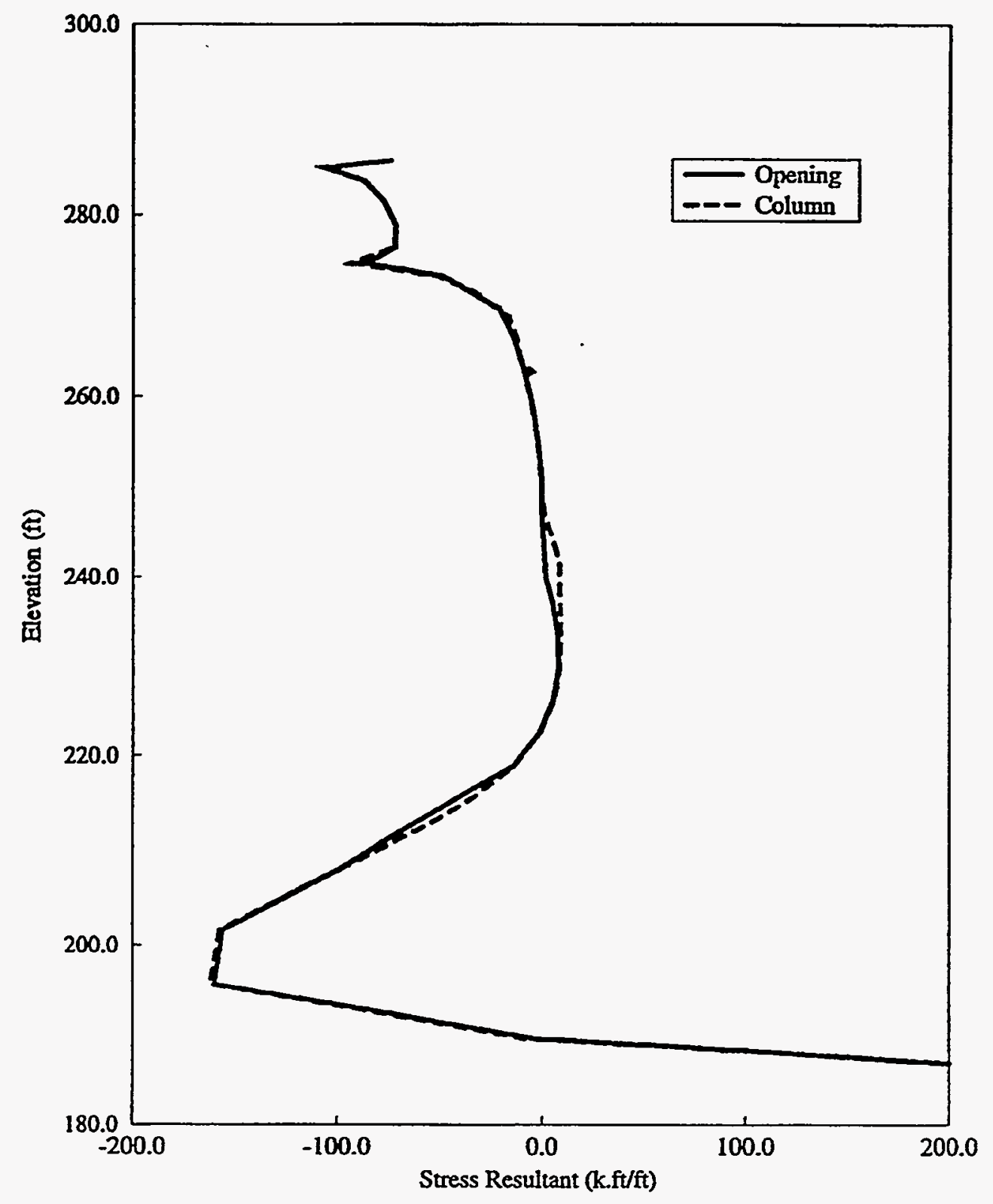

Figure 3.40 Distribution of the Meridional Moment, M1, (Temp. Decrease) 


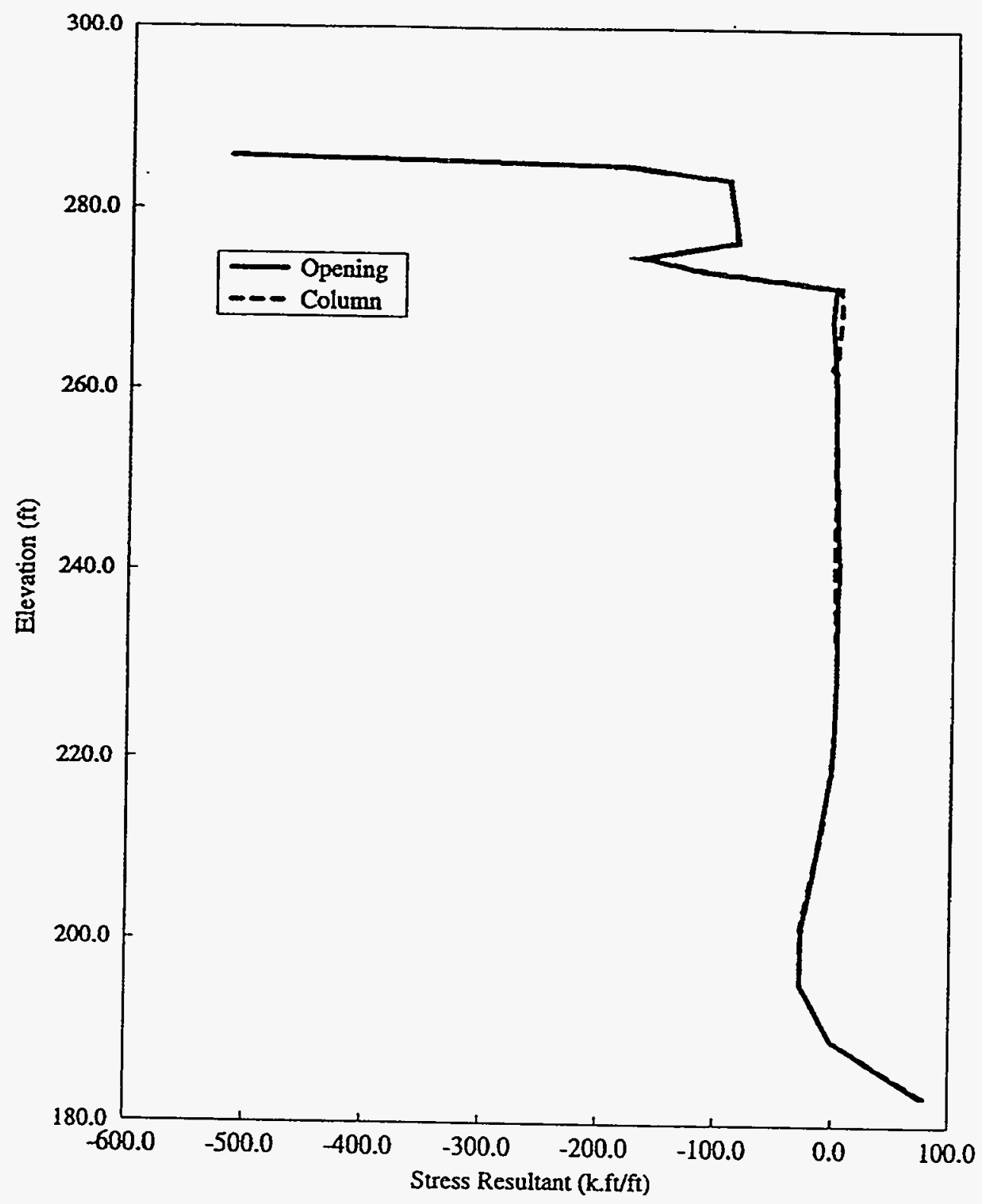

Figure 3.41 Distribution of the Circumferential Moment, M2, (Temp. Decrease) 


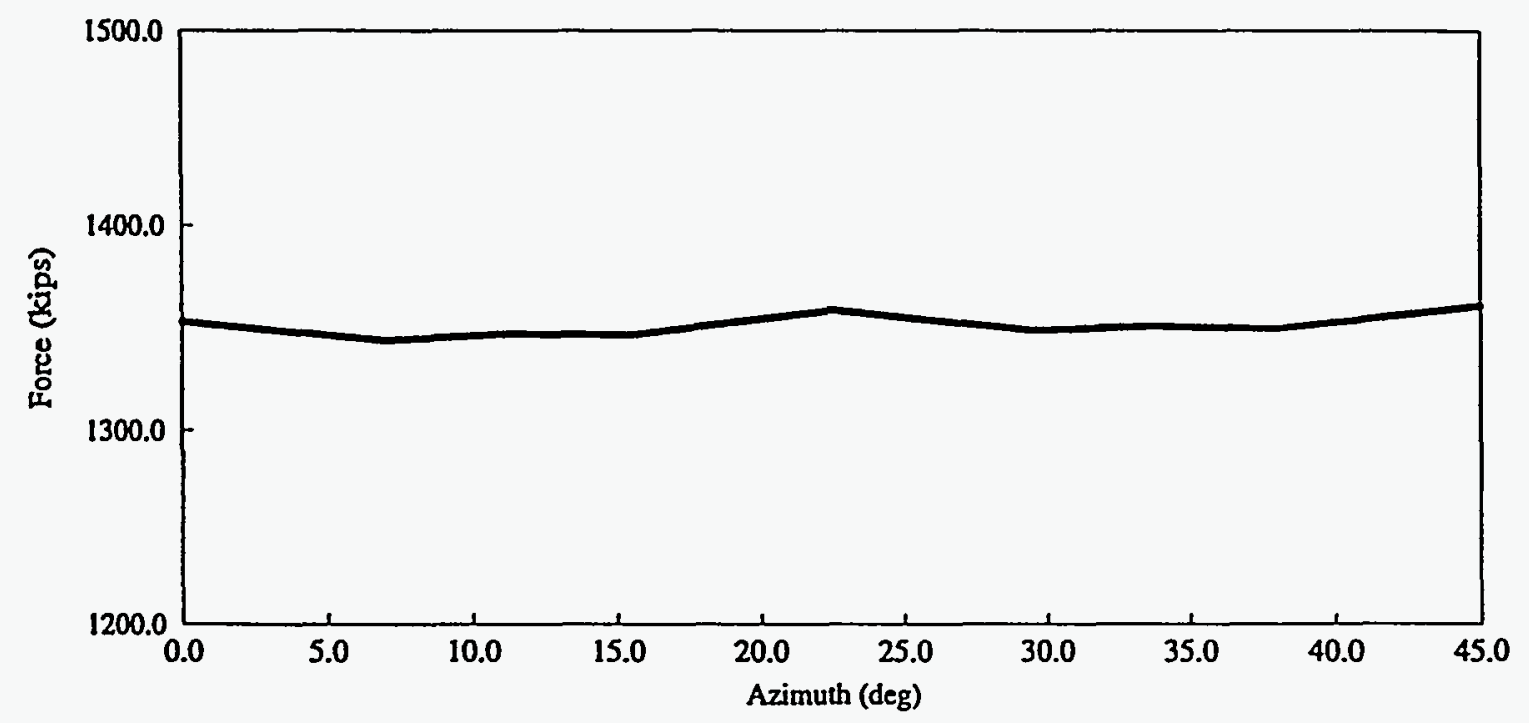

Figure 3.42 Distribution of the Axial Force in the Tension Ring (Temp. Decrease)

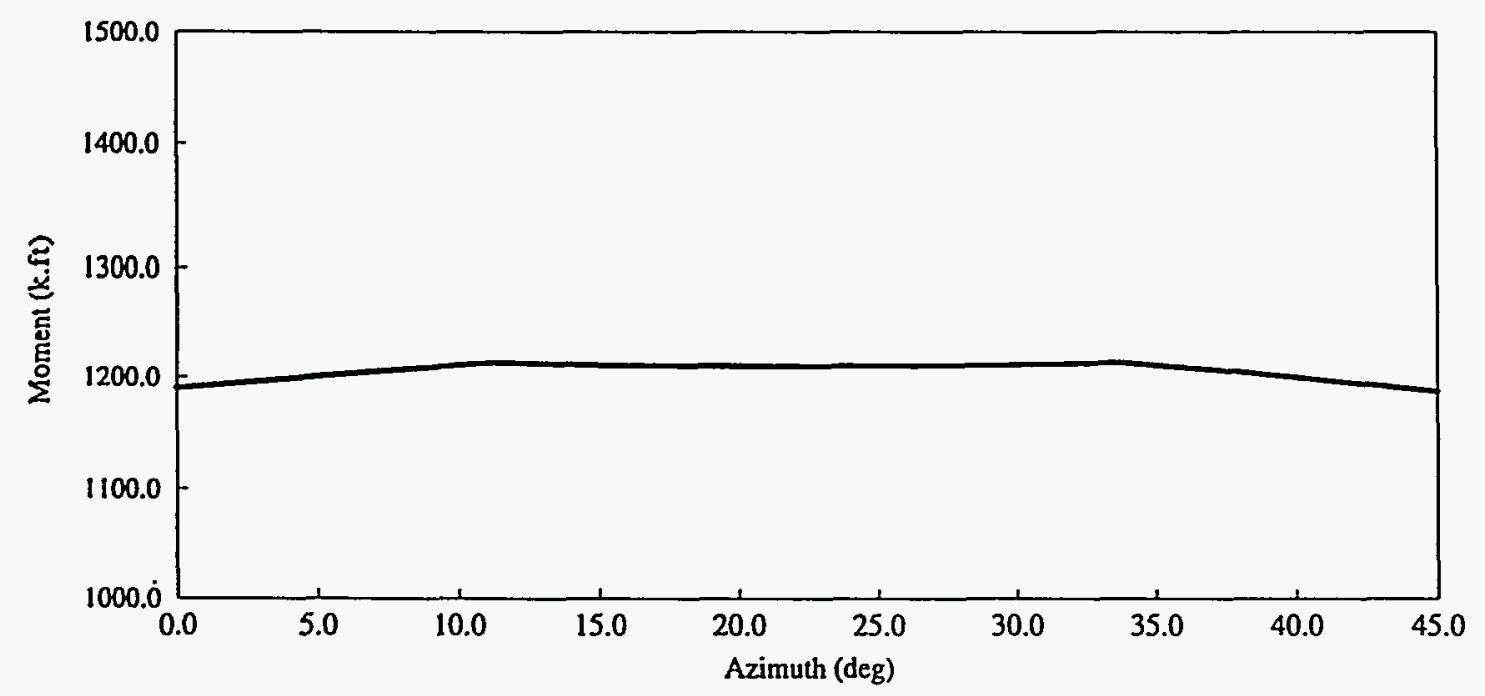

Figure 3.43 Distribution of the Moment, Mx, in the Tension Ring (Temp. Decrease) 


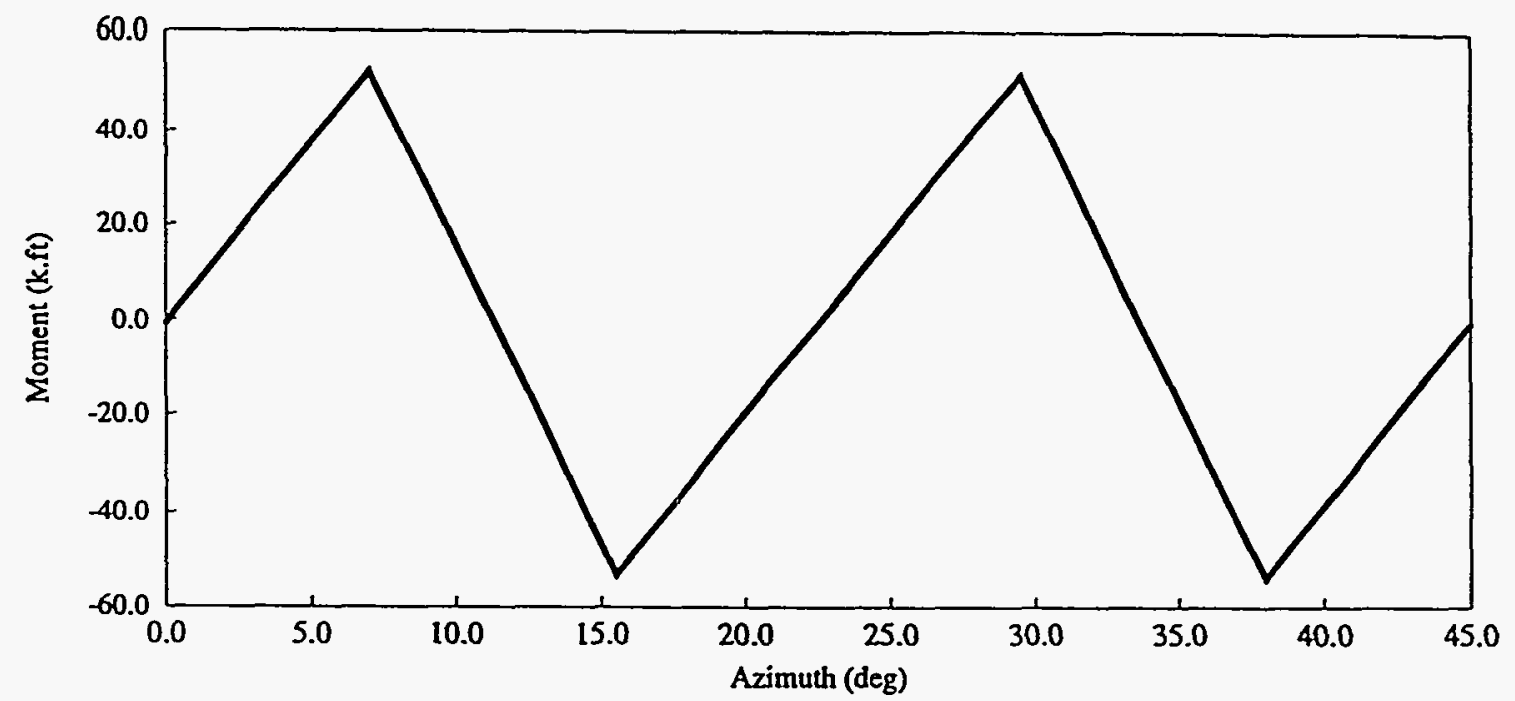

Figure 3.44 Distribution of the Torsional Moment, $T$, in the Tension Ring (Temp. Decrease)

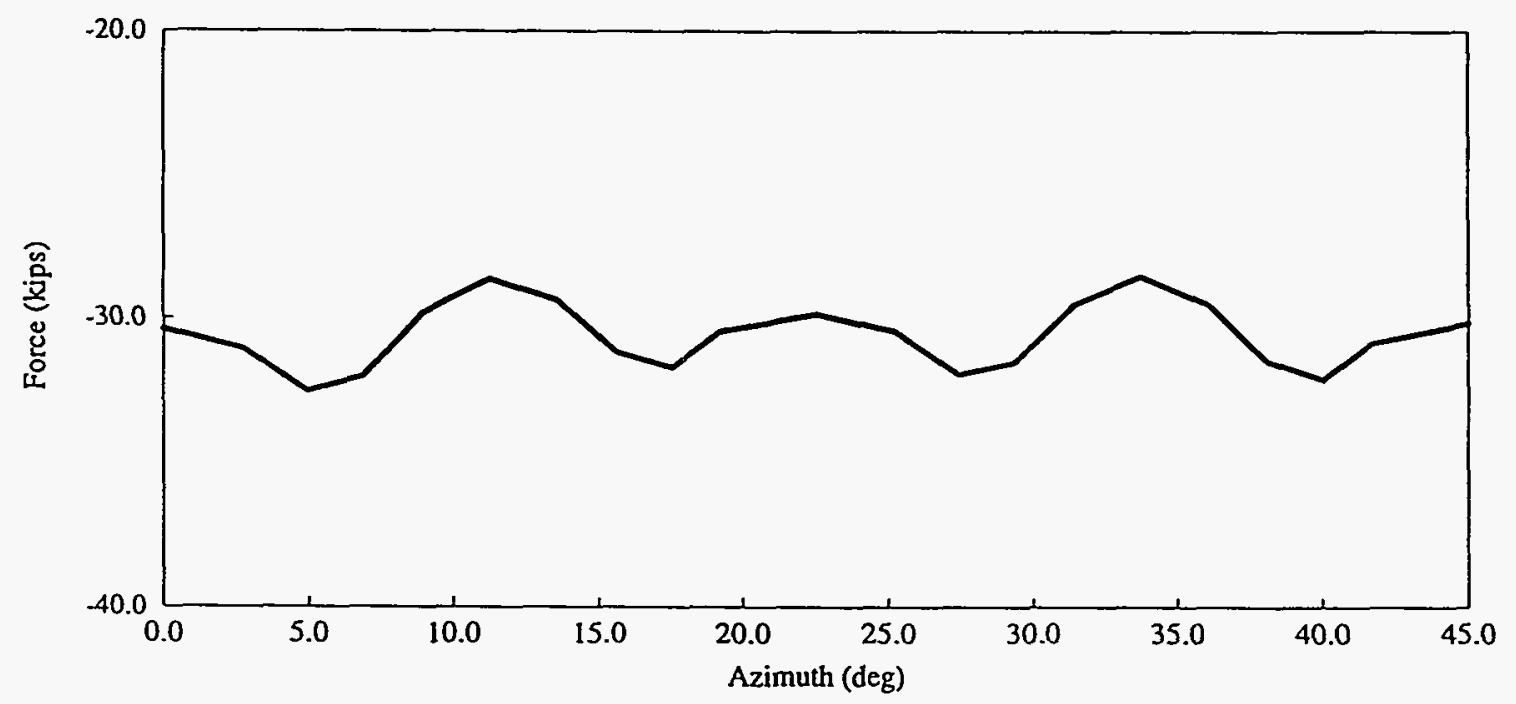

Figure 3.45 Distribution of the Axial Force in the Compression Ring (Temp. Decrease) 


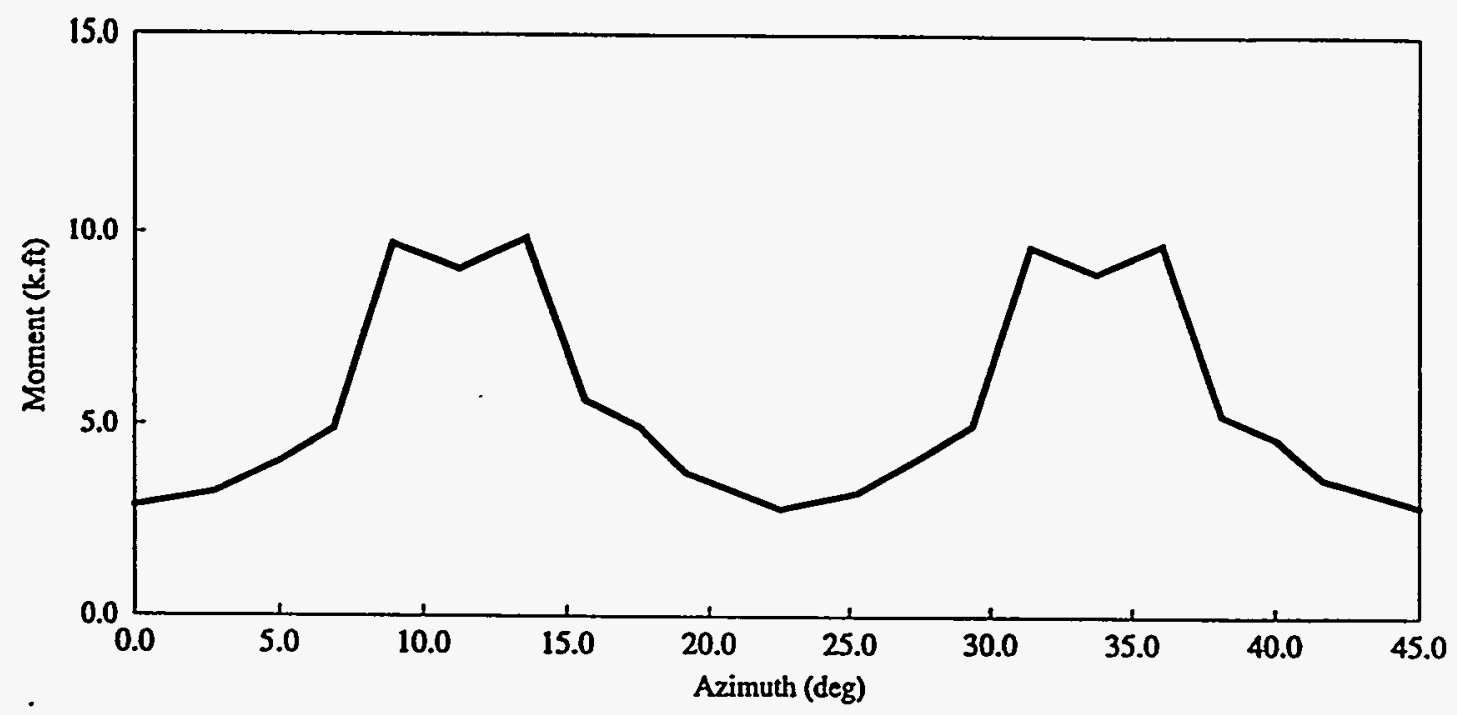

Figure 3.46 Distribution of the Moment, $\mathrm{Mx}$, in the Compression Ring (Temp. Decrease)

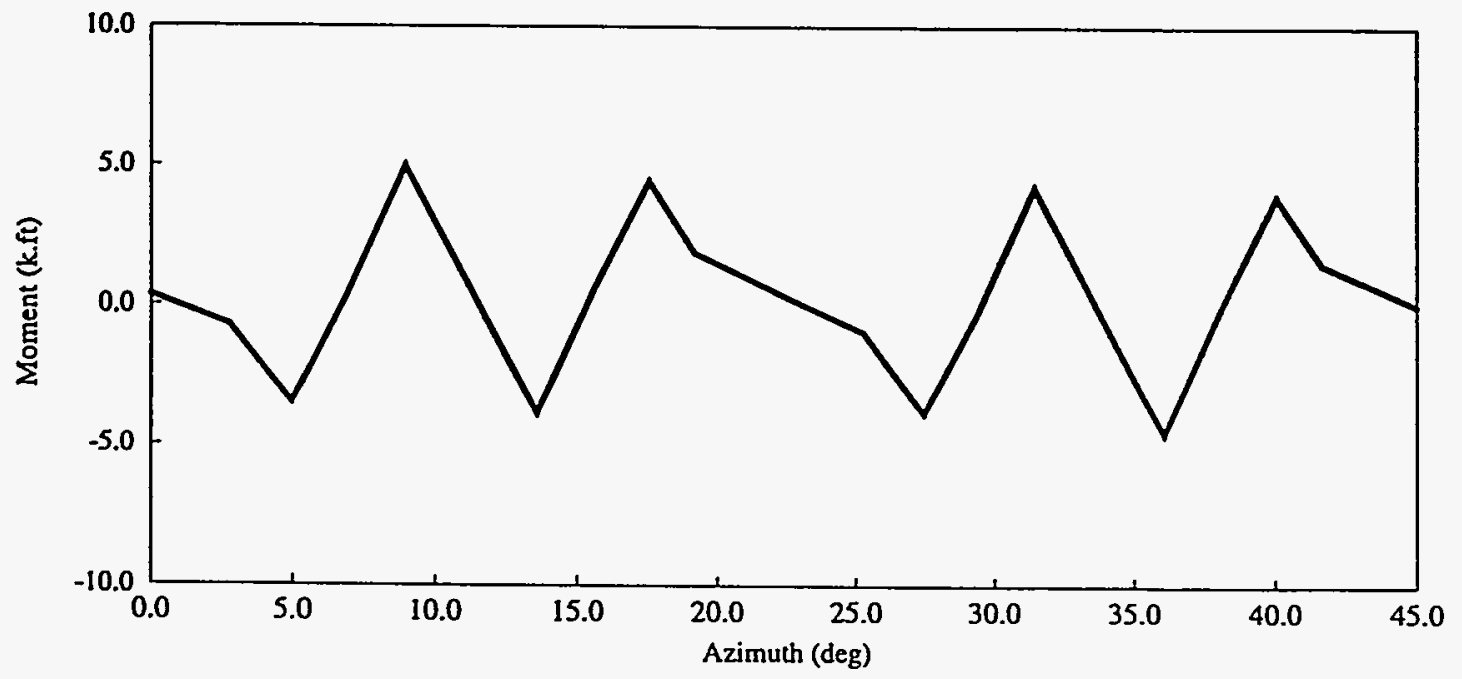

Figure 3.47 Distribution of the Torsional Moment, $\mathrm{T}$, in the Compression Ring (Temp. Decrease) 

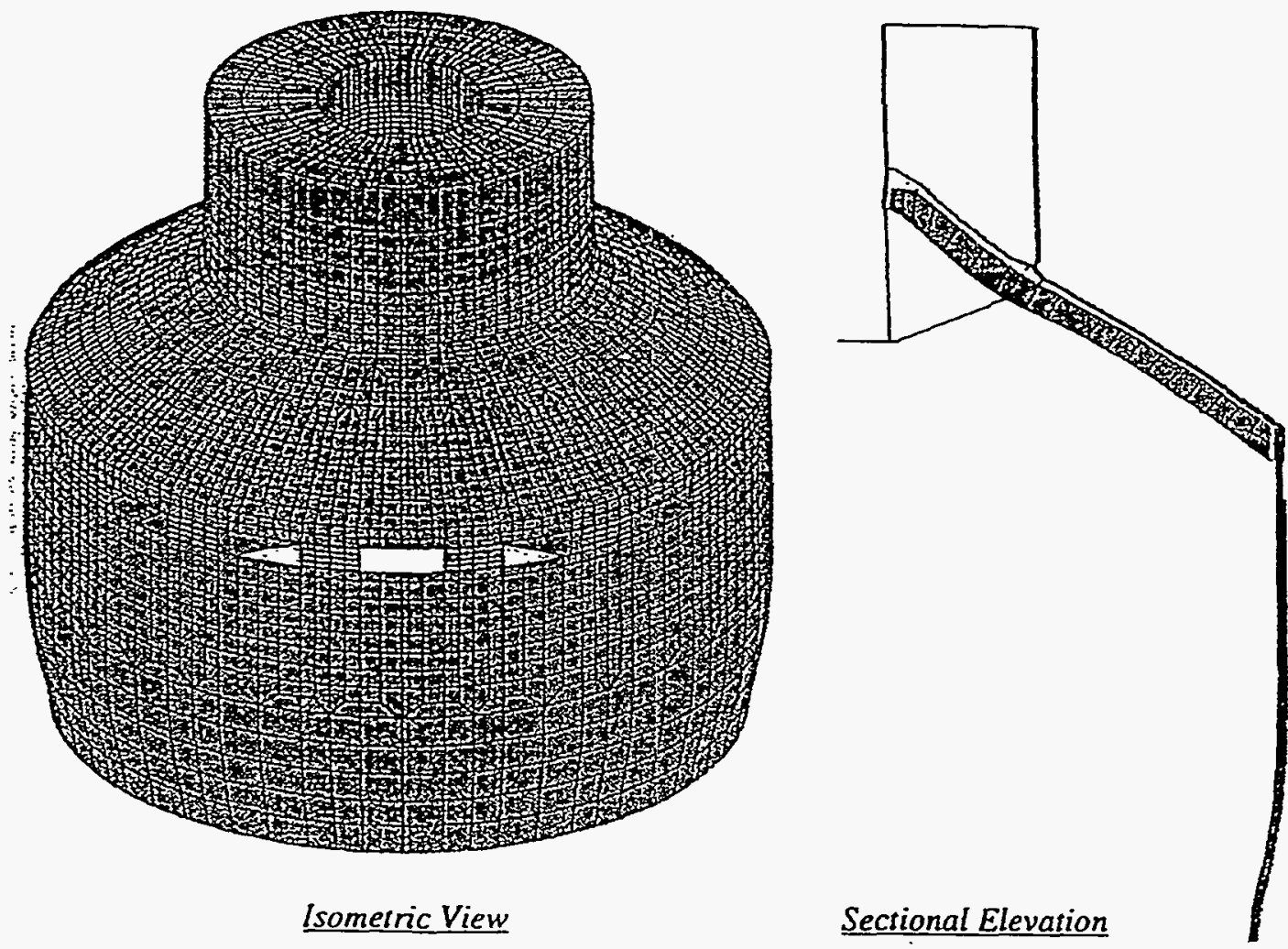

Figure 3.48 Deformed Shape of the AP600 SBR Under Temp. Increase Plus Water in the PCS Tank. 


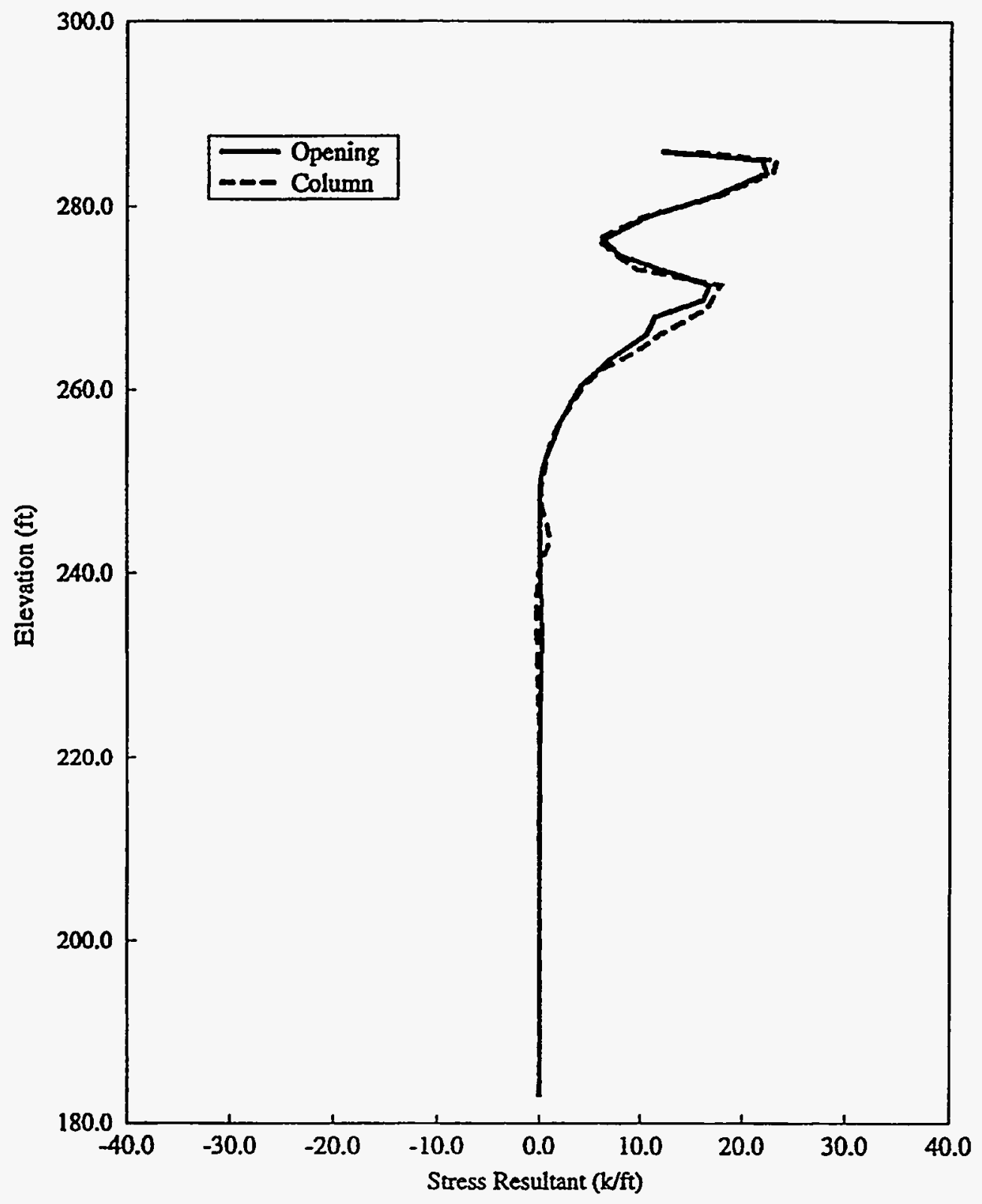

Figure 3.49 Distribution of the Meridional Stress Resultant, N1, (Temp. Increase) 


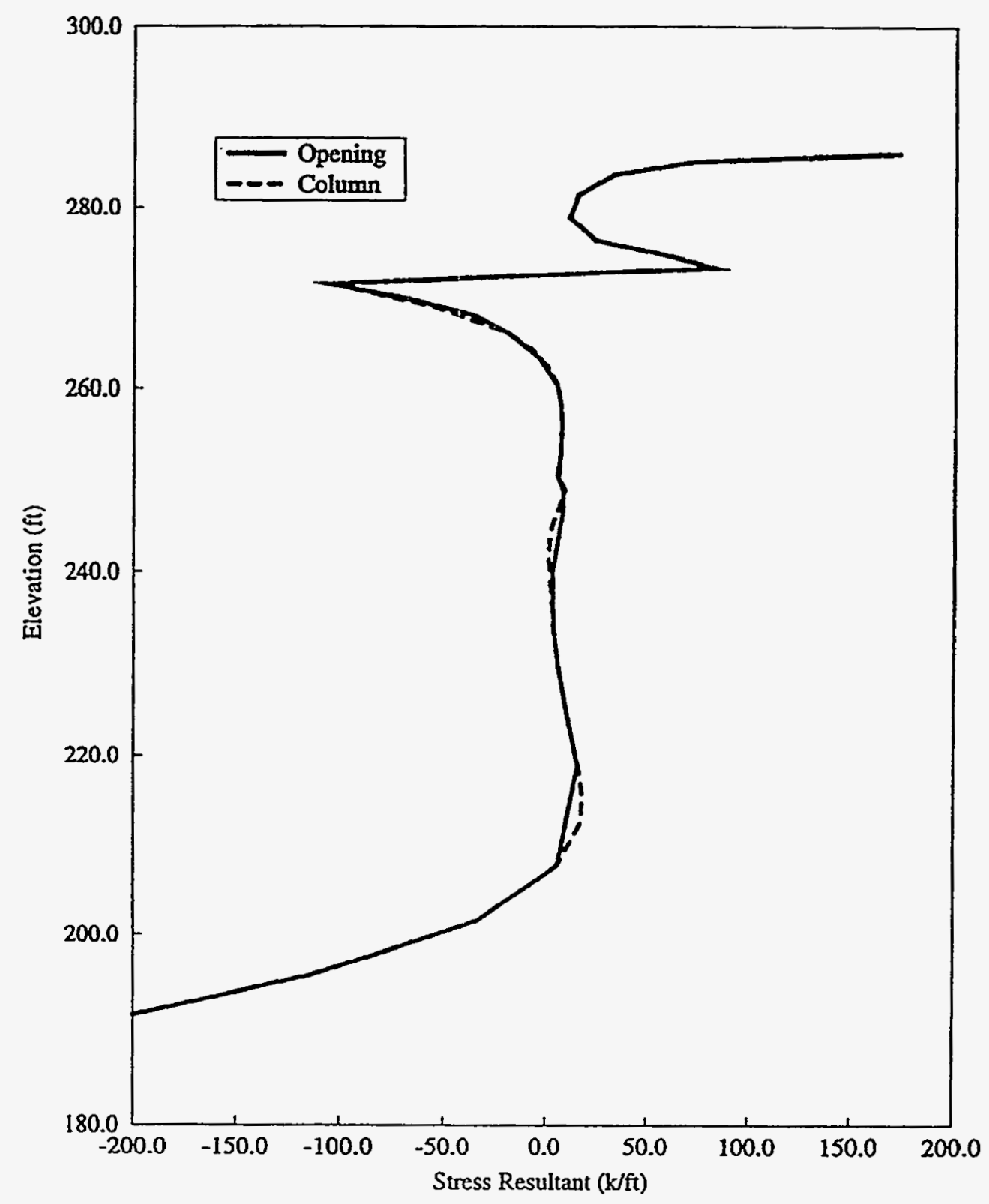

Figure 3.50 Distribution of the Circumferential Stress Resultant, N2, (Temp. Increase) 


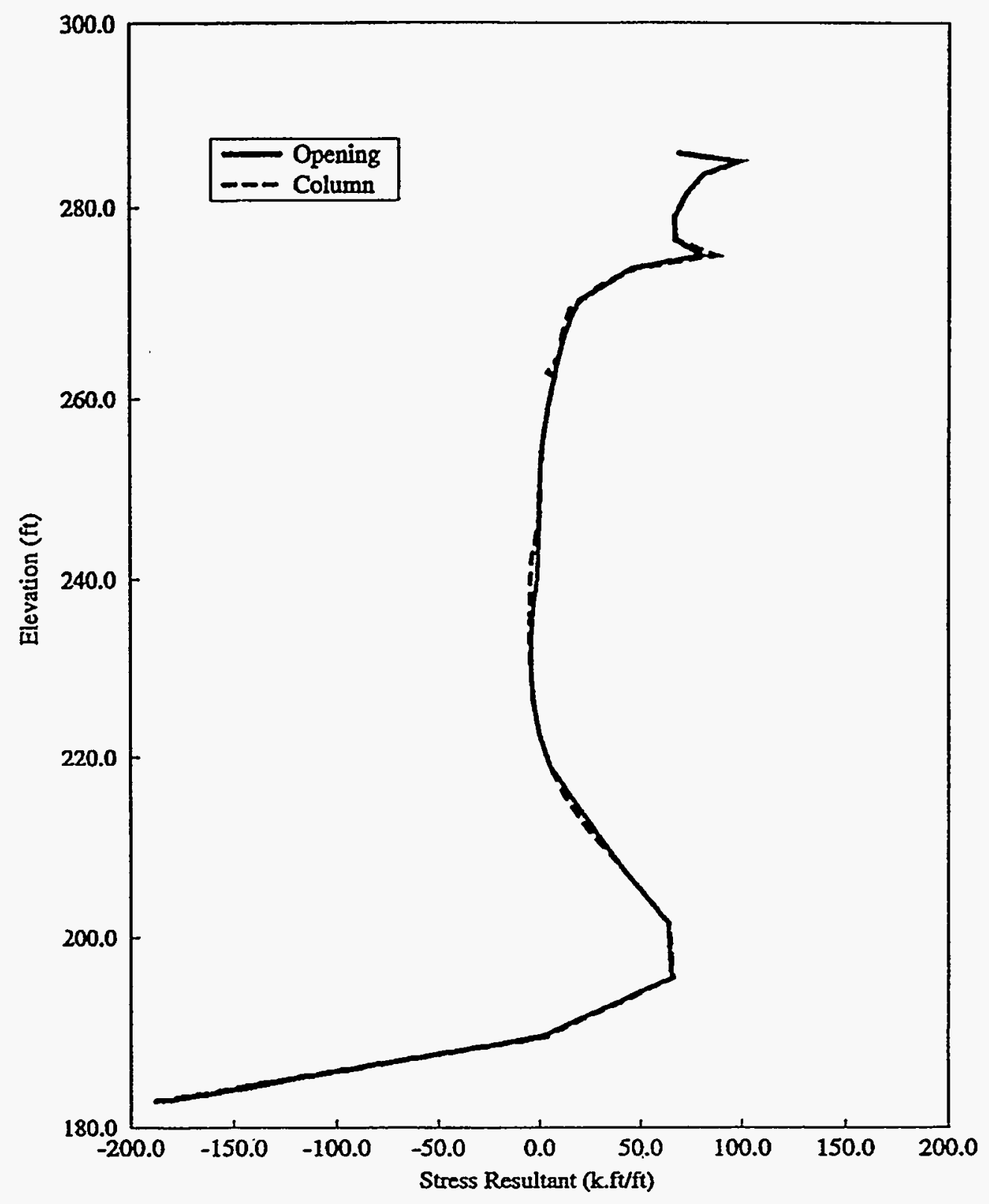

Figure 3.51 Distribution of the Meridional Moment, M1, (Temp. Increase) 


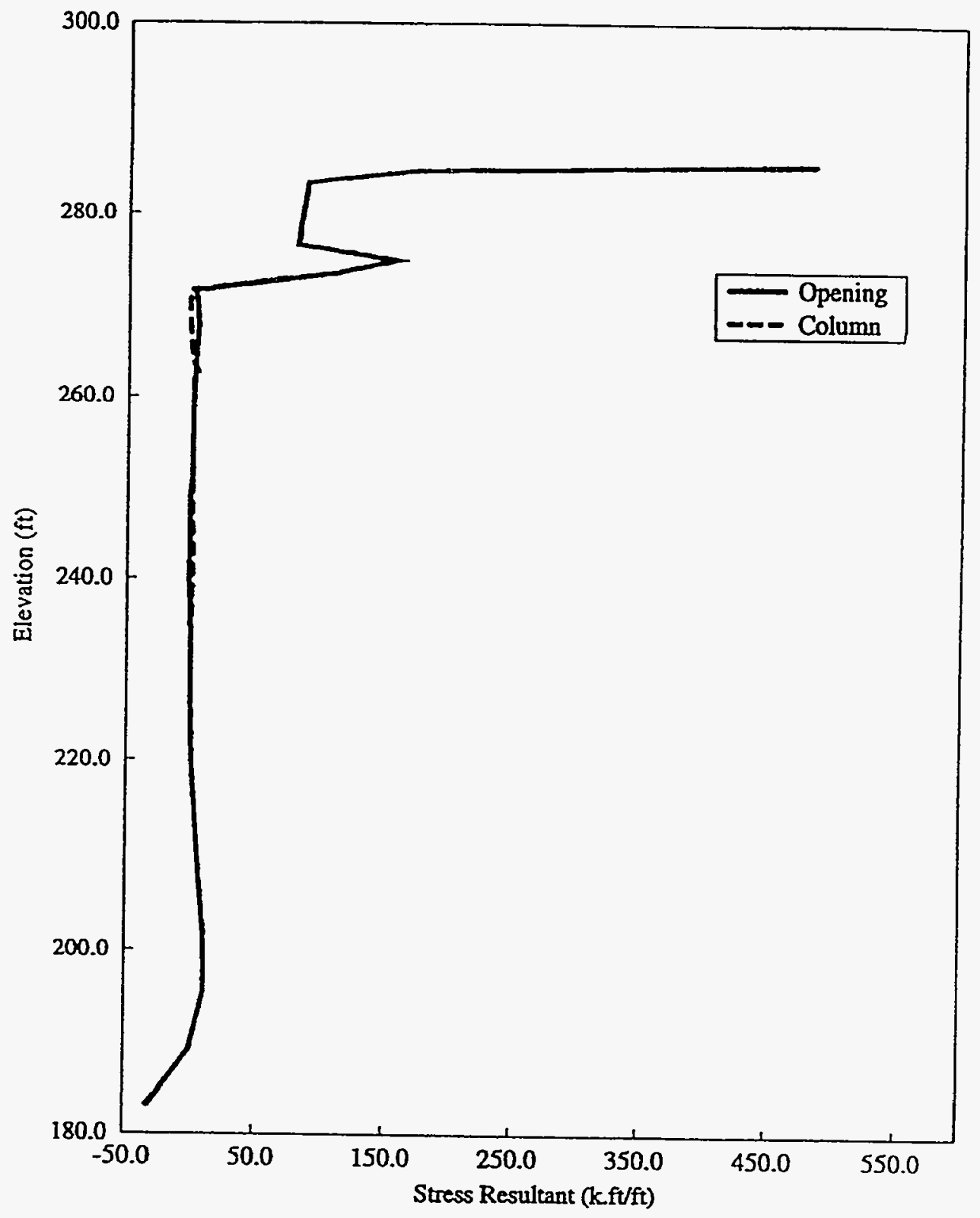

Figure 3.52 Distribution of the Circumferential Moment, M2, (Temp. Increase). 


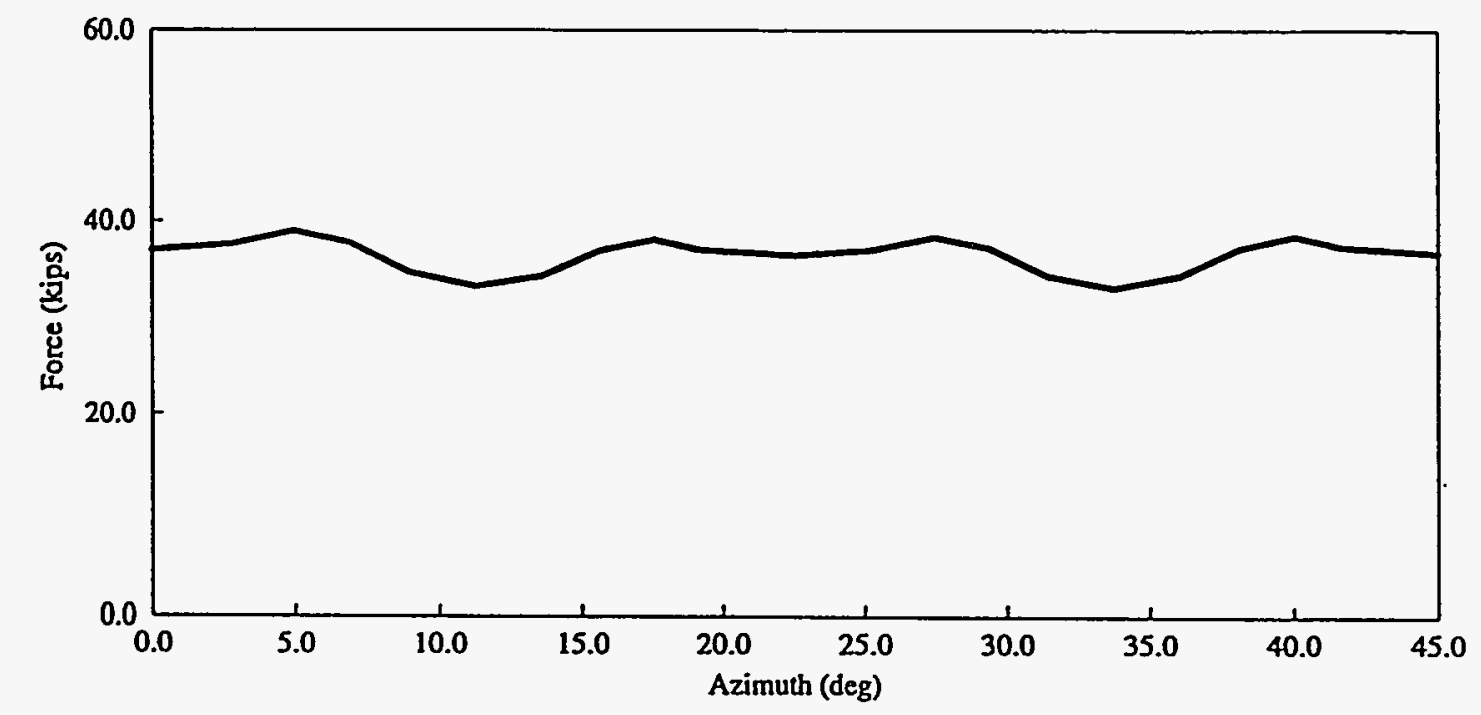

Figure 3.53 Distribution of the Axial Force in the Tension Ring (Temp. Increase)

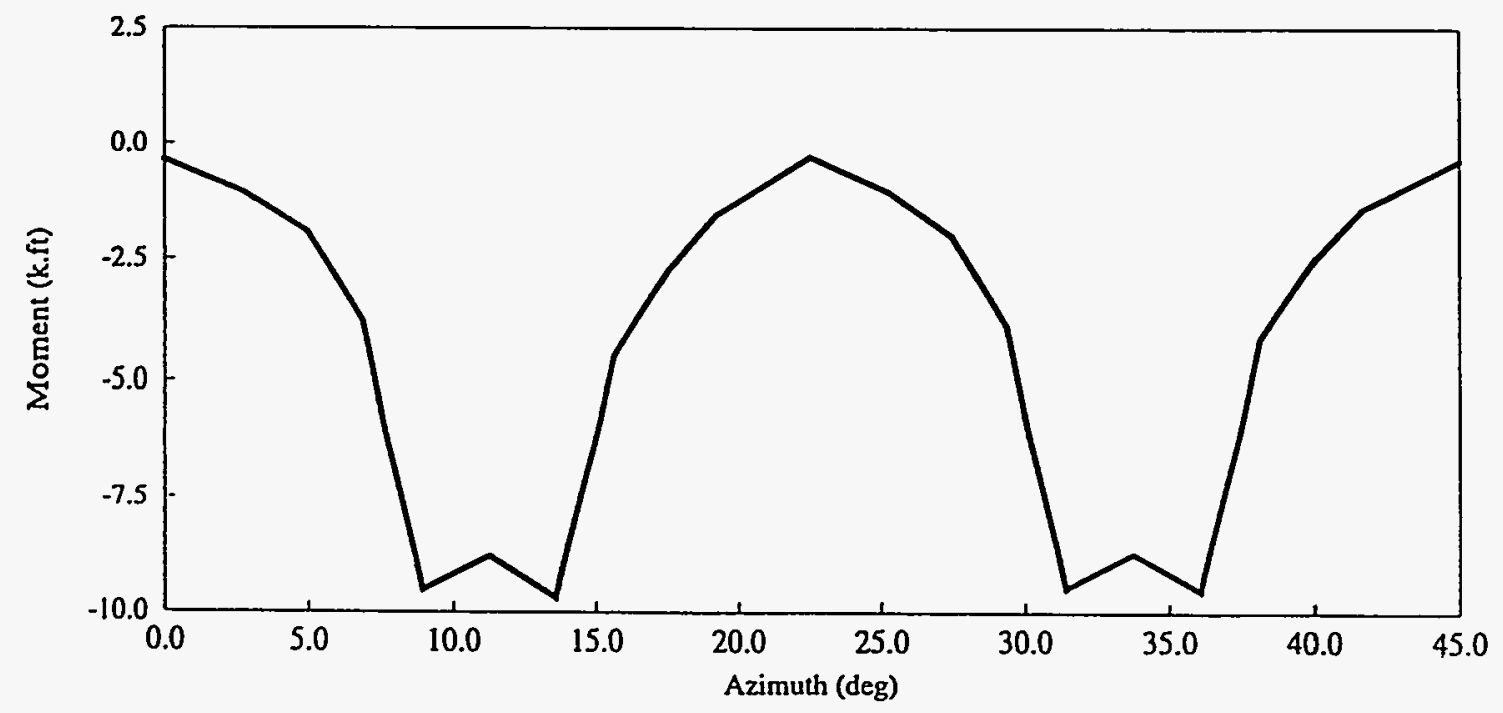

Figure 3.54 Distribution of the Moment, Mx, in the Tension Ring (Temp. Increase) 


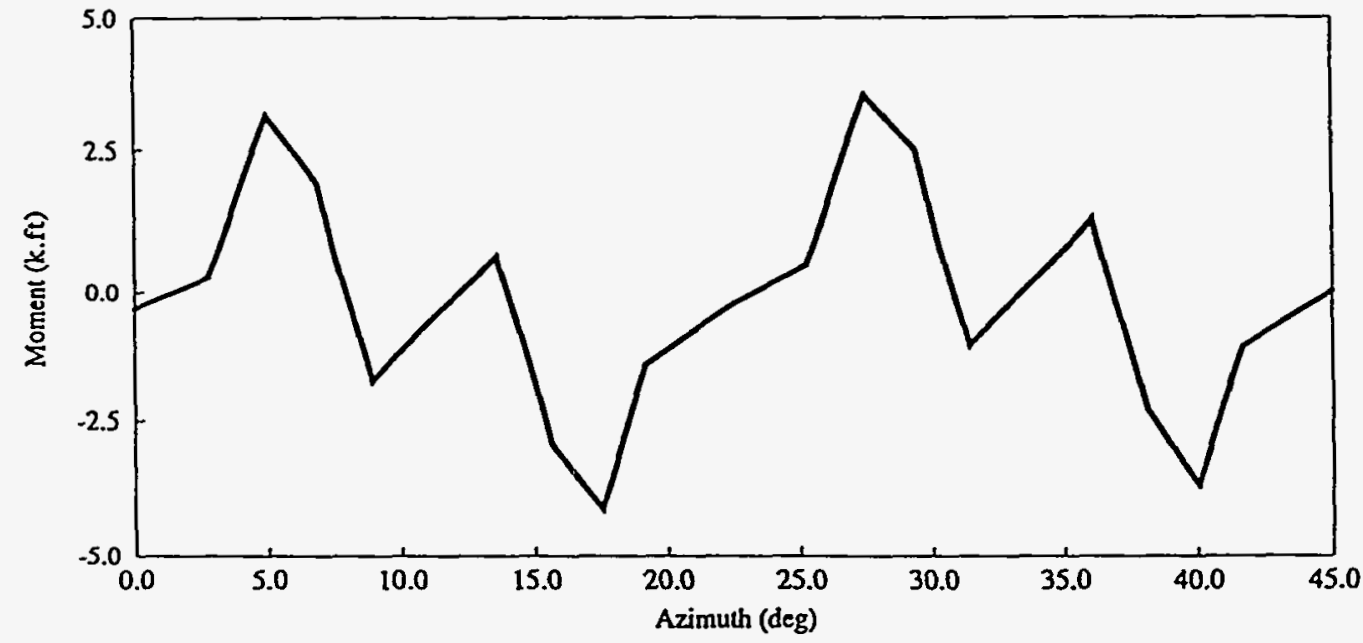

Figure 3.55 Distribution of the Torsional Moment, $\mathrm{T}$, in the Tension Ring (Temp. Increase)

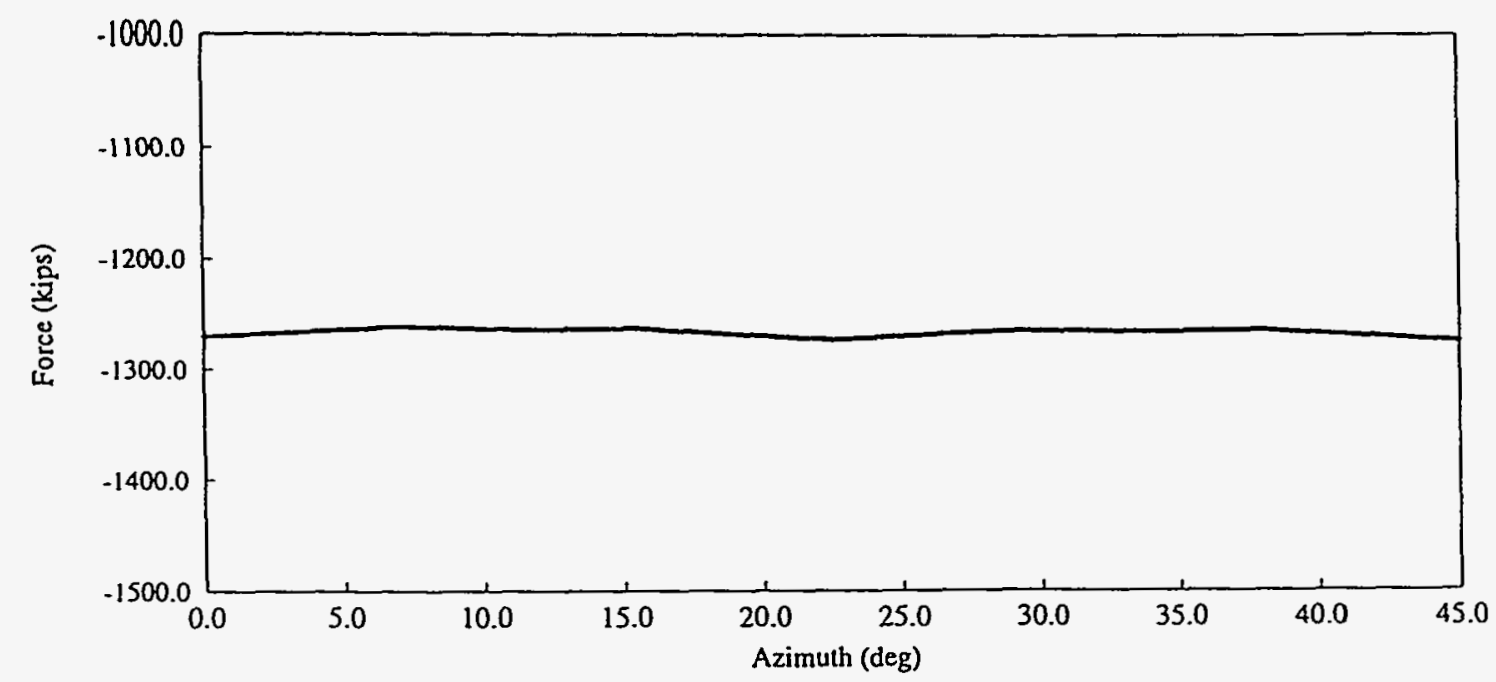

Figure 3.56 Distribution of the Axial Force in the Compression Ring (Temp. Increase) 


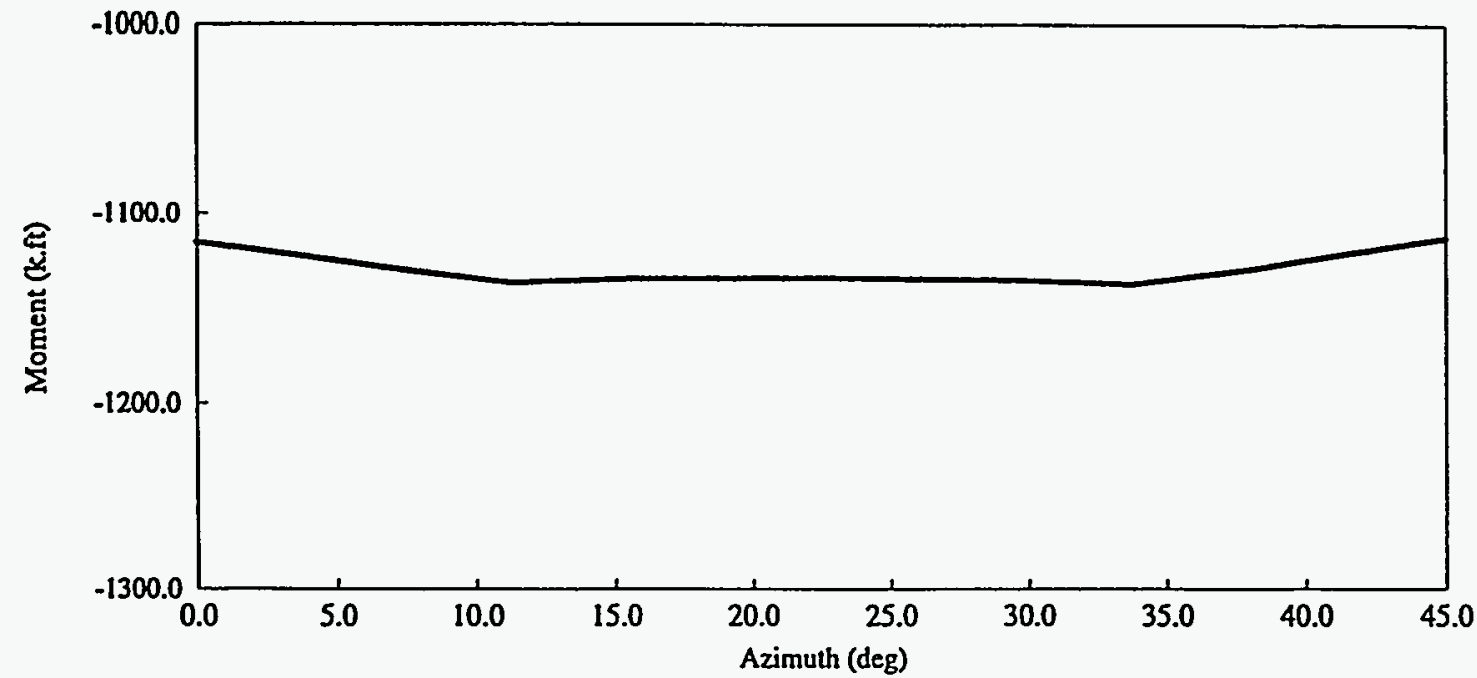

Figure 3.57 Distribution of the Moment, Mx, in the Compression Ring (Temp. Increase)

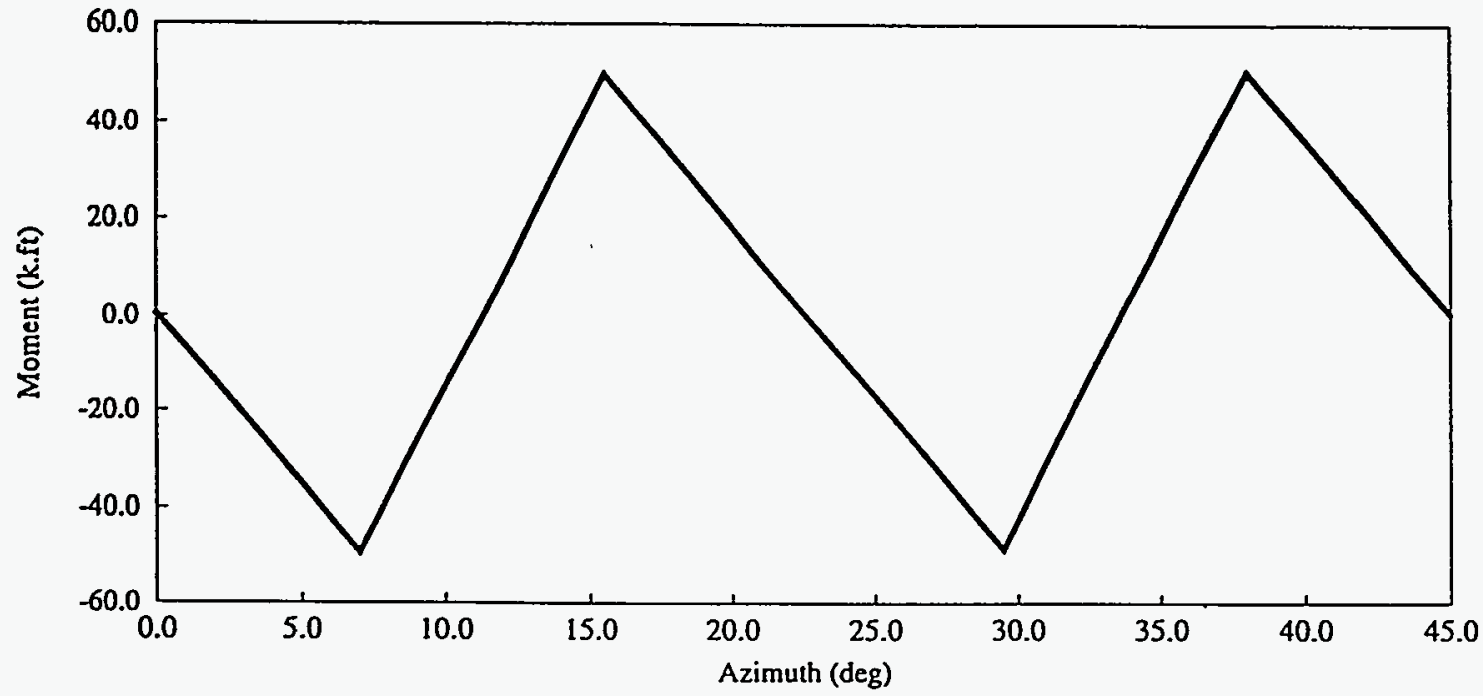

Figure 3.58 Distribution of the Torsional Moment, $\mathrm{T}$, in the Compression Ring (Temp. Increase). 


\section{RESPONSE SPECTRUM ANALYSIS OF THE AP6OO SHIELD BUILDING}

\subsection{Introduction}

When the shield building structure of the AP600 is subjected to seismic excitation along with other loads, the generated forces in some of its structural components could exceed their design values. In this chapter, the response spectrum analysis using the three-dimensional finite element model of the AP600 shield building in Fig. 2.1 is summarized. The objective was to compute the design forces at several critical sections of the shield building due to Safe Shutdown Earthquake (SSE) ground excitation. Spectra for four different soil sites: (1) hard rock; (2) soft rock; (3) soft to medium; and (4) upper bound soft to medium soil at the locations 3008,3197 , and 3167 at Elev. 180'-0" were provided by Westinghouse [4.1], see Fig. 4.1. Figures 4.2 through 4.4 illustrate the envelopes of the spectra for all soil conditions with different damping values range from $2 \%$ to 20\%. Two horizontal components in the North-South and East-West directions together with the vertical component of the SSE spectra with 7\% damping were used in the analysis [4.1].

The base shear and base moment at Elev. 180'-0" due to each of the four spectra were calculated to select the most critical spectrum. The analysis was continued using the critical spectrum to determine the design forces in several critical sections of the SBR structure: (1) cylindrical portion; (2) tension ring; (3) conical roof portion; and (4) compression ring. The locations of these sections are shown in Fig. 4.5.

\subsection{Modal Extraction Techniques}

As mentioned in Chapter 2, the SBR structure is a complex system with no exact closed form solution for natural frequencies and mode shapes. As a result, a three-dimensional finite element 
analysis using the ANSYS program was performed. As discussed in Appendix A, the contained fluid element (fluid 80) in ANSYS has the capabilities to calculate local circulation modes, acoustic modes, and sloshing modes. These circulation modes are artificial and do not contribute to the seismic response. In addition, these modes introduce a difficulty into the modal extraction process. Though the modes mathematically exist but do not contribute, it is desirable to not waste computational effort extracting the modes. That is, one wishes to skip the circulation modes during the modal extraction. This can be accomplished by shifting the modal analysis in the frequency domain past the circulation modes to the modes of interest [4.2].

Several methods are available in the ANSYS program to extract eigen modes [4.3]. The program provides a subspace iteration technique in which the full stiffness and mass matrices are used. The method allows the user to prescribe an initial frequency shift, i.e., to specify a starting frequency to be used in the eigen mode extraction [4.3, pp 3.13-3.17]. When the subspace method was utilized in this work, it was observed that ANSYS re-shifted the solution to start at zero frequency, ignoring any user specified shift frequency. This problem was discussed with ANSYS personnel. Since this method could not be used to skip the circulation modes that do not have significant participation, they suggested to use one of the other available eigen solution options provided in the program. A second solution technique is referred to as a damped eigen solver. This solver also uses the full mass, stiffness, and damping matrices. However, the modes (frequencies and mode shapes) are extracted in complex conjugate pairs. This requires large storage and computation time, particularly in solving the SBR which has many degrees of freedom. In a third solution method, Guyan reduction is used to reduce the mass and stiffness matrices, according to a specified master degrees of freedom. These degrees of freedom can be either selected by the program, specified by the user, or determined by a combination between both. With this method, the ANSYS program allows the user to use the frequency shift option to skip non-important fluid modes. 
The reduced method was used to extract several vibration modes for the AP600 SBR. Approximately 1200 master degrees of freedom were used. Eight-hundred were automatically selected by ANSYS, while the rest were user-specified master degrees of freedom. The ANSYS program selects the master degrees of freedom as those with small ratios of stiffness to mass coefficients. The user specified master degrees of freedom were selected as translations perpendicular to the free surface of the water in the passive cooling system tank.

\subsection{Mode Shapes and Frequencies}

The reduced method was used to extract 69 vibration modes. Of these modes, twenty sloshing modes of water inside the passive cooling system tank were obtained ranging from 0 to $0.4 \mathrm{~Hz}$. Figure 4.6 illustrates the first and the twelfth modes of vibration. The theoretical frequencies for a flat bottom tank [4.4] were $0.127 \mathrm{~Hz}$ and $0.356 \mathrm{~Hz}$, respectively, which are in agreement with the ANSYS results. The frequency shift option was used to skip the other fluid modes and to continue the model extraction starting at a frequency of $1 \mathrm{~Hz}$, that is, to extract significant structural modes.

The first five structural modes are illustrated in Figs. 4.7 through 4.11. The first structural mode was the cantilever mode in the northwest direction at a frequency of $6.118 \mathrm{~Hz}$. This direction aligns with the direction where the stair, the valve room and other additional masses are attached to the shield building. The second mode was in the southwest direction, at a frequency of 6.138 $\mathrm{Hz}$. The third mode was principally in the vertical direction at a frequency of $6.851 \mathrm{~Hz}$. The fourth and fifth modes were primarily the cantilever modes of the conical roof and the cooling system tank together with some of the attachments, e.g., the shield plate, valve room and stairway. The remaining forty-four modes were closely spaced with frequencies ranging from 
11.49 to $25.45 \mathrm{~Hz}$. The frequencies, participation factors and effective masses of the forty-nine structural modes are listed in Tables 4.1 and 4.2.

Table 4.1. Modal Mass and Frequency for Structural Modes

\begin{tabular}{|c|c|c|c|c|c|c|c|c|c|}
\hline Mode & Freq & Mass-x & Mass-y & Mass-z & Mode & Freq & Mass-x & Mass-y & Mass-z \\
\hline 1 & 6.118 & 19681.3 & 24710.3 & 7.8 & 26 & 18.970 & 24.3 & 14.7 & 3.8 \\
\hline 2 & 6.138 & 23954.0 & 20000.3 & 43.9 & 27 & 19.020 & 2.7 & 14.0 & 1.1 \\
\hline 3 & 6.851 & 26.9 & 4.9 & 37708.7 & 28 & 19.480 & 0.1 & 0.0 & 0.0 \\
\hline 4 & 9.728 & 1262.2 & 3075.6 & 9.7 & 29 & 19.670 & 3.6 & 7.6 & 4.1 \\
\hline 5 & 9.929 & 3419.4 & 2077.2 & 12.0 & 30 & 20.060 & 236.3 & 31.1 & 51.0 \\
\hline 6 & 11.490 & 731.6 & 658.6 & 1.7 & 31 & 20.170 & 179.7 & 110.8 & 121.7 \\
\hline 7 & 12.400 & 5.3 & 0.3 & 0.6 & 32 & 20.190 & 1282.3 & 37.8 & 2145.6 \\
\hline 8 & 12.460 & 23.1 & 18.5 & 3.0 & 33 & 20.400 & 374.5 & 352.8 & 8.2 \\
\hline 9 & 12.530 & 15.5 & 0.3 & 105.2 & 34 & 20.590 & 1241.9 & 5190.8 & 3.4 \\
\hline 10 & 12.550 & 40.5 & 0.3 & 31.9 & 35 & 20.660 & 2882.1 & 2535.9 & 139.8 \\
\hline 11 & 12.680 & 127.9 & 162.3 & 51.0 & 36 & 20.930 & 297.8 & 9.7 & 228.5 \\
\hline 12 & 13.110 & 367.4 & 416.7 & 2.8 & 37 & 21.110 & 69.1 & 184.3 & 68.2 \\
\hline 13 & 13.260 & 1.7 & 15.3 & 0.1 & 38 & 21.840 & 57.0 & 5.7 & 332.1 \\
\hline 14 & 13.380 & 0.8 & 0.6 & 0.1 & 39 & 22.280 & 25.7 & 6.5 & 56.1 \\
\hline 15 & 13.420 & 7.8 & 0.5 & 4.8 & 40 & 22.520 & 17.1 & 0.9 & 1.9 \\
\hline 16 & 13.470 & 0.1 & 90.0 & 1.0 & 41 & 22.910 & 8.3 & 16.3 & 0.1 \\
\hline 17 & 15.450 & 1.5 & 4.0 & 2.5 & 42 & 23.140 & 0.1 & 8.2 & 11.0 \\
\hline 18 & 15.700 & 0.2 & 4.4 & 0.4 & 43 & 23.340 & 9.4 & 0.0 & 48.0 \\
\hline 19 & 15.970 & 1.5 & 226.8 & 0.1 & 44 & 23.610 & 1.8 & 0.8 & 9.6 \\
\hline 20 & 16.160 & 215.5 & 0.1 & 0.5 & 45 & 23.690 & 0.0 & 0.9 & 4.2 \\
\hline 21 & 16.330 & 112.3 & 7.8 & 1.1 & 46 & 24.150 & 0.0 & 5.4 & 326.1 \\
\hline 22 & 18.770 & 8.6 & 0.0 & 3.2 & 47 & 24.760 & 62.1 & 32.5 & 9.1 \\
\hline 23 & 18.860 & 3.8 & 0.3 & 0.4 & 48 & 25.310 & 42.9 & 18.5 & 0.2 \\
\hline 24 & 18.900 & 40.7 & 3.1 & 1.1 & 49 & 25.450 & 35.1 & 4.2 & 159.1 \\
\hline 25 & 18.910 & 8.6 & 2.1 & 7.7 & & & & & \\
\hline
\end{tabular}

Mass- $\mathrm{X}=$ Modal mass in $\mathrm{x}$ direction

Mass-y $=$ Modal mass in $y$ direction

Mass- $\mathrm{z}=$ Modal mass in $\mathrm{z}$ direction 
Table 4.2. Participator Factors for Structural Modes

\begin{tabular}{|c|c|c|c|c|c|c|c|c|c|}
\hline Mode & Freq & $\mathbf{P x}$ & $\mathbf{P y}$ & $\mathbf{P z}$ & Mode & Freq & $\mathbf{P x}$ & $\mathbf{P y}$ & $\mathbf{P z}$ \\
\hline 1 & 6.118 & 140.30 & 157.20 & 2.80 & 26 & 18.970 & -4.93 & 3.84 & -1.96 \\
\hline 2 & 6.138 & 154.80 & -141.40 & 6.63 & 27 & 19.020 & 1.64 & -3.74 & -1.07 \\
\hline 3 & 6.851 & -5.19 & 2.21 & 194.20 & 28 & 19.480 & 0.37 & -0.19 & 0.04 \\
\hline 4 & 9.728 & -35.53 & -55.46 & -3.11 & 29 & 19.670 & -1.91 & 2.75 & 2.03 \\
\hline 5 & 9.929 & 58.48 & -45.58 & 3.46 & 30 & 20.060 & 15.37 & 5.58 & 7.14 \\
\hline 6 & 11.490 & 27.05 & 25.66 & -1.32 & 31 & 20.170 & -13.41 & -10.53 & -11.03 \\
\hline 7 & 12.400 & 2.31 & -0.50 & -0.78 & 32 & 20.190 & 35.81 & 6.14 & 15.67 \\
\hline 8 & 12.460 & -4.80 & -4.30 & 1.73 & 33 & 20.400 & -19.35 & 18.78 & -2.86 \\
\hline 9 & 12.530 & -3.93 & -0.57 & -10.26 & 34 & 20.590 & 35.24 & -72.05 & -1.85 \\
\hline 10 & 12.550 & 6.37 & 0.51 & -5.64 & 35 & 20.660 & 53.69 & 50.36 & -11.82 \\
\hline 11 & 12.680 & -11.31 & -12.74 & -7.14 & 36 & 20.930 & -17.26 & 3.11 & 15.12 \\
\hline 12 & 13.110 & -19.17 & 20.41 & -1.66 & 37 & 21.110 & -8.31 & 13.58 & 8.26 \\
\hline 13 & 13.260 & -1.30 & -3.91 & -0.23 & 38 & 21.840 & -7.55 & 2.40 & 18.22 \\
\hline 14 & 13.380 & 0.88 & -0.77 & 0.36 & 39 & 22.280 & -5.07 & 2.55 & 7.49 \\
\hline 15 & 13.420 & 2.79 & -0.71 & 2.18 & 40 & 22.520 & -4.13 & 0.94 & 1.39 \\
\hline 16 & 13.470 & 0.31 & 9.49 & 1.01 & 41 & 22.910 & -2.88 & 4.04 & 0.25 \\
\hline 17 & 15.450 & 1.24 & -2.00 & -1.59 & 42 & 23.140 & 0.37 & -2.87 & -3.32 \\
\hline 18 & 15.700 & -0.48 & 2.11 & -0.63 & 43 & 23.340 & 3.07 & -0.00 & 6.93 \\
\hline 19 & 15.970 & 1.24 & -15.06 & -0.38 & 44 & 23.610 & -1.34 & -0.90 & -3.10 \\
\hline 20 & 16.160 & 14.68 & 0.29 & 0.68 & 45 & 23.690 & -0.17 & -0.97 & 2.05 \\
\hline 21 & 16.330 & -10.60 & -2.80 & -1.04 & 46 & 24.150 & 0.14 & 2.32 & $-18: 06$ \\
\hline 22 & 18.770 & -2.94 & 0.16 & -1.79 & 47 & 24.760 & -7.88 & -5.70 & -3.01 \\
\hline 23 & 18.860 & 1.94 & -0.54 & 0.63 & 48 & 25.310 & -6.55 & 4.30 & 0.45 \\
\hline 24 & 18.900 & -6.38 & 1.77 & 1.02 & 49 & 25.450 & 5.92 & 2.04 & -12.61 \\
\hline 25 & 18.910 & 2.92 & -1.46 & 2.77 & & & & & \\
\hline
\end{tabular}

$\mathrm{P}_{\mathrm{X}}=$ Participation factor in $\mathrm{X}$-direction

$\mathrm{P}_{\mathrm{y}}=$ Participation factor in $\mathrm{Y}$-direction

$\mathrm{P}_{\mathrm{Z}}=$ Participation factor in Z-direction

The effective mass in the 69 modes in the $X$ and $Y$ directions were $80 \%$ and $82 \%$, respectively. The effective mass in the vertical direction, $\mathrm{Z}$, direction was $5.1 \%$. Additional vertical modes are required to meet the requirements of Sec. 3.7.2 of the NRC Standard Review Plan (SRP) [4.5].

However, due to time constraints and disc space limitation on the workstation, this was not 
pursued. The inertial forces associated with the higher modes were incorporated as outlined in the SRP (Sec. 4.4.3.).

\subsection{Response Spectrum Analysis}

A response spectrum analysis was conducted to compute the design forces. Base shear force and moments at Elev. 180'-0" due to each of the four spectrum with 7\% damping were compared. Table 4.3 summarizes the results of these analysis. These results were discussed with the NRC and Westinghouse personnel [4.7]. The response spectrum, corresponding to the soft rock soil condition, controlled and was used to calculate the design forces [4.7].

\subsubsection{Ground Excitation Spectrum}

As mentioned in Sec. 4.1, response spectra were defined at the three locations shown in Fig. 4.2. In theory the effects of the three spectra should be combined by considering multiple support excitation and the statistical correlation between the spectrum [4.8]. Another, presumably conservative, alternative is to use a response spectrum that envelopes the response spectra at these three locations. These two alternatives were discussed with the NRC staff and the latter method was selected since no correlation coefficients were readily available. Hence, the design forces that follow are determined from response spectra that envelope the four spectra provided by Westinghouse. 
Table 4.3. Base Shear and Moment Results at Elev. 180'-0" Due to the Spectra for Four Different Soils

\begin{tabular}{|c|c|c|c|c|}
\hline Force & Hard Rock & Soft Rock & $\begin{array}{c}\text { Soft-to-Medium } \\
\text { Soil }\end{array}$ & $\begin{array}{c}\text { Upper Bound of } \\
\text { Soft-to-Medium }\end{array}$ \\
\hline Qx (kips) & 21,104 & 21,152 & 16,780 & 21,511 \\
\hline Qy (kips) & 21,350 & 21,464 & 16,970 & 21,798 \\
\hline N (kips) & 17,213 & 17,375 & 16,510 & 17,815 \\
\hline Mx (k-ft) & $2,016,800$ & $2,050,300$ & $1,627,700$ & $2,092,700$ \\
\hline My (k-ft) & $2,007,600$ & $2,040,000$ & $1,619,900$ & $2,081,700$ \\
\hline T (k-ft) & 107,100 & 83,500 & 60,500 & 77,040 \\
\hline
\end{tabular}

\subsubsection{Modal Stress Resultants and Nodal Forces}

ANSYS calculates the modal stress resultants N1, N2, N12, M1, M2, M12, associated with mode

$\mathrm{i},\left[\mathbb{N}_{\phi}^{i}\right]$. Similarly, the program computes the nodal forces $f_{x}, f_{y}, f_{z}, m_{x}, m_{y}, m_{z},\left[F_{\phi}^{i}\right]$. In addition, the eigen values, eigen vectors, generalized mass and modal participation factors for each mode are obtained. The seismic modal responses $\left[N_{i j}\right]$ and $\left[F_{i j}\right]$ in the ith mode, due to the $j$ earthquake $(j=X, Y$ or $Z)$ motion are calculated as:

$$
\left[N_{i j}\right]=\frac{\left[N_{\phi}^{i}\right] \Gamma_{i j} S_{i j}}{\omega_{i}^{2}}
$$

and

$$
\left[F_{i j}\right]=\frac{\left[F_{\phi}^{i}\right] \Gamma_{i j} S_{i j}}{\omega_{i}^{2}}
$$


where

$\Gamma_{\mathrm{ij}}=$ participation factor for mode $\mathrm{i}$ in the direction $\mathrm{j}$

$S_{i j}=$ spectral acceleration corresponding to mode $i$ frequency for earthquake component in direction $j$

$\omega_{i}=$ frequency of mode $i$

\subsubsection{High-Frequency Stress Resultants and Nodal Forces}

In order to approximate the response of the high-frequency modes, the procedure outlined in Sec. 3.7.2 of the Standard Review Plan (SRP) [4.5], Appendix A, was implemented. The basic assumption is that the maximum response of high-frequency modes is not randomly phased in time. On the contrary, the maximum response in such modes will be essentially deterministic and the containment will respond to the modal inertial forces from the peak Zero Period Acceleration (ZPA) in a pseudostatic fashion. The fraction of lumped mass per degree of freedom (DOF) which was not included in the extracted modes was computed as follows:

$$
e_{k}=\sum_{i=1}^{n}\left(\Gamma_{i k} \Phi_{i k}\right)-\delta_{k j}
$$

where $e_{k}$ is the fraction of non-included mass at DOF $k, \Phi_{i k}$ is the $\mathrm{i}^{\text {th }}$ modal displacement at DOF $\mathrm{k}, \mathrm{n}$ is the total number of extracted modes, and $\delta_{\mathrm{kj}}$ is the Kronecker delta, which is one if DOF $k$ is in the direction of the earthquake, $\mathrm{j}$, and zero if DOF $\mathrm{k}$ is a rotation or not in the $\mathrm{j}$ direction. The pseudostatic inertial forces associated with the summation of all high-frequency modes for each DOF $\mathrm{k}$ were then computed as follows:

$$
\mathrm{P}_{\mathrm{kj}}=\mathrm{ZPA}_{\mathrm{j}} \cdot \mathrm{m}_{\mathrm{k}} \cdot \mathrm{e}_{\mathrm{k}}
$$


where $P_{k j}$ is the inertia force to be applied at DOF $k$ in the direction $j$ and $m_{k}$ is the lumped mass

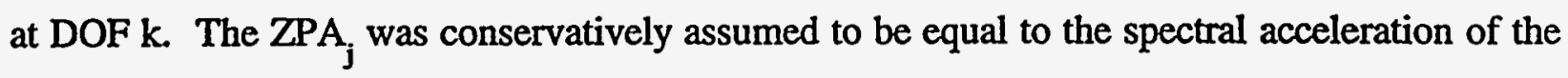
$\mathrm{j}^{\text {th }}$ spectrum corresponding to the frequency of the highest extracted mode (i.e., $25.45 \mathrm{~Hz}$ ) (see Table 4.1). The pseudostatic inertia forces in each direction $\mathrm{j}$ were applied separately and the containment was statically analyzed in each case to determine stress resultants and nodal forces.

\subsubsection{Modal and Directional Combination}

The maximum modal responses determined by Eqs. 4.1 and 4.2 . and the high-frequency modal responses (Sec. 4.4.3) were combined by the 10 percent rule [4.8] that accounts for closely spaced modes. The maximum combined response was computed as follows:

$$
N_{\max }=\sqrt{\sum_{i}^{m} N_{i j}^{2}+2 \sum_{i}^{m} \sum_{k}^{m}\left|N_{i j} N_{k j}\right|} \quad i \neq k
$$

where $\mathrm{N}_{\operatorname{maxj}}$ is the maximum response due to ground excitation in the $\mathrm{j}^{\text {th }}$ direction and $\mathrm{m}$ is the number of modes ( 70 in this case with 69 from the modal analysis and one for the high frequency modes). Modes of vibration were considered closely spaced if their frequencies differ by less than 10 percent. The maximum response of the containment, $\mathrm{N}_{\max }$, was then computed by combining the responses due to the three earthquake directions by the SRSS method [4.9] as follows:

$$
N_{\max }=\sqrt{\sum_{j}^{3}\left(N_{\max }\right)^{2}}
$$




\subsection{Discussion of Results}

\subsubsection{Stress Resultants}

Figures 4.12 and 4.13 illustrate the meridional and circumferential stress resultants N1 and N2, respectively, along two meridians through an opening and between two openings, i.e., through a column. The stress resultant $\mathrm{N} 1$ at Elev. $180^{\prime}-0^{\prime \prime}$ was $130 \mathrm{k} / \mathrm{ft}$. The maximum compressive stress resultant, $\mathrm{N} 1$, reached $223 \mathrm{k} / \mathrm{ft}$ and took place between the two openings at $11.25 \mathrm{deg}$ Azimuth because of the reduced cross-sectional area. The maximum, N1, stress resultants in the conical roof reached $180 \mathrm{k} / \mathrm{ft}$ and occurred in the vicinity of the cone-passive cooling system tank. As can be noticed from Fig. 4.13, the distribution of the circumferential stress resultants, N2, was almost uniform up to Elev. 226'-0" and rapidly increased near the openings. The maximum N2 stress resultant reached $405 \mathrm{k} / \mathrm{ft}$ along a meridian located between the two openings.

Figures 4.14 and 4.15 illustrate the distribution of the meridional and circumferential moment stress resultants $\mathrm{M1}$ and $\mathrm{M} 2$, respectively, along the two meridians. Figure 4.14 illustrates that there was no significant change in M1 stress resultant up to Elev. 220'-0". The value of M1 peaked at $265 \mathrm{k}-\mathrm{ft} / \mathrm{ft}$ in the vicinity of the air intakes. As indicated in Fig. 4.15 , the distribution of the circumferential moment, $\mathrm{M} 2$, also peaked at $60 \mathrm{k}-\mathrm{ft} / \mathrm{ft}$ near the air intakes.

\subsubsection{Member Forces in the Tension and Compression Rings}

Figures 4.16 and 4.17 show the distribution of the axial force, $N$, the moment, $M_{x}$, and the torque, $T$, in the tension and compression rings as defined in Sec. 3.2.2. These figures illustrate the distribution of these forces between $0 \mathrm{deg}$ Azimuth to $45 \mathrm{deg}$ Azimuth. For the tension ring, $\mathrm{N}$ varied from $1500 \mathrm{kips}$ to $1375 \mathrm{kips}$. The variation in $\mathrm{M}_{\mathrm{x}}$, ranged from $333 \mathrm{k}$ - $\mathrm{ft}$ to $670 \mathrm{k}$-ft and 
between $50 \mathrm{k}-\mathrm{ft}$ to $500 \mathrm{k}-\mathrm{ft}$ for $\mathrm{T}$. In the compression ring the variation in $\mathrm{M}_{\mathrm{x}}$ ranged from 130 $\mathrm{k}-\mathrm{ft}$ to $180 \mathrm{k}-\mathrm{ft}$. The variation in $\mathrm{T}$ was from $75 \mathrm{k}-\mathrm{ft}$ to $100 \mathrm{k}-\mathrm{ft}$. The maximum value for $\mathrm{N}$ in the compression ring was about 115 kips.

\subsection{References}

4.1 Letter from Westinghouse Electric Corporation to U.S. NRC, Docket No. STN-52-003, May 1996.

4.2 Bathe, K. J., "Finite Element Procedure," Prentice Hall, Englewood Cliffs, NJ, 1996, pp. 851-852.

4.3 ANSYS, Inc., "ANSYS User's Manual," Revision 5.1, Southpoint, Cansonsburg, PA, 1995.

4.4 Silverman, S. and Abramson, H. N., "Lateral Sloshing in Missing Containers," Chapter 2 of The Dynamic Behavior of Liquids in Moving Containers with Applications to Space Vehicle Technology, ed. by Abramson, H.N., NASA SP-106, 1966.

4.5 U.S. Nuclear Regulatory Commission, "Standard Review Plan (SRP) - Appendix A Section 3.7.2," 1989, pp. 3.7.2.23 to 3.7.2.25.

4.6 U.S. NRC, Westinghouse and Ames Laboratory Staff Meeting, Monroeville, PA, March 7, 1996.

4.7 U.S. NRC, Westinghouse and Ames Laboratory Staff Meeting, Monroeville, PA, Dec. 10-11, 1996.

4.8 Berrah, M. and Kausel, E., "Response Spectrum Analysis of Structures Subjected to Spatially Varying Motion," Journal of Earthquake Engineering and Structural Dynamics, Vol. 21, 1991, pp. 461-470.

4.9 American Society of Civil Engineering, "Structural Analysis and Design of Nuclear Plant Facilities - Manual and Report of Engineering Practice," No. 58, ASCE, New York, NY, $10017,1980$. 


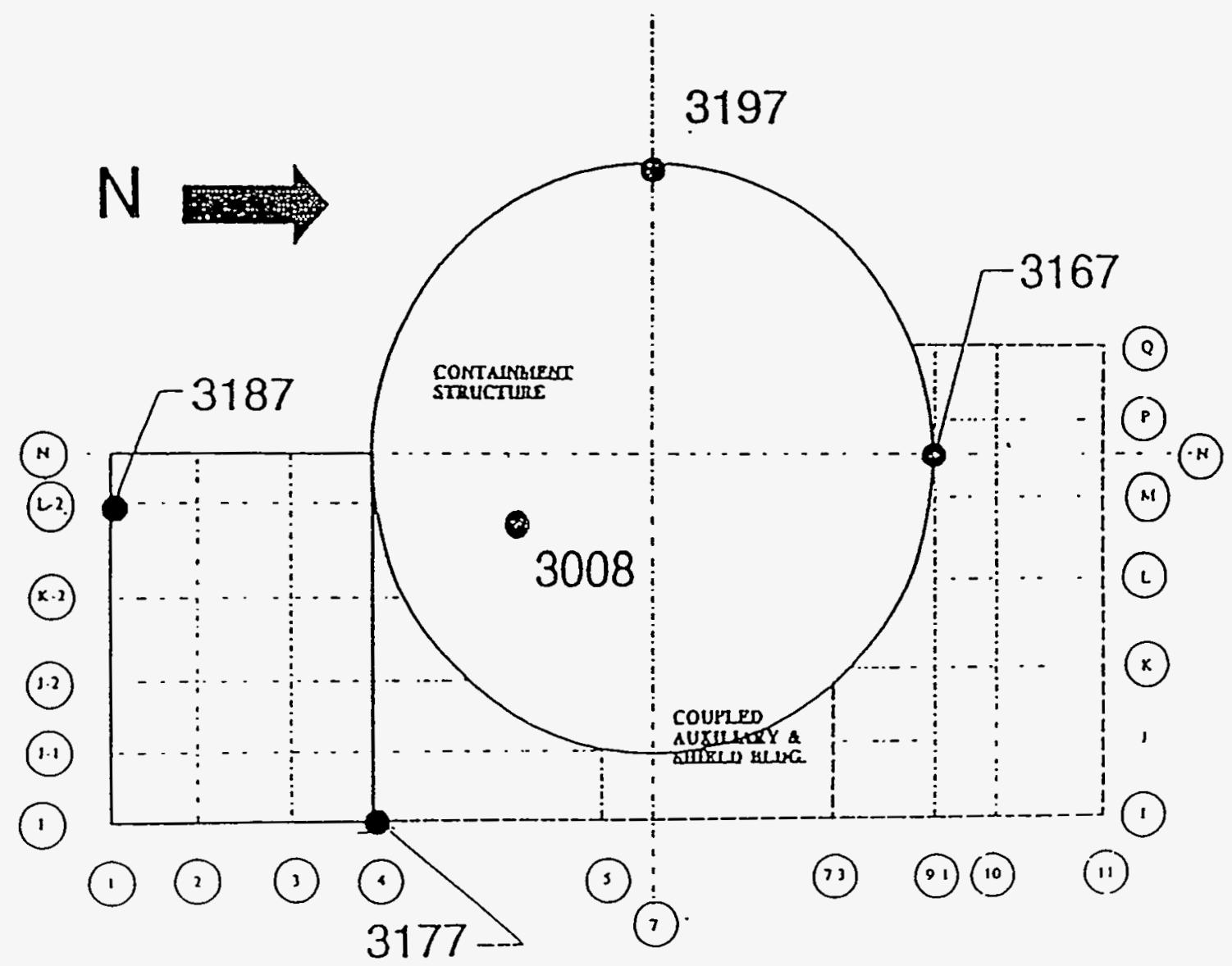

Figure 4.1 Location of Computed Spectra at Elev. 180'-0" 


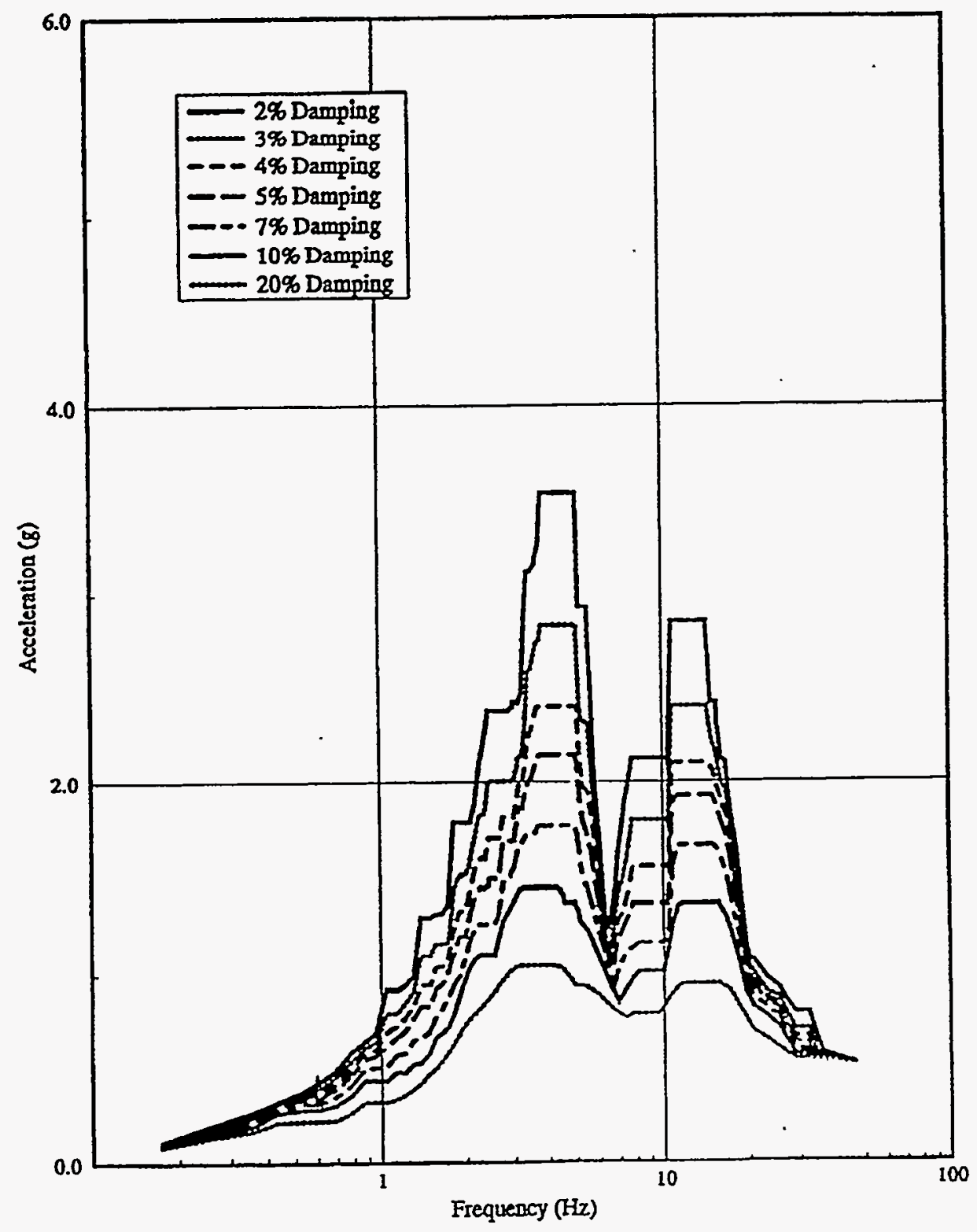

Figure 4.2 Envelope of North-South Spectra for all Soil Conditions at Center of Mass in the North-South $(X-X)$ Direction 


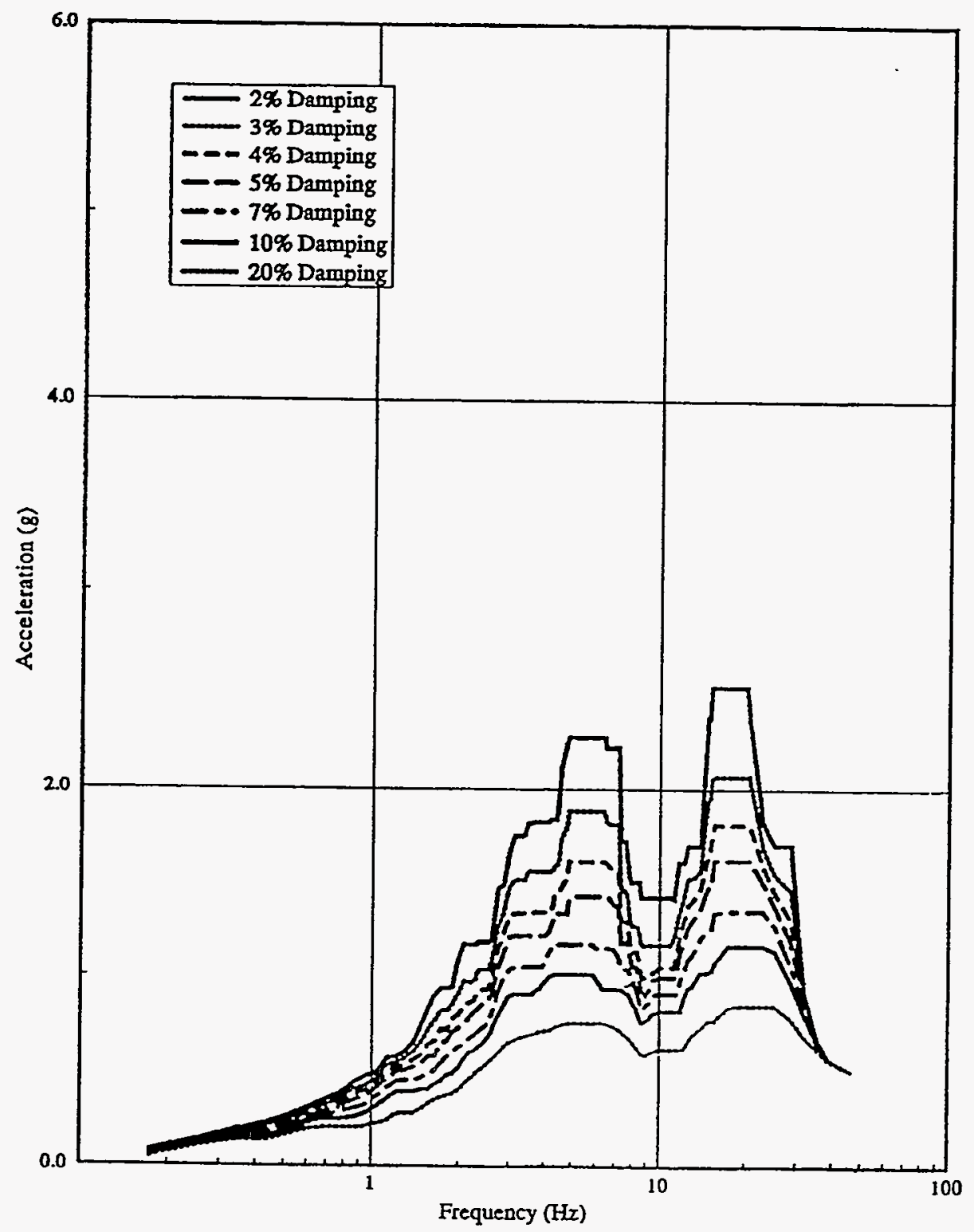

Figure 4.3 Envelope of East-West Spectra for all Soil Conditions at Center of Mass in the Vertical (Z-Z) Direction 


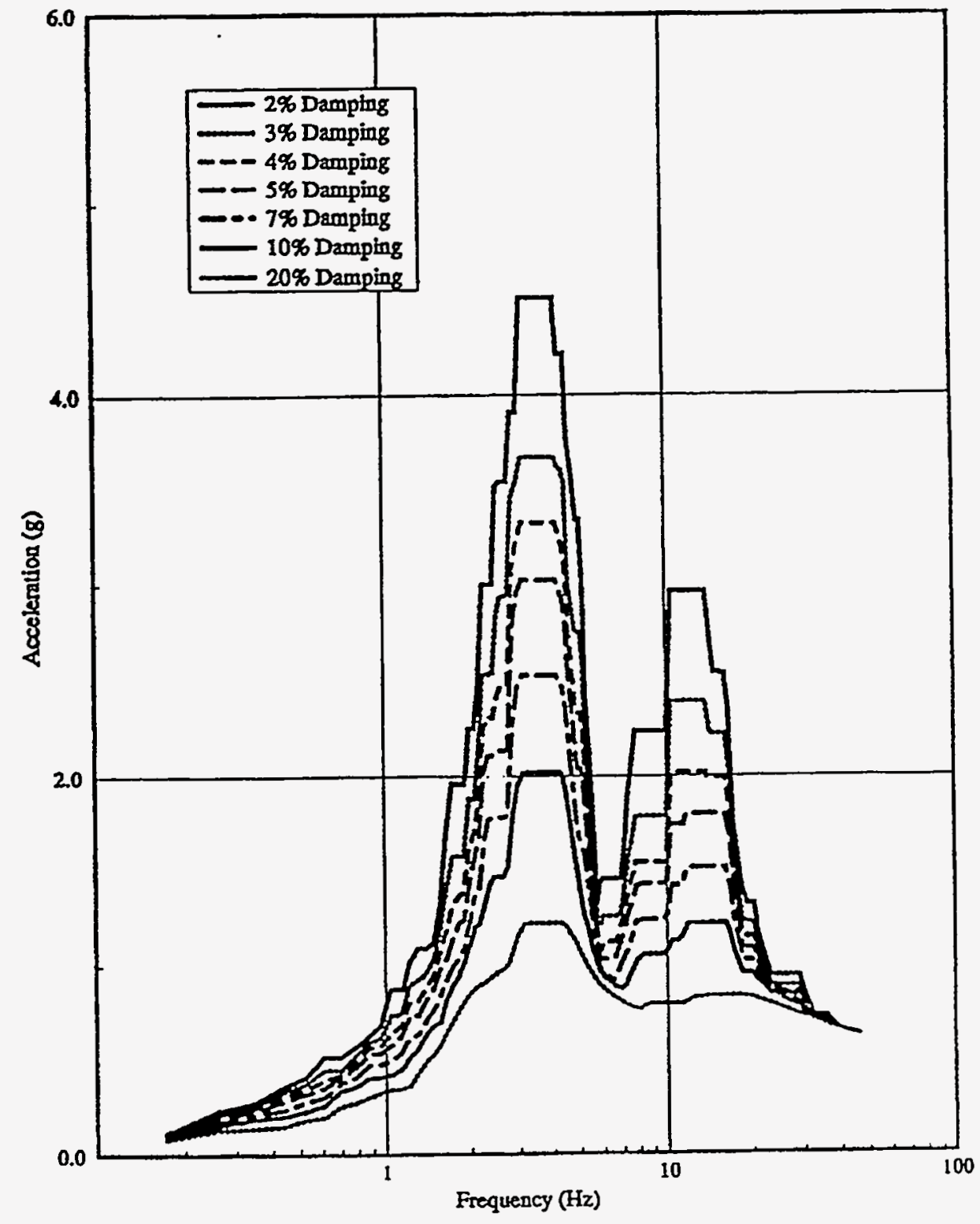

Figure 4.4 Envelope of Vertical Spectra for all Soil Conditions at Center of Mass in the East-West $(Y-Y)$ Direction 


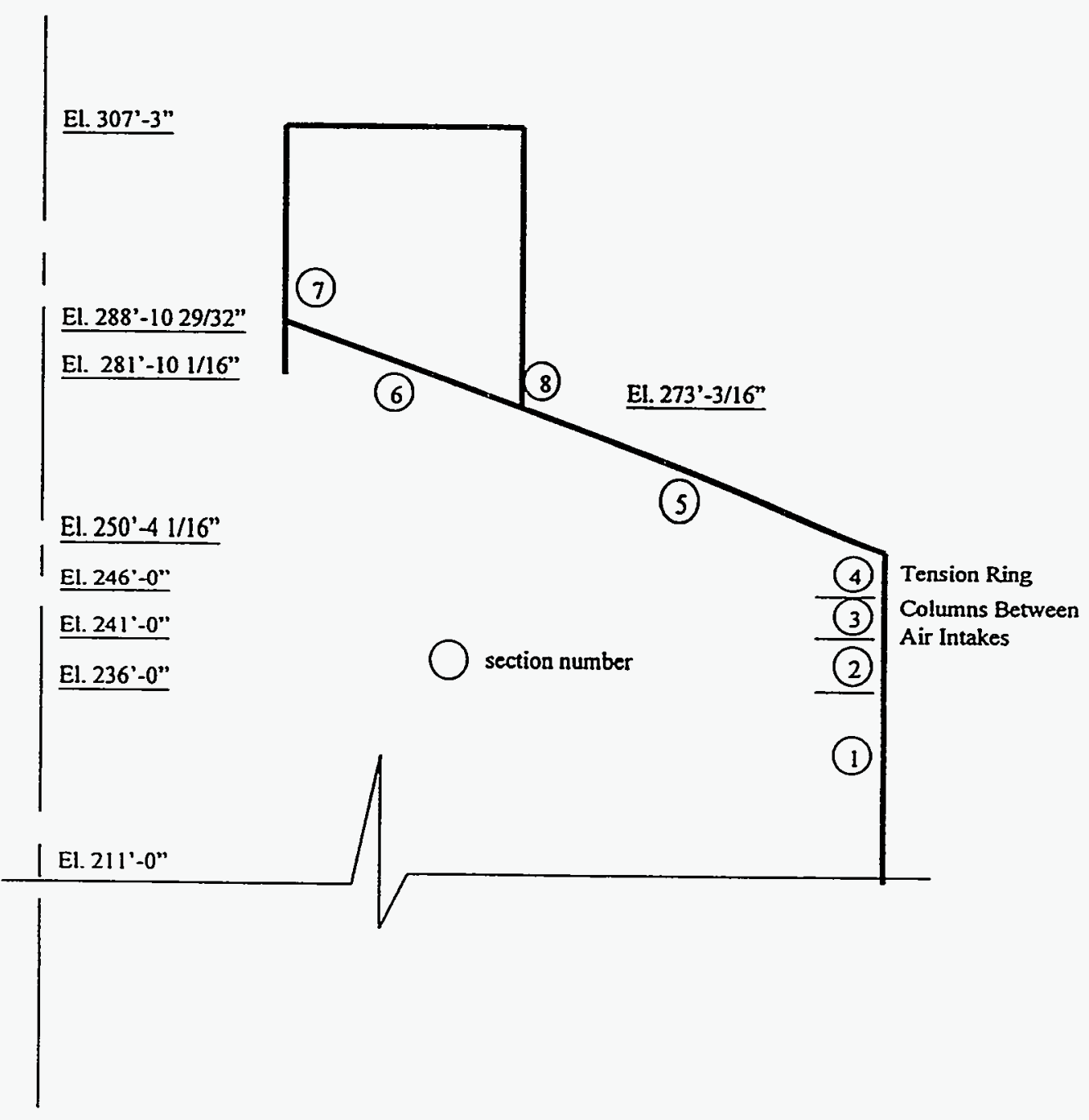

Figure 4.5 Location of the Critical Section in the SBR Structure 


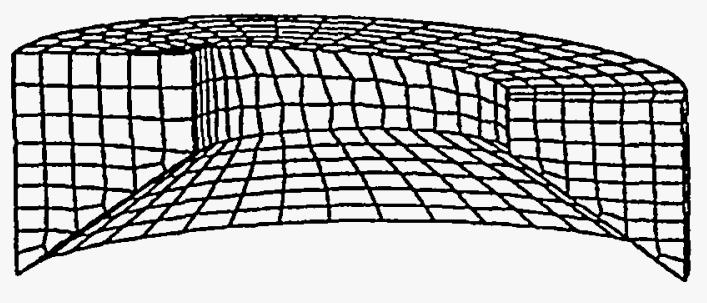

Mode (1) $\mathrm{f}=0.122 \mathrm{~Hz}$

$$
(\mathrm{i}=1, \mathrm{j}=0)
$$

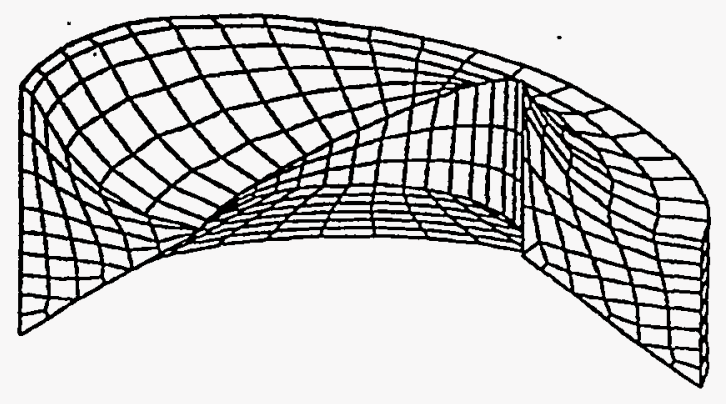

Mode (12) $\mathrm{f}=0.356 \mathrm{~Hz}$

$$
(i=1, j=1)
$$

\begin{tabular}{|c|c|c|c|c|}
\hline \multirow{2}{*}{ Mode } & \multicolumn{2}{|c|}{ Frequency $(\mathrm{Hz})$} & \multicolumn{2}{c|}{ Effective mass in X Direction } \\
\cline { 2 - 5 } & Ames & Westinghouse & Ames & Westinghouse \\
\hline 1 & 0.11 & 0.122 & 3051.4 & 2902.14 \\
\hline 12 & 0.353 & 0.356 & 1104.5 & 473.4 \\
\hline
\end{tabular}

Figure 4.6 First and Twelfth Sloshing Vibration Mode of Water in the PCS Tank 

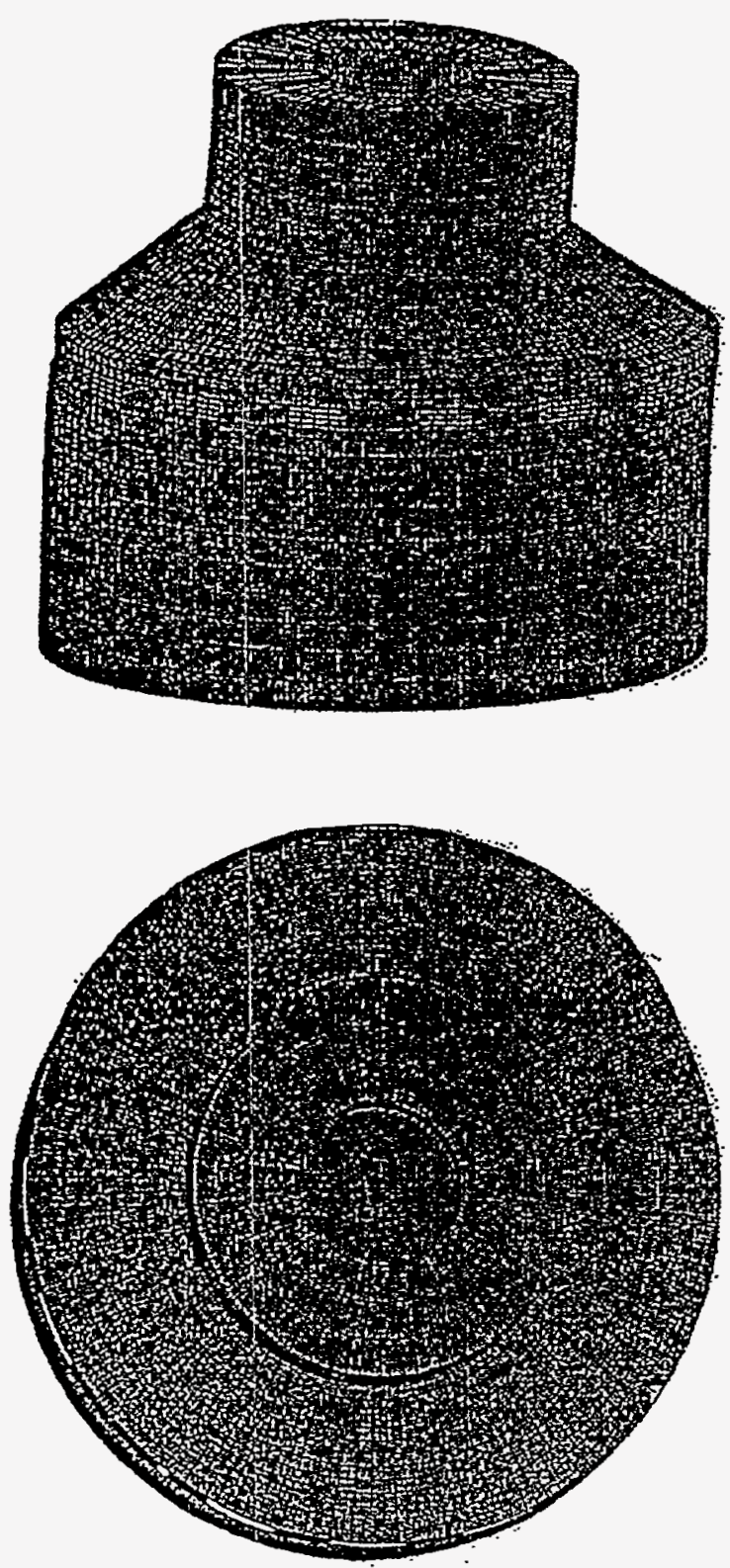

Mode (1) $\mathrm{f}=6.118 \mathrm{~Hz}$

Westinghouse $f=5.028 \mathrm{~Hz}$

Figure 4.7 First Structural Vibration Mode (Frequency $=6.12 \mathrm{~Hz})$ 

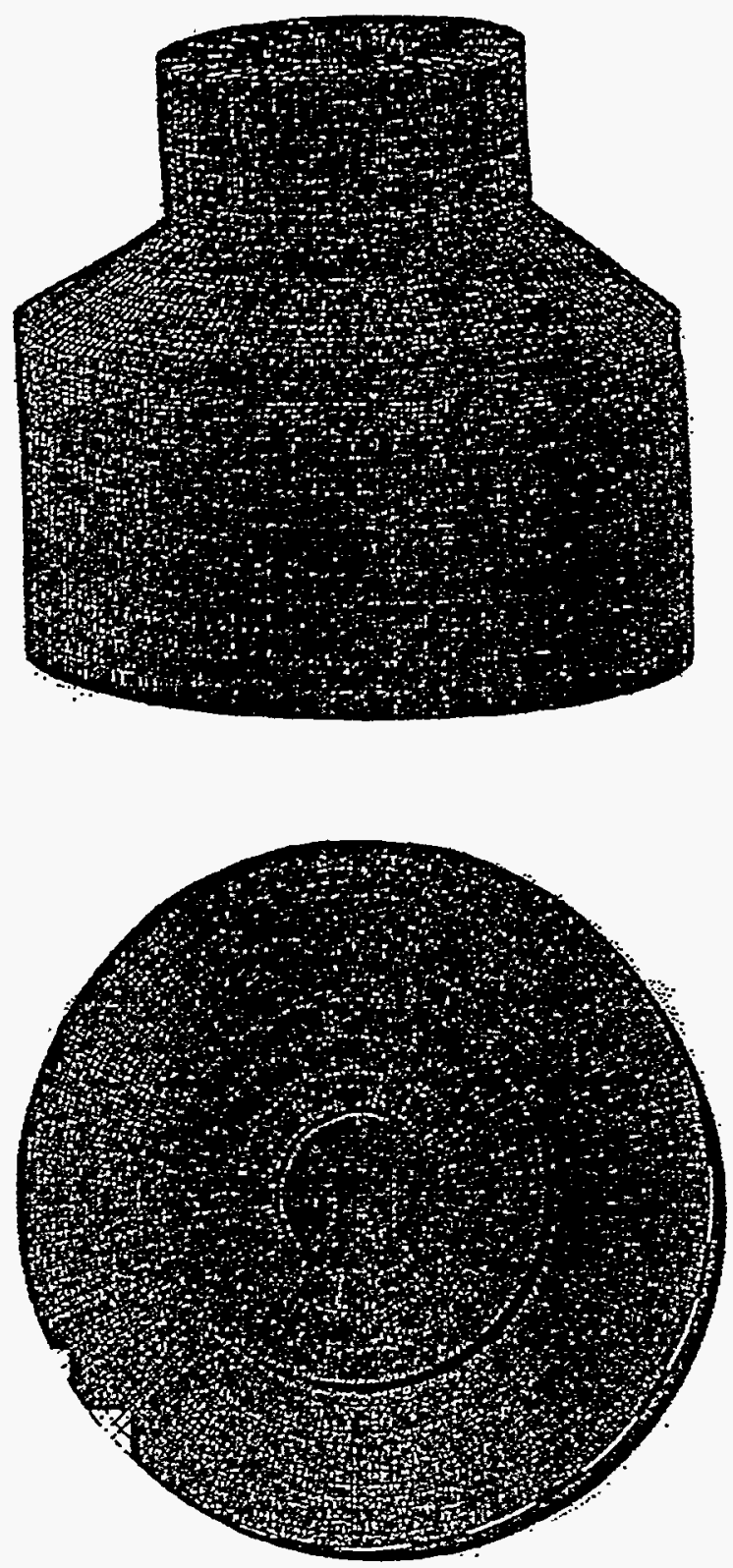

Mode (2) $f=6.138 \mathrm{~Hz}$

Westinghouse $\mathrm{f}=5.064 \mathrm{~Hz}$

Figure 4.8 Second Structural Vibration Mode (Frequency $=6.14 \mathrm{~Hz}$ ) 


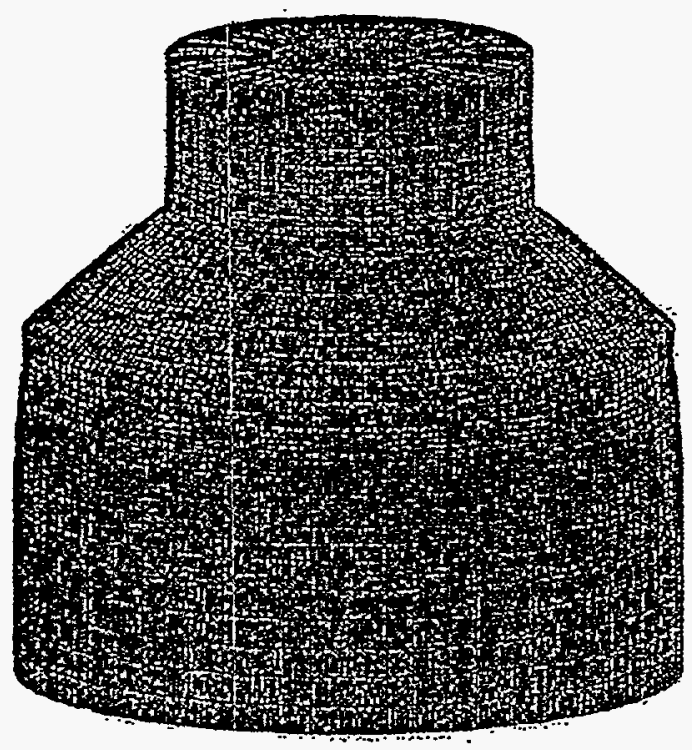

Mode (3) $\mathrm{f}=6.851 \mathrm{~Hz}$

Westinghouse $f=7.235 \mathrm{~Hz}$

Figure 4.9 Third Structural Vibration Mode (Frequency $=6.85 \mathrm{~Hz}$ ) 

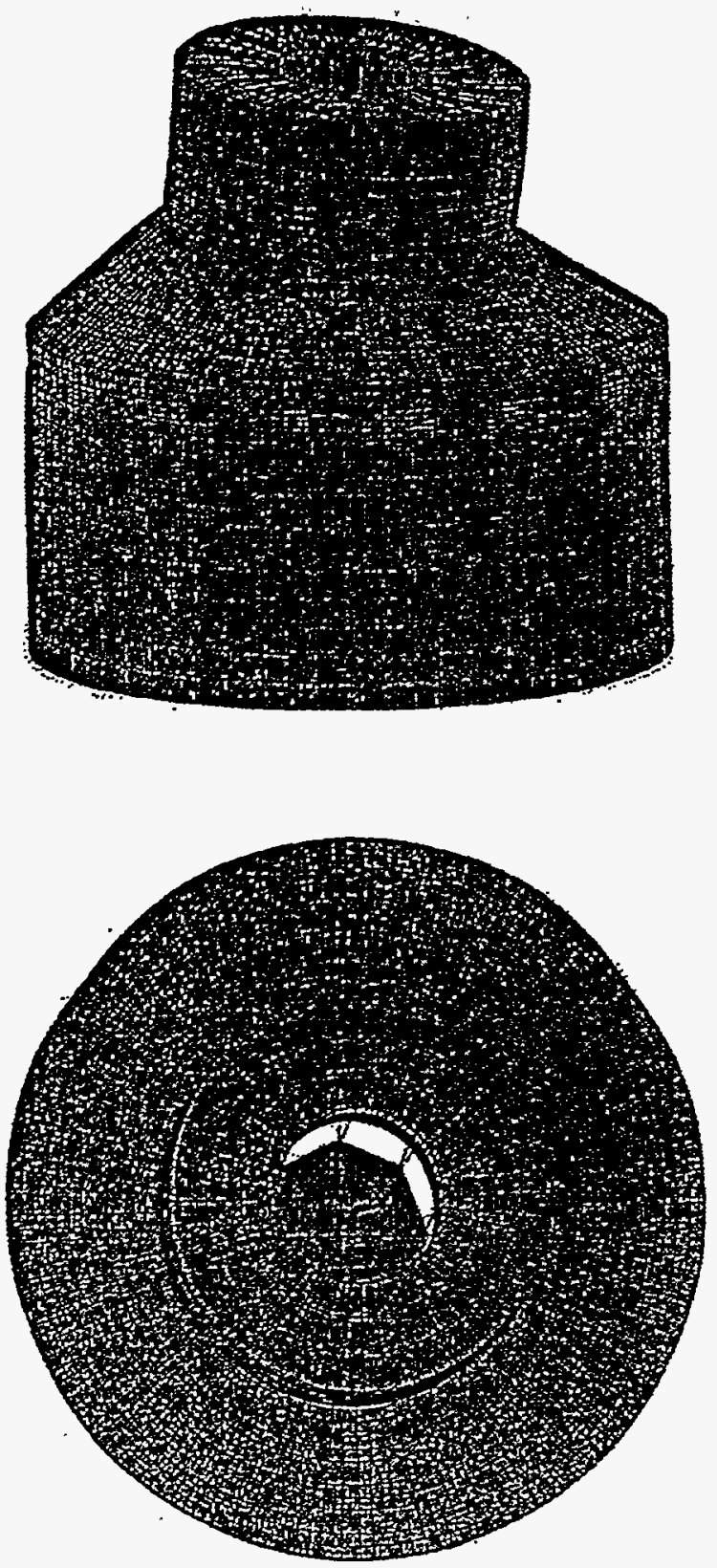

Mode (4) $\mathrm{f}=9.728 \mathrm{~Hz}$

Westinghouse $f=9.627 \mathrm{~Hz}$

Figure 4.10 Fourth Structural Vibration Mode (Frequency $=9.73 \mathrm{~Hz}$ ) 

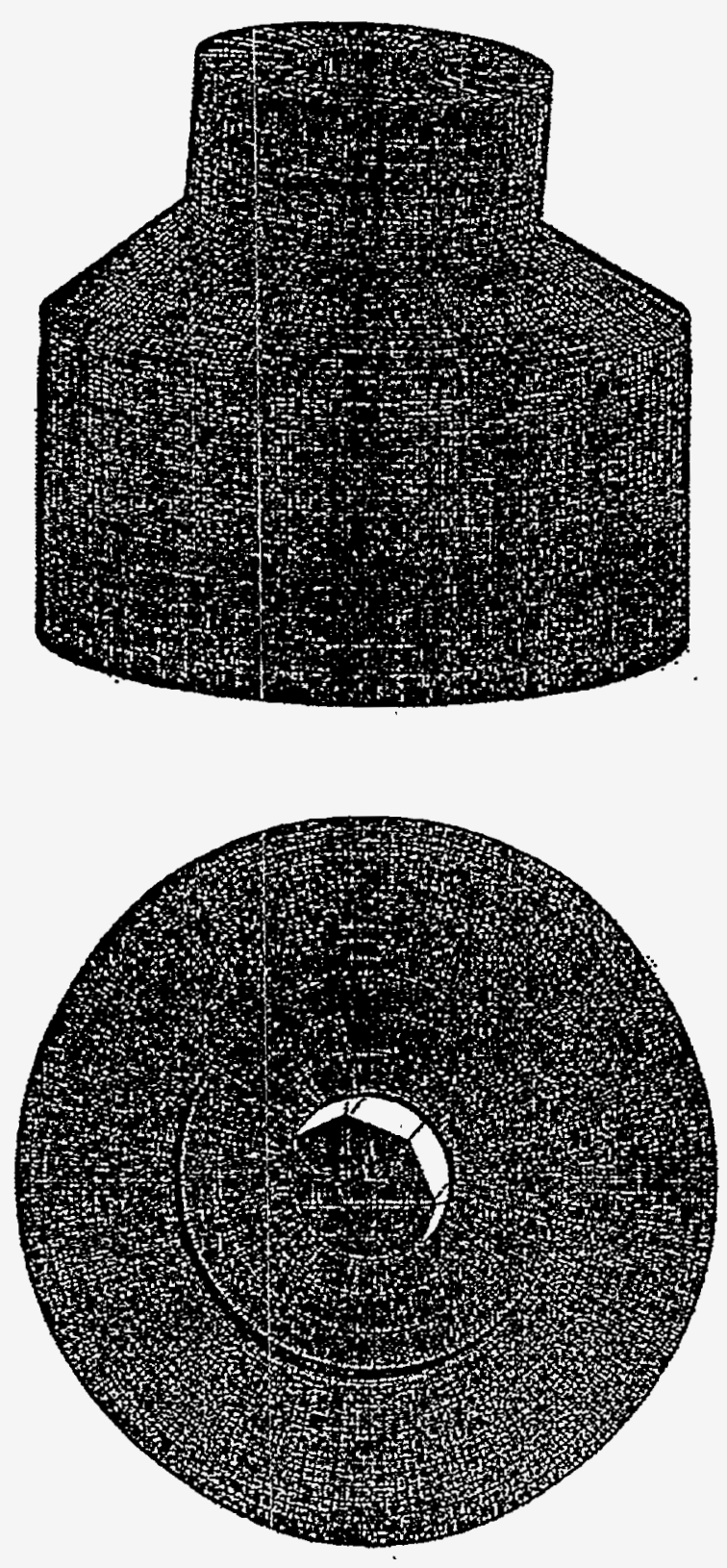

Mode (5) $\mathrm{f}=9.929 \mathrm{~Hz}$

Figure 4.11 Fifth Structural Vibration Mode (Frequency $=9.93 \mathrm{~Hz}$ ) 


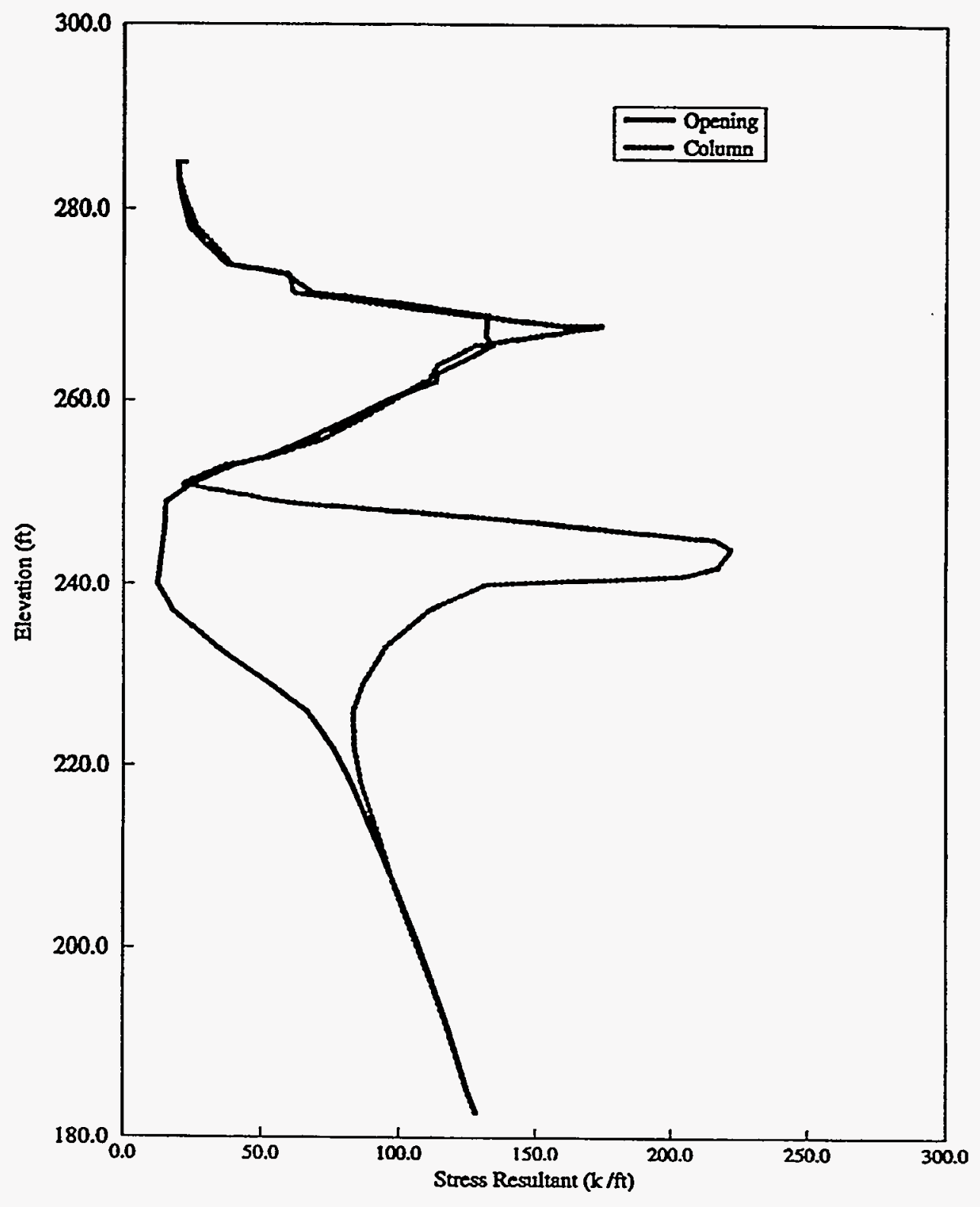

Figure 4.12 Distribution of the Meridional Stress Resultant, N1, (Seismic Load) 


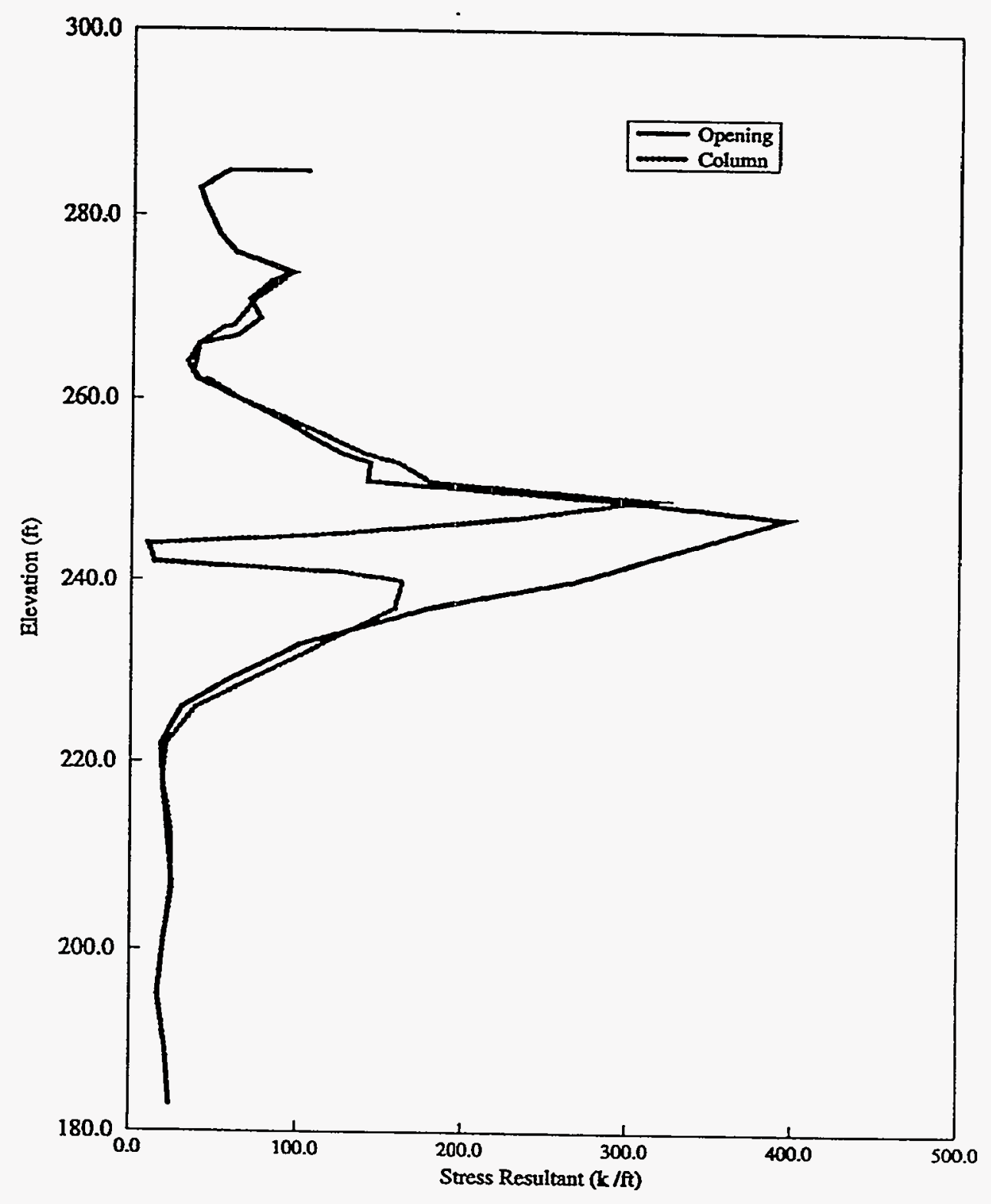

Figure 4.13 Distribution of the Circumferential Stress Resultant, N2, (Seismic Load) 


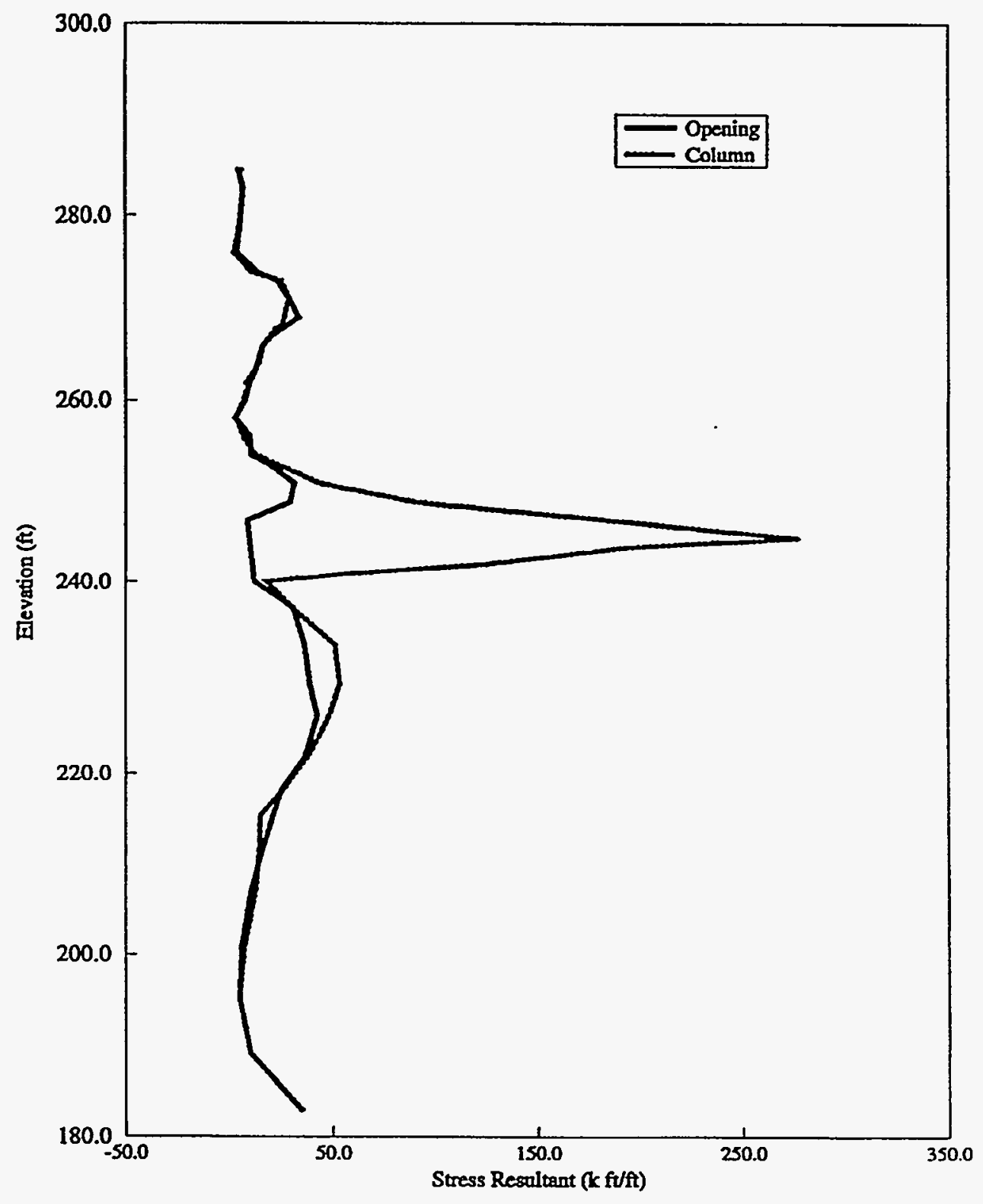

Figure 4.14 Distribution of the Meridional Moment, M1, (Seismic Load) 


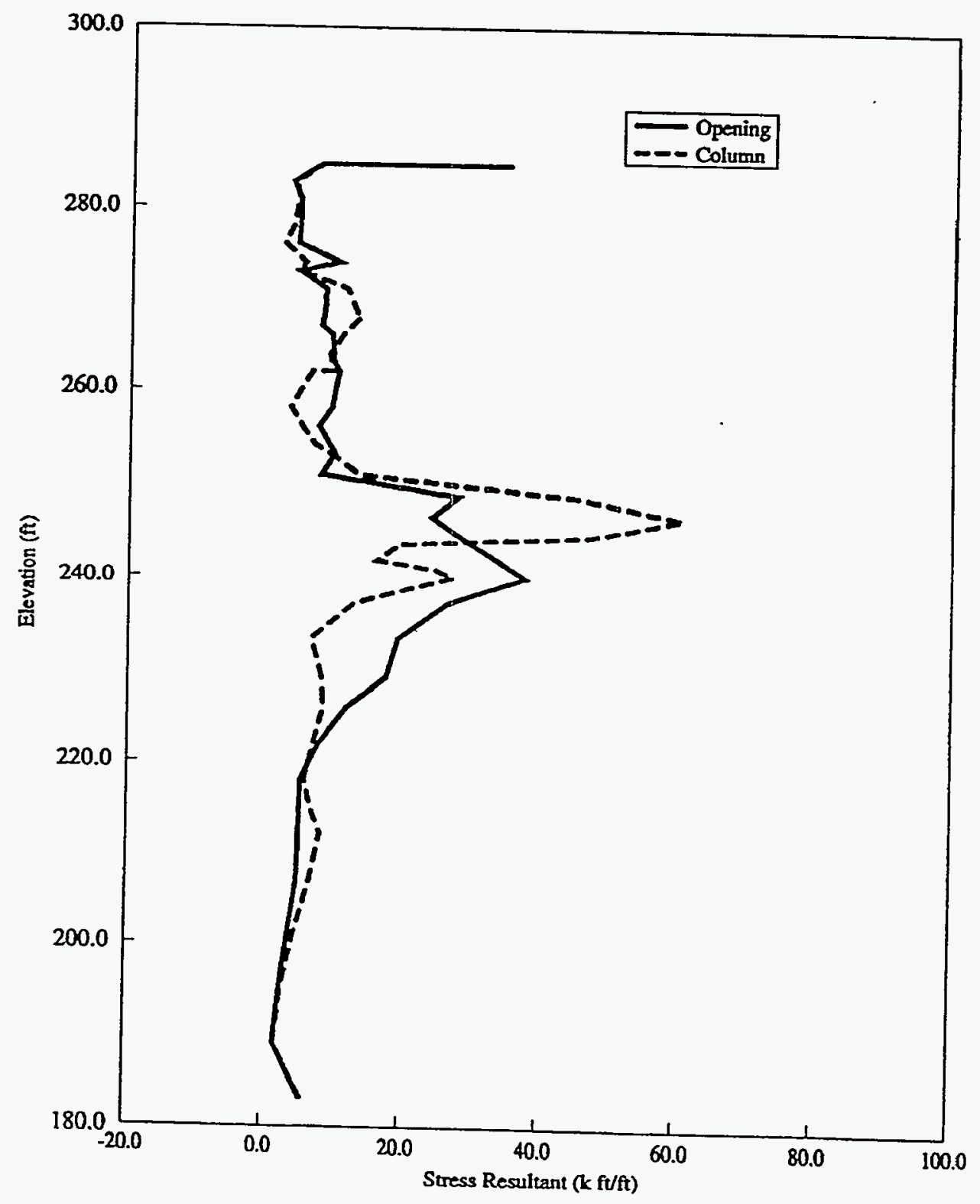

Figure 4.15 Distribution of the Circumferential Moment, M2, (Seismic Load) 


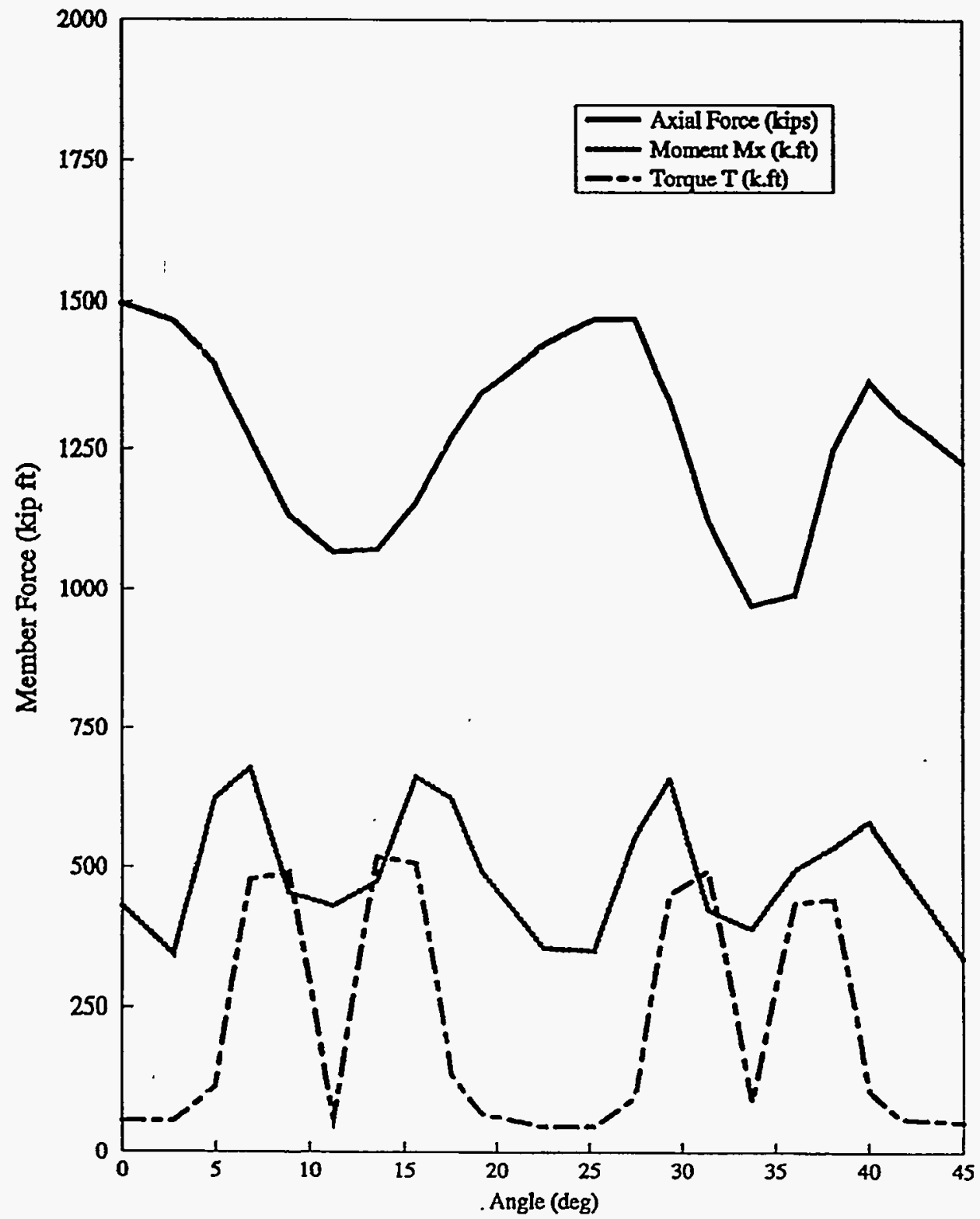

Figure 4.16 Distribution of Axial Force, Moment, Mx, and Torsion, $T$, in the Tension Ring Due to Seismic Load 


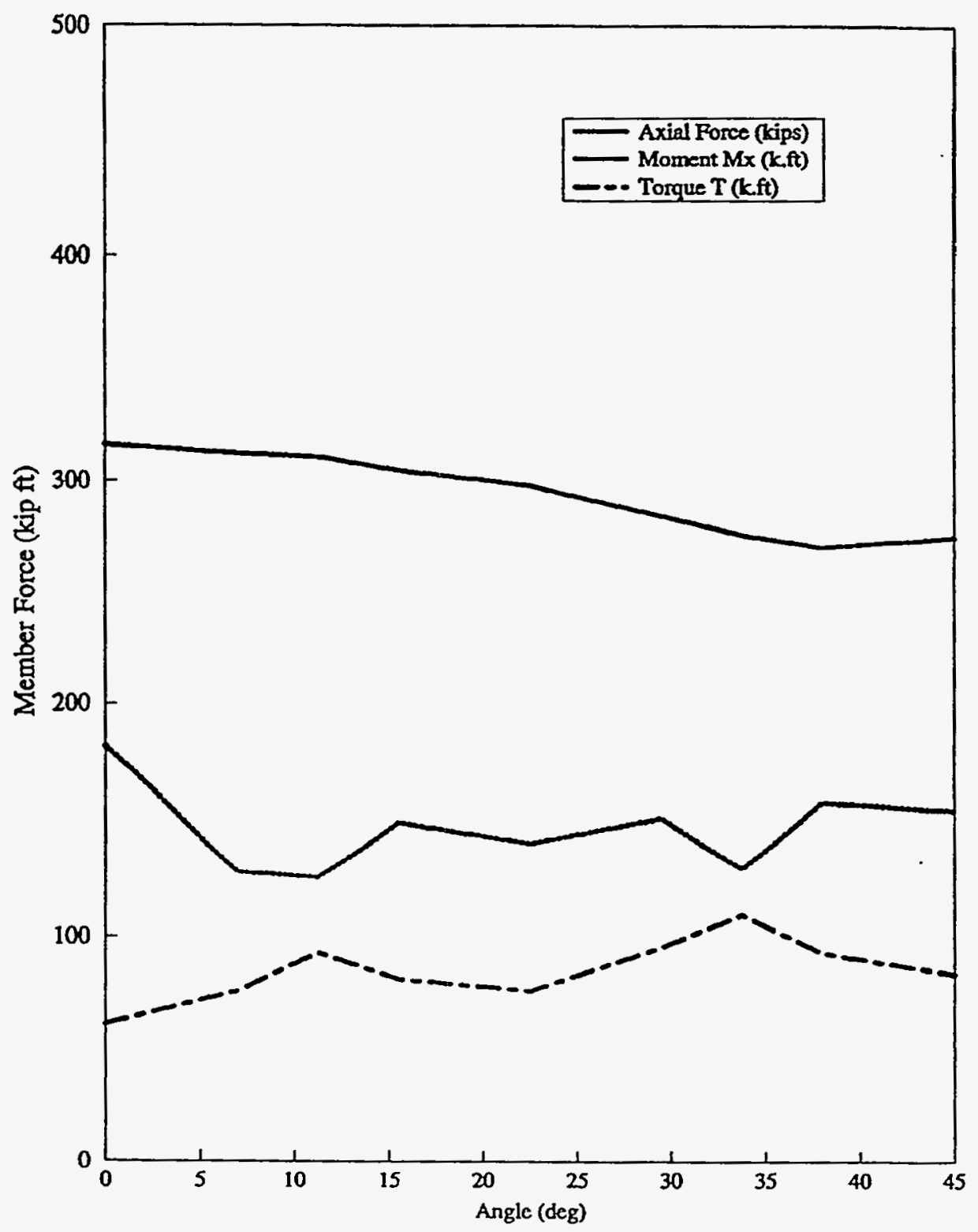

Figure 4.17 Distribution of Axial Force, Moment, $\mathrm{Mx}$, and Torsion, $\mathrm{T}$, in the Compression Ring Due to Seismic Load 


\section{LOAD COMBINATION}

Section 3.8.4 of the Standard Review Plan (SRP) [5.1] stipulates that the design loading combinations be in compliance with Sec. 9.2.1 of the ACI 349 Code Requirements for Nuclear Safety Related Concrete Structures [5.2]. These requirements mandate that the design strength, $\mathrm{U}$, for every structural member shall be at least equal to the greatest of any of the specified loads combinations. From these load combinations, the following were identified as the most critical for the AP600 SBR structure

$$
\begin{array}{ll}
\text { Load Combination } 1 & \mathrm{U}=1.4 \mathrm{D}+1.4 \mathrm{~F}+1.7 \mathrm{~L}+1.7 \mathrm{~W} \\
\text { Load Combination } 2 & \mathrm{U}=\mathrm{D}+\mathrm{F}+\mathrm{L}+\mathrm{T}+\mathrm{E}_{\mathrm{SS}}
\end{array}
$$

where:

$$
\begin{aligned}
& \mathrm{D} \quad=\text { Dead loads } \\
& \mathrm{L} \quad=\text { Live load (snow in the case of AP600 SBR structure) } \\
& \mathrm{F} \quad=\text { Lateral and vertical pressure of liquids } \\
& \mathrm{W} \quad=\text { Operating basis wind load } \\
& \mathrm{E}_{\mathrm{SS}} \quad=\text { Seismic load (SSE) }
\end{aligned}
$$

\subsection{Load Combination 1}

In Load Combination 1, the strength, $\mathrm{U}$, of any structural member shall equal the factored loads listed in Eq. 5.1. As previously noted in Sec. 3.4, wind pressure on the AP600 SBR has a sinusoidal distribution around the shield building structure. The wind can come from any direction. Therefore, in combining the wind effect with other loads, the same maximum and minimum stress resultants at a given elevation were applied to all meridians. 
Figure 5.1 illustrates the distribution of the maximum and minimum envelopes of $\mathrm{N} 1$ stress resultants at a given elevation. The envelope of $\mathrm{N} 1$ was constant along the meridian up to Elev. 220'-0". A noticeable increase in N1 took place in the vicinity of the air intakes near Elev. 243'0 ", where the maximum compressive $\mathrm{N} 1$ reached $205 \mathrm{k} / \mathrm{ft}$. A similar envelope for the $\mathrm{N} 2$ stress resultant is shown in Fig. 5.2. The maximum tensile N2 stress resultant was approximately 393 $\mathrm{k} / \mathrm{ft}$. The distribution of the meridional and circumferential moments, $\mathrm{M} 1$ and $\mathrm{M} 2$, respectively, are shown in Figs. 5.3 and 5.4. The maximum values for M1 and M2 occurred in the vicinity of the air intakes and reached $295 \mathrm{k}-\mathrm{ft} / \mathrm{ft}$ and $120 \mathrm{k}-\mathrm{ft} / \mathrm{ft}$, respectively.

The maximum and minimum design forces around the circumference of the tension and compression rings are listed in Tables 5.1 and 5.2, respectively. These forces were calculated as explained in Sec. 3.2.2. Note that the tension ring is considered to be the beam element directly above the air intake openings. The region above the columns, i.e., above the shell between the air intakes, is considered to be part of the cylindrical shell. The forces listed in the following Tables envelope around the circumference of the tension and compression rings.

Table 5.1 Maximum and Minimum Member Forces - Tension Ring

\begin{tabular}{|c|c|c|c|c|c|c|}
\hline Force & $\begin{array}{c}\text { Axial-N } \\
\text { (kips) }\end{array}$ & $\begin{array}{c}\text { Shear- } \mathrm{Q}_{\mathrm{Z}} \\
(\mathrm{kips})\end{array}$ & $\begin{array}{c}\text { Shear- } \mathrm{Q}_{\mathrm{X}} \\
(\mathrm{kips})\end{array}$ & $\begin{array}{c}\text { Moment-M } \\
(\mathrm{k}-\mathrm{ft})\end{array}$ & $\begin{array}{c}\text { Moment-M } \\
(\mathrm{k}-\mathrm{ft})\end{array}$ & $\begin{array}{c}\text { Torque- } \mathrm{T} \\
(\mathrm{k}-\mathrm{ft})\end{array}$ \\
\hline Maximum & 1250 & 205 & 60 & 420 & 486 & 339 \\
\hline Minimum & 801 & -237 & -68 & -396 & -479 & -120 \\
\hline
\end{tabular}


Table 5.2 Maximum and Minimum Member Forces - Compression Ring

\begin{tabular}{|c|c|c|c|c|c|c|}
\hline Force & $\begin{array}{c}\text { Axial-N } \\
\text { (kips) }\end{array}$ & $\begin{array}{c}\text { Shear- } \mathrm{Q}_{\mathrm{Z}} \\
\text { (kips) }\end{array}$ & $\begin{array}{c}\text { Shear- } \mathrm{Q}_{\mathrm{X}} \\
(\text { kips) }\end{array}$ & $\begin{array}{c}\text { Moment-M } \\
(\mathrm{k}-\mathrm{ft})\end{array}$ & $\begin{array}{c}\text { Moment-M } \\
(\mathrm{k}-\mathrm{ft})\end{array}$ & $\begin{array}{c}\text { Torque-T } \\
(\mathrm{k}-\mathrm{ft})\end{array}$ \\
\hline Maximum & -505 & 23 & 11 & -89 & 15 & 17 \\
\hline Minimum & -536 & 23 & -12 & -182 & -22 & -13 \\
\hline
\end{tabular}

\subsection{Load Combination 2}

Dead, snow, fluid, thermal and seismic loads are combined by Eq. 5.2. The envelopes of the stress resultants for the temperature increment and decrement were utilized when combining the thermal effects with the other loads.

Figure 5.5 shows the envelope of the N1. Below Elev. 220'-0", the variation in the N1 stress resultant was gradual. At Elev. 180'-0", the stress resultants, N1 ranged from $-200 \mathrm{k} / \mathrm{ft}$ to $75 \mathrm{k} / \mathrm{ft}$ while at Elev. 220'-0", N1 ranged from $-125 \mathrm{k} / \mathrm{ft}$ to $50 \mathrm{k} / \mathrm{ft}$. The peak compressive and tensile $\mathrm{N} 1$ were $410 \mathrm{k} / \mathrm{ft}$ and $154 \mathrm{k} / \mathrm{ft}$, respectively, that occurred at Elev. 241'-0". Shown in Fig. 5.6 is the variation of the stress resultant N2 envelope for Load Combination 2. Neglecting the high values of N2 near Elev. 183'-0" caused by the artificial restraint and temperature changes, the maximum tensile N2 reached $675 \mathrm{k} / \mathrm{ft}$ at Elev. 247'-0" while the maximum compressive N2 reached $400 \mathrm{k} / \mathrm{ft}$ at Elev. $286^{\prime}-0^{\prime \prime}$, i.e., at the junction between the compression ring and the conical roof slab.

Figure 5.7 illustrates the envelope of M1. The maximum M1 was $521 \mathrm{k}-\mathrm{ft} /$ at Elev. $245^{\prime-4}$ ", i.e., in the vicinity of the air intakes. Near the base, large values of M1 resulted from the thermal loading case and are artificial due to the effect of the assumed fixation (see Sec 3.5). These forces were not included in the check of the design adequacy of reinforcing steel in the cylindrical shell. No significant values were calculated for M2 except near the junction between 
the compression ring and the conical roof (see Fig. 5.8). The finite element analysis of the two thermal cases considered here (see Sec. 3.5 and Figs. 3.42 and 3.53) yielded peak moment values at this elevation.

Tables 5.3 and 5.4 summarize the maximum and minimum design values for the tension ring (above the air intakes openings) and compression ring, respectively. These forces were calculated as explained in Sec. 3.2.2 utilizing the finite element results without modifications to account for concrete cracking due to thermal loads.

Table 5.3 Maximum and Minimum Member Forces - Tension Ring

\begin{tabular}{|c|c|c|c|c|c|c|}
\hline Force & $\begin{array}{c}\text { Axial-N } \\
\text { (kips) }\end{array}$ & $\begin{array}{c}\text { Shear- } Q_{Z} \\
\text { (kips) }\end{array}$ & $\begin{array}{c}\text { Shear- } Q_{X} \\
\text { (kips) }\end{array}$ & $\begin{array}{c}\text { Moment-M } \\
(\mathrm{k}-\mathrm{ft})\end{array}$ & $\begin{array}{c}\text { Moment-M } \\
(\mathrm{k}-\mathrm{ft})\end{array}$ & $\begin{array}{c}\text { Torque-T } \\
(\mathrm{k}-\mathrm{ft})\end{array}$ \\
\hline Maximum & 2524 & 512 & 144 & 856 & 785 & 905 \\
\hline Minimum & -839 & -539 & -148 & -784 & -268 & -855 \\
\hline
\end{tabular}

Table 5.4 Maximum and Minimum Member Forces - Compression Ring

\begin{tabular}{|c|c|c|c|c|c|c|}
\hline Force & $\begin{array}{c}\text { Axial-N } \\
\text { (kips) }\end{array}$ & $\begin{array}{c}\text { Shear- } Q_{z} \\
\text { (kips) }\end{array}$ & $\begin{array}{c}\text { Shear- } Q_{X} \\
\text { (kips) }\end{array}$ & $\begin{array}{c}\text { Moment-M } \\
(\mathrm{k}-\mathrm{ft})\end{array}$ & $\begin{array}{c}\text { Moment-M } \\
(\mathrm{k}-\mathrm{ft})\end{array}$ & $\begin{array}{c}\text { Torque- } \mathrm{T} \\
(\mathrm{k}-\mathrm{ft})\end{array}$ \\
\hline Maximum & 1131 & 386 & 155 & 1132 & 203 & 165 \\
\hline Minimum & -1927 & -384 & -160 & -1445 & -163 & -181 \\
\hline
\end{tabular}

\subsection{Design Adequacy of the Critical Sections}

\subsubsection{Selection of Critical Section}

Figure 4.5 is a schematic showing the locations of the critical sections in the AP600 SBR that were identified by Ames Laboratory personnel, U.S. NRC staff and Westinghouse personnel [5.3]. These sections are located in the cylindrical portion, the conical shell, compression and 
tension rings and in lower portion of the internal and external walls of the passive cooling system. The section numbers shown in Fig. 5.9 corresponds to the numbering system used by Westinghouse Tables A-1 and A-5 [5.4].

\subsubsection{Strength of the Critical Sections in Shell}

Chapter 19 of the ACI 318-89 Building Code [5.5] requires that concrete shell structures be provided with reinforcement to resist tensile stresses from internal membrane, bending moments, in-plane shear and twisting moment stress resultants. The analysis of the AP600 SBR revealed that the distributions of $\mathrm{N} 1, \mathrm{~N} 2, \mathrm{M} 1, \mathrm{M} 2, \mathrm{~N} 12$, and $\mathrm{M} 12$ stress resultants around the circumference at a given elevation were not symmetric. Therefore, one should consider several different load combinations of design forces to ensure that a section is adequately reinforced. For example, in designing the required meridional reinforcement, the following design force combinations should be considered: (1) maximum absolute M1 and the corresponding N1, N12 and M12; (2) maximum tensile N1 and the corresponding M1, N12 and M12; (3) maximum absolute N12 and the corresponding N1, M1 and M12; and (4) maximum absolute M12 and the corresponding N1, M1, and N12. Similar design force combinations are also needed to calculate the required circumferential reinforcement.

A conservative alternative is to use the extreme force combination, e.g., the maximum tensile axial load, $\mathrm{N} 1$, and the maximum absolute $\mathrm{M} 1, \mathrm{M} 12$ and $\mathrm{N} 12$ to maximize the required amount of reinforcement. This conservative design approach was used here to check the adequacy of the Westinghouse design for the critical shell sections shown in Fig. 5.9. Table 5.5 summarizes the design forces used to perform this check. The listed forces are the maximums within each 
tabulated elevation range. These forces are associated with Load Combination 2, which is more critical than Load Combination $1[5.2]$.

Table 5.5 Design Forces at the Critical Shell Sections

\begin{tabular}{|c|c|c|c|c|c|c|c|c|}
\hline Wall Description & $\begin{array}{l}\text { Sec. } \\
\text { No. }\end{array}$ & $\begin{array}{c}\text { Elevation } \\
\text { (ft.) }\end{array}$ & $\begin{array}{c}\mathrm{N1} \\
(\mathrm{k} / \mathrm{ft})\end{array}$ & $\begin{array}{c}\mathrm{M} 1 \\
(\mathrm{k}-\mathrm{ft} / \mathrm{ft})\end{array}$ & $\begin{array}{c}N 2 \\
(\mathrm{k} / \mathrm{ft})\end{array}$ & $\begin{array}{c}\mathrm{M} 2 \\
(\mathrm{k}-\mathrm{ft} / \mathrm{ft})\end{array}$ & $\begin{array}{l}\mathrm{N} 12 \\
(\mathrm{k} / \mathrm{ft})\end{array}$ & $\begin{array}{c}\mathrm{M} 12 \\
(\mathrm{k}-\mathrm{ft} / \mathrm{ft})\end{array}$ \\
\hline Cylindrical wall & 1 & $211 \rightarrow 236$ & $\begin{array}{l}51.4 \\
-190\end{array}$ & $\begin{array}{c}42 \\
-94\end{array}$ & $\begin{array}{l}206 \\
-75\end{array}$ & $\begin{array}{l}27 \\
-48\end{array}$ & $\begin{array}{c}122 \\
-123\end{array}$ & $\begin{array}{c}24 \\
-23\end{array}$ \\
\hline Cylindrical wall & 2 & $236 \rightarrow 241$ & $\begin{array}{c}96 \\
-261\end{array}$ & $\begin{array}{c}81 \\
-24\end{array}$ & $\begin{array}{r}481 \\
-198\end{array}$ & $\begin{array}{r}66 \\
-85\end{array}$ & $\begin{array}{r}126 \\
-127\end{array}$ & $\begin{array}{c}40 \\
-32\end{array}$ \\
\hline $\begin{array}{c}\text { Cylindrical wall } \\
\text { between air } \\
\text { intakes }\end{array}$ & 3 & $241 \rightarrow 246.5$ & $\begin{array}{c}90 \\
-377\end{array}$ & $\begin{array}{c}521 \\
-132\end{array}$ & $\begin{array}{c}310 \\
-104\end{array}$ & $\begin{array}{l}107 \\
-45\end{array}$ & $\begin{array}{c}178 \\
-175\end{array}$ & $\begin{array}{l}24 \\
26\end{array}$ \\
\hline $\begin{array}{c}\text { Tension ring } \\
\text { above air intakes }\end{array}$ & 4 & $246.5 \rightarrow 250$ & $\begin{array}{r}75 \\
-256 \\
\end{array}$ & $\begin{array}{l}335 \\
-81 \\
\end{array}$ & $\begin{array}{c}675 \\
-266 \\
\end{array}$ & $\begin{array}{r}189 \\
-58 \\
\end{array}$ & $\begin{array}{r}115 \\
-112 \\
\end{array}$ & $\begin{array}{r}113 \\
-117 \\
\end{array}$ \\
\hline $\begin{array}{c}\text { Conical roof } \\
\text { external to PCS } \\
\text { tank }\end{array}$ & 5 & $260 \rightarrow 264.5$ & $\begin{array}{l}13.5 \\
-71.5\end{array}$ & $\begin{array}{l}106 \\
-24\end{array}$ & $\begin{array}{c}328 \\
-104\end{array}$ & $\begin{array}{l}45 \\
-20\end{array}$ & $\begin{array}{l}79 \\
-79\end{array}$ & $\begin{array}{l}9 \\
-7\end{array}$ \\
\hline $\begin{array}{c}\text { Conical roof } \\
\text { internal to PCS } \\
\text { tank }\end{array}$ & 6 & $277.2 \rightarrow 282.2$ & $\begin{array}{l}35.5 \\
-107\end{array}$ & $\begin{array}{c}69 \\
-78\end{array}$ & $\begin{array}{c}41 \\
-145\end{array}$ & $\begin{array}{c}82 \\
-90\end{array}$ & $\begin{array}{l}45 \\
-47\end{array}$ & $\begin{array}{l}8 \\
-8\end{array}$ \\
\hline $\begin{array}{c}\text { PCS tank } \\
\text { internal wall } \\
\text { lower section }\end{array}$ & 8 & $287.2 \rightarrow 292.2$ & $\begin{array}{c}32 \\
-55\end{array}$ & $\begin{array}{c}42 \\
-10\end{array}$ & $\begin{array}{c}72 \\
-147\end{array}$ & $\begin{array}{l}34 \\
-3\end{array}$ & $\begin{array}{c}125 \\
-126\end{array}$ & $\begin{array}{l}6 \\
-7\end{array}$ \\
\hline $\begin{array}{c}\text { PCS tank } \\
\text { external wall } \\
\text { lower section }\end{array}$ & 8 & $272.2 \rightarrow 277.2$ & $\begin{array}{c}39 \\
-63\end{array}$ & $\begin{array}{l}100 \\
-43\end{array}$ & $\begin{array}{c}61 \\
-125\end{array}$ & $\begin{array}{c}41 \\
-32\end{array}$ & $\begin{array}{c}138 \\
-136\end{array}$ & $\begin{array}{c}7 \\
-8\end{array}$ \\
\hline
\end{tabular}

In calculating these design forces, the moment stress resultants due to thermal loads were modified to account for concrete cracking, which was not accounted for in the finite element analysis results presented in Sec. 3.5. This was accomplished by reducing the thermal moments by the ratio of the effective moment of inertia of a cracked section, $I_{e}$, to the gross section moment of inertia, $\mathrm{I}_{\mathrm{g}}$ (see Art. A.3.3 of the ACI 349 Code [5.4]). The modified thermal 
moments were not incorporated in Figs. 5.7 and 5.8 and, hence, Table 5.5 can not be directly compared to the results in these figures.

The required area of reinforcing steel at each critical section was calculated following the guidelines given in Chapter 19 of the ACI 318-89 Code [5.5] as outlined in the following sections.

\section{a) Reinforcing steel for in-plane shear, N12:}

Section R19.4.2 of the ACI 318-89 Code requires that membrane reinforcement be provided to carry the entire membrane tension forces with no tensile stress to be carried by the concrete. Following this requirement, the area of steel $A_{s v}$ to be placed on each face in the circumferential and the meridional directions to resist the in-plane shear stress resultant, N12, was calculated as:

$$
A_{s v}=\frac{N 12}{2 \phi f_{y}}
$$

where:

$$
\begin{aligned}
& \phi=\text { Capacity reduction factor }(0.9) \\
& \mathrm{f}_{\mathrm{y}}=\text { Reinforcing bars yield strength }(60 \mathrm{ksi})
\end{aligned}
$$

\section{b) Reinforcing steel for in-plane torsional moment, M12:}

The area of steel $\mathrm{A}_{\mathrm{st}}$ required in the circumferential and meridional directions to withstand inplane torsional moment, M12, can be calculated by replacing this moment by a couple of inplane forces located at the reinforcement level at both faces of the shell. These forces are then used to determine the area of steel, $\mathrm{A}_{\mathrm{st}}$, on each face as for $\mathrm{A}_{\mathrm{sv}}$ above. 


$$
A_{s t}=\frac{M 12}{\phi\left(d-d^{\prime}\right) f_{y}}
$$

where:

$$
\begin{aligned}
& d=\text { Depth of the concrete section. } \\
& d^{\prime}=\text { Concrete cover measured from the extreme compression fiber to the concrete of the } \\
& \text { compression steel. }
\end{aligned}
$$

\section{c) Reinforcing steel for membrane and moment stress resultants N1, N2, M1 and M2:}

Calculation of the required area of steel to resist the axial and flexural moment stress resultants in the meridional and the circumferential directions were performed following the procedure outlined in Example 17 of the ACI 340-IR-91 [5.6]. For a rectangular section subjected to bending moment, $M_{u}(M 1$ or $M 2)$, and an axial tensile load, $N_{u}(N 1$ or N2), one first transfers the axial force to the tension reinforcement and calculates an adjusted moment $\mathrm{M}_{\mathrm{us}}$ as:

$$
M_{u s}=M_{u}-N_{u}\left(d-\frac{h}{2}\right)
$$

where:

$$
\mathrm{h}=\text { Thickness of concrete section. }
$$

The adjusted moment, $M_{u s}$, is then used to calculate a portion of the required area of steel, $A_{s l}$, assuming a single reinforced concrete section using the following relationship. where:

and

$$
\frac{M_{u s}}{\varphi b d^{2} f_{c}^{\prime}}=\omega(1-0.59 \omega)
$$




$$
\begin{aligned}
& \omega=\rho f_{c}^{\prime} / f_{y} \\
& \rho=A_{s 1} / b d
\end{aligned}
$$

$b=$ Width of the concrete section

$\mathrm{f}_{\mathrm{c}}{ }^{\prime}=$ Concrete compressive strength

If $\mathrm{A}_{\mathrm{s} 1}$ is more than $75 \%$ of the balanced steel area, compression reinforcement is needed.

The required area of steel, $A_{s 2}$, to resist the tensile load, $N_{u}(N 1$ or $N 2)$ is calculated as:

$$
A_{s 2}=\frac{N_{u}}{\phi f_{y}}
$$

These two areas of steel, $A_{s 1}$ and $A_{s 2}$ are then added to calculate the required reinforcing steel to resist the membrane and the moment stress resultants (N1 plus M1 for the meridional steel and $\mathrm{N} 2$ plus $\mathrm{M} 2$ for the circumferential steel). If the adjusted moment, $\mathrm{M}_{\mathrm{us}}$ was negative, the procedure given in flexural Example 18 of Ref. [5.6] was used. In this case, a compression area of steel, $A_{s}$, can be estimated as:

$$
A_{s}^{\prime}=\frac{M_{u s}}{\phi f_{,}\left(d-d^{\prime}\right)}
$$

and a tensile area of steel, $A_{s}$, can also be calculated as:

$$
A_{s}=\frac{N_{u}}{\phi f_{y}}-A_{s}{ }^{\prime}
$$




\section{d) Reinforcement for combined stress resultants}

The required area of steel to resist the combined shell stress resultants was calculated by adding the areas of steel obtained in Steps (a), (b) and (c) above. This approach was utilized to determine the required area of steel on each face at the critical shell sections listed in Fig. 5.9. The results are listed in Table 5.6. Also listed in Table 5.6 is the reinforcement provided by Westinghouse. The provided reinforcement was obtained from Ref. [5.4 (Tables A-1 and A-5)]. The ratio of the provided reinforcement on each face was compared to the calculated area of steel is also given in Table 5.6. Table 5.6 illustrates that there are several sections in the AP600 SBR structure which are inadequate. The discrepancy between Westinghouse provided steel and the steel calculated in this report is because: (1) the Westinghouse design forces and the design forces presented in Table 5.5 result from the different finite element mesh sizes; (2) the conservative assumption described above that the maximum design forces, i.e., N1, M1, N12, M12 and N2, M2, N12, M12 occur at the same azimuth; and (3) Westinghouse distributed the steel equally to each face, rather than providing the calculated areas on the inside and outside sides.

Listed in Table 5.7 is the ratio of the total provided area of steel at each section, i.e., the summation of area of steel on both faces to the total required area of steel at each section. The table illustrates that the provided area of steel per section at all locations except in the circumferential direction in the shield building cylindrical wall (between Elev. 211'-0" and Elev. $241^{\prime}-0^{\prime \prime}$ ) and the lower section of the PCS tank external wall (between Elev. 272'-3" and Elev. $\left.277^{\prime}-3^{\prime \prime}\right)$. This is related to the reasons listed above. 
Table 5.6 Provided and Calculated Area of Steel on each Face of the Critical Section in the Shell

\begin{tabular}{|c|c|c|c|c|c|c|c|c|c|}
\hline \multirow{2}{*}{$\begin{array}{l}\text { Wall } \\
\text { Description }\end{array}$} & \multirow{2}{*}{$\begin{array}{l}\text { Sec. } \\
\text { No. }\end{array}$} & \multirow{2}{*}{$\begin{array}{l}\text { Elev. } \\
\text { Ft. }\end{array}$} & \multirow{2}{*}{$\begin{array}{l}\text { Concrete } \\
\text { thickness } \\
\text { (in.) }\end{array}$} & \multicolumn{3}{|c|}{ Reinforcement Longitudinal } & \multicolumn{3}{|c|}{ Reinforcement Circumferential } \\
\hline & & & & $\begin{array}{l}\text { Provided } \\
\left(\text { in }^{2} / f t\right)\end{array}$ & $\begin{array}{l}\text { Calculated } \\
\left(\mathrm{in}^{2} / \mathrm{ft}\right)\end{array}$ & $\begin{array}{l}\text { Provided } \\
\text { Calculated }\end{array}$ & $\begin{array}{l}\text { Provided } \\
\left(\text { in }^{2} / f t\right)\end{array}$ & $\begin{array}{l}\text { Calculated } \\
\left(\mathrm{in}^{2} / \mathrm{ft}\right)\end{array}$ & $\begin{array}{l}\text { Provided } \\
\text { Calculated }\end{array}$ \\
\hline $\begin{array}{l}\text { Cylindrical } \\
\text { wall }\end{array}$ & 1 & $211 \rightarrow 236$ & 36 & $2 \mathrm{EF}^{(x)}$ & $\begin{array}{l}2.54 \\
1.39\end{array}$ & $\begin{array}{l}.78 \\
1.44\end{array}$ & $\begin{array}{l}3.12 \mathrm{EF}^{(2)} \\
3.12\end{array}$ & $\begin{array}{l}5.2 \\
1.39\end{array}$ & $\begin{array}{l}0.6 \\
2.24\end{array}$ \\
\hline $\begin{array}{l}\text { Cylindrical } \\
\text { wall }\end{array}$ & 2 & $236 \rightarrow 241$ & 36 & $3.56 \mathrm{EF}$ & $\begin{array}{l}3.54 \\
2.32 \\
\end{array}$ & $\begin{array}{l}1.00 \\
1.53 \\
\end{array}$ & $6.06 \mathrm{EF}$ & $\begin{array}{l}7.24 \\
5.74\end{array}$ & $\begin{array}{l}.83 \\
1.06\end{array}$ \\
\hline $\begin{array}{l}\text { Cylindrical } \\
\text { wall } \\
\text { Between air } \\
\text { intakes }\end{array}$ & 3 & $241 \rightarrow 246.5$ & 36 & $4.5 \mathrm{EF}$ & $\begin{array}{l}6.57 \\
1.93\end{array}$ & $\begin{array}{l}0.69 \\
2.33\end{array}$ & $4.8 \mathrm{EF}$ & $\begin{array}{l}5.65 \\
3.93\end{array}$ & $\begin{array}{l}0.85 \\
1.22\end{array}$ \\
\hline $\begin{array}{l}\text { Tension ring } \\
\text { Above air } \\
\text { intakes }\end{array}$ & 4 & $246.5 \rightarrow 250$ & 36 & $3.12 \mathrm{EF}$ & $\begin{array}{l}5.10 \\
2.02\end{array}$ & $\begin{array}{l}1.64 \\
0.65\end{array}$ & $8.83 \mathrm{EF}$ & $\begin{array}{l}9.82 \\
6.71\end{array}$ & $\begin{array}{l}0.90 \\
1.32\end{array}$ \\
\hline $\begin{array}{l}\text { Conical roof } \\
\text { External to } \\
\text { PCS tank }\end{array}$ & 5 & $260 \rightarrow 264.5$ & 18 & $2.28 \mathrm{EF}$ & $\begin{array}{l}2.56 \\
.89\end{array}$ & $\begin{array}{l}0.89 \\
2.56\end{array}$ & $4.0 \mathrm{EF}$ & $\begin{array}{l}4.93 \\
2.92\end{array}$ & $\begin{array}{l}0.81 \\
1.37\end{array}$ \\
\hline $\begin{array}{l}\text { Conical roof } \\
\text { Internal to } \\
\text { PCS tank }\end{array}$ & $\overline{6}$ & $277.2 \rightarrow 282.2$ & 18 & $1.7 \mathrm{EF}$ & $\begin{array}{l}2.03 \\
.56\end{array}$ & $\begin{array}{l}.84 \\
3.04\end{array}$ & $2.79 \mathrm{EF}$ & $\begin{array}{l}2.37 \\
0.56\end{array}$ & $\begin{array}{l}1.17 \\
5.0\end{array}$ \\
\hline $\begin{array}{l}\text { PCS tank } \\
\text { Internal wall } \\
\text { lower section }\end{array}$ & 8 & $287.2 \rightarrow 292.2$ & 24 & $1.46 \mathrm{EF}$ & $\begin{array}{l}1.18 \\
0.39\end{array}$ & $\begin{array}{l}1.23 \\
3.74\end{array}$ & $1.2 \mathrm{EF}$ & $\begin{array}{l}1.35 \\
0.50\end{array}$ & $\begin{array}{l}0.89 \\
2.40\end{array}$ \\
\hline $\begin{array}{l}\text { PCS tank } \\
\text { external wall } \\
\text { lower section }\end{array}$ & 8 & $272.2 \rightarrow 277.2$ & 24 & $3.36 \mathrm{EF}$ & $\begin{array}{l}2.94 \\
1.45\end{array}$ & $\begin{array}{l}1.14 \\
2.32\end{array}$ & $2.37 \mathrm{EF}$ & $\begin{array}{l}3.64 \\
1.45\end{array}$ & $\begin{array}{l}0.65 \\
1.63\end{array}$ \\
\hline
\end{tabular}

(a) $\mathrm{EF}=$ each face 
Table 5.7 Provided and Calculated Total Area of Steel at Each Critical Section in the Shell

\begin{tabular}{|c|c|c|c|c|c|c|c|c|c|}
\hline \multirow{2}{*}{$\begin{array}{l}\text { Wall } \\
\text { Description }\end{array}$} & \multirow{2}{*}{$\begin{array}{l}\text { Sec. } \\
\text { No. }\end{array}$} & \multirow{2}{*}{$\begin{array}{l}\text { Elev. } \\
\text { Ft. }\end{array}$} & \multirow{2}{*}{$\begin{array}{l}\text { Concrete } \\
\text { thickness } \\
\text { (in.) }\end{array}$} & \multicolumn{3}{|c|}{ Reinforcement Longitudinal } & \multicolumn{3}{|c|}{ Reinforcement Circumferential } \\
\hline & & & & $\begin{array}{l}\text { Provided } \\
\left(\mathrm{in}^{2} / \mathrm{ft}\right)\end{array}$ & \begin{tabular}{|l} 
Calculated \\
(in $\left.{ }^{2} / f t\right)$
\end{tabular} & $\begin{array}{l}\text { Provided } \\
\text { Calculated }\end{array}$ & $\begin{array}{l}\text { Provided } \\
\left(\mathrm{in}^{2} / \mathrm{ft}\right)\end{array}$ & $\begin{array}{l}\text { Calculated } \\
\left(\text { (in }^{2} / f \mathrm{t}\right)\end{array}$ & $\begin{array}{l}\text { Provided } \\
\text { Calculated }\end{array}$ \\
\hline $\begin{array}{l}\text { Cylindrical } \\
\text { Wall }\end{array}$ & 1 & $211 \rightarrow 236$ & 36 & 4 & 3.93 & 1.02 & 6.24 & 6.59 & .95 \\
\hline $\begin{array}{l}\text { Cylindrical } \\
\text { wall } \\
\end{array}$ & 2 & $236 \rightarrow 241$ & 36 & 7.12 & 5.86 & 1.22 & 12.12 & 12.98 & .93 \\
\hline $\begin{array}{l}\text { Cylindrical } \\
\text { wall } \\
\text { Between air } \\
\text { intakes }\end{array}$ & 3 & $241 \rightarrow 246.5$ & 36 & 9 & 8.5 & 1.06 & 9.6 & 9.58 & 1.00 \\
\hline $\begin{array}{l}\text { Tension ring } \\
\text { Above air } \\
\text { intakes }\end{array}$ & 4 & $246.5 \rightarrow 250$ & 36 & 7.12 & 6.24 & 1.14 & 17.66 & 16.53 & 1.07 \\
\hline $\begin{array}{l}\text { Conical roof } \\
\text { External to } \\
\text { PCS tank }\end{array}$ & 5 & $260-264.5$ & 18 & 4.56 & 3.45 & 1.32 & 8 & 7.85 & 1.02 \\
\hline $\begin{array}{l}\text { Conical roof } \\
\text { Internal to } \\
\text { PCS tank }\end{array}$ & 6 & $277.2 \rightarrow 282.2$ & 18 & 3.4 & 2.59 & 1.31 & 5.58 & 2.93 & 1.9 \\
\hline $\begin{array}{l}\text { PCS tank } \\
\text { Internal wall } \\
\text { lower } \\
\text { section } \\
\end{array}$ & 8 & $287.2 \rightarrow 292.2$ & 24 & 2.92 & 1.57 & 1.86 & 2.4 & 1.85 & 1.30 \\
\hline $\begin{array}{l}\text { PCS tank } \\
\text { external wall } \\
\text { lower } \\
\text { section } \\
\end{array}$ & 8 & $272.2 \rightarrow 277.2$ & 24 & 6.72 & 4.39 & 1.53 & 4.74 & 5.09 & 0.93 \\
\hline
\end{tabular}




\subsubsection{Reinforcement for Composite Precast T-Beam Units}

The design moment, $\mathrm{M}$, and axial force, $\mathrm{N}$ for the precast $\mathrm{T}$-beam units with the cast in place concrete roof, were calculated near Elev. 273'-0" using a procedure similar to that in Sec. 3.2.2. An enveloping design moment of $1195 \mathrm{ft}-\mathrm{k}$ and a compressive axial load of 560 kips were calculated for Load Combination 2. The T-section was taken to consist of the pre-cast concrete beam units acting compositely with the cast-in place 18 in. concrete roof. The design forces in conjunction with an effective flange width for the T-section determined following the rules outlined in the ACI 349-90 [5.2] were used to check the adequacy of the provided area of steel. The calculations demonstrated that these T-beams were adequately designed.

\subsubsection{Reinforcement of the Tension Ring Above the Air Intakes}

The tension ring is subjected to axial forces, $N$, biaxial flexural moments, $M_{x}$ and $M_{z}$, shear forces $Q_{x}$ and $Q_{z}$ and a torsional moment, $T$ (see Fig. 3.8). The design procedure for beams under combined axial load, torsion, shear and moment requires providing stirrups and longitudinal reinforcement to resist the shear and torsional forces [5.2 (Section 11.6.7)]. Section 11.6.4 of Ref. [5.2] requires that sections located less than one depth of the beam from the face of the support may be designed for the same shear and torsional moment as that computed at this location. The calculated longitudinal steel is in addition to the steel required to resist the axial load and flexural moments. This approach was utilized herein to calculate the reinforcement for the compression ring and the portion of the tension ring above the air intakes. Only the forces induced in these rings due to Load Combination 2 were utilized. The design adequacy of the reinforcing steel in the portion of the tension ring between the air intakes was checked in Sec. 5.4.2 (see Section 4) Tables 5.6 and 5.7). 
Torsional moment at sections located one depth from the edges of the openings were calculated. The maximum of these was $110 \mathrm{k}-\mathrm{ft}$ and occurred at $26 \mathrm{deg}$ Azimuth. This was used in conjunction with the moments and the shear forces listed in Table 5.3 to check the adequacy of the tension ring. Calculations were carried out to determine the required area of stirrups to resist the shear forces, $Q_{\chi}$ and $Q_{L}$, and the torsion, $T$ [5.2 (Section 11.6.7)]. Also, calculations were performed to calculate the required longitudinal steel, $A_{1}$ for torsion. This amount of steel was subtracted from the longitudinal reinforcement provided by Westinghouse [5.4]. The remaining area of steel was used to check the adequacy of the ring to withstand the biaxial maximum $M_{x}$, $\mathrm{M}_{\mathrm{y}}$ and $\mathrm{N}$ using the PCACOL software [5.8]. Figure 5.9 shows the interaction diagrams for the tension ring.

The calculation performed herein demonstrated that the tension was adequately designed. The design point, indicated by the number 1 , are within the limiting interaction curve.

\subsubsection{Reinforcement for the Compression Ring}

In a manner similar to Section 5.4.4, the reinforcing steel in the compression ring described in Section 3.2.2 and Figure 3.7 was analyzed for the forces in Table 5.4. The design for this compression ring was found to be adequate (see the interaction diagram in Fig. 5.10).

However, high forces occur in the thickened conical shell, i.e., at the junction between the compression ring and the conical roof (see Fig. 5.12) slab just outside the compression ring (in particular N2 and M2). The high forces are due, principally, to the thermal loading condition 
distribution in the vicinity of the compression ring as explained in Sec. 3.5. Tension and compression forces are introduced into the compression ring by a temperature decrease (Figure 3.40) and increase (Figure 3.49), respectively. Because of a ring effect, meridional stress resultants at the conical shell/compression ring interface are resisted by large circumferential forces and moments in the compression ring. The reinforcement that is provided in this thickened portion is not adequate if it is analyzed by the procedures in Section 5.4.2.

In effect, the thickened portion of the conical shell acts as part of the compression ring and a more realistic temperature distribution than that used in Sec. 3.5 needs to be considered. To account for this, a new compression ring (Compression Ring 2) was identified which included the prior compression ring and the thickened portion of the conical shell, as illustrated in Figure 5.10. The thermal analyses given in Sections 3.5.1 and 3.5.2 were repeated considering a linear temperature distribution through the thickened portion of the conical roof. This was then used to define the temperature variation on the exposed portion of the compression ring. Hence, this compression ring does not have a uniform temperature, as assumed in the first analysis. The member forces for Compression Ring 2 were then computed using the new analyses results following Equation 3.1 and the design values are summarized in Table 5.8 (similar to Table 5.4 for the original compression ring). The reinforcing steel for Compression Ring 2 was analyzed similarly to the tension ring (see Sec. 5.4.4). The interaction diagram in Figure 5.13 shows that the reinforcement is adequate. 
Table 5.8 Maximum and Minimum Member Forces - Compression Ring 2

\begin{tabular}{|c|c|c|c|c|c|c|}
\hline Force & $\begin{array}{l}\text { Axial-N } \\
\text { (kips) }\end{array}$ & $\begin{array}{l}\text { Shear-Q } \\
\text { (kips) }\end{array}$ & $\begin{array}{l}\text { Shear- } Q_{x} \\
\text { (kips) }\end{array}$ & $\begin{array}{l}\text { Moment-M } \\
(\mathrm{k}-\mathrm{ft})\end{array}$ & $\begin{array}{l}\text { Moment-M } \\
\text { (k-ft) }\end{array}$ & $\begin{array}{l}\text { Torque-T } \\
(\mathrm{k}-\mathrm{ft})\end{array}$ \\
\hline Maximum & 821 & 660 & 216 & 535 & 1268 & 230 \\
\hline Minimum & -2157 & -568 & -32 & 60 & -2837 & -202 \\
\hline
\end{tabular}

\section{$5.4 \quad$ References}

5.1 U.S. NRC Standard Review Plan (SRP), Section 3.8.4 - Other Seismic Category I Structures, NUREG-0800, 1981.

5.2 ACI Manual of Concrete Practice-Part 4, Code Requirements for Nuclear Safety Related Concrete Structures (ACI 349-90), American Concrete Institute, Farmington Hills, MI 48333, 1996.

5.3 U.S. NRC, Westinghouse, Ames Laboratory Staff Meeting, Monroeville, PA, Dec. 10-11, 1996.

5.4 Shield Building Roof Structures, Table A-1 and Table A-5, Appendix A, Document No. 1200-S3R-001, Draft 1996.

5.5 ACI 318-89 (Revised 1992)-Building Code Requirements for Reinforced Concrete, American Concrete Institute, Detroit, MI 48333, 1992.

5.6 ACI 340.IR-91, Design Handbook In Accordance with the Strength Design Method of ACI 318-89, Vol. 1- Beams, one-way Slabs, Brackets, Footing, and pile Caps, Publication SP-17 (91), Detroit, MI48219.

5.7 Westinghouse Electric Corporation, Shield Building Roof Concrete Reinforcement Transversal Section, AP600 Doc. No. 1277-CR-902, 1996.

5.8 PCACOL - Design and Investigation of Reinforced Concrete Column Sections, Version 2.3, Portland Cement Association, Skokie, IL, 1993. 


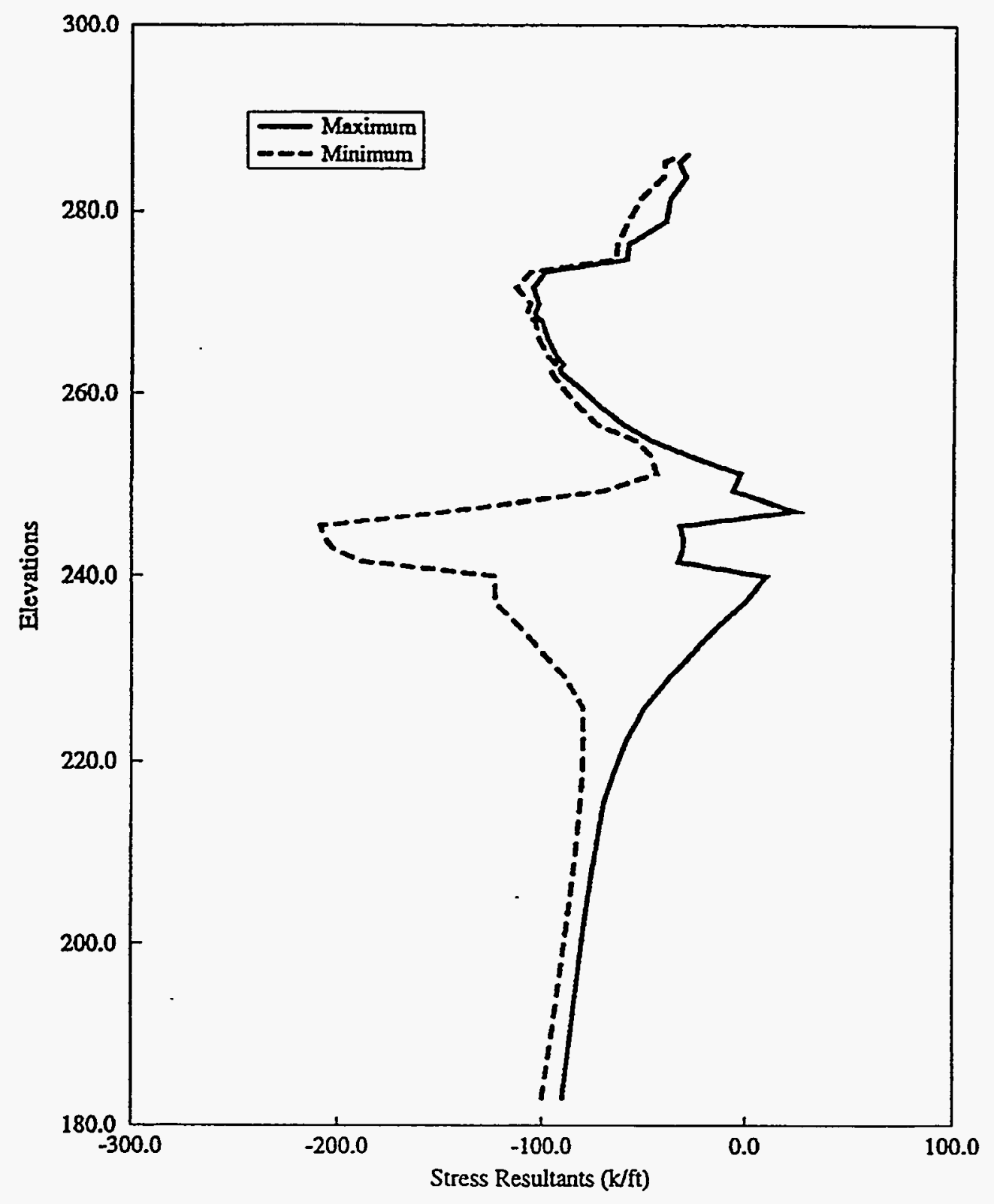

Figure 5.1 Envelopes of Meridional Stress Resultants, N1, for Load Combination 1 


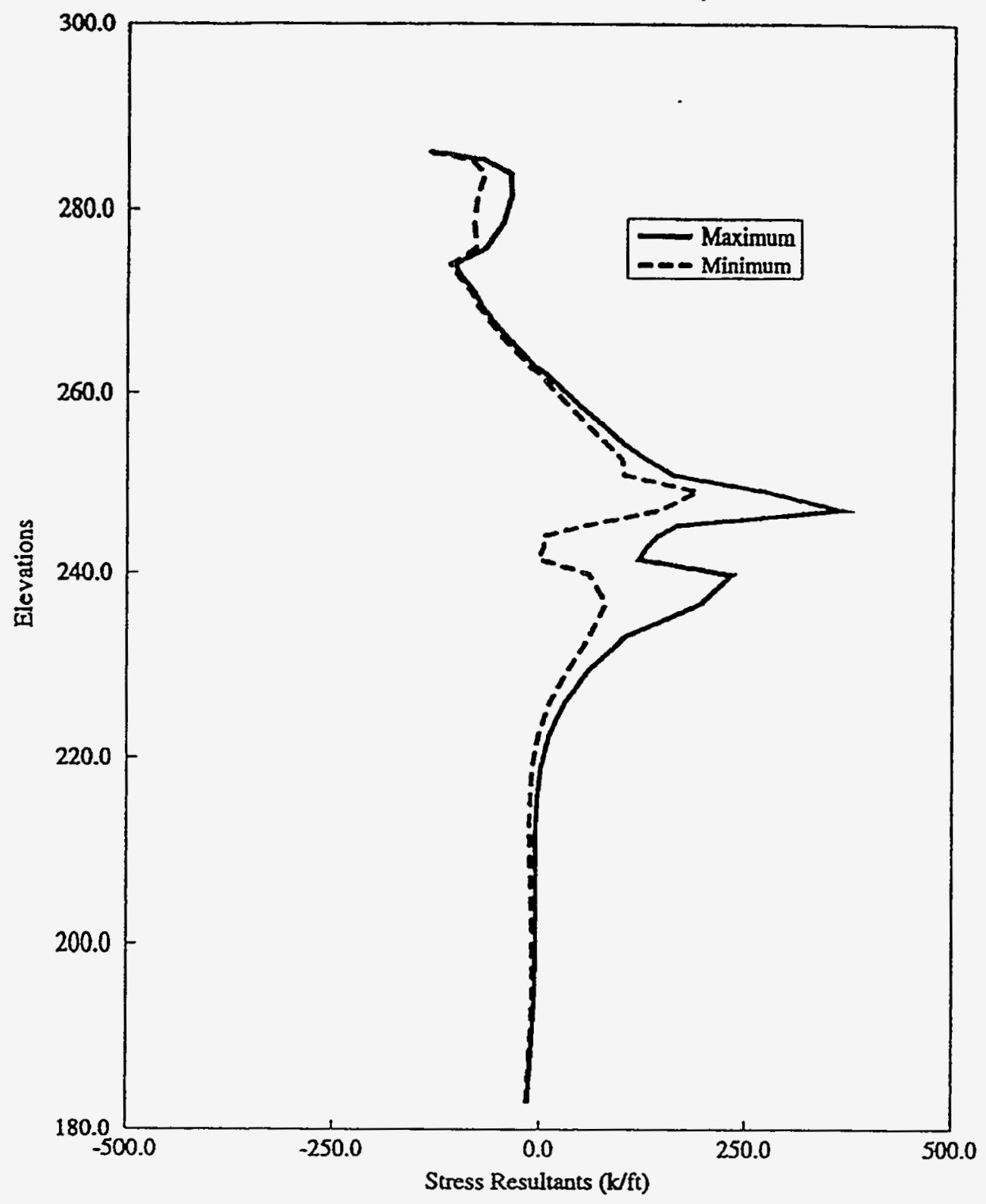

Figure 5.2 Envelopes of Circumferential Stress Resultants, N2, for Load Combination 1 


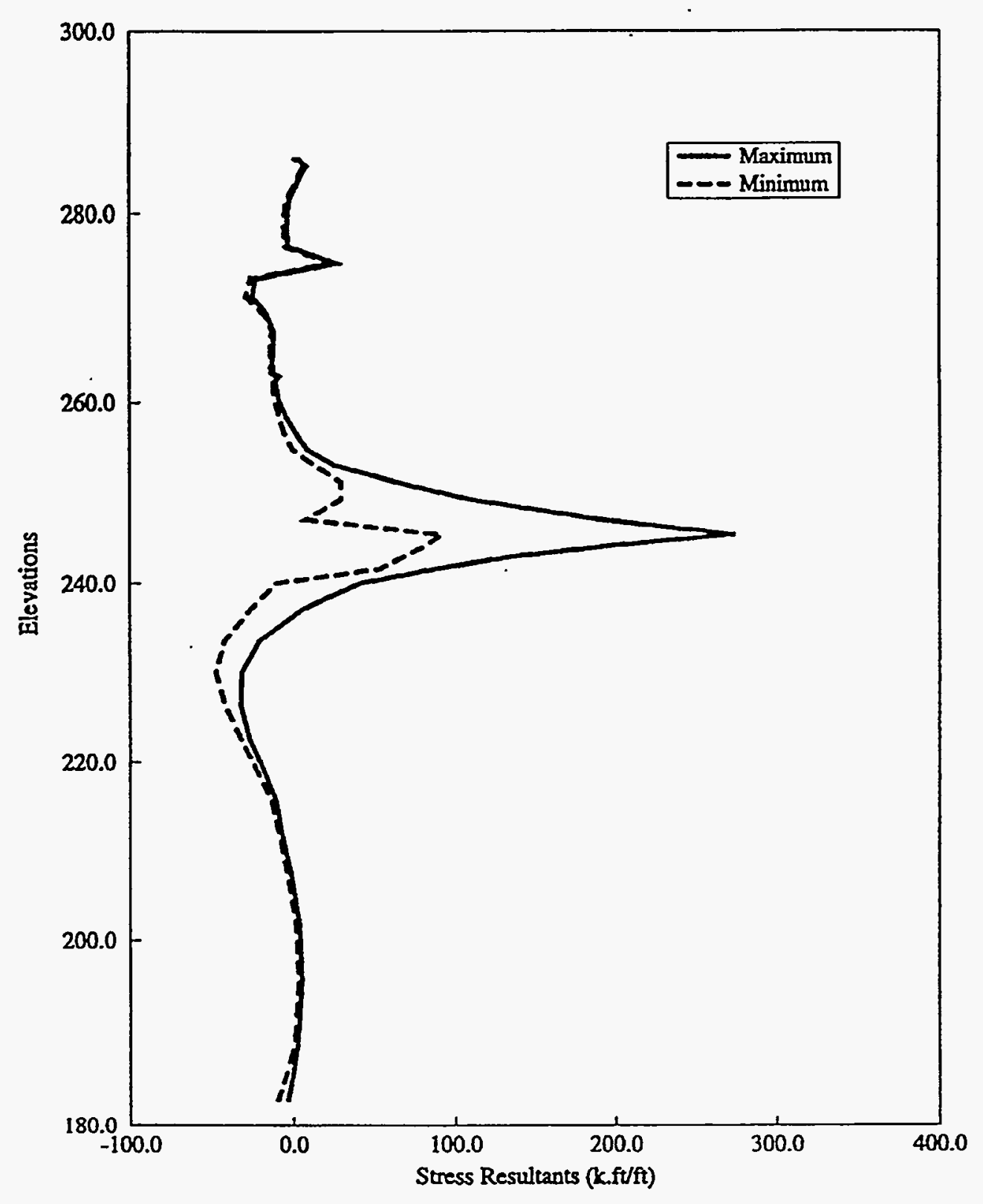

Figure 5.3 Envelopes of Meridional Moment Stress Resultants, M1, for Load Combination 1 


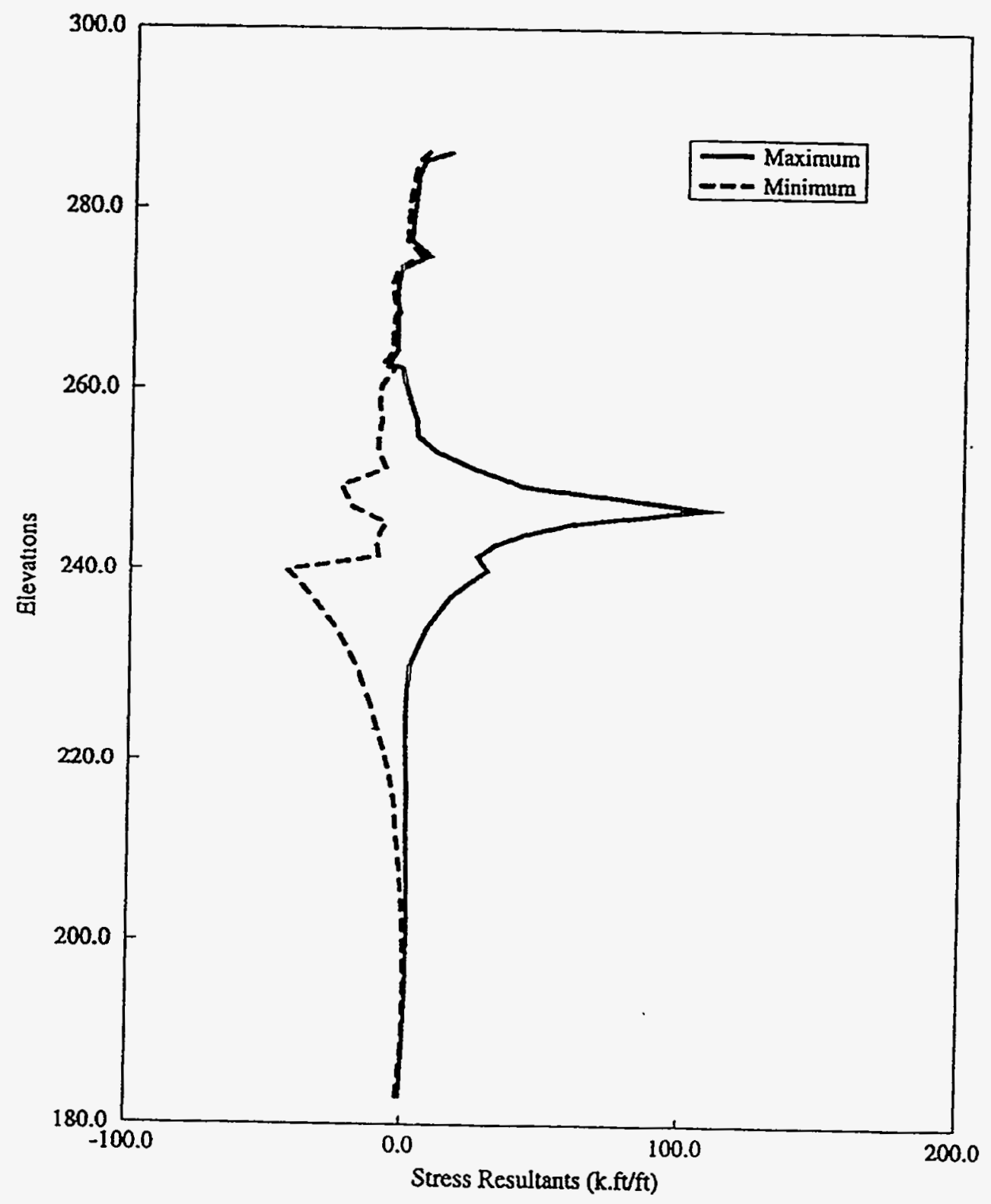

Figure 5.4 Envelopes of Circumferential Moment Stress Resultants, M2, for Load Combination 1 


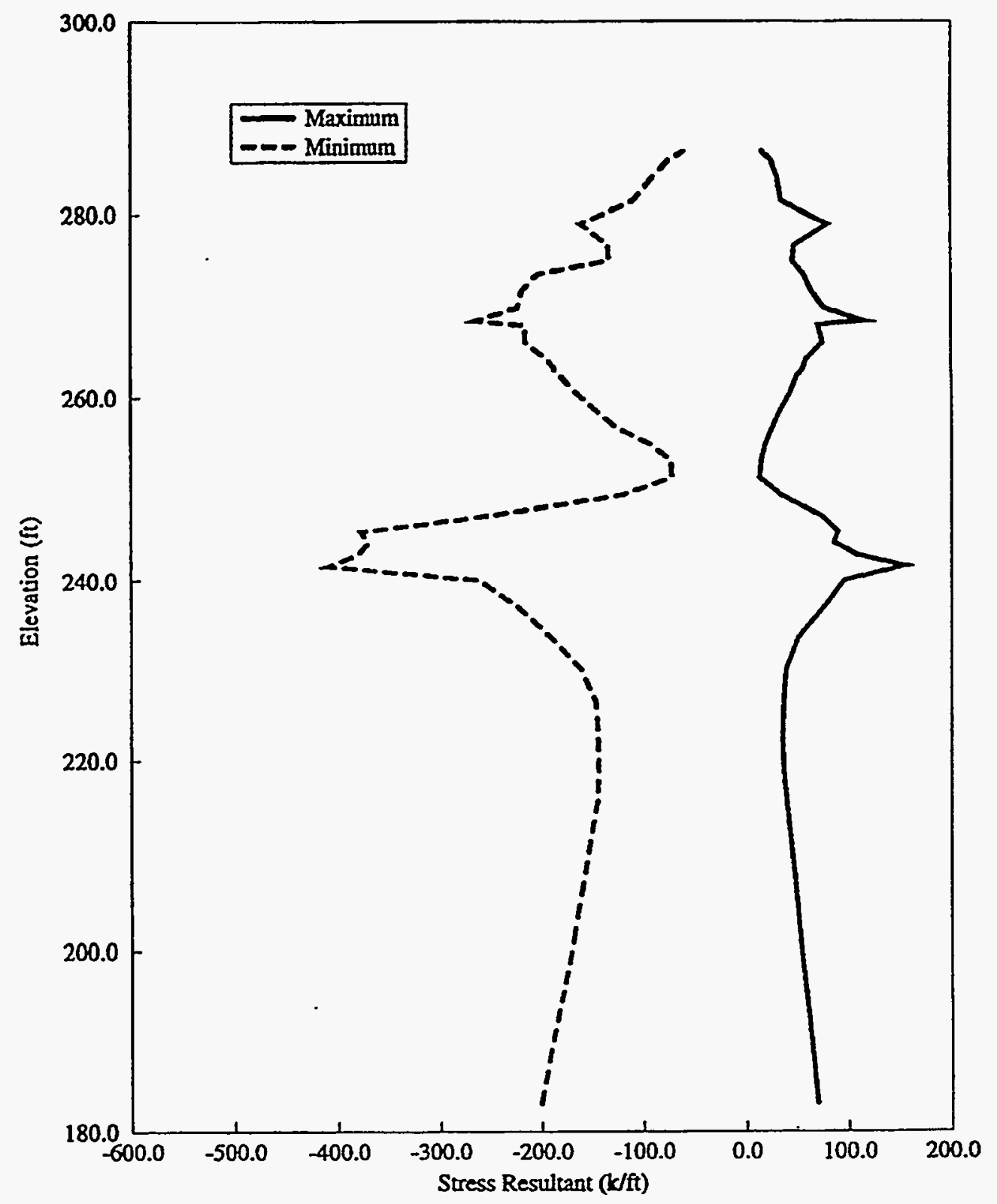

Figure 5.5 Envelopes of Meridional Stress Resultants, N1, for Load Combination 2 


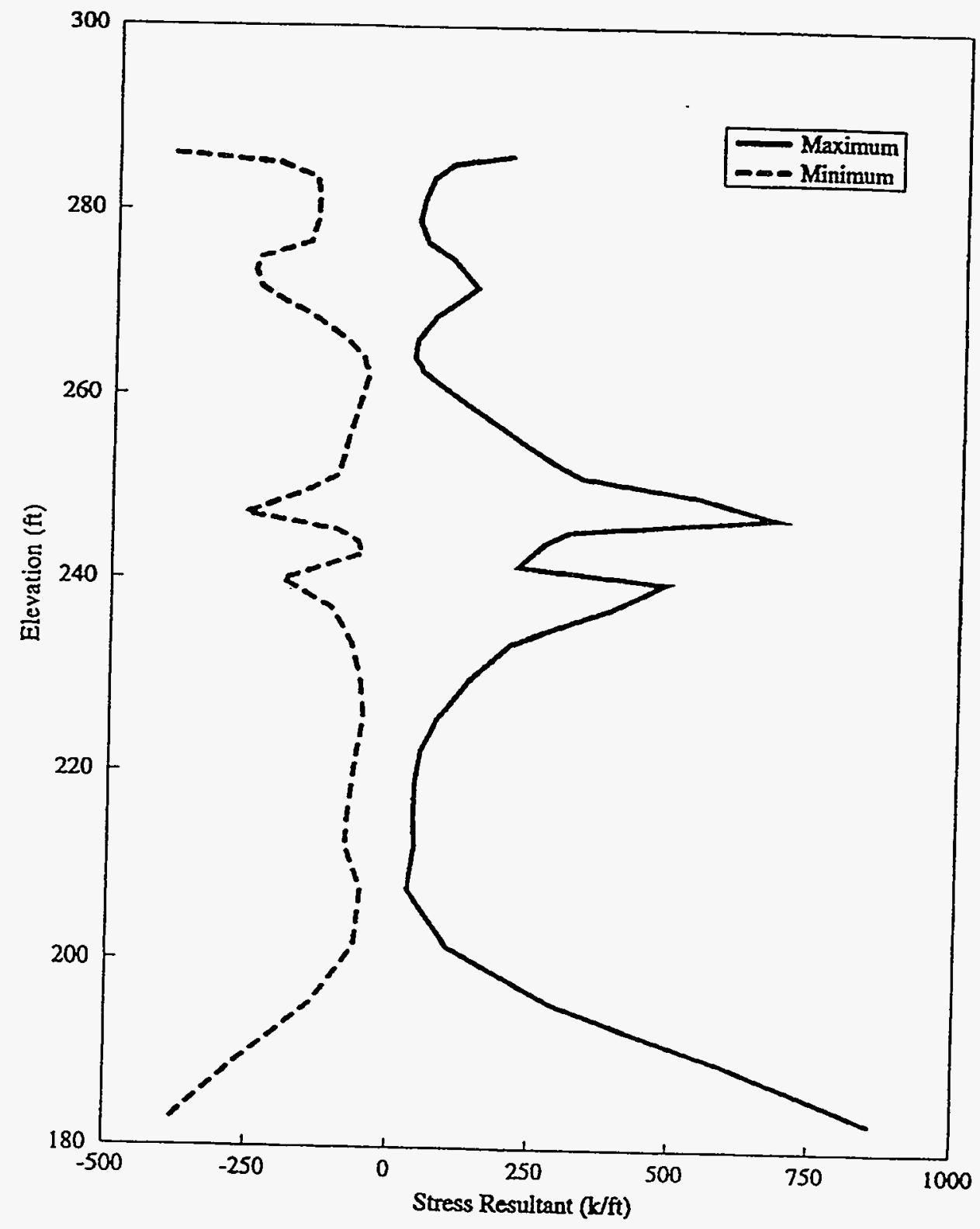

Figure 5.6 Envelopes of Circumferential Stress Resultants, N2, for Load Combination 2 


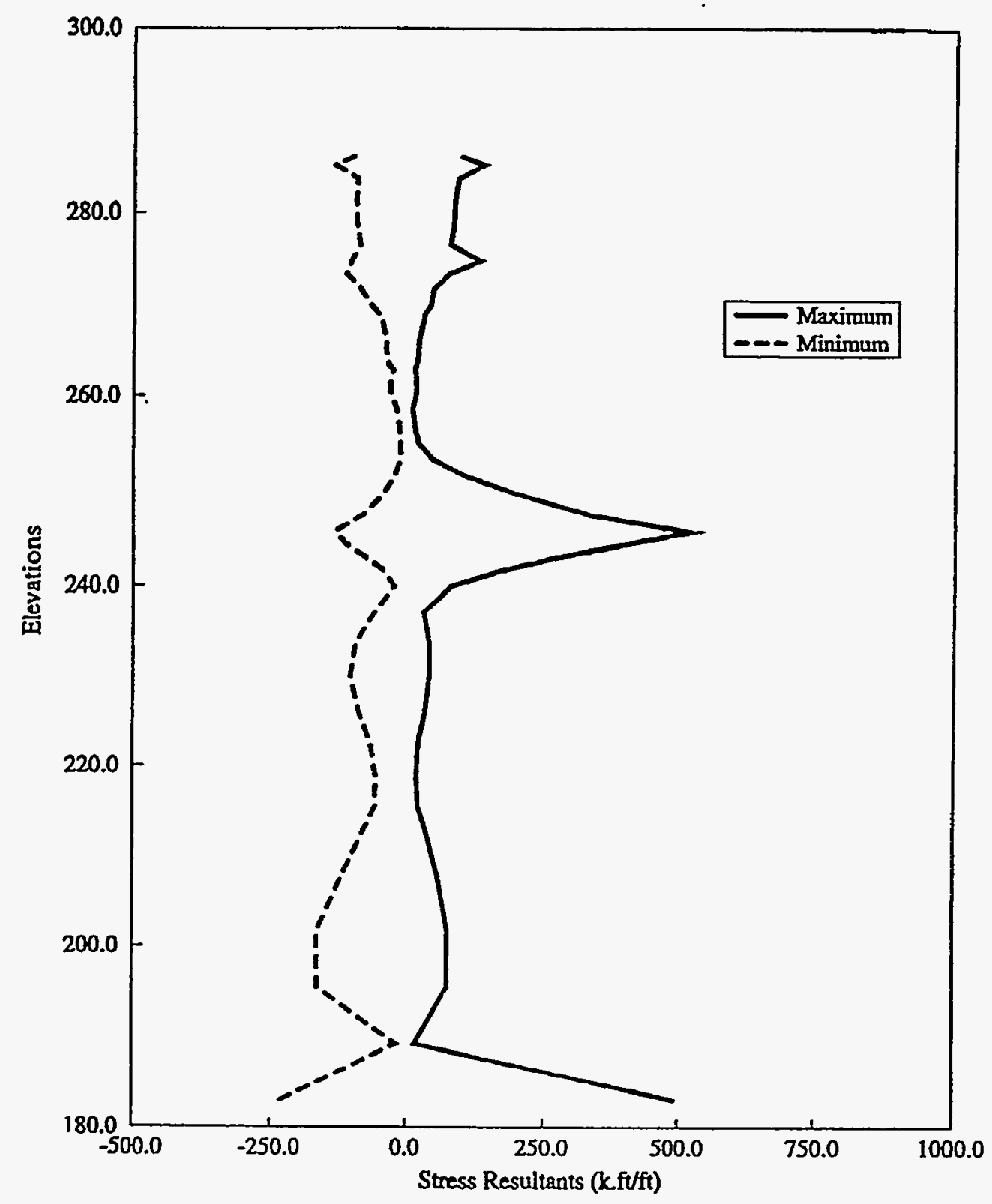

Figure 5.7 Envelopes of Meridional Moment Stress Resultants, M1, for Load Combination 2 


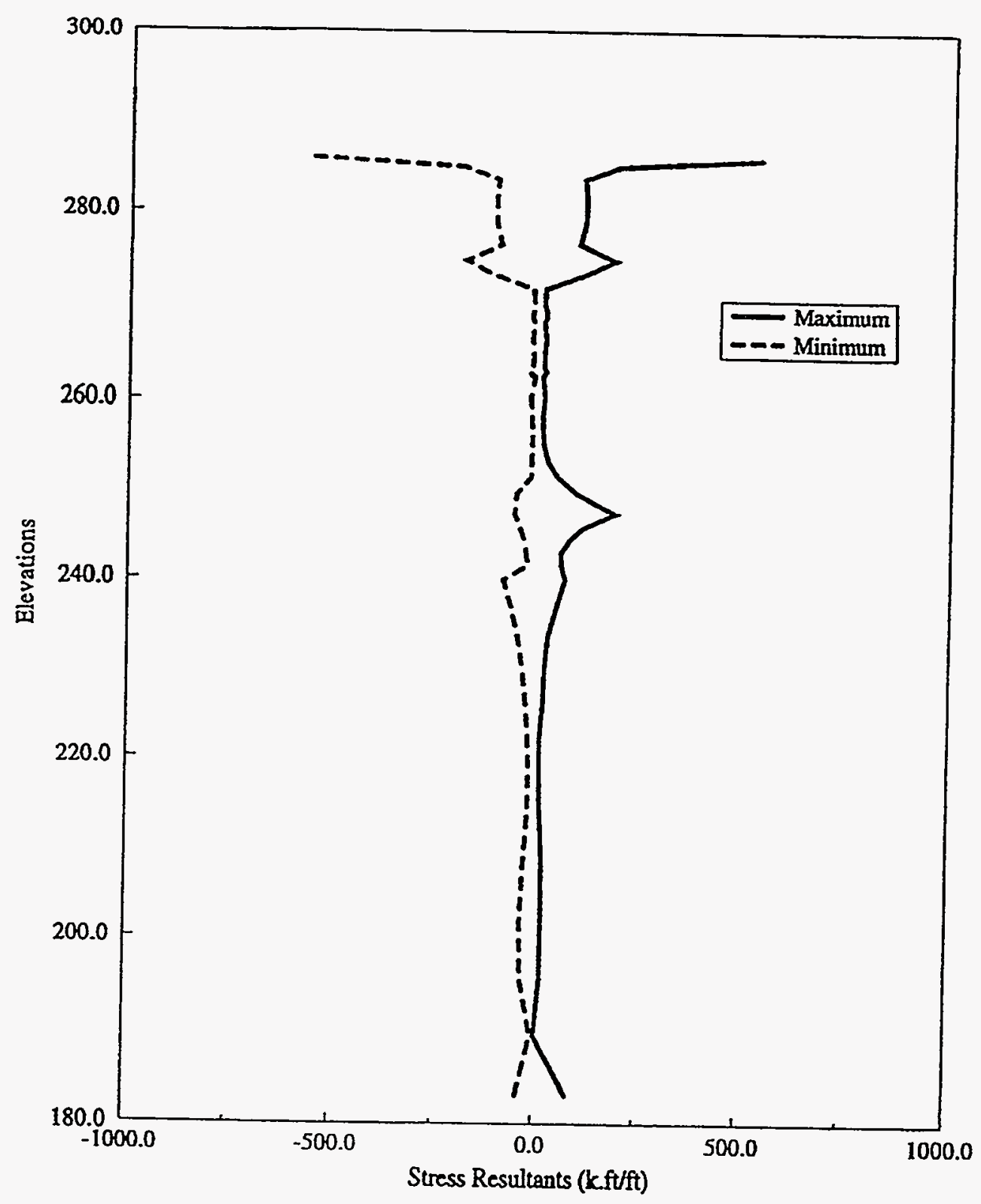

Figure 5.8 Envelopes of Circumferential Moment Stress Resultants, M2, for Load Combination 2 


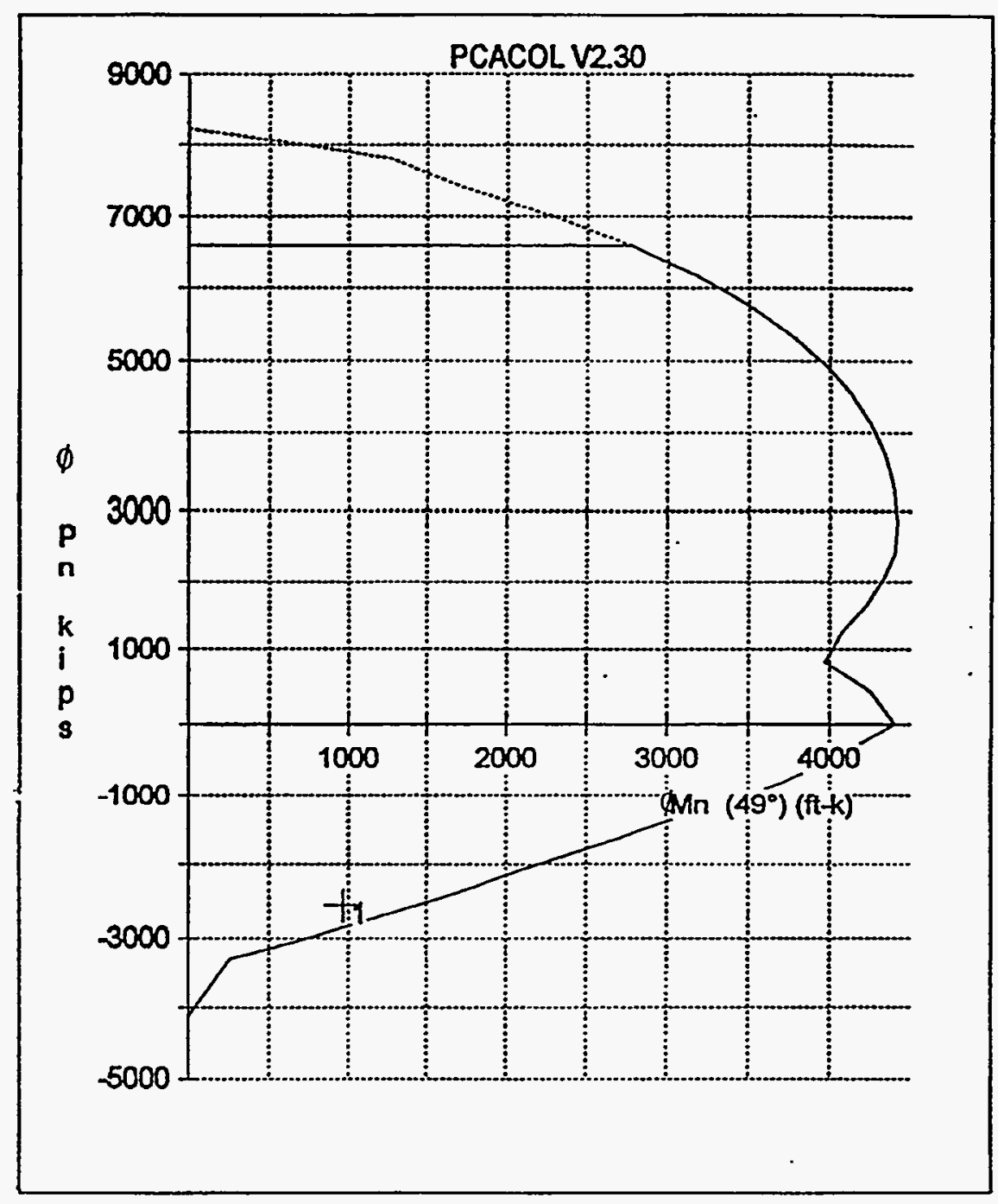

Figure 5.9 Interaction Diagram for the Tension Ring Above Two Air Intakes 


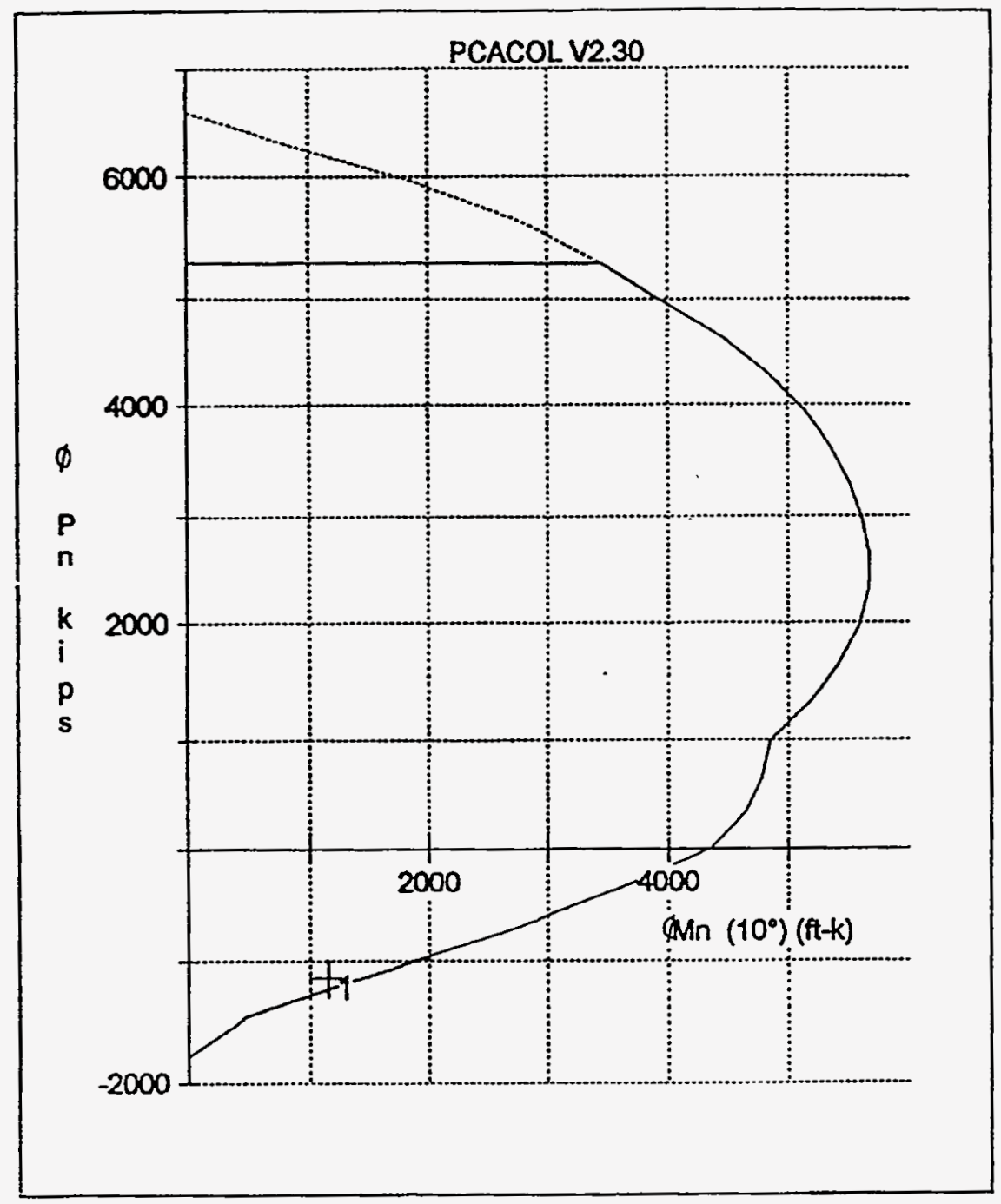

Figure 5.10 Interaction Diagram for the Compression Ring 


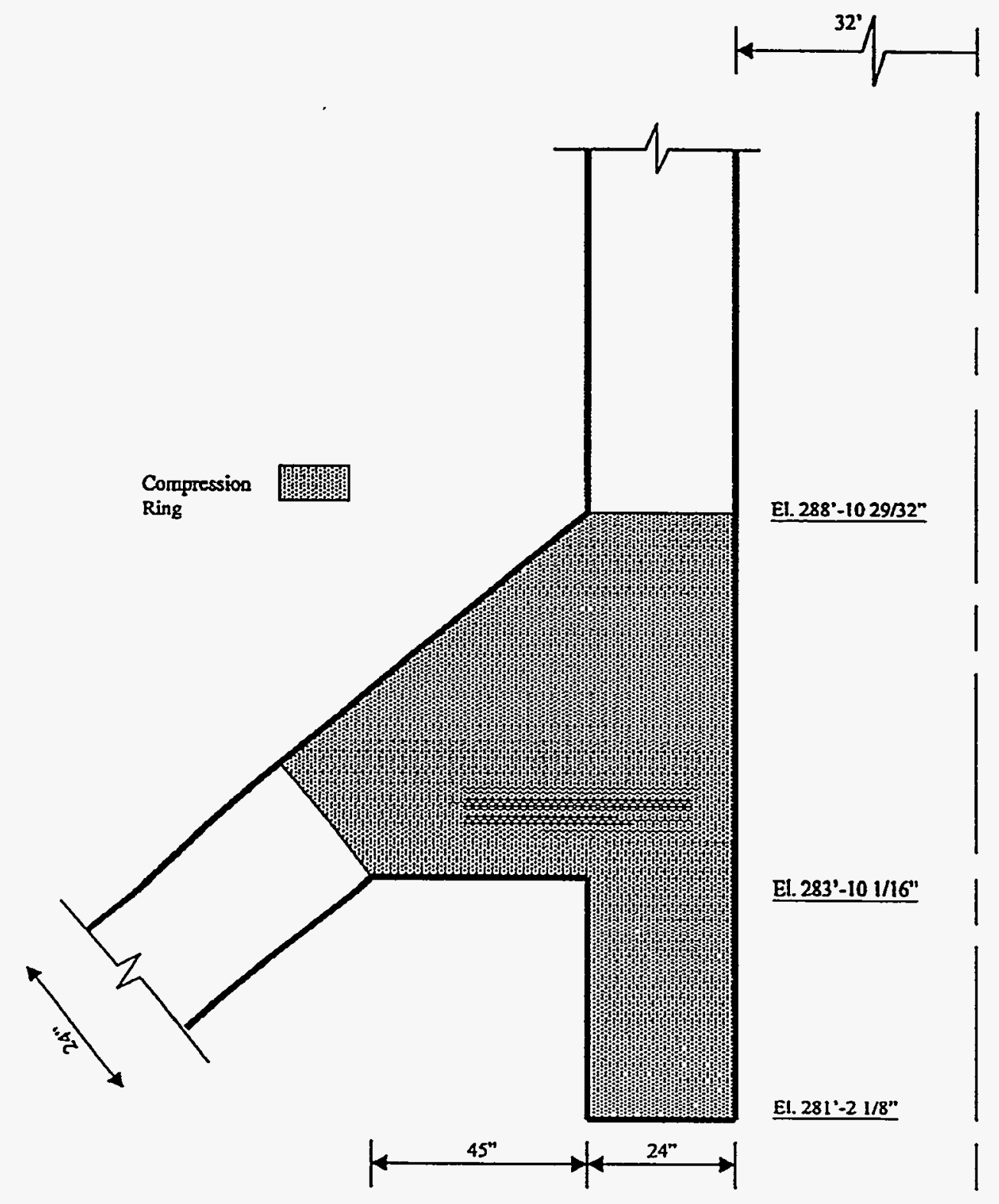

Figure 5.11 Compression Ring Including the Thickened Portion of the Conical Shell. 


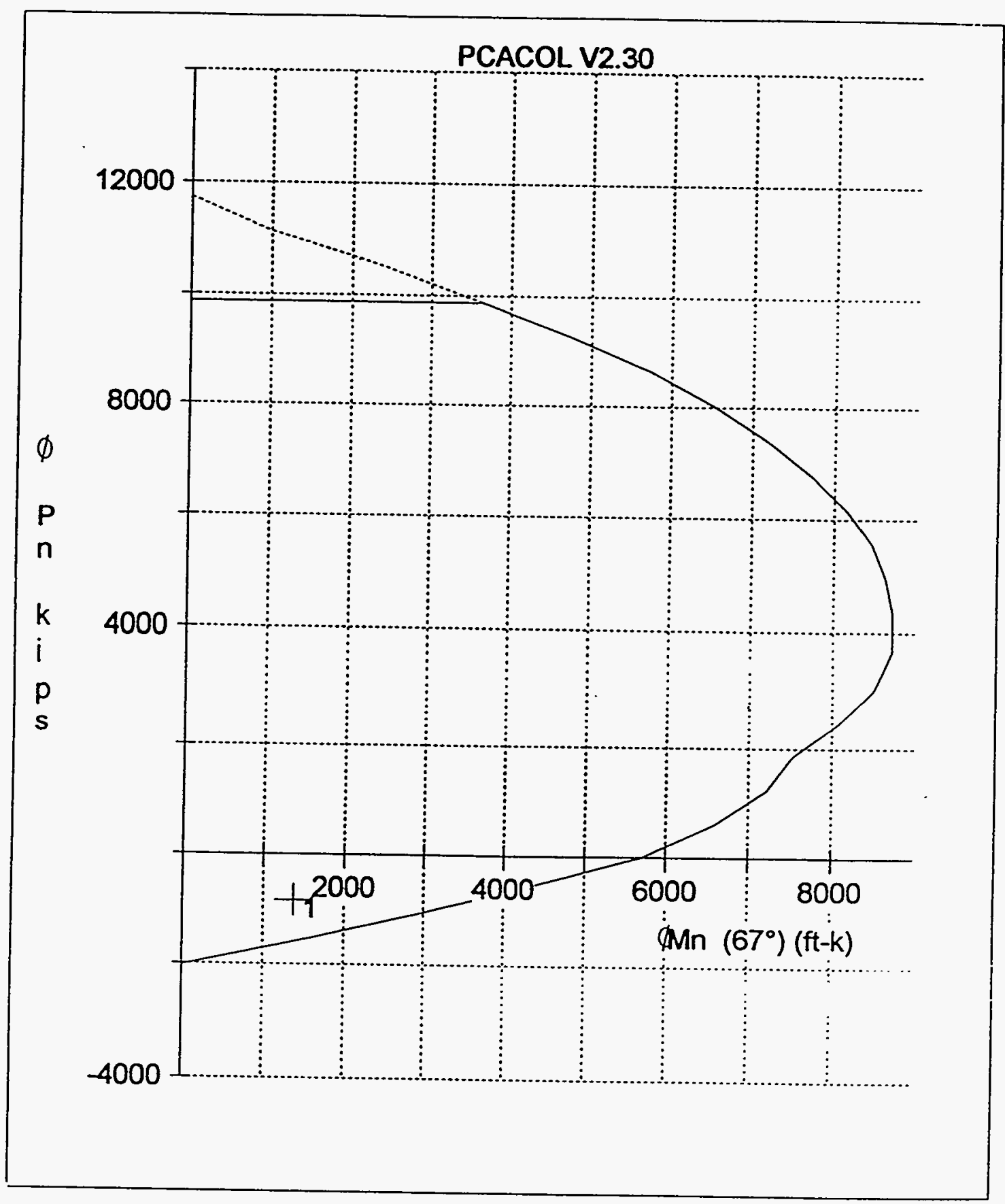

Figure 5.12 Interaction Diagram for the Compression Ring in Fig. 5.11 


\section{APPENDIX A \\ CAPABILITIES OF THE ANSYS PROGRAM IN FLUID AND FLUID STRUCTURE- INTERACTION PROBLEMS}

\section{A.1 Introduction}

The current release of the ANSYS general purpose computer program for finite element analysis is Revision 5.3. In this appendix, the various types of fluid elements in ANSYS general purpose computer program for finite element analysis are introduced with special focus on the types that may be used in problems of fluid-structure interaction. Four problems were solved using ANSYS and compared to the available theoretical solutions to verify the program in the field of fluid analysis. These problems are: (1) acoustic and sloshing modes of water in a rectangular container having rigid walls; (2) sloshing modes of water in an annular tank with rigid walls; (3) harmonic excitation of a fluid column supported on a spring; and (4) response of an elevated tank using the response spectrum method.

\section{A.2 Fluid Elements in ANSYS}

\section{A.2.1 Acoustics}

Acoustics is the study of generation, propagation, absorption and reflection of pressure waves in the fluid medium. An acoustic analysis usually involves modeling the fluid medium and part of the surrounding structure. The analysis is coupled if the fluid-structure interaction at the interface is taken into account or uncoupled if only the fluid is modeled and any fluid-structure 
interaction is ignored. Acoustic elements provided in ANSYS are FLUID29 and FLUID30. FLUID29 is a two-dimensional, four-noded element, but FLUID30 is a three-dimensional, eightnoded element. These elements may be used to model fluid medium and the interface in the fluid-structure interaction problems. The elements have pressure and transitional degrees of freedom at each node. The transitional degrees of freedom are activated only at the nodes on the interface with structural elements. The formulation of these elements is based on the wave equation [A.1], [A.2], [A.3]. The main assumptions are: the fluid is inviscid but compressible; the velocity is small compared to the sound velocity in the fluid; and the change in pressure is small compared to the mean pressure (at rest pressure). The formulation of these elements takes into account the coupling of acoustic pressure and the structural motion at the interface. Figure A.1 shows both FLUID29 and FLUID30.

\section{A.2.2 Contained Fluid}

A second type of fluid elements in ANSYS is the contained fluid which treats the fluid as if it were a solid with special material proprieties. The elements in this type are displacement-based elements with translations as degrees of freedom. The elements are used to model fluid having no net flow. The sloshing stiffness is included in the element formulation by introducing springs at the free surface of the fluid [A.1]. The fluid compressibility and viscosity are also included. The basic equations governing material properties for the element stiffness and damping matrices are [A.1],

$$
\varepsilon_{\text {bulk }}=\mathrm{p} / \mathrm{K}
$$




$$
\dot{\gamma}=\frac{1}{\mu} \tau
$$

where $\varepsilon_{\text {bulk }}=$ volumetric strain $=\frac{\partial u_{x}}{\partial x}+\frac{\partial u_{y}}{\partial y}+\frac{\partial u_{z}}{\partial z}, u_{x}, u_{y}, u_{z}=$ displacements in the

$\mathrm{x}, \mathrm{y}$ and $\mathrm{z}$ respectively,

$$
\mathrm{p} \text { = pressure, }
$$

$K$ = bulk modulus of the fluid,

$\dot{\gamma}=$ rate of shear strain,

$\tau \quad=$ shear stress, and

$\mu=$ viscosity of the fluid.

The element is given a very small value of shear stiffness (1E-9 times the bulk modulus) to avoid a singular stiffness matrix. Using the contained fluid elements, with or without structural elements, produces symmetric stiffness and mass matrices. The two-dimensional version of these elements is called FLUID79, and the three-dimensional is called FLUID80. Both FLUID79 and FLUT80 elements are shown in Fig. A.2.

\section{A.3 Acoustic and Sloshing Modes of Water in a Rigid Container}

Fluids inside rigid containers have two distinct types of free of vibrations: acoustic modes in which the particles of the fluid vibrate around the equilibrium position due to pressure change and sloshing modes in which standing waves are forming at the free surface of the fluid. In acoustic modes, the waves propagate due to the fluid compressibility. In sloshing modes, however, no change in volume of the fluid occurs. In the following, the natural frequencies, 
associated with both modes, are obtained using the finite element analysis and verified using the theory.

\section{A.3.1 Acoustic Modes of a Fluid-Filled Cavity}

The theoretical solution for finding the frequencies and the corresponding pressure distribution for the acoustic modes of water in a fluid filled cavity can be found in [A.5]. The finite element model is the water-filled, 120 inches square cavity shown in Fig. A.3. Water was modeled using the four-noded acoustic elements, FLUID29. The value of the bulk modulus, $K$, was 316,000 $\mathrm{lb} / \mathrm{in}^{2}$ and the density, $\rho$, was $9.35 \times 10^{-5} \mathrm{lb}^{2} \mathrm{~s}^{2} / \mathrm{in}^{4}$. The displacement normal to the vertical sides as well as that normal to the base were set equal to zero and the dynamic pressure was set to zero at the free surface. The natural frequencies of the first three modes were computed and are compared to the theoretical values in Table A.1. Figure A.4 shows the dynamic pressure contour plot associated with the these modes. Comparisons of the pressure distribution from the closed form solution and dynamic pressure distribution indicate full agreement between the finite element results and theory.

The same finite element model illustrated in Fig. A.3 was used except that the FLUID29 elements were replaced by the contained fluid elements, FLUID79. The subspace iteration method was used to obtain the modes of vibration. The finite element solution predicted the mode frequencies and mode shapes accurately (Table A.1). Figure A.5 shows the displaced shape as well as the dynamic pressure predicted by the finite element analysis for the first three modes. 


\section{A.3.2 Sloshing Modes of Water in Rectangular Tanks}

An example with water in a rectangular tank demonstrates the ability of ANSYS to formulate the stiffness, slosh and mass matrices of a fluid medium. The theoretical solution for sloshing modes in deep tanks is presented in [A.5]. The finite element model of the water in a two-dimensional rigid container 120 inches wide and 120 inches deep is the same as shown in Fig. A.3. The water was modeled using several FLUID79 elements (i.e., using two-dimensional four-noded contained fluid elements). Displacements normal to vertical edges and to the base were prevented. The bulk modulus, the mass density and the gravity acceleration were given in Sec. A.3.1. Table A.2 lists the natural frequencies of the first three sloshing modes computed by [A.5] and by the finite element method. Figure A.6 shows the displaced shape and the dynamic pressure contour plots for the first three modes.

Circulation modes [A.1], [A.4] were produced (about one mode per each unrestrained node) with frequencies much lower than that of the first sloshing mode. However, circulation modes are not associated with any change in the surface level or in the element volume. The number of vertical degrees of freedom at the surface controls the number of sloshing modes. In this analysis, sixty three circulation modes were obtained with frequencies lower than $0.05 \mathrm{~Hz}$. Eight sloshing modes were obtained in the range of frequencies from $0.5 \mathrm{~Hz}$ to $1.2 \mathrm{~Hz}$. After the sloshing modes, the sub-space iteration solution next converged to the acoustic modes with frequencies starting around $120 \mathrm{~Hz}$ (see Sec. 3.1). To avoid calculation time obtaining circulation modes, other mode extraction methods may be used instead of the subspace iteration method (see Chapter 3). If additional sloshing modes are required, the number of the surface degrees of freedom should be increased. 
In order to compare the dynamic pressure obtained by the finite element method and theory, the inertia forces $\left\{F_{1}\right\}$ corresponding to mode one were applied to the model to produce an amplitude, $A_{l}$, of 10 inches, where

$$
\left\{F_{1}\right\}=\omega_{1}^{2}[M]\left\{\phi_{1}\right\}
$$

where $\omega_{1}=$ circular natural frequency,

$\left\{\phi_{1}\right\}=$ modal displacement vector, and

[M] = mass matrix of the structure.

The resulting dynamic pressure was plotted in Fig. A.7. Figure A.8 shows a comparison between the dynamic pressure distribution from [A.5] and ANSYS at the vertical walls. Excellent agreement was obtained between the theoretical and finite element results.

\section{A.4 Sloshing Modes of Water in Annular Tank}

An annular tank example is used to show the capabilities of ANSYS to solve for sloshing modes in a three-dimensional problem. The assumption used for calculating the natural frequencies and modes of vibration are [A.6]: (1) the flow of water is incompressible; (2) the water is invisicid; and (3) water is acted only by its own weight. The natural frequencies for water filling an annular tank as shown in Fig. A.9 are given as,

$$
\begin{gathered}
\mathrm{f}_{\mathrm{ij}}=\frac{1}{2 \pi}\left(\frac{\lambda_{\mathrm{ij}}}{\mathrm{R}_{1}} \tanh \lambda_{\mathrm{ij}} \frac{\mathrm{h}}{\mathrm{R}_{1}}\right) \\
\mathrm{P}=\operatorname{Ag} \rho \frac{\cosh \mathrm{m}(\mathrm{h}+\mathrm{z})}{\cosh \mathrm{mh}} \tilde{\phi} \cos \left(\omega_{\mathrm{ij}} \mathrm{t}+\psi_{\mathrm{ij}}\right)
\end{gathered}
$$


in which $\tilde{\phi}=Y_{i}\left(\lambda_{i j}\right) J_{i}\left(\lambda_{i j} \frac{r}{R_{1}}\right)-J_{i}^{\prime}\left(\lambda_{i j}\right) Y_{i j}\left(\lambda_{i j} \frac{r}{R_{1}}\right) \cos (i \theta)$,

where $\mathrm{i}=$ number of half sin waves in the tangential direction,

$\mathrm{j}=$ number of half $\sin$ waves in the radial direction,

$\mathrm{m}=$ wave number,

$\mathrm{h}=$ the height of the tank,

$\mathrm{z}=$ distance normal to the mean surface (positive are upwards),

$\mathrm{R}_{\mathbf{l}}=$ outer radius,

$\mathrm{J}_{\mathrm{i}}=$ Bessel function of the first kind and $\mathrm{i}$ order, and

$Y_{\mathfrak{i}}=$ Bessel function of the second kind and $i$ order.

Fig. A.10 shows the finite element model used for the annular tank filled with water. The inner radius was 216 inches, the outer radius was 456 inches, and the height was 204 inches. The material properties are the same as described in Sec. A.3.1. The boundary conditions are as follows: at the vertical edges, the radial displacements were prevented; whereas the vertical displacements were prevented at the base. There were 650 circulation modes with frequencies less than $0.03 \mathrm{~Hz}$. the first sloshing mode frequency was $0.307 \mathrm{~Hz}$. Table A.3 shows a comparison among the first six frequencies obtained by the theory and the finite element solution. The table indicated a very good agreement between the results. The displaced shape in modes $1(\mathrm{i}=1, \mathrm{j}=0), 2(\mathrm{i}=2, \mathrm{j}=0)$ and $5(\mathrm{i}=0, \mathrm{j}=1)$ as well as the dynamic pressure distributions are plotted in Figs A.11, A.13. The modal frequencies as well as the mode shapes obtained by ANSYS are in a very good agreement with the theory. 


\section{A.5 Harmonic Excitation of a Fluid Column Supported by a Spring}

To verify that ANSYS has the ability to solve fluid-structure interaction dynamic problems, a fluid column supporting column is analyzed. In this example, a fluid column supported by a rigid massless plate and a grounded spring was subjected to harmonic excitation (see Fig. A.14a). Two configurations were solved: (a) a plate attached to a spring with $\mathrm{K}$, equals $0.001 \%$ of the fluid column axial stiffness, $\mathrm{K}_{\mathrm{f}}$ (weak spring); and (b) a plate attached to a stiff spring with $\mathrm{K}$ equals $10 \%$ of $\mathrm{K}_{\mathrm{f}}$ (shift spring). The exciting frequency was, in both cases, equal to the natural frequency of the fluid column.

\section{A.5.1 Approximate Theoretical Solution}

The problem was approximated as shown in Fig. A.14-b. In this figure, the mass of the fluid column is lumped at the rigid plate position, Point (B). The axial stiffness of the fluid column was represented by a spring of equivalent stiffness, $\mathrm{K}_{\mathrm{f}}$. An exciting sinusoidal displacement was applied to Point (A) with circular frequency $\Omega$ equals to the fundamental frequency of the fluid column and an amplitude of 0.1 inches. The equilibrium equation is,

$$
\begin{gathered}
\dot{m}_{1}+\left(\mathrm{K}_{\mathrm{f}}+\mathrm{K}\right) \mathrm{x}_{1}=0.1 \mathrm{~K}_{\mathrm{f}} \sin \Omega \mathrm{t} \\
\Omega=\sqrt{\frac{\mathrm{K}_{\mathrm{f}}}{\mathrm{m}}}
\end{gathered}
$$


where $\bar{x}_{1}=$ acceleration of the rigid plate (lumped mass),

$x_{1}=$ displacement of the plate.

Eq. A.6 may be solved for the force in the grounded spring [A.7],

$$
F_{s}=\frac{0.1 K_{f}}{\left(K+K_{f}\right)\left[1-\left(\frac{\Omega}{\omega}\right)^{2}\right]}\left(\sin \omega t-\frac{\Omega}{\omega} \sin \Omega t\right)
$$

where

$$
\omega=\sqrt{\frac{K+K_{\mathrm{f}}}{\mathrm{m}}}
$$

If the stiffness of the spring is very small with respect to that of the fluid column, resonance occurs and the displacement of the plate and consequently the force in the spring increases dramatically (Case a). Increasing the stiffness of the spring causes the rigid plate to oscillate with a frequency higher than that of the resonance and the force in the spring is bounded (Case b).

\section{A.5.2 Finite Element Using Acoustic Elements}

Fig. A.14-c shows the finite element model of the fluid column, supporting plate and spring. The fluid column is of height 10 inches with a unit square cross section. It was modeled using the eight-noded acoustic element, FLUID30 (Acoustic 30) the rigid plate was modeled using the four-noded shell element, SHELL63, and the fluid-structure interaction flag was activated at the interface. The plate was attached to a two-noded spring element LINK 8 . The bulk modulus was $16000 \mathrm{lb} / \mathrm{in}^{2}$. The density was $0.001 \mathrm{lb} \cdot \mathrm{s}^{2} / \mathrm{in}^{4}$. The calculated fundamental frequency of the fluid column was $100 \mathrm{~Hz}$. The forcing function was defined as,

$$
\mathrm{X}_{\mathrm{f}}=0.1 \sin 200 \pi \mathrm{t}
$$

A transient dynamic analysis was performed with a time step equal to $6.25 \times 10^{-4} \mathrm{sec}$ to determine the response. The problem was solved twice: (a) spring constant, $K$, equals to $0.16 \mathrm{lb} / \mathrm{in}$. and (b) 
spring constant, $K$, equals to $1600 \mathrm{lb} / \mathrm{in}$. The associated r.m.s. wavefront [A.1] of the stiffness matrix for the solution was 34.6. Figure A.15 shows the displaced structure and the pressure distribution at a time of 0.009 second for both Cases $a$ and $b$.

\section{A.5.3 Finite Element Using Contained Fluid Elements}

The same model, materials, and forcing function were used except that the acoustic elements were replaced by the eight-noded containing fluid elements, FLUID80 (Mack80). The r.m.s. wavefront associated with the solution was 24.2. Figure A.16 shows the pressure distribution and the displaced structure at time 0.0096 seconds for Case a.

Figures A.17 and A.18 show comparisons between the grounded spring force obtained with the approximate theoretical solution, the acoustic elements and the contained fluid elements. From the figures, it can be concluded that the finite element solution correctly predicts the response of the fluid-structure system to dynamic loading in both cases. Both acoustic and contained fluid elements give excellent results. However, the associated wavefront and, consequently, the solution time for the contained fluid are lower than that of the acoustic elements.

\section{A.6 Response of Elevated Tank to EI-Centro Earthquake}

The purpose of the next example is to verify the ability of ANSYS to solve for the forces and displacements in a fluid container excited by an earthquake. The modal characteristics, the mode shapes and frequencies of an elevated tank filled with water and supported by a column (Fig. A.19) were determined. These characteristics were utilized to solve for the response of the tank 
to the El-Centro earthquake using the response spectra technique provided in ANSYS. The results of the analysis were compared to a simplified theoretical solution.

\section{A.6.1 Simplified Theoretical Solution}

The precise procedure to determine the seismically induced fluid pressure developed in a tank and, hence, the force acting on the tank and it supporting elements is complex. A method was developed to simplify the calculations [A.8]. This method applies to flat-bottom, vertically oriented tanks of circular or rectangular cross section. In this method, the tank walls and floors are assumed to be rigid. The fluid weight, $\mathrm{W}$, which is accelerated in the horizontal direction, is divided into two portions (see Fig. A.20). Part One, $\mathrm{W}_{0}$, remains in rigid contact with the tank walls. Consequently this mass exerts a maximum horizontal force directly proportional to the maximum horizontal acceleration of the tank wall and bottom. Part Two, $\mathrm{W}_{1}$, behaves as if it were a solid oscillating mass connected to the walls with a spring $K_{1}$. Part Two causes additional dynamic pressure on the wall and the bottom. The method in [A.8] gives simplified procedures to calculate the weights $W_{0}$ and $W_{1}$ as well as their locations and the effective elastic link constant $\mathrm{K}_{\mathbf{l}}$.

\section{A.6.2 Finite Element Analysis Using Contained Fluid Elements}

Figure A.21 shows the finite element idealization of the water, tank and the supporting column. Water was idealized using the four noded, two-dimensional contained fluid elements, FLUD79. The tank and the column were modeled using the two-dimensional, two-noded beam elements, BEAM3. The bulk modulus was $316,000 \mathrm{lb} / \mathrm{in}^{2}$ and the density was $9.25 \mathrm{lb} . \mathrm{s}^{2} / \mathrm{in}$. The stiffness 
of the column was $5000 \mathrm{lb} / \mathrm{in}$. A relatively high stiffness was given to the tank walls and floor to approximate rigidity. The dimensions are shown in Fig. A.20 and the width was taken as $1 \mathrm{ft}$. The column height was $69 \mathrm{ft}$. The simplified solution was obtained for this problem using the procedure described in [A.8]. Figure A.22 shows the first two sloshing modes as well as the fundamental bending mode from the ANSYS analysis. Table A.4 lists the frequencies obtained from both the simplified theory and the finite element results. It should be noted that the simplified theory gives only the first sloshing and bending frequencies. Good agreement was obtained between the results.

The response spectrum of the El-Centro earthquake was input into ANSYS for different damping ratios. The response spectrum analysis was conducted twice: Case (a) only the fundamental sloshing and bending modes were included (for direct comparison with the theoretical solution) and Case (b) the first ten modes were included. The damping ratio for the fundamental sloshing frequency was $0.5 \%$ and that of the fundamental bending mode was $2 \%$. The results were combined using the SRSS method. Figure A.23 shows the displaced shape of the tank and water as a result of using the SRSS method (Case (a)). In Table A.5, comparisons between the maximum horizontal displacement of the tank, maximum vertical displacement of the water, and maximum shear and moment at the base of the supporting column are presented for the simplified theory. Case (a) results compared well to the simplified theory. However, the Case (b) result shows that the simplified theory and Case (a) yield slightly non-conservative results because higher modes are neglected. 


\section{A.7 Summary and Conclusion}

In this appendix, the various types of fluid elements provided in ANSYS were introduced. Two types, the acoustic elements and the contained fluid elements, may be used in fluid-structure interaction problems. Dynamic and vibration problems that include fluid-structure interaction were solved using ANSYS. The ability of ANSYS to compute modes of vibration of a fluid medium were checked by solving two problems: sloshing and acoustic modes of water in a rigid container and sloshing modes of water in annular tanks. The modal frequencies and pressure distribution showed excellent agreement with those calculated by the theory. A third problem (harmonic excitation of a fluid column supported by a spring) showed that ANSYS correctly predicted the dynamic response of a structure in contact with a fluid medium. Results of both the acoustic and contained fluid elements showed excellent agreement with that of the theory. The last problem was the response of an elevated filled tank to the El-Centro earthquake. The bending moments and shearing forces in the supporting column calculated using ANSYS compared well to those predicted by the simplified theory.

In conclusion, the four problems confirmed the applicability of ANSYS to fluid-structure interaction problems. Either contained fluid elements or acoustic elements may be used in such an analysis. However, the use of the contained fluid elements is preferred. 


\section{A.8 References}

A.1. Swanson Analysis Systems, Inc., ANSYS User's Manual, Houston, PA., 1993.

A.2. White, F. M., Fluid Mechanics, McGraw Hill, First Edition, New York, 1979.

A.3. Park, K. C., Felippa, C. A., Recent Developments in Coupled Field Analysis Methods, in Numerical Methods in Coupled Systems, John Wiley and Sons, New York, 1984, pp.327351.

A.4. Cook, R. D., Malkus, D. S. and Plesha, M. E., Concepts and Application of Finite Element Analysis, John Wiley and Sons, Third Edition, New York, 1989.

A.5. Belgians, R. D., Formulas for Natural Frequency and Mode Shape, Van Norstrand Reinhold, New York, 1979.

A.6. Eagleson, P. S., Dean, R. G., Small Amplitude Wave Theory, in Esturay and Coastline Hydrodynamics, McGraw Hill, New York, 1966, pp. 1-92.

A.7. Chopra, A. K., Dynamics of Structures, Prentice Hall, First Edition, New Jersey, 1995.

A.8. Liu, L. K., "Seismic Analysis of Boiling Water Reactor," First National Congress on Pressure Vessels and Piping Technology, San Francisco, California, May 1971. 

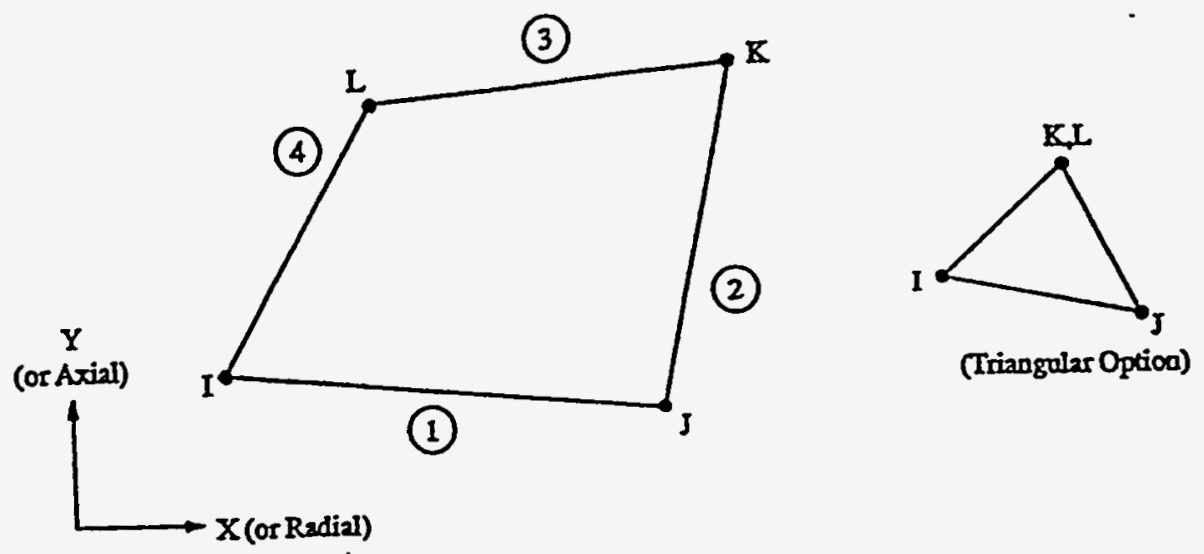

FLUW29 2-D Acoustic Fluid
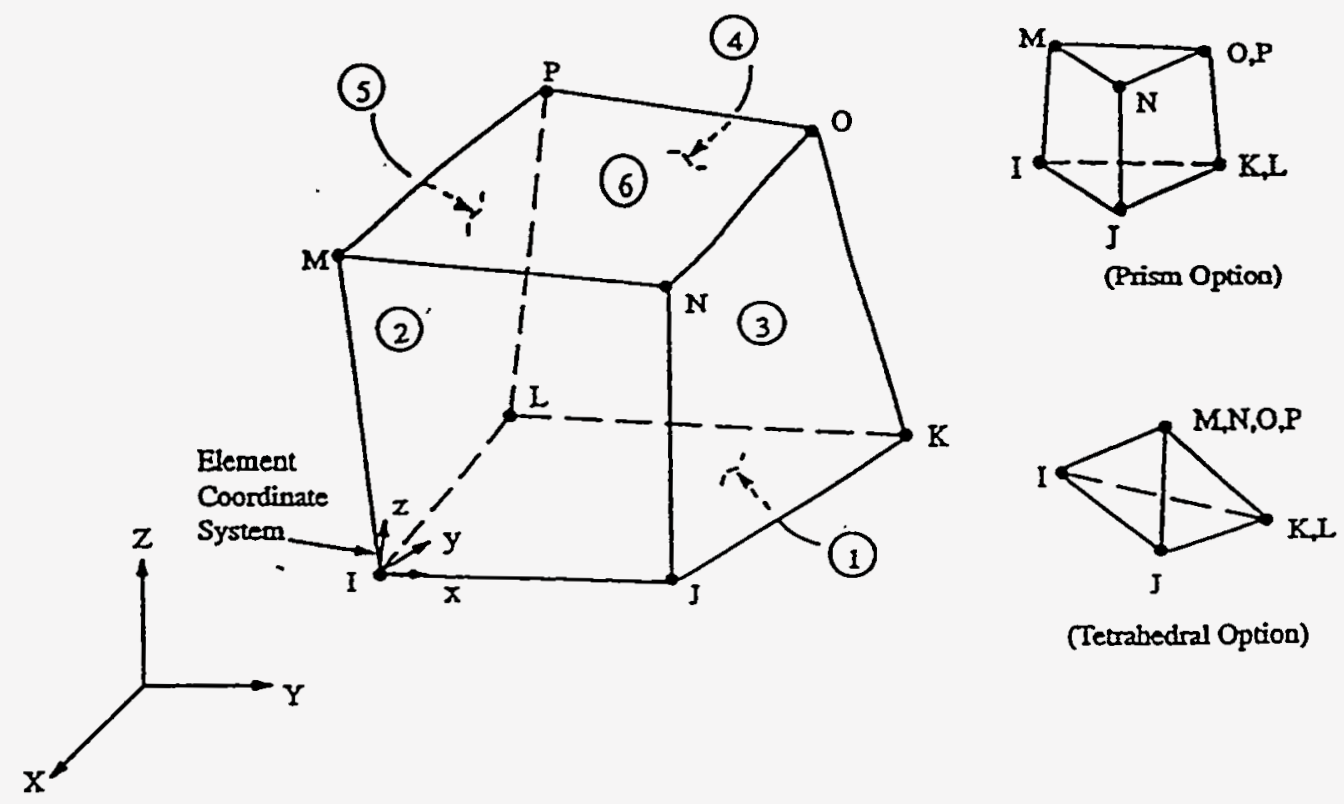

(Tetrabedral Opcion)

FLUID30 3-D Acoustic Fluid

Figure A.1 Acoustic Elements 


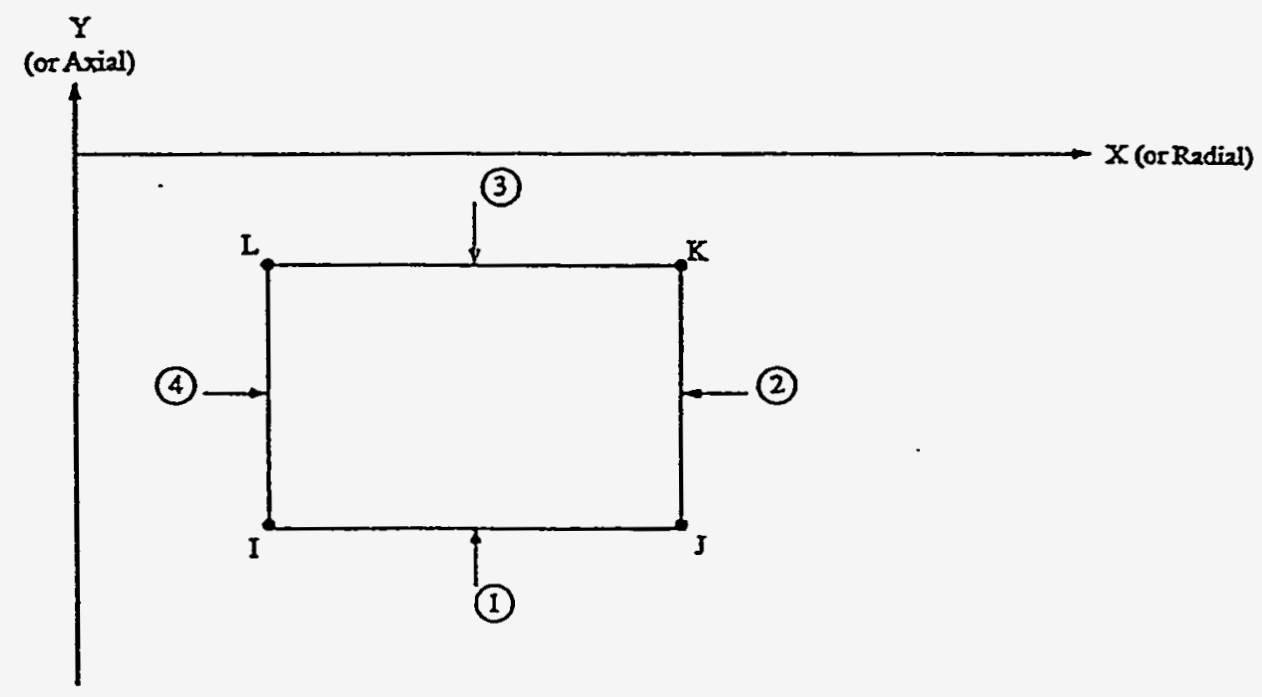

FLUm79 2-D Contained Fluid Element

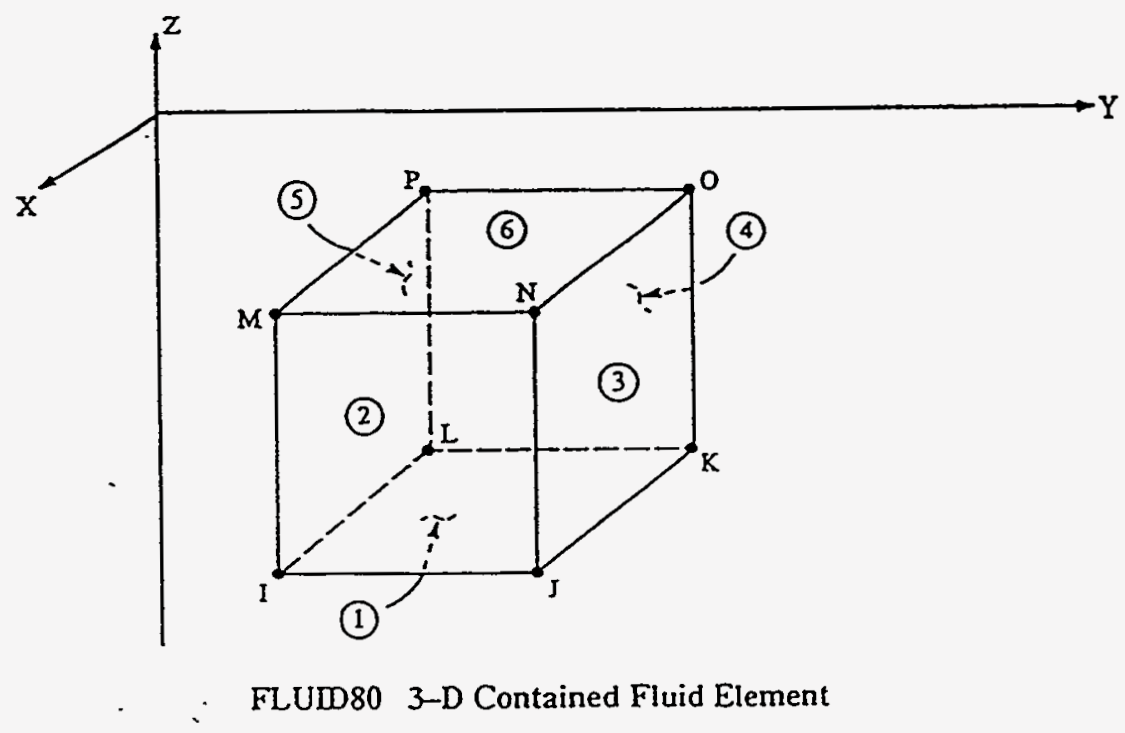

Figure A.2 Contained Fluid Elements 


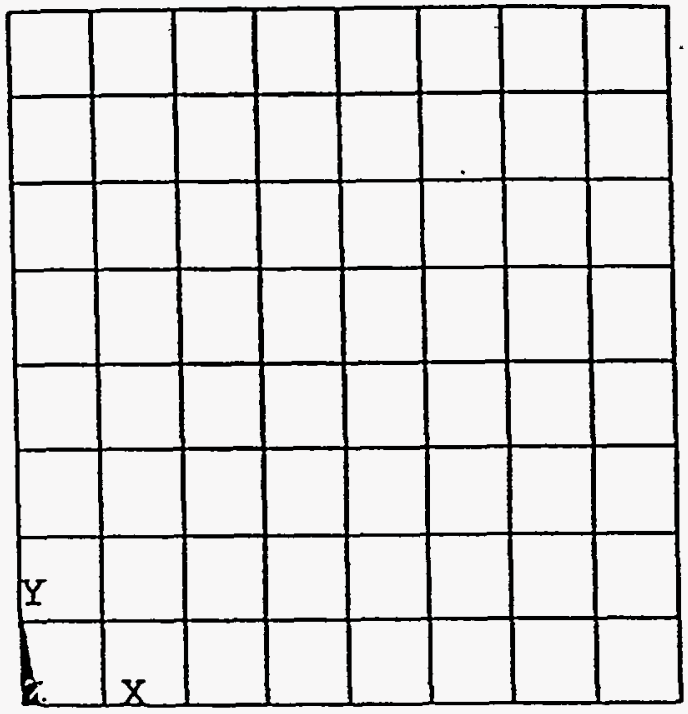

Figure A.3 Finite Element Model for Acoustic Modes 


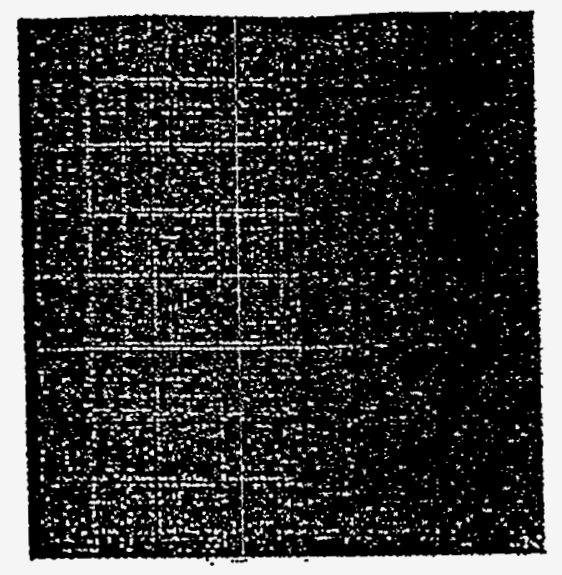

m

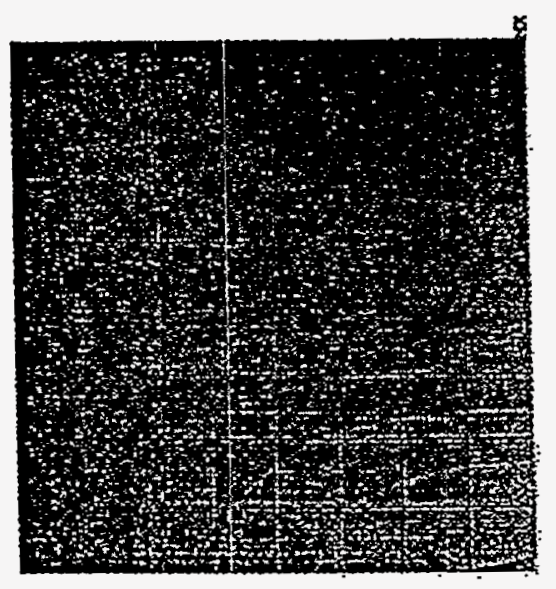

ro

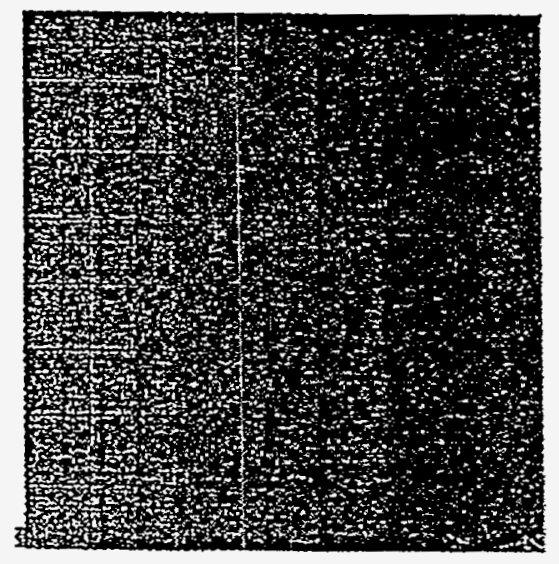

$\bar{z}$

Figure A.4 Dynamic Pressure Contour Plots Using Acoustic Elements. 

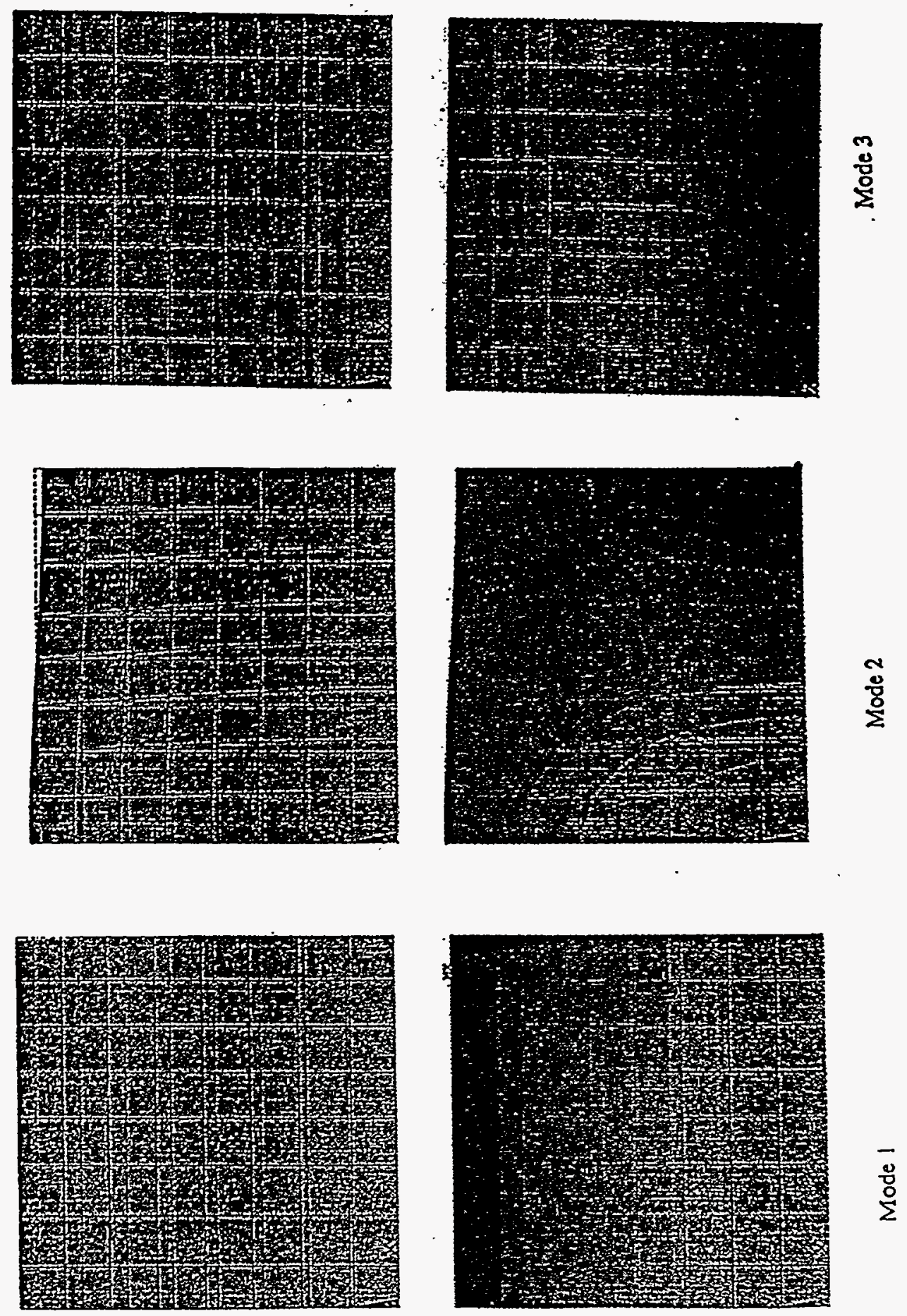

Figure A.5 Displaced Shape and Dynamic Pressure Contour Plots Using Contained Fluid Elements 

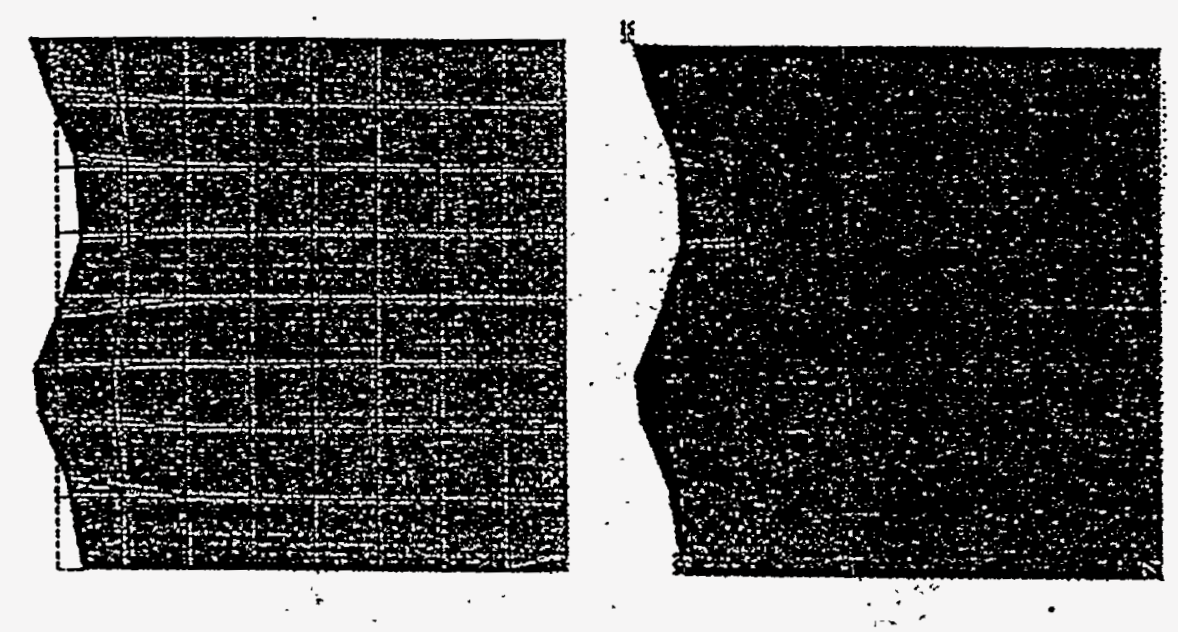

m
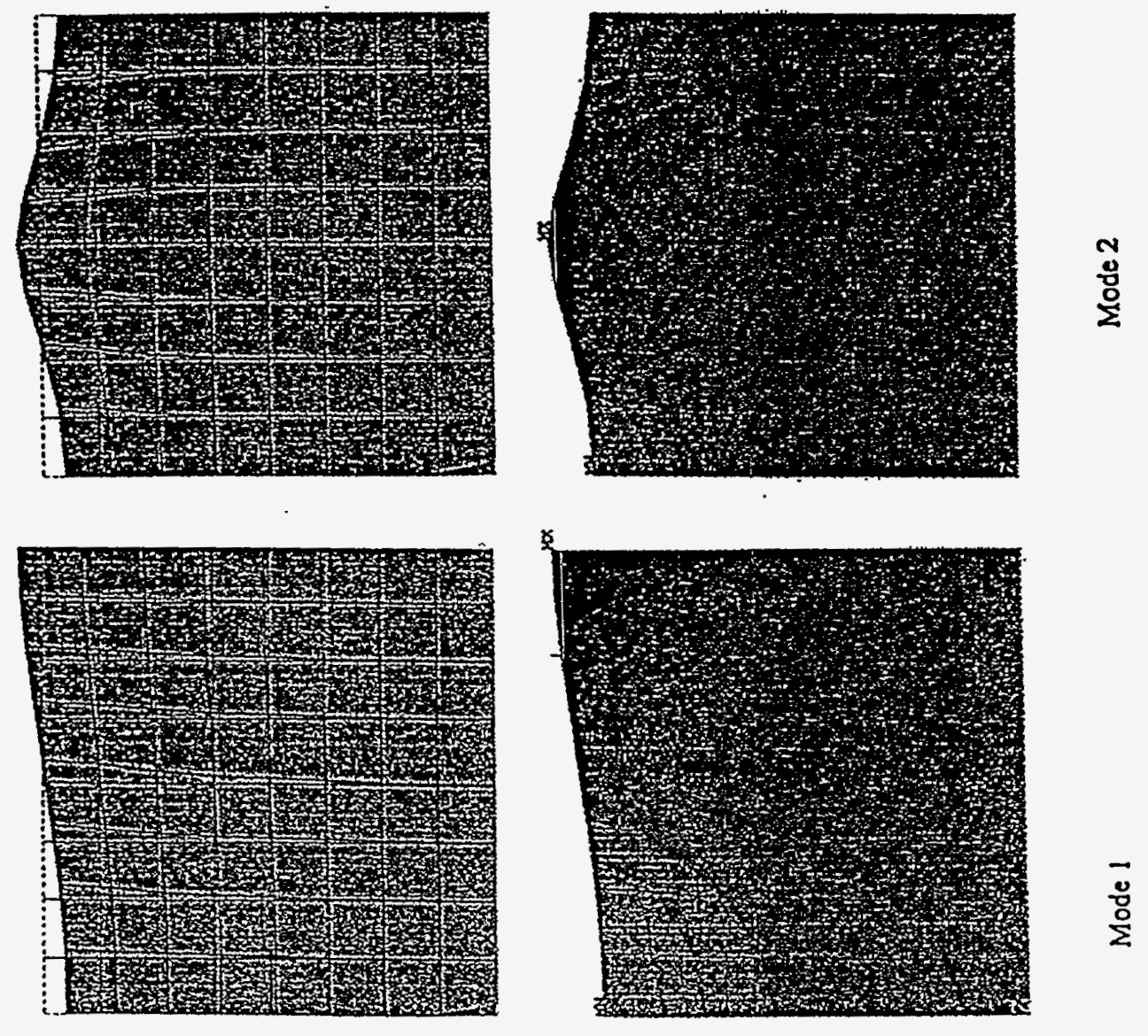

Figure A.6 Mode Shapes and Dynamic Pressure Contour Plots Using Contained Fluid Elements 


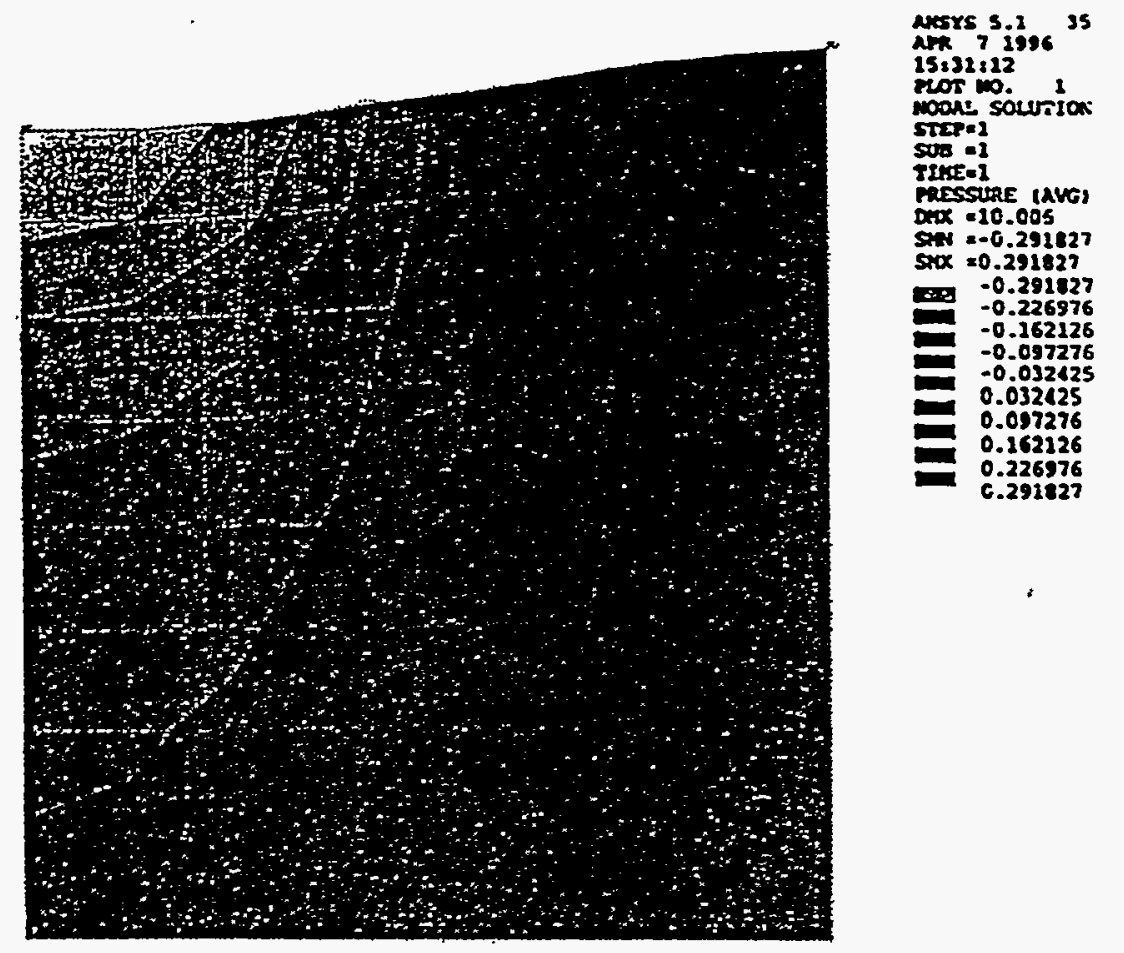

Figure A.7 Dynamic Pressure Due to Inertia Forces of Mode 1

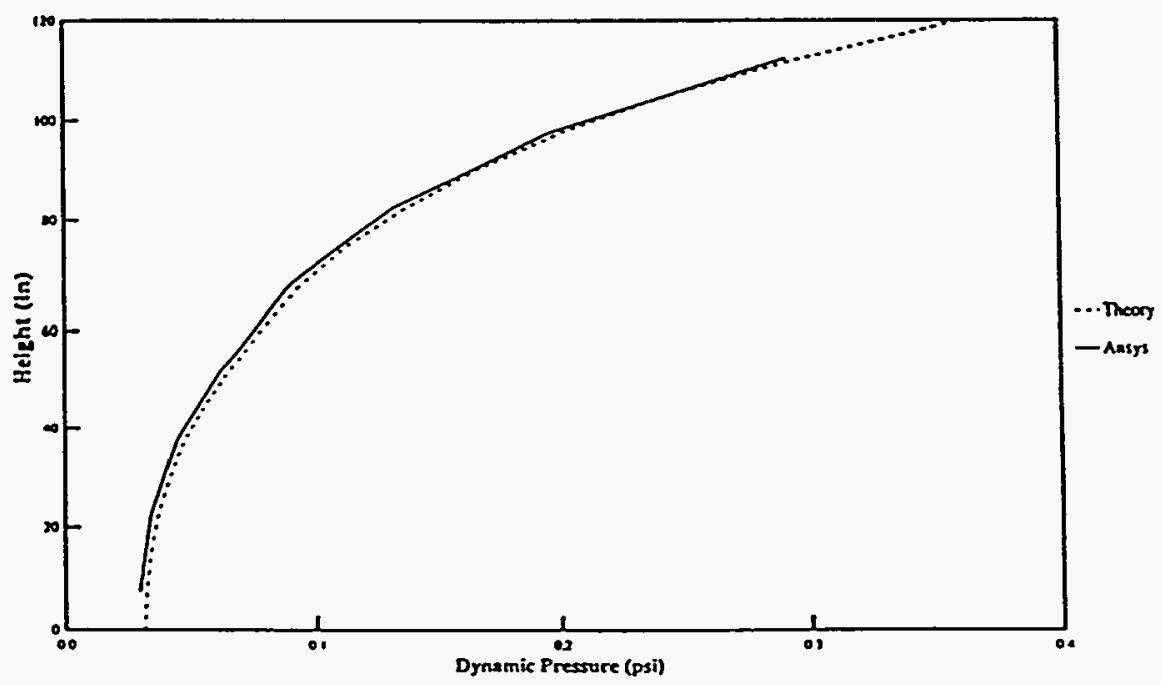

Figure A.8 Comparison Between Dynamic Pressure Calculated by Theory and ANSYS 

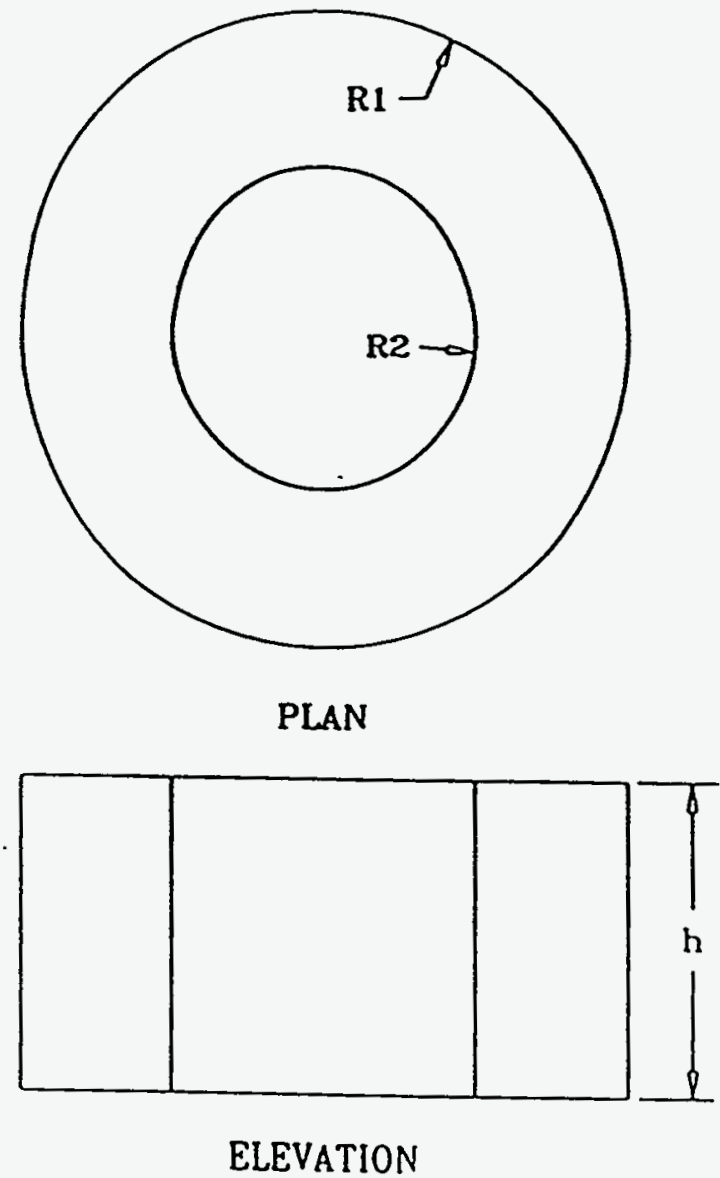

Figure A.9 Annular Tank Filled with Water

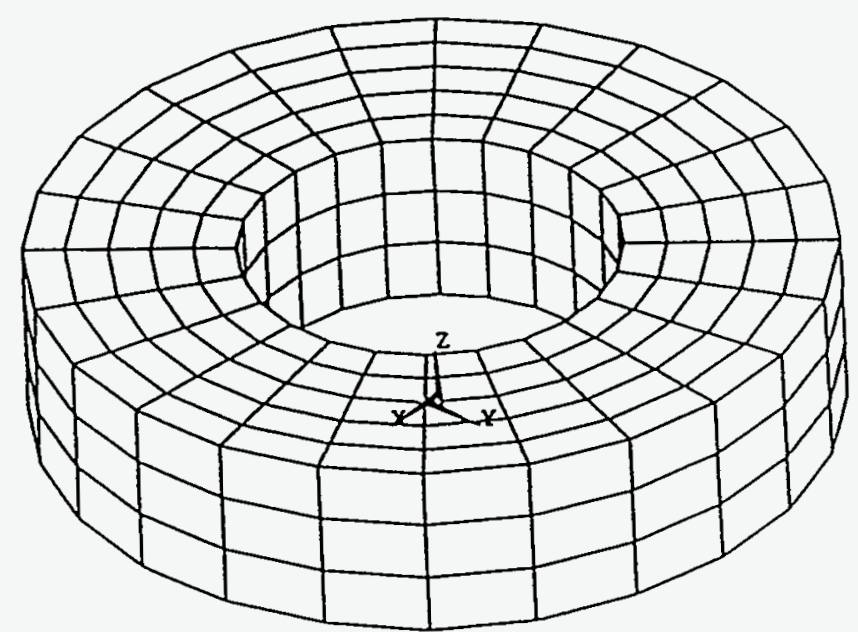

Figure A.10 Finite Element Model for the Annular Tank 

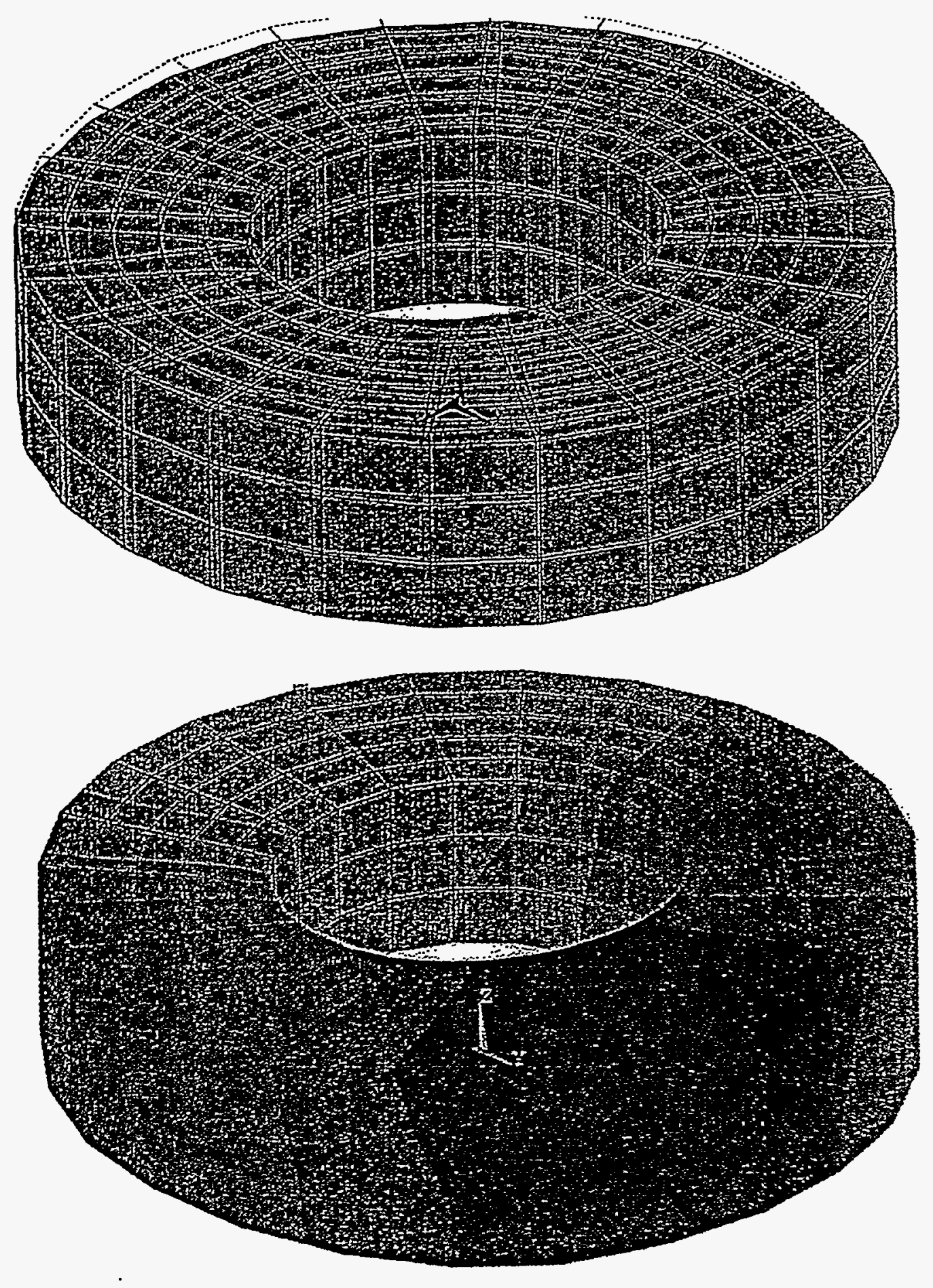

Figure A.11 Mode Shapes and Dynamic Pressure for Mode 1 

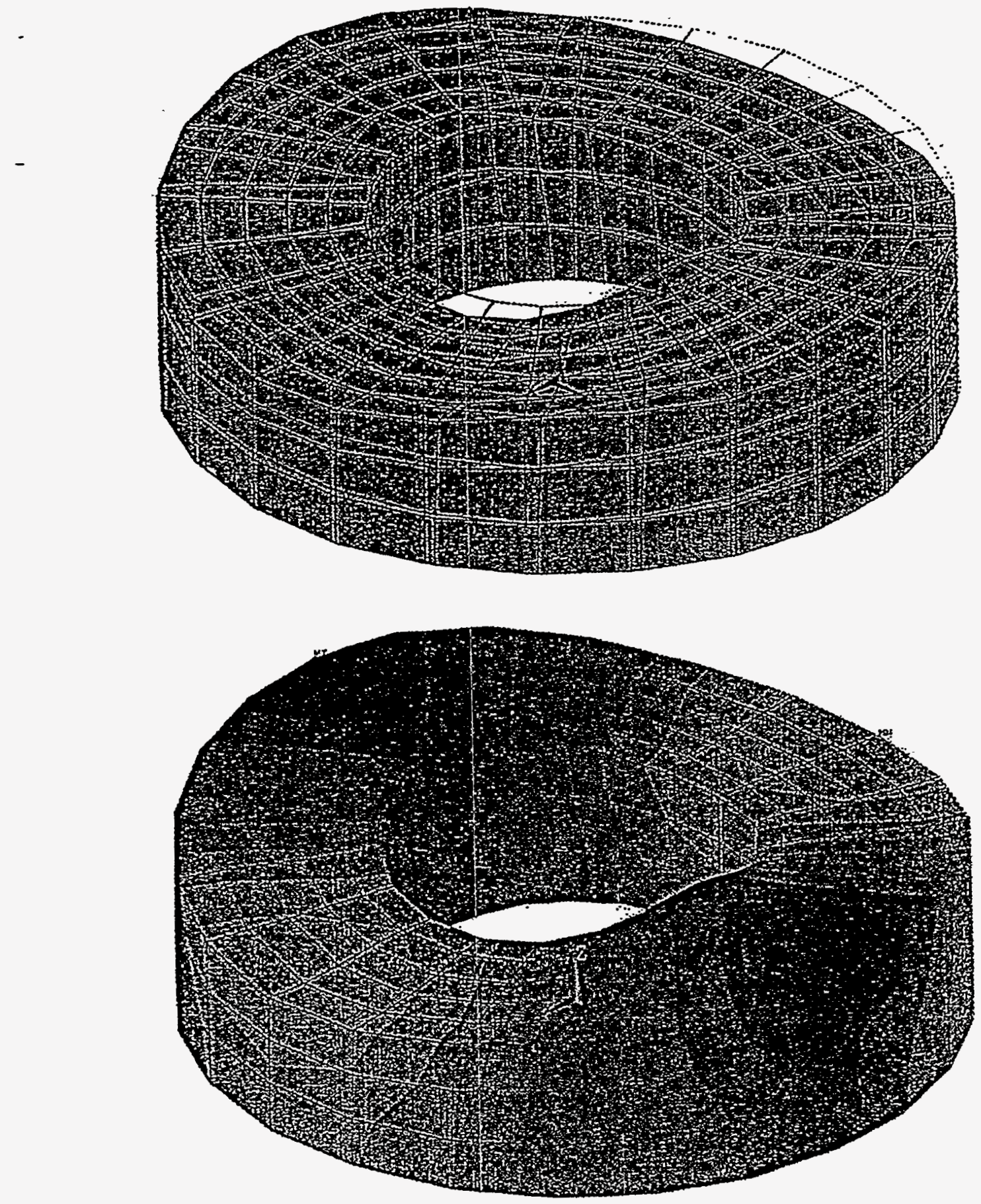

Figure A.12 Mode Shapes and Dynamic pressure for Mode 2 

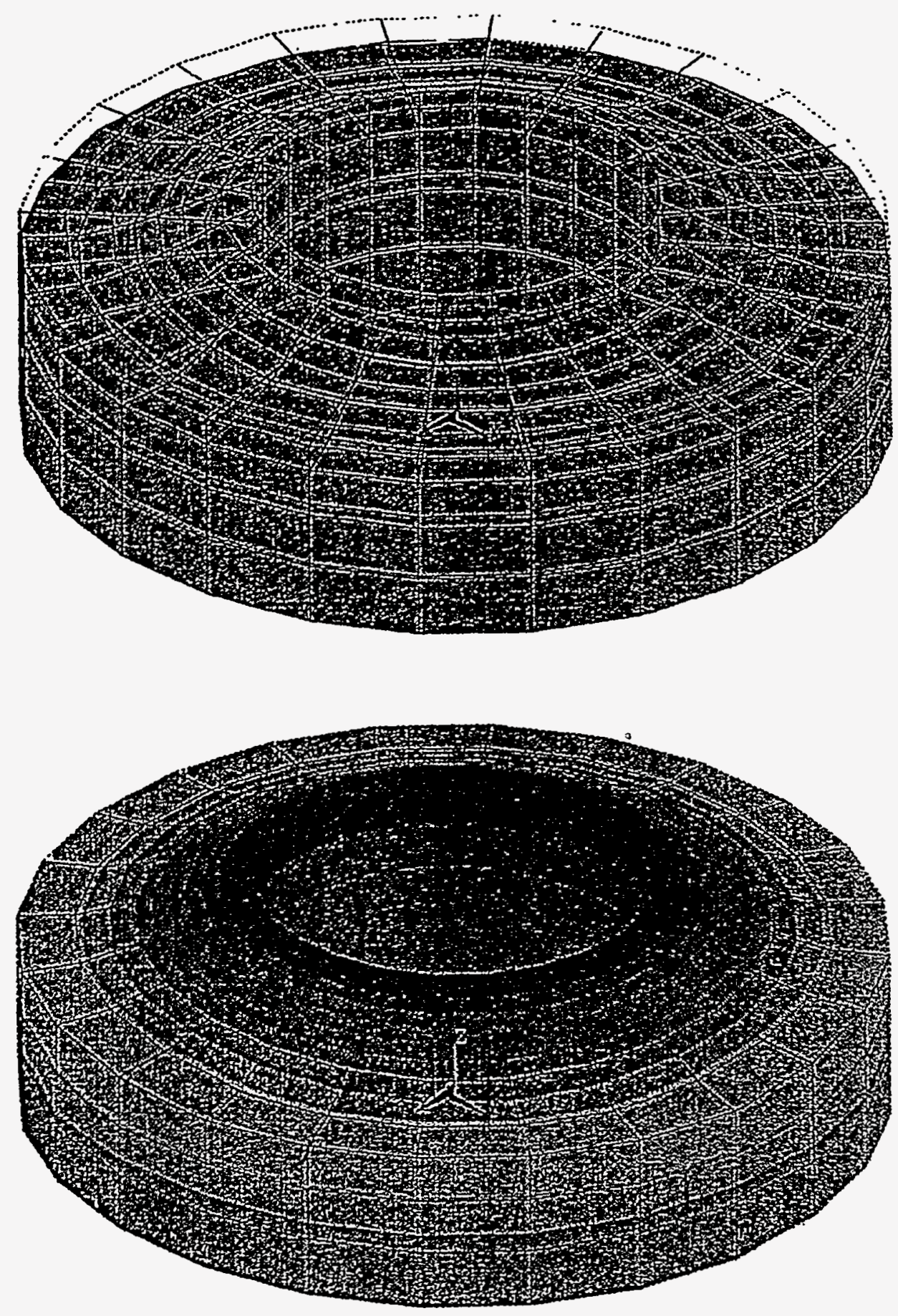

Figure A.13 Mode Shapes and Dynamic Pressure for Mode 5 


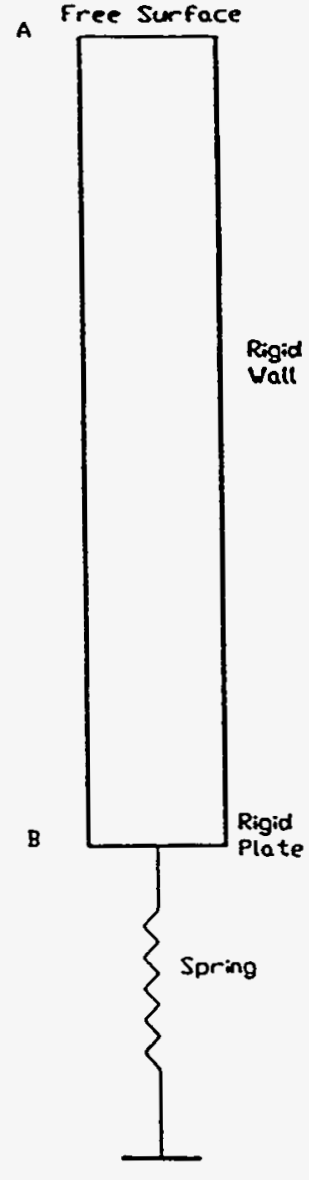

(a) Fluid Column

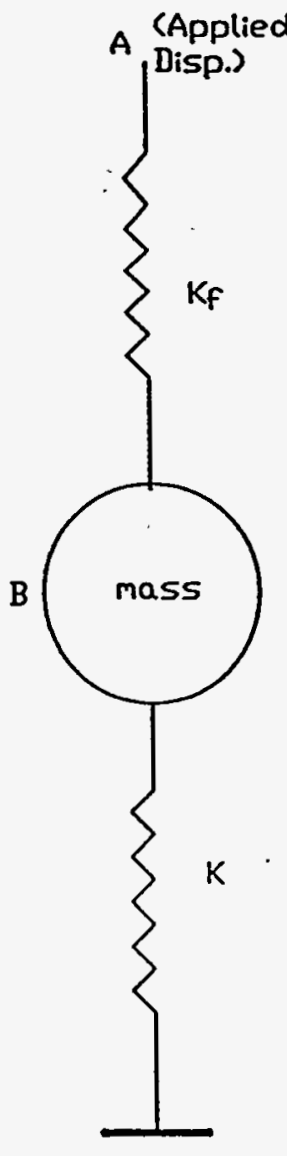

(b) Idealization of the Fluid Column

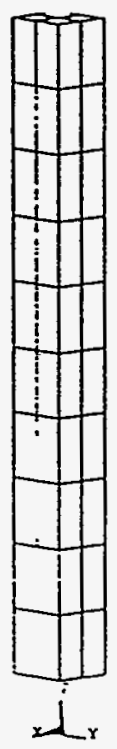

(c) Finite Element Model

Figure A.14 Fluid Column Supported by a Spring 


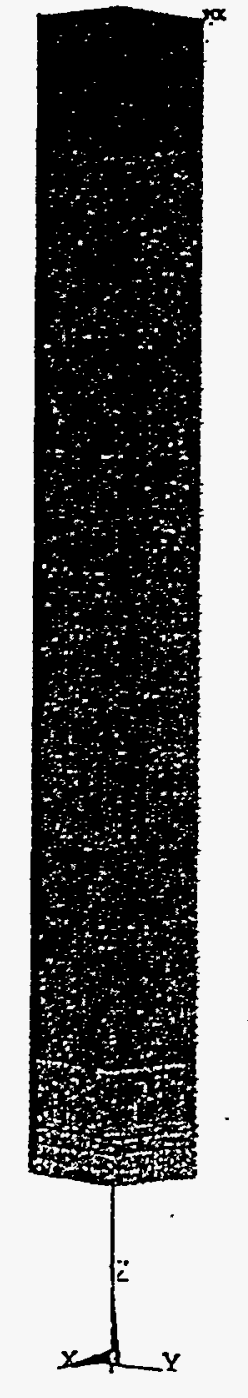

(a) Case a

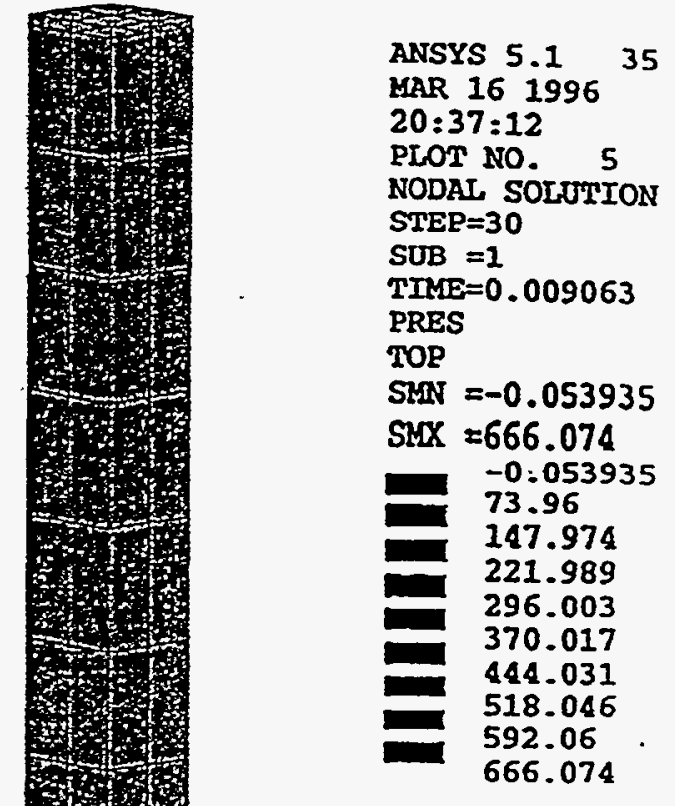

ANSYS $5.1 \quad 35$

$0.37=12$

PLOT NO. 5 NODAL SOLUTION STEP $=30$

SUB $=1$ PRES

TOP

SLA $=-0.053935$

$\operatorname{SMX}=666.074$

73.96

147.974

221.989

296.003

370.017

518.046

666.074

Figure A.15 Deformed Shape and Pressure Distribution for the Fluid Column in Fig. A.14 at Time $=0.009$ Second 


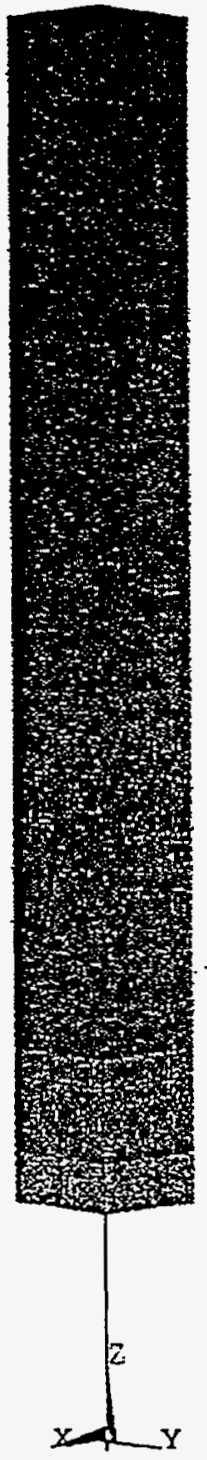

(a) Pressure

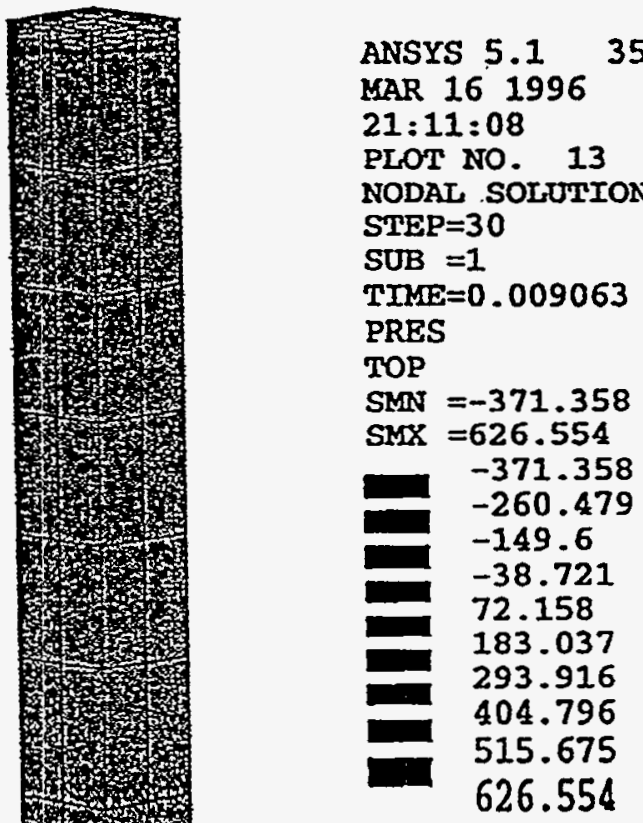

MAR 161996

21:11:08

LOT NO. 13

STEP $=30$

SUB $=1$

$=0.009063$

SMN $=-371.358$

SMX $=626.554$

$-371.358$

$-149.6$

$-38.721$

72.158

183.037

293.916

515.675

626.554

Figure A.16 Deformed Shape and Pressure Distribution at $\mathrm{t}=0.0096 \mathrm{Sec}$. using Contained Fluid Elements (Case (a)) 


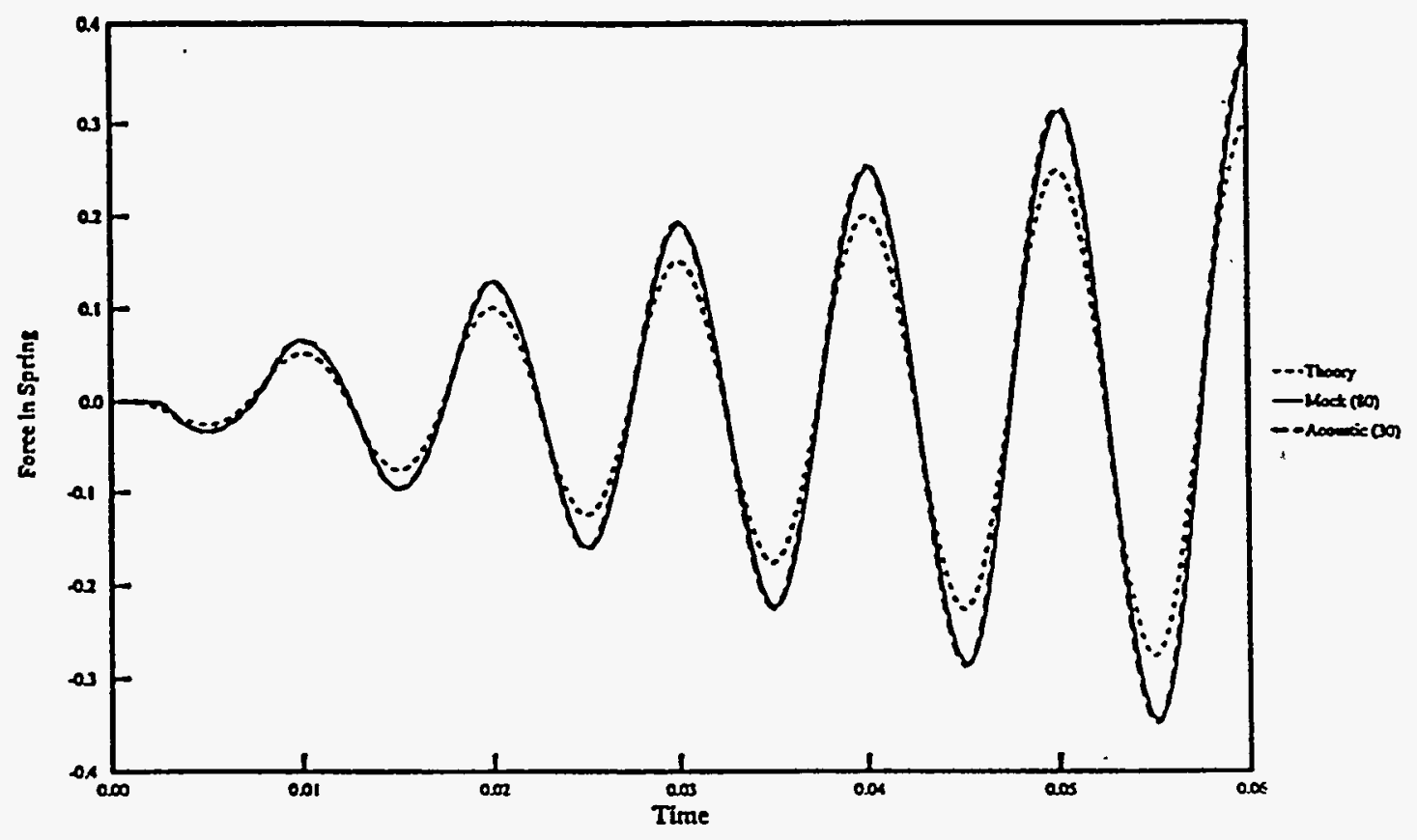

Figure A.17 Comparison Between Results (Case (a))

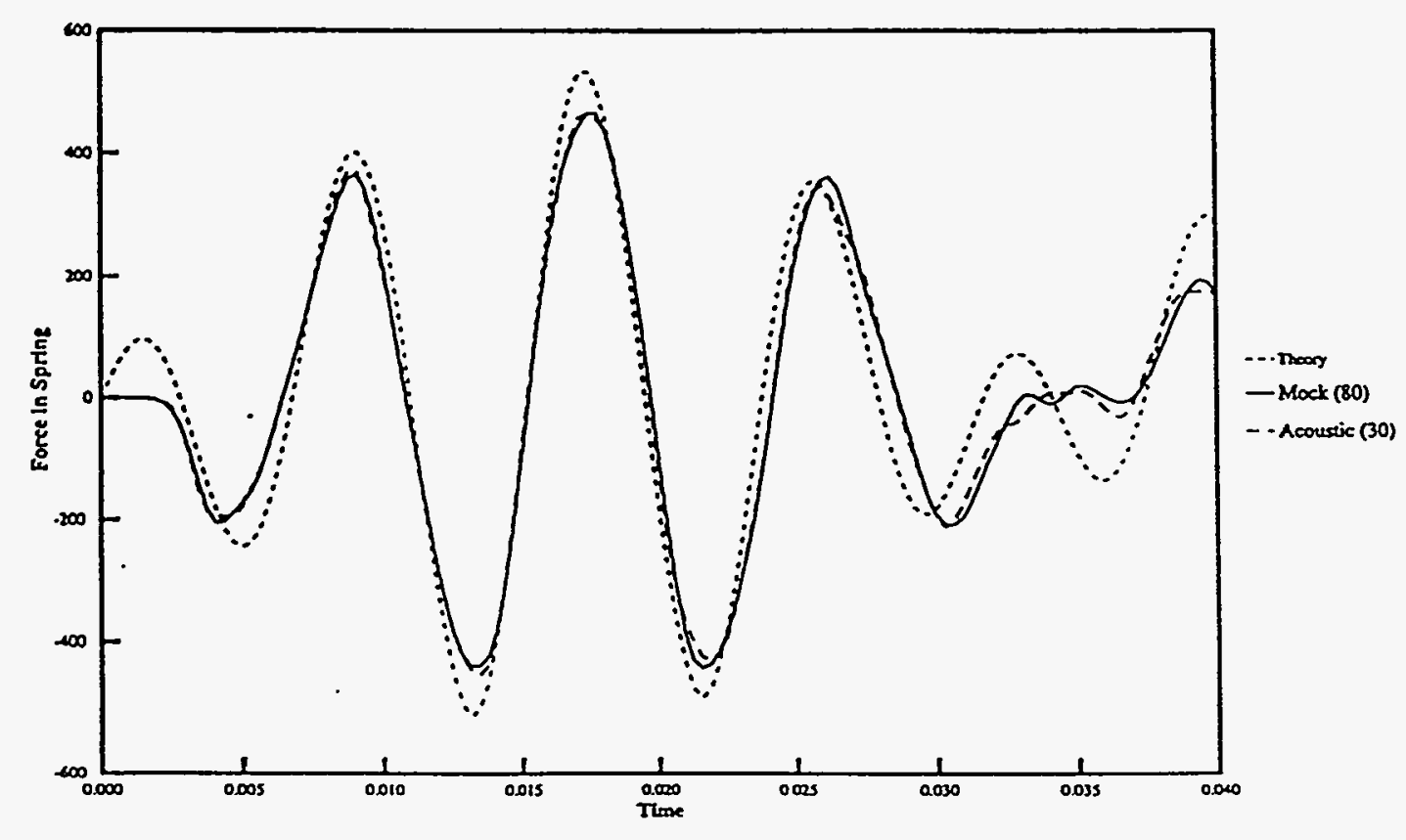

Figure A.18 Comparison Between Results (Case (b)) 


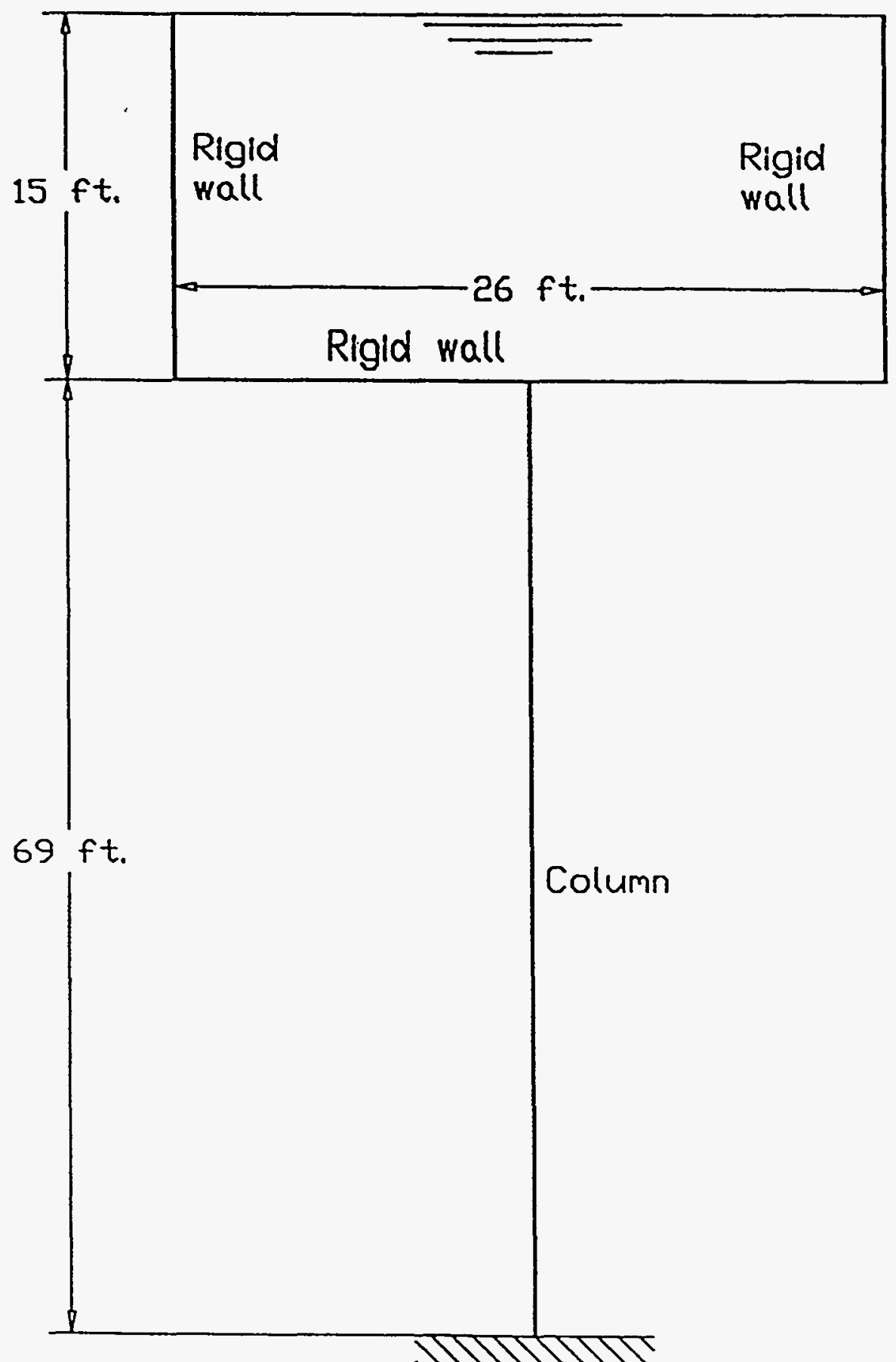

Figure A.19 Example of an Elevated Tank Filled with Water 


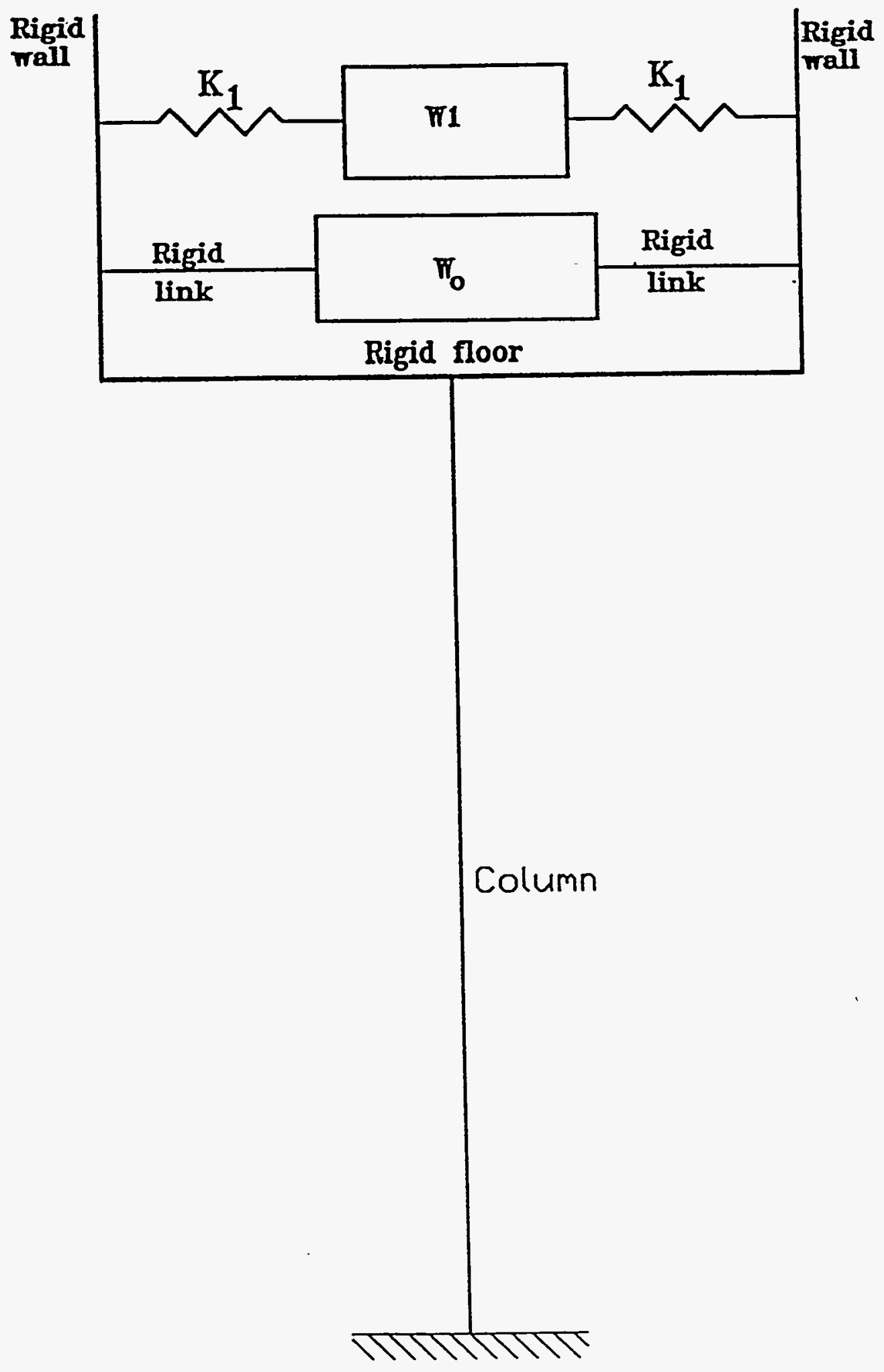

Figure A.20 Theoretical Idealization of the Tank in Fig. A.19 


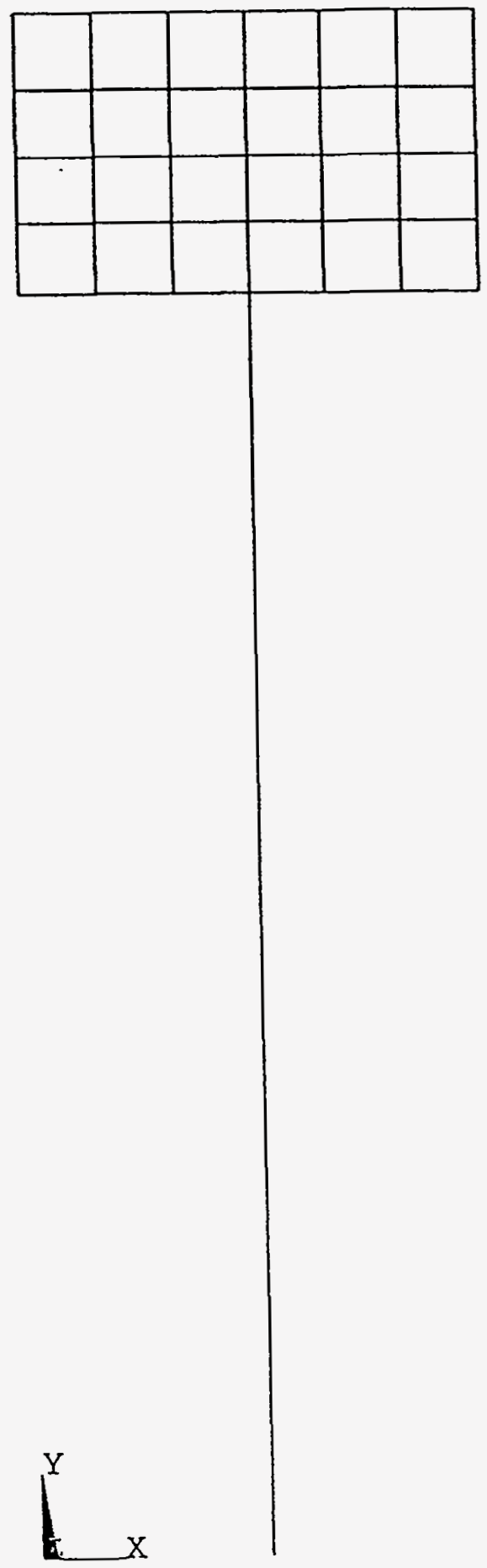

Figure A.21 Finite Element Model for the Tank in Fig. A.19 


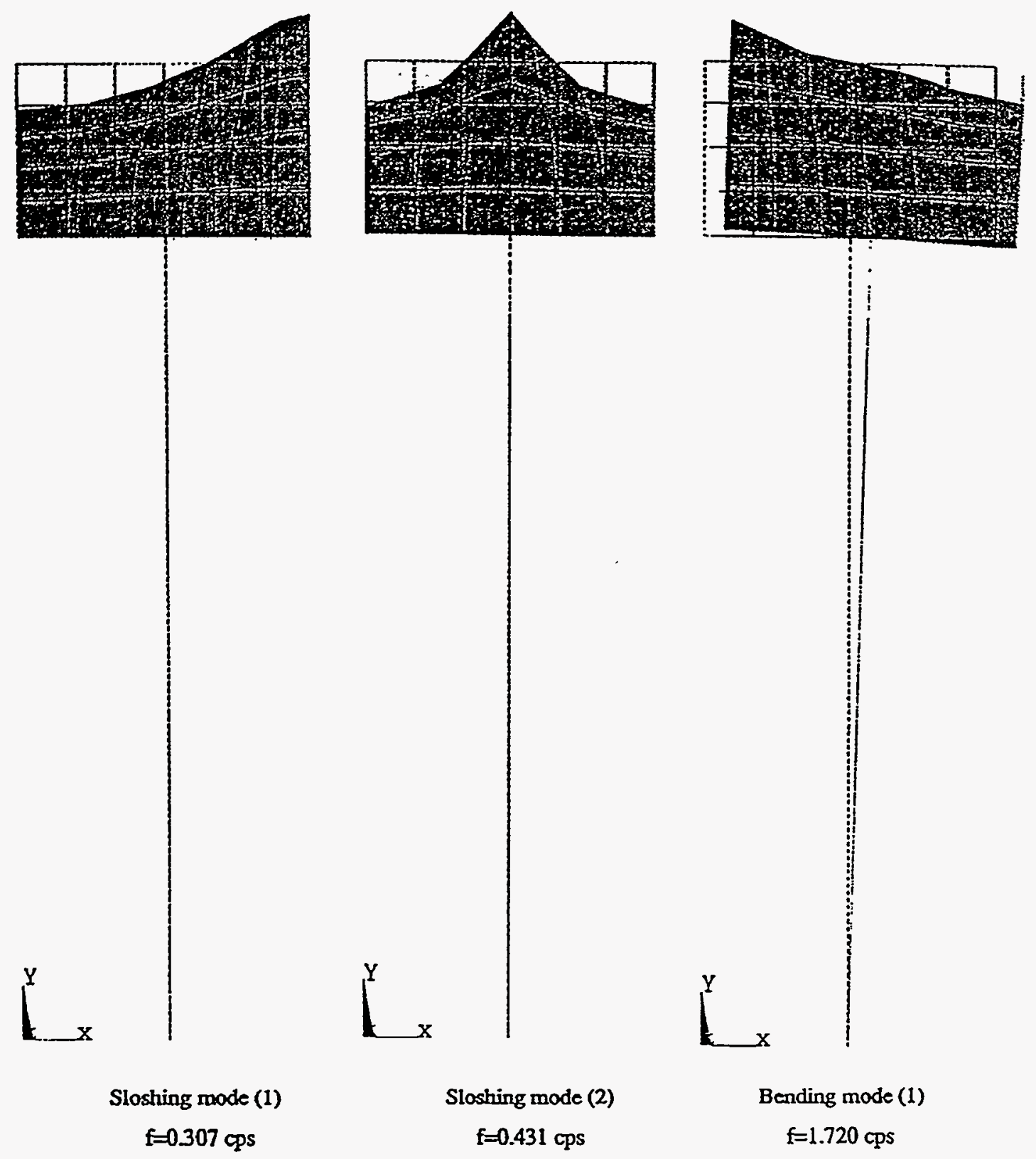

Figure A.22 Modes of Vibration for the Tank in Fig. A.19 


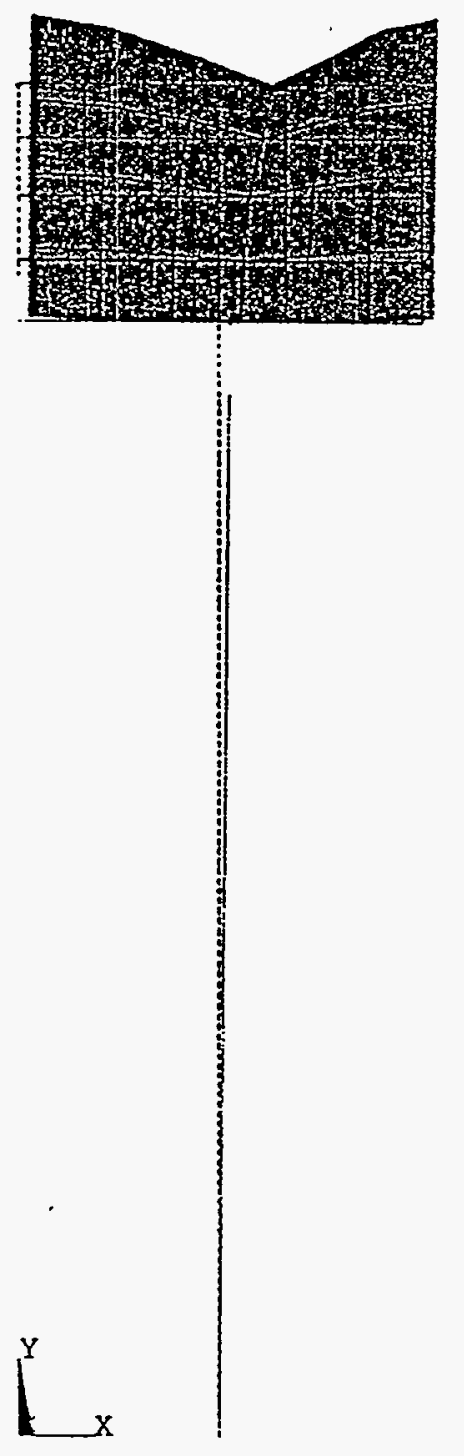

Figure A.23 Displaced Shape Due to Application of the SRSS Method 